

\section{La presente obra está bajo una licencia de:}

\section{http://creativecommons.org/licenses/by-nc-sa/3.0/deed.es MX}

\section{Atribución-No Comercial-Licenciamiento Reciproco 3.0 Unported}

Eres libre de:

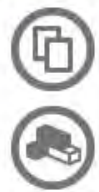

copiar, distribuir y comunicar públicamente la obra

hacer obras derivadas

Bajo las condiciones siguientes:

Atribución - Debes reconocer la autoría de la obra en los términos

especificados por el propio autor o licenciante.

No comercial - No puedes utilizar esta obra para fines comerciales.

Licenciamiento Reciproco - Si alteras, transformas o creas una obra a

partir de esta obra, solo podrás distribuir la obra resultante bajo una licencia

igual a ésta.

\section{Esto es un resumen fácilmente legible del: texto legal (de la licencia completa)}

\section{En los casos que sea usada la presente} obra, deben respetarse los términos especificados en esta licencia.

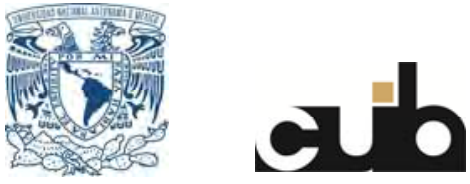




\section{La brecha digital y sus determinantes}




\section{COLECCIÓN}

TECNOLOGÍAS DE LA INFORMACIÓN

Centro Universitario de Investigaciones Bibliotecológicas 


\section{La brecha digital y sus determinantes}

Adolfo Rodríguez Gallardo

Universidad Nacional Autónoma de México 2006 
HM851

R64

Rodríguez Gallardo, Adolfo

La brecha digital y sus determinantes / Adolfo Rodríguez Gallardo. - México: UNAM, Centro Universitario de Investigaciones Bibliotecológicas, 2006.

xxiv, 254 p. - (Tecnologías de la información)

ISBN: 970-32-3853-X

1. Brecha Digital 2. Tecnologías de la información 3.

Tecnologías de la información y las Comunicaciones 4 . Internet 5. Estadísticas I. t. II Ser.

Diseño de portada: Christopher Barrueta Álvarez y Mario Ocampo Chávez

Primera Edición, 2006

DR (C) UNIVERsidad NACIONAL AUtÓNOMA DE MÉXICO

Ciudad Universitaria, 04510, México, D.F.

Impreso y hecho en México

ISBN: 970-32-3853-X 
A Carmen

Por cuarenta razones 



\section{Agradecimiento}

Muchas personas han intervenido para que yo pudiera concluir este trabajo. Todas ellas han contribuido de diferentes formas, con materiales o con sus comentarios, $y$ me ban auxiliado en la organización de toda esta información.

Especial agradecimiento debo a la Lic. Minerva del Ángel Santillán por el cuidado con que trabajó los manuscritos elaborados por mí. Señaló ausencias y duplicaciones de información y contribuyó de forma relevante a la conclusión de este libro. 



\section{Contenido}

ÍNDICE DE FIGURAS $\ldots \ldots \ldots \ldots \ldots \ldots \ldots \ldots$

ADVERTENCIA $\ldots \ldots \ldots \ldots \ldots \ldots \ldots \ldots \ldots \ldots \ldots \ldots \ldots$ xxiii

ACERCÁNDONOS A LA BRECHA DIGITAL $\ldots \ldots \ldots \ldots$

¿QUÉ ES LA BRECHA DIGITAL? . . . . . . . . . . . . . 21

ACCESO A LA TECNOLOGÍA DE LA INFORMACIÓN

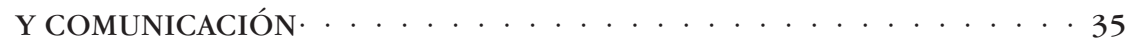

Conceptuando el acceso a la TIC . . . . . . . . . . . . . . . . . 38

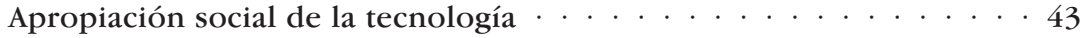

Uso de la tecnología de la información y comunicación . . . . . . . 51

LA TECNOLOGÍA DE LA INFORMACIÓN Y COMUNICACIÓN

EN EL MUNDO . . . . . . . . . . . . . . . . . . . . . . . . . 59

Estados Unidos . . . . . . . . . . . . . . . . . . . .

América Latina y el Caribe . . . . . . . . . . . . . . . . . . 103

México . . . . . . . . . . . . . . . . . . . . . . . 113

Europa . . . . . . . . . . . . . . . . . . . . . . 121

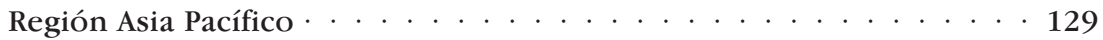

El Medio Oriente . . . . . . . . . . . . . . . . . . . . . . . 132

África . . . . . . . . . . . . . . . . . . . . . 134

\section{DETERMINANTES ECONÓMICOS DE LA}

BRECHA DIGITAL . . . . . . . . . . . . . . . . . 137

El ingreso económico como determinante de la brecha digital $\ldots . .138$

El costo de la computadora y la suscripción a Internet . . . . . 150

El caso de los Estados Unidos . . . . . . . . . . . . . . . . . . . 159 
DETERMINANTES DEMOGRÁFICOS DE LA BRECHA DIGITAL . . . . . . . . 171

El género factor de distinción en la brecha digital . . . . . . . . . 171

La edad también hace la diferencia . . . . . . . . . . . . . . . . . 189

Origen étnico y brecha digital, el caso estadounidense . . . . . . . 197

DETERMINANTES CULTURALES DE LA BRECHA DIGITAL . . . . . . . . 205

La lengua en que está la información . . . . . . . . . . . . . . . . 205

Educación y brecha digital . . . . . . . . . . . . . . . . . . . . . . . 212

Lectura y tecnología de la información . . . . . . . . . . . . . . . . 226

Brecha digital e inclusión y marginación social . . . . . . . . . . . . . 233

La participación civil . . . . . . . . . . . . . . . . . . . . . 236

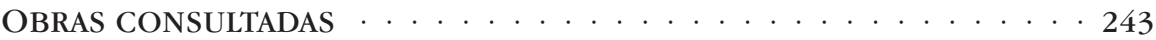




\section{Índice de figuras}

\section{Figura 1}

La brecha digital es la diferencia entre quienes tienen y quienes no tienen... . . . . . . . . . . . . 12

\section{Figura 2}

La brecha digital es la diferencia entre................ 13

\section{Figura 3}

Estratos horizontales, sectores verticales y áreas diagonales de la sociedad de la información. . . . . . . . . 16

\section{Figura 4}

Líneas telefónicas y televisiones por cada 1000

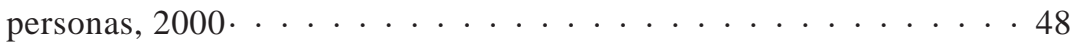

\section{Figura 5}

Proporción 01 de la población que utiliza nuevos y viejos medios $\ldots \ldots \ldots \ldots$

\section{Figura 6}

Distribución mundial de los usuarios de Internet, 2002 . . . . . . . 61

\section{Figura 7}

Servidores de Internet por cada 10,000 personas en países de la OCDE, $1998 \ldots \ldots \ldots 2 \ldots \ldots \ldots \ldots$

\section{Figura 8}

Los 12 países que no pertenecen a OCDE con más de 50 millones de habitantes y más de 1,000 servidores

-Datos de Network Wizard, 1998 ... . . . . . . . 63

\section{Figura 9}

Usuarios de Internet: un enclave global $\ldots \ldots \ldots 5$ 


\section{Figura 10}

Usuarios de Internet por región y tipo de sociedad,

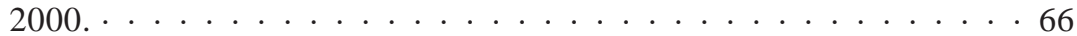

\section{Figura 11}

Porcentaje de la población en línea por nación,

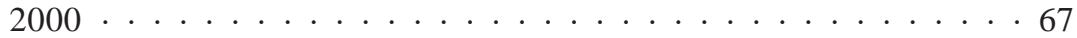

\section{Figura 12}

Explicando la expansión de la tecnología $\ldots \ldots \ldots . \ldots 68$

\section{Figura 13}

Difusión mundial de la radio, televisión e Internet, $1950-2000 . \ldots \ldots \ldots \ldots \ldots$

\section{Figura 14}

Proporción en línea, EU-15, 1996-1999. . . . . . . . . . 71

\section{Figura 15}

Población mundial conectada, $2002 \ldots \ldots \ldots$. . . . . . 72

\section{Figura 16}

Crecimiento mundial del número de usuarios de Internet $1993-2002 \ldots \ldots \ldots$. . . . . . . . . . 73

\section{Figura 17}

Usuarios de Internet por localización geográfica,

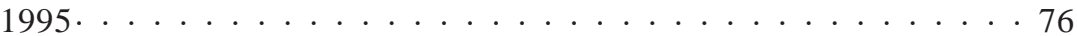

\section{Figura 18}

Tasa de penetración de Internet por continente $\ldots \ldots . . .77$

\section{Figura 19}

Tasa de penetración de Internet por continente (gráfico) $\ldots \ldots 78$

\section{Figura 20}

Número de servidores de Internet y usuarios por continente . . . . . 79

\section{Figura 21}

Proporción de usuarios y no usuarios de Internet . . . . . . . . . 80 


\section{Figura 22}

Tasa de acceso a Internet, Agosto de 2001 . . . . . . . . . . . 80

\section{Figura 23}

Proporción de la población en línea por principales regiones, $2000 \ldots \ldots \ldots \ldots$

\section{Figura 24}

Tendencias en el uso de Internet en Europa y Estados Unidos, 1996-1999. . . . . . . . . . . . . . . 83

\section{Figura 25}

Tendencias en el uso de computadora en Europa y Estados

Unidos, 1996-1999 . . . . . . . . . . . . . . . . . . 84

\section{Figura 26}

Periodo en el que la tecnología ha sido adoptada por un tercio de los hogares estadounidenses . . . . . . . . . . 86

\section{Figura 27}

Tecnología estadounidense Siglo XX . . . . . . . . . . 87

\section{Figura 28}

Porcentaje de hogares estadounidenses que tenían teléfono en 1998, apreciación general y división por zona rural, urbana y central de las ciudades (inner) . . . . . . . . . . . . 89

\section{Figura 29}

Porcentaje de hogares estadounidenses que tenían teléfono en 1998, dividido por zona rural, urbana y central de las ciudades (inner) y por raza o antecedente racial . . . . . . . . . 89

\section{Figura 30}

Porcentaje de hogares estadounidenses que tenían teléfono en 1998, organizado por raza e ingreso económico $\ldots \ldots 90$ 


\section{Figura 31}

Porcentaje de hogares estadounidenses que tenían teléfono en 1998, dividido por zona rural, urbana y central de las ciudades (inner) y por nivel educativo . . . . . . . . . . 91

\section{Figura 32}

Porcentaje de hogares estadounidenses que tenían teléfono en 1998, dividido por zona rural, urbana y central de las ciudades (inner) y por las características del jefe

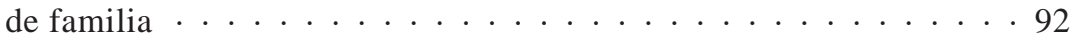

\section{Figura 33}

Porcentaje de hogares estadounidenses que tenían computadora en 1998, dividido por zona rural, urbana y central de las ciudades (inner), agrupado por las cuatro regiones en que se divide el país . . . . . . . . . . . . . . 93

\section{Figura 34}

Porcentaje de hogares estadounidenses que tenían computadora en 1998, dividido por zona rural, urbana y central de las ciudades (inner) y por ingreso . . . . . . . . . . . . . . . 94

\section{Figura 35}

Porcentaje de hogares estadounidenses que poseían una computadora en 1998, dividido por zonas rural, urbana y central de las ciudades (inner) en las diferentes regiones que integran el país . . . . . . . . 95

\section{Figura 36}

Distribución geográfica de los usuarios de Internet en Estados Unidos, subdividida de acuerdo a su origen étnico. . . . . . . . . . . . . . . . 966

\section{Figura 37}

Porcentaje de estadounidenses que usaban Internet en 1998 fuera de casa dividido por lugar de conexión . . . . . . . . . . 97 


\section{Figura 38}

Porcentaje de hogares estadounidenses con acceso

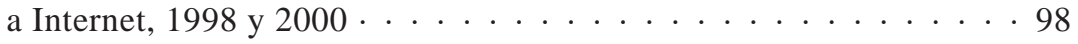

\section{Figura 39}

Porcentaje de hogares estadounidenses con acceso a computadora e Internet . . . . . . . . . . . . . . 100

\section{Figura 40}

Porcentaje de estadounidenses usuarios de Internet, por lugar de conexión, $1998 \ldots \ldots \ldots$

\section{Figura 41}

Porcentaje de estadounidenses que usan Internet en sus casas desagregado por tipo de uso, $1998 \ldots \ldots \ldots$

\section{Figura 42}

América Latina mira al Sur . . . . . . . . . . . . . . . . . 104

\section{Figura 43}

Distribución de usuarios de Internet en América

Latina.

\section{Figura 44}

Acceso a Internet en América Latina . . . . . . . . . . . . . . . 112

\section{Figura 45}

Usuarios mexicanos de Internet por disponibilidad de computadora en el hogar, según lugar de acceso

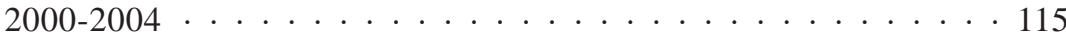

\section{Figura 46}

Variación porcentual anual de los usuarios de mexicanos

Internet según la disponibilidad de computadora e

Internet . . . . . . . . . . . . . . . . . 116

\section{Figura 47}

De Sur a Norte a lo largo de la brecha digital en

Europa Occidental 


\section{Figura 48}

Tasa de penetración de Internet en algunas naciones

de Europa Occidental . . . . . . . . . . . . . . . 126

\section{Figura 49}

Lo mejor y el resto de Europa Oriental . . . . . . . . . 127

\section{Figura 50}

Tasa de penetración de Internet en algunos países de Europa Oriental . . . . . . . . . . . . . . . . . 128

\section{Figura 51}

Penetración de Internet en Medio Oriente . . . . . . . . . . . . 133

\section{Figura 52}

Una visión sobre las diferencias entre el Norte y

el Sur de África . . . . . . . . . . . . . . . . . 135

\section{Figura 53}

Penetración de Internet: comparación entre la Republica de Sudáfrica y otras naciones africanas . . . . . . . . 136

\section{Figura 54}

Comparación entre el PIB, líneas telefónicas y computadoras por continente . . . . . . . . . . . . . 140

\section{Figura 55}

La brecha digital, 1998. . . . . . . . . . . . . . 140

\section{Figura 56}

Distribución de computadoras y servidores por cada 1000 habitantes . . . . . . . . . . . . . . . . 142

\section{Figura 57}

Líneas telefónicas y computadoras a nivel regional, naciones industrializadas vs naciones en desarrollo . . . . . . . . . . . 142 


\section{Figura 58}

Proporción de hogares estadounidenses con acceso a

Internet por nivel de ingreso económico . . . . . . . . . . . . 143

\section{Figura 59}

Proporción del uso de computadoras en el hogar.

B Por ingreso familiar . . . . . . . . . . . . . . . . . 144

\section{Figura 60}

Tigres asiáticos de Internet... y gatos... y gatitos . . . . . . . . . 147

\section{Figura 61}

Países asiáticos por debajo del nivel regular del continente . . . . . . . . . . . . . . . . . . . 148

\section{Figura 62}

Hogares mexicanos con computadora por ingreso económico, 1996 a 2002 . . . . . . . . . . . . . . . . 150

\section{Figura 63}

Disminución del precio de la computadora "modelo básico" . . . . . . . . . . . . . . . . . . 152

\section{Figura 64}

Precio promedio de una computadora personal, modelo básico, en Estados Unidos, 1996-2002 . . . . . . . . . . . . . . 153

\section{Figura 65}

Explicando la expansión de la tecnología . . . . . . . . . . . 158

\section{Figura 66}

Porcentaje de hogares norteamericanos que tenían computadoras en 1998, dividido por raza e ingreso económico .

\section{Figura 67}

Porcentaje de hogares estadounidenses que usaban Internet en 1998, organizado por etnia e ingreso económico . . . . . . . 161 


\section{Figura 68}

Porcentaje de hogares estadounidenses con computadora y acceso a Internet por ingreso económico 1998, 1999 . . . . . . . . 162

\section{Figura 69}

Porcentaje de hogares estadounidenses que usaban Internet en 1998, organizados por zonas rural, urbana y central de las ciudades (inner) y por ingreso económico . . . . . . . . 163

\section{Figura 70}

Porcentaje de estadounidenses que usaban Internet en 1998, organizado por ingreso y lugar de conexión . . . . . . . . . 164

\section{Figura 71}

Porcentaje de ciudadanos de los Estados Unidos que usan Internet, dividida por el estatus en cuanto a su trabajo y si trabaja en casa o fuera de ella para el año $1998 \ldots \ldots \ldots$

\section{Figura 72}

Motivos para no tener una computadora en casa $\ldots \ldots \ldots$

\section{Figura 73}

Porcentaje de ciudadanos que usan Internet fuera de casa, dividido por la ubicación en que lo usan y el ingreso de la familia para el año de $1998 \ldots \ldots$. . . . . . . . . 167

\section{Figura 74}

Relación entre ingresos económicos y nivel educativo de los hogares estadounidenses que usaban Internet en 2000 . . . . 168

\section{Figura 75}

Usuarios de Internet por género $1995 \ldots \ldots \ldots \ldots$

\section{Figura 76}

Usuarios de Internet por género, $1996 \ldots \ldots \ldots \ldots$

\section{Figura 77}

Categorías de edad analizadas por género . . . . . . . . . . 174 


\section{Figura 78}

Usuarios de Internet por género $1997 \ldots \ldots \ldots$. . . . . 175

\section{Figura 79}

Usuarios de Internet por género $1998 \ldots \ldots \ldots$. . . . . . 176

\section{Figura 80}

Usuarias de Internet como proporción del total de usuarios

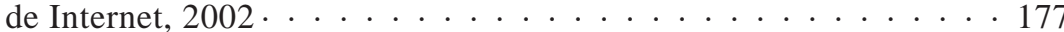

\section{Figura 81}

Proporción de estadounidenses que usaban Internet en 1998 de acuerdo a su género y lugar de uso . . . . . . . . . . . 183

\section{Figura 82}

Porcentaje de estadounidenses que usaban Internet en 1998 fuera de casa, dividido por género y lugar de acceso . . . . . . . . 184

\section{Figura 83}

Proporción de estadounidenses que utilizan Internet en las bibliotecas por género . . . . . . . . . . . . 185

\section{Figura 84}

Porcentaje de estadounidenses que usaban Internet en 1998 en casa dividido por género y tipo de uso . . . . . . . . . . 186

\section{Figura 85}

Proporción de hogares que usaban Internet en 1998, dividido por zona rural, urbana y central de las ciudades (inner) y por tipo de integración familiar . . . . . . . . . . . 187

\section{Figura 86}

Porcentaje de hogares que tenían computadora en 1998, dividido por zona rural, urbana y central de las ciudades (inner) y por tipo de hogar $\ldots \ldots \ldots \ldots \ldots$

\section{Figura 87}

Usuarios estadounidenses de Internet por grupos de edad, $1995 \ldots \ldots \ldots \ldots \ldots$ 


\section{Figura 88}

Proporción de usuarios estadounidenses de Internet

por grupos de edad . . . . . . . . . . . . . . . . . 191

\section{Figura 89}

Porcentaje de hogares estadounidenses que tenían una

computadora en 1998, dividido por zona rural,

urbana y central de las ciudades (inner) y por

grupo racial u origen étnico . . . . . . . . . . . . . . . 198

\section{Figura 90}

Porcentaje de hogares estadounidenses que tenían una computadora en 1998, dividido por zona rural, urbana y central de las ciudades (inner) y por raza/origen . . . . . . . . . . . . . . . . . . 199

\section{Figura 91}

Proporción de hogares estadounidenses con computadora por raza $\ldots \ldots \ldots \ldots$

\section{Figura 92}

Proporción de hogares estadounidenses con acceso a Internet, basado en la raza y origen étnico . . . . . . . . . 200

\section{Figura 93}

Diferencias demográficas sobre le acceso y uso del Web por blancos . . . . . . . . . . . . . . 201

\section{Figura 94}

Diferencias demográficas sobre le acceso y uso del Web por afroamericanos. . . . . . . . . . . . 202

\section{Figura 95}

Diferencias demográficas sobre le acceso y uso del

Web por hispanos . . . . . . . . . . . . . . 203

\section{Figura 96}

Distribución de páginas Web por lengua . . . . . . . . . 208 


\section{Figura 97}

Proporción de hablantes de una lengua y páginas

Web en esa lengua, $2001 \ldots \ldots \ldots$

\section{Figura 98}

Porcentaje de hogares estadounidenses que tenían

computadora en 1998, dividido por zona rural, urbana y central de las ciudades (inner) y

por nivel educativo . . . . . . . . . . . . . . . . 221

\section{Figura 99}

Porcentaje de hogares estadounidenses que usaban Internet

en 1998 dividido por zona rural, urbana y central de las

ciudades (inner) y nivel educativo . . . . . . . . . 221

\section{Figura 100}

Comparación entre alfabetismo y tecnología

de la información . . . . . . . . . . . . . . . 226

\section{Figura 101}

Analfabetismo y expectativa de vida al nacer . . . . . . . . . . 229

\section{Figura 102}

El mundo de los periódicos en línea. . . . . . . . . . 232

\section{Figura 103}

El mundo de los medios noticiosos en línea $\ldots \ldots . \ldots 233$

\section{Figura 104}

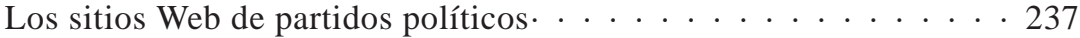

\section{Figura 105}

Tipificación de partidos electorales en línea . . . . . . . 238 



\section{Advertencia}

n el congreso de IFLA en Boston, agosto de 2002, por primera vez abordé el tema de la brecha digital; en esa ocasión presenté una ponencia que intentaba comprender ese fenómeno. A partir de entonces me di cuenta de que el tema daba para mucho más que una ponencia y empecé a reunir información sobre sus manifestaciones en distintas partes del mundo. La información que compilé me permitió analizar con cierto detalle las diferentes perspectivas que adquiere la brecha digital: de género, políticas, educativas, económicas, generacionales y otras más que son estudiadas a lo largo de este libro.

Aunque este fenómeno ha sido analizado en distintas partes del mundo tanto por investigadores individuales, organismos internacionales, ONG y gobiernos, no todos han emprendido su estudio desde la misma óptica, lo que origina que la información de que disponemos, aunque contribuye al análisis de los diferentes aspectos, no admite una investigación en la que predominen criterios similares, pues la información difiere considerablemente de una fuente a otra.

Esta característica hace difícil contar con datos actualizados y confiables que permitan conocer la brecha digital con total certeza. Además, las estadísticas y datos disponibles cambian tan rápido en algunos lugares, que es posible que la información para algunos aspectos del estudio sea totalmente cierta, mientras que en ocasiones se localizan datos diferentes en distintas fuentes que cubren el mismo periodo, lugar o aspecto, sin que exista una explicación de por qué se producen esas discrepancias. En cualquier circunstancia, los 
datos con que contamos nos permiten exponer aquí las características de la brecha digital como fenómeno mundial y su relación con otros aspectos que nos auxilian en su comprensión, para ofrecer el conjunto de explicaciones que le dan sentido a esa enorme masa de datos.

La información en que se basa esta obra se obtuvo de diferentes fuentes documentales impresas y electrónicas, entre ellas libros, folletos, informes y artículos de publicaciones periódicas, por lo tanto es una obra cuyas fuentes son totalmente documentales. En todos los casos se señalan aquellas de donde se obtuvo la información.

Debo señalar que siempre que fue posible se tradujeron las gráficas y los cuadros presentados en el trabajo, sin embargo hay algunos en que no fue posible hacerlo. 


\section{Acercándonos a la brecha digital}

5 ste trabajo tiene por objetivo estudiar el fenómeno conocido en la literatura especializada como la brecha digital (Digital Divide); que no surge con la automatización de los procesos, sino que se empieza a hablar de él a partir de los primeros años de la década de 1990, con la popularización de las computadoras personales.

Contribuyen también a su aparición el uso y desarrollo de las telecomunicaciones en el manejo y utilización de información; pero surge propiamente con la popularización de Internet. Antes de las computadoras personales, las telecomunicaciones e Internet, el manejo de la tecnología de computación se limitaba casi exclusivamente a los centros de cómputo y a las actividades que se realizaban en éstos: operación de grandes computadoras o mainframes, para lo cual contaban con personal que operaba las máquinas, perforistas y otros especialistas, entre ellos programadores. El desarrollo de los procesos de globalización que actualmente vivimos no hubieran sido tan exitosos, ni se hubieran realizado con la velocidad y exactitud con que se han producido, sin la introducción de las computadoras personales, el mejoramiento de las telecomunicaciones y el desarrollo de Internet, que se ha convertido en la red de redes y en el instrumento que une culturas, países, economías, y procesos de todo tipo.

Los problemas que se generan debido a que una fracción de la sociedad cuenta con los recursos de los que otra carece no son nuevos y han existido en todas partes y a lo largo de la historia de la humanidad. La utilización de las tecnologías lo que ha producido es que se 
cree un brecha entre quienes tienen acceso a la Tecnología de la Información y Comunicación (TIC) y aquellos que no lo tienen.

Los problemas de iniquidad en el acceso a la educación, la cultura y el bienestar, han existido en toda la historia humana, y por lo tanto no se pueden ni deben atribuir al uso de las TIC ni al acceso y utilización de los recursos digitales.

Kelley-Salinas ve con claridad que el problema de la incorporación de las tecnologías de la información puede resultar contraproducente desde el punto de vista de la igualdad de oportunidades que la sociedad ofrece a los diferentes segmentos de la misma:

El problema de la igualdad de oportunidades debe ser estudiado cuando se adoptan políticas relacionadas con las TIC, porque las desigualdades existentes pueden ser agudizadas por la brecha digital. En todo proceso a larga escala hay riesgos inherentes, tanto como grandes oportunidades. 1

Kofi Annan, secretario general de las Naciones Unidas, ha descrito con dramatismo la marginación de grupos sociales importantes que carecen de casi todo y cómo al marginarlos del acceso a las telecomunicaciones no solamente se les margina en este aspecto, sino que se contribuye a que se agudicen sus otras carencias.

Mucha gente carece de muchas cosas como por ejemplo: trabajo, habitación, alimentación, cuidados de salud y agua potable. Si hoy los privamos del acceso a los servicios de telecomunicaciones básicas esto es tan grave como las otras privaciones y en realidad reduce las oportunidades para encontrarles solución. ${ }^{2}$

1 Guillermo Kelley-Salinas, "Different educational inequalities: ICT an option to close the gaps", en Centre for Educational Research and Innovation [y] National Center on Adult Literacy, Learning to bridge the digital divide. Education and skills (París: Organisation for Economic Co-operation and Development [OCDE], 2000), 22.

2 Kofi Annan citado por Pippa Norris, Digital divide: civic engagement, information poverty, and the Internet worldwide (Cambridge: Cambridge University Press, 2001), 40. 
Posiblemente por las expectativas que provocó el uso de las TIC, se pensó que su utilización resolvería casi todos los problemas de iniquidad que aquejan a la sociedad en su conjunto.

No cabe duda de que el optimismo de los profesionales de la computación en el uso de sus instrumentos y equipos como elementos para lograr la igualdad social, desconoció las históricas diferencias sociales. Diferencias tan recónditas que no es sencillo borrarlas o eliminarlas si no se atacan en su origen y, por desgracia, el uso de las TIC no es suficiente. Si los problemas sociales, educativos, económicos y de otra índole se resolvieran usando sólo tecnología, su solución por costosa que fuera sería relativamente sencilla. Y no lo es porque muchos de los problemas que generan las diferencias sociales tienen hondas raíces y complejas soluciones; pero como se verá más adelante, los profesionales del cómputo no son los únicos optimistas, también políticos de diferentes países han confiado en que el uso de la tecnología resuelva parte de la problemática que enfrentan sus naciones.

Muchos observadores piensan que el uso de las tecnologías de la información proporciona muchas oportunidades para el desarrollo socioeconómico. Las redes digitales tienen la capacidad de ampliar y fortalecer el acceso a la información y a la comunicación en las áreas remotas o rurales y en los barrios pobres, con el fin de fortalecer el proceso democratizador de los gobiernos en transición, así como disminuir los problemas endémicos de pobreza en el mundo en desarrollo. Con la conectividad como el cordón umbilical, los entusiastas del uso de Internet esperan que eventualmente ésta adopte múltiples funciones tales como biblioteca pública, aula, base de datos médicos, oficina de correos y teléfonos, mercado y centro comercial, canal para el entretenimiento cultural y musical, fuente de noticias diarias, casa de bolsa, centro de predicción del clima y otros servicios heterogéneos en la esfera pública. ${ }^{3}$

3 Norris, Digital divide, 6. 
Como se ve, los entusiastas del uso de las tecnologías de la información tienen expectativas que van más allá de la realidad y no toman en cuenta que para poder lograr todo lo que esperan de Internet, primero se debe plantear que ésta sirva a los individuos y a los grupos sociales para fines específicos, y no generales como se menciona en el párrafo precedente. Las soluciones finalmente tienen que ser locales, pues no se puede aplicar la misma respuesta a ambientes diversos, en los que no se conocen los componentes del problema así como los elementos que forman la solución.

Para los profesionales de las TIC, el uso de estas nuevas tecnologías presuponía la desaparición de otras manifestaciones tecnológicas previas. Una característica importante de destacar es que una nueva tecnología no es capaz de sustituir totalmente a las ya existentes, que los desarrollos coexisten, a veces por poco tiempo y otras por periodos muy largos, pero las tecnologías no son sustitutivas sino suplementarias. Esto es, aun aquellas que han llegado a remplazar totalmente a una tecnología previa, lo han hecho después de muchos años; en un principio y en ocasiones durante muchos años, la nueva ha convivido con la vieja tecnología.

Posiblemente un buen ejemplo sea el de los medios de comunicación como la radio y la televisión. Con la aparición de la radio se pensó que la lectura, los libros y las revistas estaban en vías de extinción. La televisión creó otra serie de expectativas y de nueva cuenta se dijo que la lectura, los libros y las publicaciones desaparecerían; la misma radio, en la que tantas esperanzas se habían fincado, desaparecería remplazada por la televisión.

Lo mismo ha ocurrido con el surgimiento de las tecnologías de comunicación e información, que hizo suponer que todas las formas anteriores de comunicación desaparecerían, desde la escritura y la lectura hasta la televisión.

Pero la tecnología de la información o digital cubre más que sólo la computación. En realidad, cuando hablamos de la brecha digital nos 
estamos refiriendo al menos a cuatro aspectos: electricidad, teléfono, computadora e Internet. ${ }^{4}$

La instalación de computadoras y conexiones es sólo una parte del problema que se tiene que enfrentar para conseguir que la sociedad haga uso de las tecnologías de la información. En el uso de esa tecnología se han puesto demasiadas esperanzas, ya que se piensa que con Internet no sólo se tiene la posibilidad de comunicación y búsqueda de información, sino que se espera que la sociedad en su conjunto se transforme. ${ }^{5}$

Teresa Peters, quien forma parte del grupo de autores que confían demasiado en la capacidad de la TIC para la transformación social, sostiene que el uso de dicha tecnología es un arma importante en la lucha en contra de la pobreza. Argumenta que cuando se usan de manera adecuada, ofrecen un gran potencial para que los habitantes de los países en desarrollo y comunidades marginadas superen los obstáculos que los problemas sociales los obligan a enfrentar, así como fortalecer las instituciones democráticas, una prensa libre y las economías locales; posteriormente reflexiona sobre lo mucho que espera del uso de la tecnología y señala que para que la TIC tenga realmente un impacto en las vidas de los individuos, es crucial que los esfuerzos por lograr el desarrollo vayan más allá del mero uso de las computadoras y de la conexión a Internet. ${ }^{6}$

Es prudente que reflexionemos en que la tecnología de la información cumple una gran variedad de propósitos, no solamente el de proporcionar información a las personas, aunque éste puede ser el más destacado. La TIC sirve como medio de comunicación, como instru-

4 Elena Murelli, Breaking the digital divide: implications for developing countries (S. 1.: Commonwealth Secretariat: SFI Pub., 2002), 2.

5 Donna L. Hoffman, Thomas P. Novak y Ann E. Schlosser, "The evolution of the digital divide: how gaps in Internet access may impact electronic commerce”, Journal of Computer-Mediated Communication 5, marzo 3, 2000, disponible http:// www.ascusc.org/jcmc/vol5/issue3/hoffman.html [Agosto 4, 2004].

6 Teresa Peters, "Bridging the digital divide", Global Issues, noviembre 2003, disponible http:/usinfo.state.gov/journals/itgic/1103/ijge/gj08.htm [Marzo 23, 2004]. 
mento de trabajo al permitir la composición de trabajos escritos, como auxiliar en el diseño gráfico, en la preparación y divulgación de temas financieros y de organización que requieren la cuantificación de información. La TIC es al menos dos cosas: una materia sobre la cual debemos y podemos aprender, y un instrumento de aprendizaje de gran efectividad. ${ }^{7}$

Wadi D. Haddad ha señalado en forma acertada que el problema de la brecha no se refiere en exclusiva a los aspectos tecnológicos, él piensa que esta situación tiene que ver principalmente con aspectos educativos; nosotros añadiremos que también con aspectos sociales y culturales. Asimismo indica que con el avance de las tecnologías de la información y comunicación hay una preocupación genuina sobre quién tiene y quién no tiene acceso a dichas tecnologías. Pero objeta que se pretenda eliminar la brecha exclusivamente publicando un periódico en cada población, logrando que todas las casas cuenten con aparatos de radio y televisión, instalando computadoras en cada salón de clases y colocando en cada edificio los cableados necesarios para conectarse a la red; todo esto no resuelve de manera automática el problema.

La brecha más importante está en la extensión y calidad del conocimiento humano y su aprendizaje. No es una brecha digital, es educativa. 8

Aquí llegamos a un aspecto clave para entender la brecha digital: ésta es mucho más que el acceso a la red. Cuando se aborden los diferentes aspectos de la red se verá con claridad qué elementos sociales

7 Stephen McNair, "The emerging policy agenda", en Centre for Educational Research and Innovation [y] National Center on Adult Literacy, Learning to bridge the digital divide. Education and skills (París: Organisation for Economic Co-operation and Development, 2000), 12.

8 Wadi D. Haddad citado por OECD Secretariat, "Emerging trends and issues: the nature of the digital divide in learning", en Centre for Educational Research and Innovation [y] National Center on Adult Literacy, 52. 
son determinantes y en qué sentido, para comprender la complejidad de variables que influyen en la llamada brecha digital.

No hay duda de que Internet y las tecnologías asociadas han hecho un enorme aporte a la comunicación de la humanidad y por ello nos referimos no sólo a la posibilidad de comunicación mediante el correo electrónico, sino a las charlas (chat) mediante el uso de la computadora, a la incorporación de voz e imagen complementada con la capacidad de transmisión de datos e imagen. Todo esto sorprende a las personas que crecieron en un medio en el que la correspondencia escrita era común, por sus bajos costos, y donde los otros métodos de comunicación como el telégrafo y el teléfono tenían serias limitaciones, en especial cuando la comunicación se establecía entre lugares remotos.

En la actualidad Internet ha sorprendido a todos, y su apropiación y uso por millones de personas la han convertido en una de las tecnologías más importantes del siglo XX. El correo electrónico maravilló al mundo y transformó la comunicación humana, pues antes de Internet era impensable que millones de personas pudieran comunicarse unas con otras en cuestión de segundos, o tener una comunicación escrita o de voz e imagen con la eficiencia y amplitud con que se hace hoy en día por Internet entre lugares remotos. Tampoco se pensó que la localización y uso de información se pudiera hacer con la rapidez que permite la navegación en la red, y la libertad y eficiencia con que se hace. 9

Vamos pues a intentar comprender y explicar los diferentes problemas a los que se enfrenta la TIC para lograr su éxito; cómo las condiciones sociales de una comunidad, sea ésta una localidad, una región, un país o el total de la humanidad, son importantes y condicionan el éxito en la utilización de la tecnología de la información.

El fenómeno de la brecha digital no se crea por sí mismo con el uso de las TIC, la sociedad ha tenido desde siempre diversos desajustes entre sus miembros. Estos desajustes se refieren a niveles educati-

9 Murelli, 1. 
vos: alfabetizados versus analfabetos; personas con educación básica versus quienes no la tienen, personas que pueden obtener todo lo que desean versus personas con carencias de todo tipo, problemas generacionales que conducen al enfrentamiento entre jóvenes y viejos, diferencias entre géneros, en especial en las comunidades en que la mujer no es considerada como igual, diferencias entre quienes habitan una zona geográfica rica versus quienes habitan regiones de muy escasos recursos o comunidades urbanas contra grupos rurales.

La brecha entre quienes tienen acceso a la información y quienes carecen de esta posibilidad es un fenómeno global que lo mismo cubre a los individuos que a los habitantes de un barrio, de un país, de varios países e inclusive de continentes. ${ }^{10}$ La brecha digital existe entre países y se mide usando una serie de elementos, y no sólo los aspectos tecnológicos. Estos elementos son los que pretendemos analizar en este trabajo. Así, por ejemplo, para Peters ${ }^{11}$ la brecha se mide en relación al número de teléfonos, computadoras y número de usuarios. Entre grupos de personas en un mismo país, se mide en términos de raza, género, edad, discapacidad, ubicación e ingreso económico. Esta multiplicidad de factores hace difícil el estudio de la brecha digital pues es posible que mientras algunos grupos mejoran, otros sufran retrocesos, ganando en una parte y perdiendo en otra.

El impacto benéfico del uso de Internet puede ser mayor para los países pobres que para los países ricos ya que los primeros podrían saltar algunas etapas de desarrollo y realizar actividades productivas mediante la utilización de la TIC. Los países ricos cuentan con una infraestructura en comunicaciones que les permite el intercambio de mensajes con gran eficiencia, poseen también sistemas bibliotecarios que los proveen de información en todos los niveles. Si los países pobres logran superar los obstáculos básicos, tendrán acceso a una verdadera revolución de las comunicaciones y de la búsqueda, localización y uso de la información. La TIC también promete dar voz

10 McNair, 17.

11 Peters, 1. 
a quien no la tiene y a quien no cuenta con canales de publicación, o acceso a la televisión y otros medios de comunicación. ${ }^{12}$

Pero así como Internet es una gran oportunidad, si no se logran superar los obstáculos básicos puede convertirse en un elemento más de división social a nivel global. No en balde el informe de las Naciones Unidas sobre el desarrollo nos advierte que la productividad obtenida por el uso de Internet puede ampliar la brecha entre los países que hacen un uso efectivo de la red y aquellos que no logran superar las barreras más elementales. ${ }^{13}$

El problema de la brecha digital no es solamente el fenómeno de acceso a la red y a la información, es un reto para los funcionarios encargados de establecer e impulsar políticas que tiendan a disminuir la iniquidad e injusticia social. Por ejemplo, es necesario que nos preguntemos: ¿Qué deben hacer los gobiernos para lograr la equidad y justicia social? ¿Qué pueden hacer los gobiernos para asegurar que las nuevas tecnologías no marginarán a parte de la población? ¿Cómo posibilitar que las oportunidades que ofrece la tecnología de la información puedan ser disfrutadas por la mayoría de la sociedad? ${ }^{14}$ Porque existe el riesgo de que si los gobiernos no intervienen la brecha se expanda y llegue a tener características catastróficas para la sociedad y que

Las personas educadas y que por lo tanto son ricas en información sean cada vez más ricas y las no educadas y pobres en información cada vez estén en una situación de menor información, o sea, cada vez más pobres. 15

12 Pippa Norris, The worldwide digital divide: information poverty, the Internet and development (Cambridge, Mass.: John F. Kennedy School of Government, Harvard University, 2000), 2. Disponible http://ksghome.harvard.edu/ pnorris/acrobat/psa2000dig.pdf [Agosto 1, 2005].

13 UNDP, Human development report (Nueva York: UNDP, 1999), 63. Citado por Pippa Norris, The worldwide digital divide, 3.

14 McNair, 9.

15 Ibíd., 10. 
En Estados Unidos la preocupación de que el acceso a la información no tenga restricciones se basa al menos en tres premisas, que creo deberían ser aceptadas en otras naciones: primera, el servicio universal es visto como algo esencial para la democracia en ese país, los ciudadanos no pueden participar en forma efectiva en el proceso democrático si no tienen un uso igual e irrestricto de los medios de comunicación. Segundo, el servicio universal es necesario para asegurar igualdad de oportunidades para todos tanto social como económicamente. Tercero, el servicio universal promueve el avance personal, por ejemplo, los servicios básicos de telecomunicaciones son necesarios para conservar un buen trabajo y para buscar mejores oportunidades. ${ }^{16}$

Existe también un grupo de personas que piensan que el tema de la brecha digital se ha exagerado y que en realidad no tiene las características catastróficas que en algunos escritos se le asignan. Después de todo, dicen, el mayor uso de Internet es para correo electrónico y para otras cosas que no necesariamente están relacionadas con la información. Para este grupo de personas es más importante que los ciudadanos tengan otras habilidades que tienen que ver más con la educación en general, y la lectura en particular, que con los aspectos tecnológicos. Si bien es cierto que hay aspectos que deben ser contemplados antes que los tecnológicos, también lo es que éstos tienen relevancia aunque no sean más que la muestra más moderna de las iniquidades que sufre la sociedad y que una sociedad más justa no tendría por qué enfrentar.

La brecha digital mundial tiene dos formas. La primera es la brecha internacional, que como el presidente Mandela ha expresado, es entre los países ricos y los pobres, y la segunda es la brecha intranacional, que divide a cada uno de los países de una forma diferente y con características propias. ${ }^{17}$

16 Appu Kuttan y Laurence Peters, From digital divide to digital opportunity (Lanham, Maryland: Scarecrow Press, 2003), 7.

17 Ibid., 105. 
Sin embargo, el uso de la tecnología es visto por muchos dirigentes políticos como una forma de igualar a las personas en sus procesos de aprendizaje y de darles herramientas para poder competir en un mundo moderno, tecnologizado, que ofrece nuevos puestos de trabajo para los cuales se requiere contar con conocimientos sobre la TIC. En 1999 Bill Clinton, entonces presidente de los Estados Unidos, hizo la siguiente afirmación:

Las computadoras, la Internet y los paquetes de programación educativos pueden hacer una diferencia en la forma en que los profesores enseñan y los estudiantes aprenden. Debido a nuestros esfuerzos, los niños de lugares muy alejados y aislados tanto de los suburbios o de las zonas rurales tienen la misma posibilidad de acceder al mundo del conocimiento que los niños que viven en los suburbios más ricos. Los padres tendrán la posibilidad de comunicarse más frecuentemente con los profesores y estar informados de los avances de sus hijos en la escuela. Nuestros niños serán alfabetizados en tecnología y estarán mejor preparados para los trabajos de alta tecnología y altos salarios que el futuro demandará. 18

Sin una comprensión del papel que juega o jugará la tecnología en sus vidas, así como en sus trabajos, la gente no será capaz de entender por qué necesita la tecnología en sus vidas. ${ }^{19}$ Esto nos lleva a que la brecha digital no podrá ser cerrada desde dentro si las personas no han utilizado previamente otras tecnologías que les permitan entender el papel de la tecnología misma en sus actividades diarias. Sólo quien cuenta con experiencias previas aceptará fácilmente la utilización de las TIC, las otras personas estarán de acuerdo con ella dependiendo de intereses personales en tanto que algunos se opondrán a ellas por no comprender para qué les son de utilidad.

18 Bill Clinton citado por David B. Bolt y Ray A. K. Crawford, Digital divide: computers and our children's future (Nueva York: TV Books, 2000), 48.

19 Ibíd., 64. 
Figura 1

La brecha digital es la diferencia entre quienes tienen y quienes no tienen...

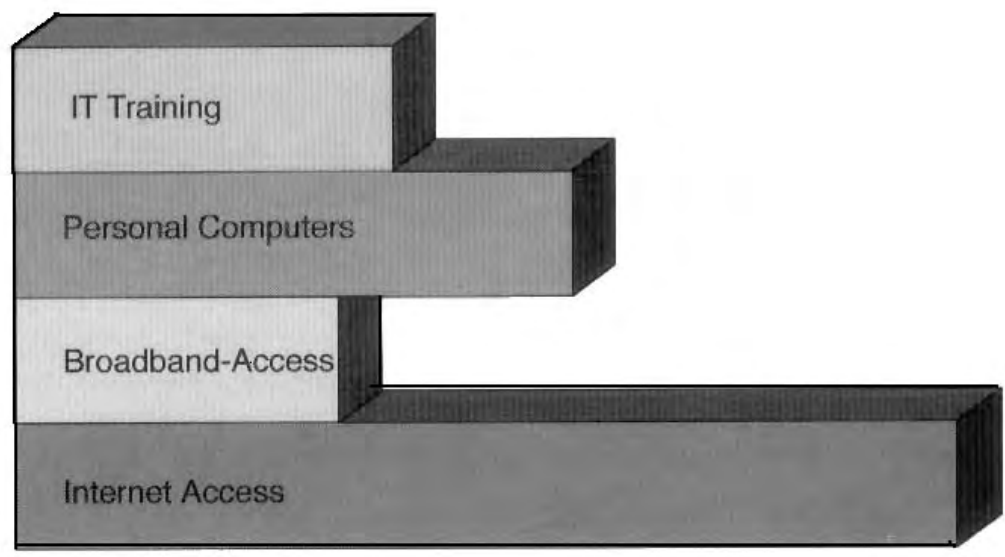

Tomado de Appu Kuttan y Laurence Peters, From digital divide to digital opportunity (Lanham, Maryland: Scarecrow Press, 2003), 2.

Algunos autores, entre ellos Kuttan y Peters, dividen la brecha digital atendiendo a las características tecnológicas y a las características sociales. Entre las primeras señalan cuatro aspectos que se ilustran en la figura 1, y que consideran relevantes para la caracterización de la brecha digital en Estados Unidos: 1. El entrenamiento en tecnologías de la información; 2. La posesión de computadoras personales; 3 . La utilización de banda ancha; y 4 . El acceso a Internet. Estos cuatro aspectos corresponden a la naturaleza tecnológica de la brecha digital, que será analizada en el capítulo "Acceso a la tecnología de la información y comunicación”, por ahora digamos solamente que estos cuatro aspectos influyen en la brecha entre aquellos que tienen acceso a la tecnología de la información y quienes no. Como se puede ver en la gráfica, la mayor parte de las personas utilizan la línea telefónica normal para navegar por la red; una tercera parte de las personas utilizan la red mediante una conexión de banda ancha y sólo la mitad de todos los incluidos en esta muestra poseen una computadora. 
Figura 2

La brecha digital es la diferencia entre...

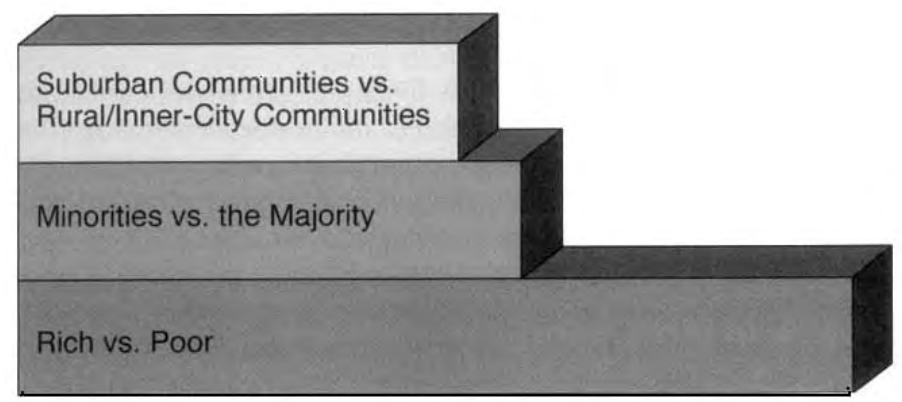

Tomado de Appu Kuttan y Laurence Peters, 3.

Las características sociales de la brecha digital en Estados Unidos, como se observa en la figura 2 , están relacionadas con aspectos tales como ingreso económico, mayorías-minorías y etnia. También incluyen la distribución geográfica de la población: zonas rurales, zonas suburbanas y ciudades. Esta caracterización es importante pues relaciona la diferencia en el acceso tecnológico con las características sociales que determinan y/o condicionan de alguna forma la brecha digital y que serán tratadas en el capítulo "La tecnología de la información y comunicación en el mundo”.

Dos aspectos favorecen la utilización de las tecnologías de la información, con lo que se tiende a disminuir la brecha cuando los esfuerzos para reducirla son consistentes en ambos lados de ella. Uno es el firme y decreciente precio de las TIC y el otro es el aumento constante de su utilización. ${ }^{20}$

20 Benjamin M. Compaine, ed., The digital divide: facing a crisis or creating a myth? (Cambridge, Mass.: MIT Press, 2001), ix. 
La lectura y la escritura durante siglos han utilizado el lenguaje en sí mismo, pero también adicionalmente otros instrumentos físicos entre papiros, códices, libros, lápices, plumas fuente y máquinas de escribir. El desarrollo y la aceptación social de cada uno de estos instrumentos ha significado un profundo efecto en la práctica de la lectura y la escritura; del mismo modo es lógico suponer que el uso de las TIC provocará que las actuales prácticas se modifiquen sin que necesariamente tiendan a desaparecer las formas anteriores. ${ }^{21}$

Hay varios enfoques sobre lo que una política pública de apoyo y fomento a la TIC debe comprender, y para aclarar algunas de las formas que pueden adoptar, analicemos a continuación los siguientes aspectos: ${ }^{22}$

1. Asegurar un acceso universal a los equipos de cómputo y a otros instrumentos necesarios para el establecimiento de una conexión a la red, así como la posibilidad de usar los paquetes de programación que ayuden a un uso óptimo de las TIC;

2. Cambiar los papeles que juegan los maestros y los estudiantes en el proceso educativo, lo cual incluye el entrenamiento que los profesores necesitan para ayudar a sus estudiantes;

3. Promover la educación continua como un elemento de mejoramiento individual y colectivo;

4. Asegurar que el uso de las TIC derive en una mayor calidad en el proceso educativo, así como en la investigación y en la prestación de los servicios;

5. Dirigir el esfuerzo del Estado a fortalecer la participación ciudadana en las actividades comunitarias y gubernamentales;

6. Establecer agencias de servicio que sean intermediarias entre la oferta de servicios y su demanda social, con el objeto de optimizar su uso;

21 Mark Warschauer, Technology and social inclusion: rethinking the digital divide (Cambridge, Mass.: MIT Press, 2003), 110.

22 McNair, 17-19. 
7. Apoyar la investigación, la cual puede obtener un gran apoyo en la utilización de las TIC; y

8. Cambiar el papel que los elaboradores de las políticas educativas juegan en este aspecto.

Un aspecto que debe cuidar toda política pública, y las relacionadas con las TIC no son la excepción, es el tema de los derechos humanos.

El punto de partida en la tarea de crear un marco regulatorio para la sociedad de la información es el respeto a los derechos humanos fundamentales. La brecha digital tiene implicaciones que superan las condiciones económicas y materiales. Se trata de un abismo simbólico en la distribución de información, la participación ciudadana, la inclusión y la representación política, los servicios sociales, la seguridad y las medidas preventivas, el disfrute del arte y los bienes culturales y la participación en la vida cultural de una comunidad en el sentido más amplio (ya sea local, nacional o mundial). El derecho "de investigar y recibir información y opiniones, y el de difundirlas sin límite de fronteras" es uno de los derechos humanos fundamentales que sirve de apoyo a todos los demás. El surgimiento de la sociedad de la información debería ampliar y reforzar este derecho básico (APC, 2002; CRIS, 2002; Bonilla, 2002). En este sentido, las TIC, en tanto favorecedoras de la información y la comunicación, son simultáneamente derechos y herramientas, "bienes de valor social" de acuerdo con la terminología de la economía del bienestar. La infraestructura global de información es un instrumento para los demás derechos económicos, sociales y culturales, y es uno de los ejemplos más tangibles de un "bien público global" que proporciona los fundamentos de la ciudadanía mundial $\left(\right.$ CEPAL, 2002 ${ }^{\mathrm{a}}$ ). El objetivo consiste en hacer efectivo el derecho a la información y a la comunicación mediante el bien público global que debe ser la participación en las TIC. 23

La CEPAL ha realizado un análisis de los diferentes aspectos que conforman las tecnologías de la información. Los elementos que contiene este análisis se encuentran en la figura 3.

23 CEPAL, Los caminos hacia una sociedad de la información en América Latina y el Caribe (Santiago de Chile, CEPAL, 2003), 42. 
Figura 3

Estratos horizontales, sectores verticales y áreas diagonales de la sociedad de la información

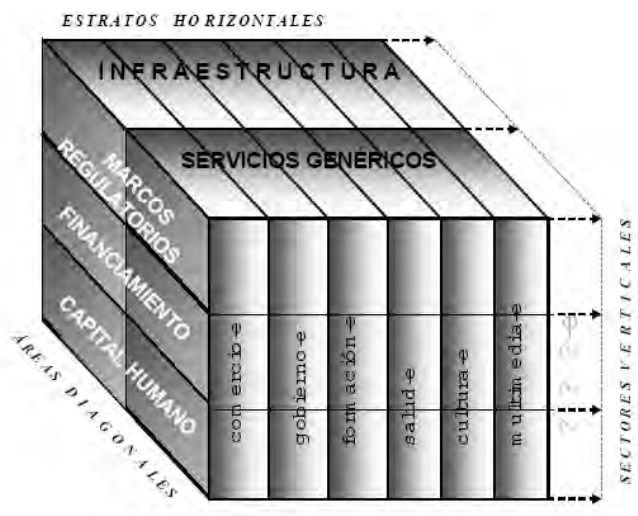

Tomado de CEPAL, Los caminos hacia una sociedad de la información en América Latina y el Caribe (Santiago de Chile, CEPAL, 2003), 15.

El modelo de la CEPAL propone que el problema sea analizado desde un plano tridimensional; así, parte de un estrato horizontal que se compone de dos aspectos: el primero vinculado a los equipos de cómputo y comunicaciones que ha denominado "infraestructura", y el segundo relacionado con los aspectos de programación y software a los cuales ha nombrado "servicios genéricos."

El segundo eje que considera es aquel que se refiere a los apoyos que el sector público tiene que ofrecer a la sociedad para que las tecnologías de la información no se conviertan en un elemento de marginación. Estas son las llamadas "áreas diagonales", que se integran por tres aspectos. El primero es un marco regulatorio, políticas de información, leyes que regulen las actividades o que promuevan el desarrollo de éstas; a continuación está el financiamiento que se debe otorgar como resultado de las políticas públicas y que debe asegurar que se logren los objetivos que las políticas han trazado; y por último los recursos humanos calificados que garanticen la adecuada ejecución de los 
programas para que la tecnología de la información sea utilizada en la construcción de una sociedad más informada y más justa.

Por último, están los aspectos sobre los que inciden las tecnologías de la información y a los cuales se les conoce genéricamente con el sufijo e- (e-comercio, e-educación, e-gobierno, y muchas otras más), que son expresiones de la vida diaria en las cuales las tecnologías de la información han tenido un gran impacto.

Pero para muchas de las sociedades menos desarrolladas, que sufren de todo tipo de problemas que avivan su atraso - una deficiente estructura económica, una importante deuda externa, enfermedades, retraso educativo e insuficiencia tecnológica- su incorporación al mundo digital puede tomar muchos años, e incluso es posible que no se consiga de forma satisfactoria, ya que cuando alcancen los actuales niveles del desarrollo, los países desarrollados habrán dado pasos muy importantes ampliando la brecha que los separa de los países menos avanzados; parece que es una carrera contra el tiempo en la cual los más pobres están condenados a permanecer rezagados. ${ }^{24}$ Este planteamiento es muy pesimista y nos lleva a preguntarnos si todas las brechas son iguales y si se comportan de la misma forma. Porque no es lo mismo superar la diferencia entre los miembros de una misma sociedad con diferentes niveles de desarrollo que hacerlo entre sociedades distintas, según los elementos mencionados anteriormente.

La Unesco ha presentado un informe gris sobre las posibilidades de estrechar la brecha entre los países pobres y los países ricos, basado en los avances que se logran en el campo de las tecnologías de la información y su uso como instrumentos necesarios para tener acceso a la información. La sociedad conectada en red está creando sistemas de comunicación paralelos: uno para aquellos que tienen un ingreso, una educación y las conexiones literarias que les permiten tener acceso a información a bajo costo y alta velación, y el otro para aquellos que no cuentan con conexiones, que están bloqueados por

24 Norris, Digital divide, 5. 
las altas barreras de costo del tiempo, que no tienen certidumbre y que están condenados a utilizar información obsoleta. ${ }^{25}$

A partir del concepto de que la sociedad de la información es aquella que utiliza información como motor de desarrollo, se ha dejado atrás a otros tipos de sociedad que han tenido motores diferentes como en su momento lo fueron la tierra, la industria y el capital. La información está estrechamente relacionada con los individuos y las sociedades, son estos elementos quienes reciben las modificaciones que produce el conocimiento o know-bow. Este conocimiento no es externo a los individuos, no se puede comparar con la tierra, la industria o el capital; lo que enriquece a la sociedad es que sus miembros estén mejor educados e informados, por lo que el conocimiento se convierte en el motor de la sociedad y por ello es tan importante el acceso a la información. Con información la sociedad encuentra una forma de acelerar su desarrollo y superar los rezagos a los que se ve sometida como producto del retraso educativo, cultural e informativo.

Existe una dificultad mayor al tratar de caracterizar a la brecha digital, ésta es que las condiciones tecnológicas, individuales y sociales son cambiantes, por lo que los datos de que se dispone son como fotografías que describen la situación en el momento en que fueron obtenidos. Posiblemente muchos de los datos con que se cuenta y que han sido empleados en la elaboración de este documento han cambiado en los últimos años y meses; además la intención al presentar la información aquí contenida es explicar el fenómeno y lo complejo que resulta su estudio, ya que no es un fenómeno que esté relacionado únicamente con los aspectos tecnológicos, sino que tiene una profunda influencia en el desarrollo individual y social y que al modificarse a diario hace que lo que era exacto en el momento de compilar la información, no lo sea más. Sin embargo la información presentada nos es útil para explicar lo que es la brecha digital, sus relaciones con diferentes variables y cómo se ha modificado en el curso de los últimos años.

25 UNDP, Human development report (Nueva York: UNDP, 1999), 63. 
Las visiones que existen sobre el uso de las tecnologías de la información son contrastantes. Dependiendo del enfoque que se tenga de su utilidad se puede apreciar a la tecnología como un elemento positivo o negativo.

El debate sobre el impacto que tienen en el surgimiento de la Sociedad de la Información ha producido visiones profundamente contrastantes sobre su futuro y sus tendencias. Los optimistas esperan que el desarrollo de Internet tenga la capacidad de reducir, aunque no erradicar totalmente, las iniquidades tradicionales entre quienes son ricos en información y quienes son pobres en ella, así como otras diferencias sociales. En contraste, los pesimistas piensan que las tecnologías digitales reforzarán y exacerbarán las disparidades existentes. Los escépticos sugieren que tanto los miedos como las esperanzas son exagerados, con las tecnologías incorporándose al statuo quo social y político.26

Las posturas relativas a la bondad o maldad de la TIC no ponen en duda el paradigma de la sociedad de la información, es decir, que a diferencia de las teorías económicas precedentes, el conocimiento es valorado como recurso indispensable para el desarrollo económico y social que permitirá que los individuos y los pueblos mejoren su calidad de vida.

En este contexto las TIC se han colocado en el centro del debate no sólo como catalizadoras de un cambio positivo, como instrumento de liberación, a través del cual los individuos logren acceder y disfrutar de sus derechos y dignidad como personas, sino como una más de las iniquidades que han caracterizado la historia de la humanidad y que limitan la posibilidad del desarrollo individual y colectivo.

Algunos estudios sobre la brecha digital se han restringido al vertiginoso desarrollo tecnológico y su difusión, despojándola de su connotación social incluso como instrumento de dominio y superioridad individual y colectiva, por arriba de los valores y derechos universales.

Las diferentes apreciaciones del problema se valoran más claramente cuando se trata de definir el concepto de brecha digital.

26 Norris, Digital divide, 26. 



\section{¿Qué es la brecha digital?}

- stablecer la definición correcta e inequívoca de la brecha digital resulta más complicado de lo que a primera vista parece. Los criterios para definirla varían de una comunidad a otra, de un país a otro y de una sociedad a otra. Al tratar el tema, algunos países orientan la información sólo a la población adulta, en tanto que otros también consideran a los niños y a los adolescentes. Unos desglosan la población por grupos étnicos mientras que otros no lo hacen, la información en ocasiones se proporciona agregada incluyendo a hombres y mujeres, mientras que en otras se establece la distinción de género. Otro elemento es el tiempo de uso o conexión con la red, sin embargo en algunos lugares esta variable no es considerada importante y en las encuestas no se recoge información al respecto, o no se usa para conocer el tamaño real de la brecha.

La premisa básica de la brecha digital es la diferencia que existe entre individuos y sociedades que tienen acceso a los recursos tecnológicos de cómputo, telecomunicaciones e Internet. Pero como se pretende demostrar en este estudio, eso no es suficiente, hay otros aspectos que también tienen que ser estudiados como la educación, la lengua, el género, la tecnología disponible (teléfonos, electricidad, cómputo e Internet), la diferencia económica, la generacional y la geográfica entre otras.

Una diferencia más amplia es la que enfatiza el acceso a la información como el elemento relevante y no tanto el acceso a la tecnología. Este enfoque resulta más significativo, pues le da un sentido más am- 
plio al uso de la tecnología, con un propósito determinado, y no el uso de la tecnología en sí mismo.

Chen y Wellman han argumentado con gran claridad este aspecto al expresar que:

Fundamentalmente la brecha digital se refiere a la brecha que existe entre individuos y sociedades que tienen los recursos para participar en la era de la información y aquellos que carecen de ellos. 1

Llama la atención el énfasis de Chen en el valor que tiene la información para que la sociedad funcione adecuadamente; quien no tiene acceso a la información o lo tiene de modo marginal, se ve excluido del desarrollo social y de la incorporación exitosa al curso del mismo.

Con una visión semejante sobre Internet, Gomez la concibe como un reflejo acertado de las diferencias e injusticias sociales, de las cuales la posibilidad de acceso a la red es tan sólo una más:

Internet es un salón de espejos. En sus múltiples imágenes, sus usos reflejan las iniquidades y las injusticias de las sociedades en las cuales se encuentra inserto. Así, las tecnologías de la información no son positivas o negativas en ellas mismas, pero tampoco son neutrales. Ellas toman la forma y dirección de la sociedad en la que son introducidas y al mismo tiempo contribuyen a darle forma a las relaciones y modelos de interacción en esas sociedades. 2

La utilización de Internet ha cambiado en cierta medida la concepción que teníamos del uso de las tecnologías de la información: de una serie de tecnologías aisladas, o más o menos conectadas, pasamos a tener el concepto de que vivimos en un mundo donde las redes de comunicación y de información son esenciales. La idea de red

1 Wenhong Chen y Barry Wellman, Charting and bridging digital divides: comparing socio-economic, gender, life stage, and rural-urban Internet access and use in eight countries, disponible http:www.amd.com/us-en/assets/content_type/ DownloadableAssets/FINAL_REPORT_CHARTING_DIGI_DIVIDES.pdf [Agosto 6, 2004], 24.

2 Ricardo Gomez citado por Appu Kuttan y Laurence Peters, From digital divide to digital opportunity (Lanham, Maryland: Scarecrow Press, 2003), 1. 
es en la actualidad básica para la transmisión de la información y para su incorporación al grupo de habilidades con que cuentan en la actualidad quienes hacen usos exitosos de la red. Por ello es necesario pensar que quienes están excluidos de la TIC lo están de los beneficios que les puede proporcionar la red.

Los criterios para evaluar la brecha en diferentes sociedades son un obstáculo difícil de superar ya que no hay pautas claras para definir quién es un usuario de Internet. En algunos casos para determinar las características del usuario de Internet se han formulado los siguientes cuestionamientos: ¿Qué tan frecuentemente utiliza la red? ¿Dónde la utiliza, en la casa o en los lugares públicos como escuelas o bibliotecas?, o bien, ilos usuarios de Internet son aquellos que tienen acceso a la red desde sus propias computadoras?

¿Debe hablarse de una brecha o de varias brechas que impiden el acceso a los recursos digitales? Esta circunstancia hace difícil establecer una política semejante a todos los individuos y a todas las sociedades; así como entre los individuos, las sociedades poseen características diferentes y lo que es adecuado para una persona o para una comunidad, no necesariamente lo es para otra, incluso con el mismo nivel de desarrollo.

No sólo no se reduce la brecha, sino que en algunos casos la diferencia entre quienes tienen acceso y quienes no lo tienen se ha ampliado, pues paradójicamente algunos esfuerzos para reducirla han tenido como efecto secundario ampliarla en otros aspectos. Por ejemplo, al instalar computadoras en las escuelas se reduce la brecha entre los alumnos que no tienen acceso en sus casas, pero se amplía con respecto a quienes no están asociados a una escuela. No existen medidas que satisfagan todas las necesidades existentes o que cierren todas las brechas.

Otro obstáculo para una correcta definición de la brecha digital se encuentra en la frecuencia con la que se usa la red. ¿Quién es usuario de Internet? En algunos lugares se considera como usuario a quien tiene acceso a la red, sin importar la frecuencia con que la use; en otros, se establecen mínimos de uso a la semana o al mes para que un individuo pueda ser clasificado como usuario de la red. 
Por otra parte, también surgen discrepancias sobre la contabilidad de los usuarios de Internet, ¿cómo contabilizarlos, por hogar o por individuo? Estos criterios pueden conducir a que las cifras varíen considerablemente, pues contabilizar a todos los miembros de una familia como usuarios de Internet por el solo hecho de que la casa tenga conexión, permite que se incremente artificialmente el número de usuarios. No todos los miembros de una familia utilizan la red, ya sea por ser muy pequeños o bien por ser mayores y resistirse a la utilización de recursos electrónicos.

El concepto de brecha digital es aceptado ya por muchos individuos y organizaciones. En Estados Unidos se reunieron los principales ejecutivos de 45 empresas, entre ellas Microsoft, Cisco y General Electric. Este grupo llegó, entre otras conclusiones, a caracterizar a la brecha digital como una amenaza para la prosperidad de los Estados Unidos.

Sin embargo, cuando se trata de definir el problema de la brecha es conveniente tener en cuenta que ésta se relaciona con las políticas públicas de acceso a la información y no debe confundirse con la simple disponibilidad o carencia de instrumentos tecnológicos. Cuando se comete ese error se intenta sustituir la política con la tecnología.

Hay que aclarar que la dificultad para tener acceso a ciertos servicios no es algo nuevo y exclusivo del uso de las tecnologías de la información. Las sociedades, desarrolladas o no, han necesitado largos periodos para llegar a tener una cobertura total de los servicios telefónicos, de la misma forma en que lo hicieron para disfrutar de la electricidad. Los grupos con mayores recursos tuvieron acceso a esos servicios más fácil y rápidamente en las zonas urbanas que en las rurales. Aún en muchos países desarrollados la posibilidad de disfrutar de servicios telefónicos en áreas rurales y lejanas de los centros urbanos e industrializados es un problema por enfrentar.

La brecha digital puede ser considerada también como una forma de segregación basada en la aplicación de la tecnología; pero como lo ha expresado el presidente de la National Association for the Advancement of Colored People (NAACP), Kweisi Mfume, la brecha digital es una "segregación tecnológica". Si se contempla como una forma de exclusión basada en las capacidades de tener acceso a los recursos en línea, la segregación es en realidad una exclusión tecno- 
lógica, pero que como muchas segregaciones está basada en la carencia de recursos económicos que permitan tener acceso a los recursos digitales. ${ }^{3}$

La "brecha digital" es una metáfora adecuada para describir la desventaja de aquellos que no son capaces o que deciden no hacer uso de las tecnologías de la información para sus actividades diarias. ${ }^{4}$

El problema del acceso a la red no se puede plantear como un asunto de ganar o perder, es necesario tener acceso a la red y permanecer en ella. La brecha no podrá cerrarse si solamente se tiene la intención de lograr el acceso y no se le da importancia a su uso, pues en realidad su utilización es lo más importante en el momento de definir el significado de brecha digital.

La brecha digital es un fenómeno cambiante que se estima debe tender a cerrarse a la larga, pero desde que este fenómeno ha sido estudiado no se ha podido establecer un patrón en ese sentido ya que sus diferencias están basadas en diversas iniquidades. ${ }^{5}$ Parece que las características de la brecha digital están cambiando constantemente, aunque algunos rasgos se mantengan en forma permanente; además, sería más justo hablar no de una sola brecha sino de un conjunto de brechas o diferentes características de una brecha.

Los elementos que se pueden analizar para entender el problema de la brecha son muchos, pero entre los más importantes están los relacionados con el estatus económico, el género, la edad, el nivel educativo, la localización geográfica, la pertenencia a ciertos grupos étnicos y el nivel educativo.

Sin temor a equivocarnos podemos sostener, como lo hacen Chen y Wellman, ${ }^{6}$ que la mayor brecha es aquella que se encuentra entre

3 Sonia Arrison, "What digital divide?", CNET News.com, marzo 13, 2002, disponible http://news.com.com/2010-1071-858537.html [Marzo 21, 2004].

4 Rowena Cullen, "The digital divide: a global and national call to action", The Electronic library 21, 3 (2003), 247. Disponible http:/www.emeraldinsight. com/0264-0473.html.

5 Chen y Wellman, 2.

6 Ibid., 26. 
dos tipos de personas: una que se encuentra en el lado positivo de la brecha y que tiene como características ser una persona joven, bien educada, que tiene un buen manejo del idioma inglés y habita en una zona urbana desarrollada, y otra que está en el lado negativo de la brecha y que es una mujer, de edad avanzada, pobre, sin manejo del idioma inglés, y que adicionalmente vive en una zona rural pobre.

No todos los elementos mencionados se encuentran en una sola sociedad, lo que nos presenta Chen es una visión global y sintética. Ni que decir que hay brechas muy grandes entre las personas que hablan el inglés como lengua materna y quienes no, o que hay sociedades en las que la brecha entre hombres y mujeres es muy pequeña. Pero si tuviéramos que describir los elementos que producen la brecha en el ámbito global, estos serían la mayoría.

Moorhead comparte una visión inglesa sobre el mismo problema de la caracterización y al establecer los perfiles de los usuarios y de los no usuarios de Internet ha identificado en qué lado de la brecha se encuentran. Moorhead señala:

Usted es blanco, hombre, entre 16 y 24 años de edad, posee un alto ingreso, vive en Londres, usa la Internet para realizar sus compras y está conectado a la red, aproximadamente nueve horas a la semana, entonces usted está en el lado "correcto" de la brecha digital. Pero si sus características son diferentes y es usted una mujer, no cuenta con 16 años de escolaridad (nivel superior), es mayor de 50 años de edad, habita en la zona rural de China y no tiene acceso a Internet, entonces usted está en el lado "incorrecto o equivocado" de la brecha digital. 7

Hay que entender que en esta caracterización las menciones a los países no representan una actitud de superioridad ni de menosprecio, simplemente se trata de ejemplificar las diferencias entre un país desarrollado y otro en vías de desarrollo.

7 Patrick Moorhead, A profile of the digital divide, Advanced Micro Devices, 2004, disponible http://www.amd.com/de-de/Corporate/Careers/0\%2C\%2C51_82_621 _ 52^5806^9935\%2C00.html [Marzo 23, 2004], 1. 
Los gobiernos son especialmente importantes para clarificar los términos de la discusión, así como los límites de la solución y la búsqueda de respuestas a la problemática existente. No hay que dejar de tomar en cuenta que los argumentos que se presentan a favor de tal o cual acción para cerrar la brecha digital se convierten en parte de la definición que se pretende dar al problema. Toda solución implica una concepción del problema y una conceptualización de los elementos que lo componen, por lo tanto ofrecer una respuesta sólida y rigurosa, que no sea simplemente una ocurrencia, conlleva la definición que se tiene del problema.

Light nos ofrece tres conceptos que no son excluyentes pero sí diferentes sobre la brecha digital. Estos conceptos han sido expresados por tres autores diferentes de la siguiente manera:

Tres definiciones breves equiparan a la brecha digital con distintas cosas y las caracterizan de diversa manera: disparidad entre varios grupos en las áreas de computación y de utilización de Internet (Henderson, 200, p. 60), diferencia entre los que tienen acceso a la información y los que no lo tienen ("Digital Divide Goes Beyond Internet Access", 1999), y la desigualdad en la posesión de una computadora y su uso (Crew, 2000). 8

Light nos invita a reflexionar sobre la solución simple que se le ha querido dar al problema de la brecha digital, que al considerarlo como un asunto de mera disponibilidad tecnológica circunscrito a la carencia de computadoras y equipo de tecnología de la información, no se ha reconocido que detrás hay un problema de iniquidad en las condiciones sociales de los grupos humanos. ${ }^{9}$

El tema de la brecha digital también es discutido por diferentes grupos sociales, cada uno de los cuales ve ventajas en reducir la brecha, aunque sus objetivos no sean necesariamente los mismos. Así por ejemplo, es distinto el enfoque entre liberales y conservadores,

8 Jennifer S. Light, "Rethinking the digital divide", Harvard Educational Review 71, 4 (Invierno 2001), 713.

9 Ibid., 711. 
es decir entre quienes lo ven como un problema, hasta quienes piensan que no es tal y dan mayor énfasis a otros aspectos.

Los liberales sostienen que es necesario aumentar el gasto en educación pública como una medida para cerrar la brecha, y los conservadores desean una fuerza de trabajo más capacitada, mejor preparada pero con una mínima intervención del Estado. Están también los líderes tanto del sector público como del privado, que desean ser vistos por la comunidad como aquellos que están contribuyendo a que la brecha educativa y tecnológica se cierre. ${ }^{10}$

En el otro extremo del debate político están quienes piensan que éste ha sido exagerado y que no existe realmente una brecha que sea significativa para la sociedad. Después de todo, argumentan, la mayor parte de las personas que están conectadas a la red hacen uso de la tecnología para su esparcimiento ya sea para chatear o para jugar y conectarse a sitios que no proporcionan sino diversión. Al mismo tiempo piensan que quienes no están conectados no sufrirán un gran daño en el futuro por no utilizar Internet.

Muchas personas se mofan de que la brecha digital sea considerada una crisis, una crisis realmente es el hambre en el mundo, las guerras, el VIH, y los problemas ambientales. Cuando Internet pueda resolver esos problemas entonces realmente se podrá necesitar una computadora y una conexión a Internet. 11

Si la brecha fuera la posesión de una computadora, habría razón para pensar que se exagera pues la posesión de un instrumento, por importante y eficiente que éste sea, no es suficiente para enfrentar la problemática social. Pero en el caso de la brecha digital, la discusión en el fondo es la posibilidad de tener acceso a la información que permita a las personas mejorar su educación, capacitarse laboralmente, y tomar decisiones oportunas y bien informadas.

10 Ibid., 717.

11 Mick Brady, "The digital divide myth", E-Commerce Times, disponible http://www.ecommercetimes.com/story/3953.html [Agosto 11, 2004]. 
Otro grupo de personas se pregunta si Internet es realmente necesaria en esta vida moderna, o tal vez sólo sea conveniente o incluso un lujo. Este grupo equipara la utilización de la TIC con otras tecnologías como la electricidad, el teléfono y la televisión, que en sus inicios fueron vistos como un lujo de las capas más ricas; sugiere que estos instrumentos fueron utilizados cuando mediante otros medios se podían lograr los mismos beneficios. Así, tener o no un televisor en casa fue visto como un capricho de ricos, ya que la radio podía ofrecer diversión e información de la misma forma y además no propiciaba que las familias dejaran de hablar por estar viendo la pantalla. ${ }^{12}$

Bill Gates, uno de los grandes personajes en el desarrollo de la computación y de Internet, rechaza la idea de que la brecha digital exista y expresa al respecto: "La mayoría de las personas carecen de un automóvil y no por ello hablamos de una brecha del automóvil."13

Pero en este caso Gates se equivoca, la brecha puede ser considerada como un mero asunto de implementos de cómputo, pero lo realmente relevante de la brecha digital es el análisis de las posibilidades de que los individuos tengan acceso a información de todo tipo, noticiosa, académica, de difusión, etcétera, que les permita enriquecerse con el acceso a las tecnologías de la información. Porque Internet no es solamente comunicación, es también información. ${ }^{14}$

El concepto de brecha digital ha variado y sigue haciéndolo constantemente en cuanto se incorporan nuevas tecnologías que significan una diferencia entre quienes las tienen y aquellos que carecen de ellas. El concepto de brecha digital surge en un principio para distinguir a quienes poseen una computadora de quienes no la tienen, este primer concepto de la brecha digital refiere al problema de la propiedad de una computadora y no surge sino hasta que los equipos personales son puestos en el mercado y las personas los pueden adquirir para sus casas u oficinas. En 1983 se realiza la primera en-

12 Kuttan y Peters, 10.

13 Dan Richman, "Gates rejects idea of E-Utopia", Seattle Post-Intelligencer, octubre 19, 2000.

14 Kuttan y Peters, 10. 
cuesta sobre este tema en los Estados Unidos y se encontró que las escuelas en los distritos ricos tenían computadoras en una proporción de dos tercios, mientras que las escuelas pobres tenían computadoras exclusivamente en el $41 \%$ de los distritos escolares. ${ }^{15}$

La forma más simple, y tal vez la más limitada, de concebir el acceso a las tecnologías de la información, parte del supuesto de que un individuo es propietario de los instrumentos necesarios. En este sentido, el acceso se define en términos de posibilidades físicas de uso de una computadora y de otros instrumentos tecnológicos. La posesión de una computadora es parte del acceso a la TIC pero no representa el acceso completo, también requiere de una conexión a Internet tanto como poseer la comprensión y las destrezas para usar aquellas en forma tal que tengan un valor social.

En 1989 se inventó la World Wide Web precedida de otros esfuerzos similares pero no tan exitosos; conocida también como la red (Web) o Internet, en un principio no pareció ser valorada del todo aunque pronto adquirió un ritmo de crecimiento espectacular y una importancia similar. La comunidad en línea se duplica cada año según afirma Norris, ${ }^{16}$ y con un crecimiento tan vertiginoso se pensó que la utilización de la tecnología de la información produciría el cierre de la brecha entre quienes tienen acceso a la información y quienes no lo tienen, tanto entre las comunidades locales como a escala mundial.

En el estudio de Norris ${ }^{17}$ se ofrecen tres diferentes definiciones de la brecha digital. La primera describe la brecha mundial o global como la desigualdad que se presenta entre los países industrializados y los que se encuentran en proceso de desarrollo, así como las consecuencias que esto produce. La segunda es la brecha social, que se refiere a la discrepancia que existe en una sociedad o nación determinada entre quienes tienen acceso a la información y quienes carecen de él. Por último, la tercera brecha es democrática, es decir, la disparidad que existe entre

15 Compaine, 3.

16 Norris, Digital divide, 3.

17 Ibid., 4. 
quienes usan y quienes no usan los recursos digitales para participar, movilizarse y comprometerse con la vida pública de una nación.

Las tecnologías de la información que precedieron a Internet también permitían el acceso a la información, pero de forma pasiva: el receptor la recibía y la procesaba internamente, la comunicación era entre el emisor y un grupo de personas aisladas. Con Internet podemos decir que el patrón de comunicación cambia al permitir que la información sea transmitida a muchos que tienen la posibilidad de jugar un papel activo agregando, cuestionando o reelaborando información, es decir, facilita la participación de todos aquellos que estando conectados deseen participar en este proceso de intercambio de ideas o información.

El último eslabón en el proceso de ir definiendo la brecha digital se relaciona con la tecnología empleada en la conexión a Internet, es decir, una conexión de alta velocidad o banda ancha o una conexión vía módem. Por lo tanto, como podemos observar, el concepto de brecha digital no permanece estático, sino que va cambiando en la medida que se utilizan recursos tecnológicos más modernos. ${ }^{18}$

La brecha digital no se compone exclusivamente por el acceso a las computadoras y la conectividad a Internet; sin embargo, este ha sido el enfoque prevaleciente aun cuando debían de incluirse los factores culturales, sociales y económicos que se desarrollarán a lo largo de este trabajo. Algunos de estos factores tienen que ver con aspectos estrechamente relacionados con la tecnología, su adquisición y su uso; otros no tienen una relación tan clara pero son igualmente importantes para comprender el fenómeno de esto que se ha denominado la brecha digital. En el último caso están el contenido de la información, el lenguaje en que está escrita, la educación con que cuentan los usuarios, el nivel de alfabetismo y los recursos comunitarios y sociales. ${ }^{19}$

18 Compaine, xiii.

19 Warschauer, Technology, 6. 
Definir quiénes tienen acceso y quiénes carecen de él es una parte de la explicación, aunque limitada, de la brecha digital. Hay muchos otros elementos que interactúan en este fenómeno y que nos permiten dar sentido y contexto al mismo, esos elementos son determinados por las brechas previas. Quienes se encuentran en el lado negativo de las otras brechas tienen muy pocas posibilidades de estar del lado correcto en la brecha digital, no es una relación estricta de causa-efecto, pero sí es más fácil de superar si se han superado los otros factores mencionados.

La definición de la brecha digital, si bien explica la problemática de acceso a las tecnologías de la información, indica que no estamos ante un fenómeno meramente tecnológico sino más bien ante un fenómeno social que expone parte de las iniquidades sociales. Sólo en la medida en que se comprendan esas iniquidades es posible definir con claridad el problema que representa la brecha digital, para abordarlo desde una gama más amplia de aspectos que le den solución, pero que estén relacionados con matices sociales de los cuales la tecnología es una parte importante.

Para entender mejor lo que la brecha digital es, debemos recurrir al concepto europeo de "inclusión social", que está relacionado con la medida en que los individuos, familias y comunidades participan plenamente en la sociedad y controlan sus propios destinos, tomando en cuenta una variedad de factores relacionados con los recursos económicos, el empleo, la salud, la educación, la habitación, la recreación, la cultura y el compromiso social. La inclusión social no es solamente participar de una parte de los recursos sino también una participación en la determinación de las oportunidades tanto individuales como colectivas.

Para concluir, en un ejercicio de síntesis, se puede decir que la brecha digital es un fenómeno dinámico cuya primera manifestación consistió en la diferencia entre individuos y comunidades que tenían acceso a la tecnología de la comunicación e información y aquellos individuos y comunidades que no tenían acceso a las mismas tecnologías. La idea subyacente en este primer acercamiento fue la importancia que las redes de comunicación e información adquirieron 
para el desarrollo social y económico en el marco de la sociedad del conocimiento.

Aunque el estudio de la brecha digital se inicia en los Estados Unidos, a lo largo de los últimos años otras naciones y organizaciones se han sumado al esfuerzo de definir y evaluar local y globalmente las causas y efectos de la brecha digital. A pesar de que los criterios han variado de un país a otro, ha sido posible identificar algunas variables y su combinación como causales de la brecha digital.

Así entonces se acepta que la brecha digital se determina por:

1. La tecnología disponible, es decir la infraestructura en servicios y la apropiación de la tecnología como resultado de la disponibilidad de recursos financieros;

2. La apropiación social de la TIC como resultado de su utilidad o valor social;

3. La capacidad de las personas para beneficiarse de la TIC, habilidades y aptitudes desarrolladas por los procesos educativos formales e informales;

4. Las condiciones de desarrollo económico de las comunidades;

5. La distribución geográfica de las comunidades; y

6. Las características demográficas de la población.

Ninguna de estas variables es suficiente por sí misma para explicar la brecha digital, ya que como comprobaremos a lo largo de este trabajo, unas y otras están interrelacionadas, convirtiéndose a su vez en origen y consecuencia. 



\section{Acceso a la tecnología de la información y comunicación}

\footnotetext{
l concepto de brecha digital (digital divide), fue popularizado por la publicación del informe Falling Through the Net: A Survey of the 'Have nots' in Rural and Urban America (1995) de la Administración Nacional de Telecomunicaciones e Información de Estados Unidos. Este informe creó conciencia, entre quienes se encargaban de elaborar las políticas públicas de acceso a Internet y aquellos interesados en la prestación de servicios de información, sobre la existencia de amplios grupos de personas que no tenían acceso a Internet e inició el análisis de las variables que intervenían en este escenario. Aunque la información se refería exclusivamente a los Estados Unidos, fue una alerta generalizada sobre la existencia de elementos comunes en otras latitudes que incidían, y aún lo hacen, en la accesibilidad de los servicios de información mediante el empleo de las tecnologías de la información, especialmente Internet. Algunas de las conclusiones más importantes de este informe fueron:

1. Los hogares urbanos que cuentan con un ingreso familiar mayor a los 75 mil dólares anuales tienen 20 veces más posibilidades de tener acceso a Internet que los hogares rurales que tienen el nivel más bajo de ingresos.

2. Mientras que la mayoría de los norteamericanos (58.9 por ciento) que tienen ingresos superiores a los 75 mil dólares anuales usan
} 
frecuentemente Internet, sólo el 16 por ciento del nivel más bajo (entre 5 y 10 mil dólares) también la usa.

3. Entre 1997 y 1998 la brecha digital para el acceso a Internet desde la casa, entre quienes tienen los ingresos más altos y quienes tienen los más bajos, se amplió en 29 por ciento.

Posteriormente, en 1999, se publicó un segundo informe con el título Falling Through the Net: New Data on the Digital Divide; este trabajo amplió la información contenida en el reporte anterior, y sus principales conclusiones se pueden resumir de la siguiente manera:

1. Las personas con formación universitaria tienen ocho veces más posibilidades de poseer una computadora en casa y 16 veces más probabilidad de contar también con una conexión a Internet, que aquellas personas que sólo tienen el nivel de educación básica o elemental.

2. Una familia con ingresos altos, en una zona urbana, tiene 20 veces más posibilidades de tener acceso a Internet que otra familia que vive en una zona rural y que es de bajos ingresos económicos.

3. El niño de una familia blanca de bajos ingresos tiene tres veces más posibilidades de tener acceso a la red que el niño de una familia negra similar y cuatro veces más si se le compara con el niño de una familia hispana.

4. Una familia adinerada descendiente de isleños de la zona Asia/Pacífico tiene trece veces más posibilidad de tener una computadora en casa que una familia pobre negra, y casi 35 veces más de estar conectados a Internet.

5. Aproximadamente el 95 por ciento de las casas de blancos tienen teléfono, desciende a 76 por ciento si se trata de americanos indios, esquimales y aleutianos y 85 por ciento si son hispanos y negros.

En el año 2000 se publicó el tercer informe Falling Through the Net: Toward Digital Inclusion que intenta describir la tendencia hacia la inclusión de sectores sociales a los servicios de la red. El último trabajo publicado es el que lleva por título A Nation Online - How Americans are Expanding Their Use of the Internet (2002). El conte- 
nido sigue muy de cerca la información de los informes anteriores, pero en esta ocasión el cambio de título refleja también un cambio en torno al acceso a la red ya que éste ha llegado a ser un tema importante en la vida social y económica de los Estados Unidos.

Los informes anteriores han puesto de manifiesto, a quienes piensan que el uso de la tecnología es indispensable para eliminar la brecha digital, que si bien el uso de la tecnología de la información es un elemento necesario, aún no es lo suficientemente poderoso para eliminar la brecha; la TIC todavía no es tan importante como el agua y la electricidad. El uso de la tecnología puede servir para cerrar la brecha, pero son las desigualdades previas las que hay que resolver primero para poder ofrecer una solución con efectos profundos y permanentes, ya que la tecnología por sí misma, aunque importante, no tiene la fuerza suficiente para cambiar la estructura de la sociedad.

El debate sobre la brecha digital se basa en el determinismo tecnológico que asume que cerrando la brecha digital, tanto el acceso a las computadoras como a la red mitigarán las grandes iniquidades. Este es un supuesto que requiere de una gran fe en la capacidad de la tecnología para provocar cambios sociales. Los reportes sobre la brecha digital frecuentemente mencionan problemas raciales y de ingreso económico, y lo hacen para que se pueda comprender que el problema de la brecha es más amplio que tan sólo la falta de acceso a las computadoras y otras tecnologías. Las declaraciones retóricas sobre las consecuencias sociales, económicas y educativas que produce el acceso a la tecnología de la información continúan siendo amplias. ${ }^{1}$

Los estudios estadounidenses pusieron de manifiesto la relación que existe entre la brecha digital y el ingreso económico, la educación, la distribución geográfica y la disponibilidad de otras tecnologías; es decir la relación entre los aspectos socioeconómicos y el acceso a las tecnologías de la comunicación y la información.

1 Light, $722-723$. 


\section{Conceptuando el acceso a la TIC}

Si bien por acceso entendemos la posibilidad de adentrarse en algún lugar, o tener la posibilidad de utilizar ciertos recursos, es necesario que aclaremos qué entendemos por acceso en el caso del tema que estamos estudiando. Para lograrlo nos apoyaremos en la opinión de Katz y Rice, quienes nos ofrecen una definición sucinta que parece cubrir diferentes aspectos y nos ubica en un contexto apropiado:

Podemos definir acceso en forma mínima de la siguiente manera: si una persona con un esfuerzo o sin él, puede utilizar una computadora que esté conectada a la red y si es capaz de usar esa computadora para encontrar materiales, como por ejemplo páginas web o comunicarse con otros (mediante el uso de correo electrónico) entonces podemos decir que esa persona tiene acceso a Internet. Saber qué es lo que está en la red, pero no tener la posibilidad de obtenerlo, o tener la tecnología, pero no el conocimiento de cómo usar la red, no constituye acceso. ${ }^{2}$

En la mayoría de los casos que estudian la brecha digital se tienen datos sobre la disponibilidad tecnológica, pero casi nunca información respecto de la habilidad y el conocimiento para navegar exitosamente en la red.

Así, cuando se habla de Internet, automáticamente se piensa sólo en la red. Pero en primera instancia se debe tener en cuenta que para llegar a ella se requiere de diversos elementos, entre los que se encuentran el hardware (que comprende computadoras, ruteadores, concentradores y equipos similares) y el software o la paquetería operativa y de trabajo que permite utilizar el equipo, tanto para almacenar y recuperar como para transmitir y recibir información. Pero incluso antes del hardware y del software están otros servicios que podríamos considerar como tradicionales porque estamos acostumbrados a ellos desde antes de la era de la computación, tanto, que en ocasiones olvidamos que son imprescindibles para que las computadoras e Internet trabajen adecuadamente. Estos servicios son la elec-

2 James E. Katz y Ronald E. Rice, Social consequences of Internet use: access, involvement and interaction (Cambridge, Mass.: MIT Press, 2002), 4. 
tricidad, el teléfono y los equipos de comunicación más complejos, entre los que destacan la fibra de vidrio o la banda ancha en el campo de las comunicaciones electrónicas, que permiten la comunicación más rápida que aquella que establecemos vía telefónica utilizando un módem; en la actualidad la comunicación más eficiente se hace con banda ancha de alta velocidad. ${ }^{3}$

El acceso instrumental a Internet se puede lograr de diferentes formas, entre las que se encuentran el acceso telefónico por medio de módem y DSL (Digital Suscriber Line) o línea de conexión digital de alta velocidad, esta conexión puede ser desde $10 \mathrm{mbps}$ hasta varios gigas de velocidad. En este contexto el servicio telefónico es un indicador de accesibilidad importante reconocido por la Unión Internacional de Telecomunicaciones:

Teledensidad es la medida aplicada por la Unión Internacional de Telecomunicaciones [ITU 97], para definir la tasa que corresponde al número de líneas telefónicas por cada 100 personas. La teledensidad para los países en desarrollo es de 1.5. En los países más pobres como es el caso de Afganistán, Guinea, Liberia, Nigeria y Somalia, la cifra cae a 0.002 lo que significa que en esos países existe un teléfono por cada 500 personas, mientras que en Camboya, Chad y Zaire existe un teléfono por cada 1000 habitantes. Al mismo tiempo en los países desarrollados la situación es totalmente otra, en los Estados Unidos hay 57 teléfonos por cada 100 habitantes y en Suecia el índice es de 68 teléfonos por cada 100 personas. 4

Hay que aclarar que el acceso a la tecnología es muy importante, pero es tan sólo uno de los aspectos que tienen relación con la brecha digital. La tecnología es la punta del iceberg del problema, bajo su nivel podemos observar otros muchos problemas que serán analizados a lo largo de este trabajo.

Hay tres elementos que hacen distinta a Internet de otras tecnologías. Primero, Internet tiene un conjunto más complejo de requisitos previos para su uso. Segundo, Internet ofrece mejores servicios a los

3 Chen y Wellman, 4 .

4 Murelli, 40. 


\section{La brecha digital y sus determinantes}

usuarios expertos y tercero, la velocidad de innovación de Internet hace que prácticamente se esté modificando continuamente e incluso se esté reinventando ella misma, en comparación de las otras tecnologías que son en gran parte estáticas como el teléfono y la televisión.5

El acceso es más que la simple utilización de los instrumentos tecnológicos, y se relaciona con el contenido de la información y con el uso que de ella se pueda hacer, tanto porque se cuenta con la capacidad para utilizar los instrumentos como porque se posee la habilidad para utilizar la información e incorporarla a las actividades diarias de las personas.

Hay diferentes factores que influyen en la relación uso/aplicación de la tecnología, las diferencias entre países y regiones se dan en función de la velocidad de adopción de la tecnología, y en esta etapa encontramos al menos tres factores que determinan esa relación:

(1) Las infraestructuras de comunicación que identifican la disponibilidad de los recursos físicos que facilitan el acceso a la economía digital y estimulan su desarrollo. Este factor incluye aspectos relacionados con la expansión de Internet y el acceso a la red mediante dispositivos, tanto como indicadores vinculados con la penetración y el grado de avance tecnológico que están relacionados y que son importantes para determinar el grado de conectividad del sistema, como por ejemplo conexiones de banda ancha y satelitales.

(2) Los recursos humanos, que son importantes para determinar la capacidad de absorción del sistema de innovaciones tecnológicas sobre la base de conocimiento disponible y educación. En este contexto las políticas y programas de educación formal y de adiestramiento juegan un papel central, así como las condiciones de empleo en el sector de las comunicaciones.

(3) La competitividad de los proveedores de información y comunicación y el grado de competencia entre diferentes operadores, los que tienen un papel bien definido en el establecimiento de las previsio-

5 Kuttan y Peters, 65. 
nes de nuevos servicios y determinar el ritmo de adopción de nuevas plataformas y aplicaciones. 6

El estudio del acceso a Internet no termina con la cuestión de si está aumentando el número de personas conectadas o que tienen acceso a la red. Hay otra serie de preocupaciones relacionadas con el uso que se le da a Internet, para saber si las personas están en uno u otro de los grupos en que las ha separado la brecha digital.

Gary Chapman, profesor de la Lyndon B. Johnson School of Public Affairs de la Universidad de Texas en Austin (www.utexas.edu/lbj/ 21cp), ha establecido que el problema no disminuye con el incremento en el número de usuarios de Internet; por el contrario, es cuando se agudiza más:

Cuando el grupo de personas que no tienen acceso a Internet es pequeño se crea un gran problema porque es cuando las instituciones tienden a ignorarlos. 7

Chapman argumenta que el Estado, la iniciativa privada y en general todas las instituciones se preocupan por resolver los problemas que afectan a los grandes grupos sociales, pero que cuando los grupos son pequeños no logran atraer el interés de todas esas organizaciones y se corre el peligro de que los problemas persistan por mucho más tiempo.

En el mismo sentido Blau señala que la brecha digital llega a ser un problema crucial, como tema de discusión social, cuando se incrementa el número de personas que tienen acceso a Internet; porque es entonces cuando la falta de acceso deja de ser un inconveniente,

6 Nicolleta Corrocher y Andrea Ordanini, "Measuring the digital divide: a framework for the analysis of cross-country differences", Journal Information Techno$\operatorname{logy} 17,1$ (2002), 12. Disponible EbscoHost_doi_10.1080/02683960210132061 (AN 6705498)

7 Gary Chapman citado por Andrew Blau, “Access isn't enough”, American Libraries (Junio/Julio 2002), 51. 
para transformarse en una verdadera barrera para quienes no están conectados. ${ }^{8}$

Por otro lado no sólo se debe enseñar a las personas a utilizar la computadora y la Web, sino la convicción de que tener acceso significa obtener más y mejores oportunidades de recibir información para la vida o para el trabajo o incluso algo tan simple como un correo electrónico.

Las diferencias en el acceso a Internet se están haciendo evidentes pues en tanto que en la mayoría de los países occidentales es de 25 por ciento, en las naciones más avanzadas es del 50 por ciento, como en los Estados Unidos y los países escandinavos. Este acceso va más allá del que realizan los científicos, académicos y estudiantes en universidades y escuelas en los países en vías de desarrollo, y cubre una comunidad diversa de ciudadanos comunes que tienen acceso a Internet. Además debe incluir información sobre fuentes de información muy valiosas como índices, texto completo, bases de datos y revistas electrónicas que no están incluidas en los materiales que se localizan libremente en Internet. 9

$\mathrm{Al}$ analizar las diferencias en el acceso a Internet, el Gartner Group ha señalado lo siguiente:

Es cierto que los grupos minoritarios se encuentran en distintos niveles de desventaja, pero cuando se les relaciona con el acceso a Internet la principal razón de su exclusión no es que sean minorías, sino sus desventajas socioeconómicas debido a un bajo nivel educativo y un pobre ingreso...

Encontrarse en el lado equivocado de la brecha digital es sólo un síntoma de ser pobre. Los grupos socioeconómicos más bajos tienen también un bajo ingreso familiar, menor acceso a las oportunidades educativas y se enfrentan a posibilidades más escasas de ofertas de trabajo... una de las claves para mejorar el estatus socioeconómico de los ciudadanos pobres de Estados Unidos es otorgarles acceso igual y jus-

8 Blau, 51.

9 Cullen, 247. 
to a las oportunidades educativas y económicas y la Internet nos ofrece una oportunidad excepcional para hacerlo. 10

En suma, mientras que es difícil cuestionar el ritmo en que ha sido adoptada Internet, es un error asumir que el rápido proceso de adopción será igual al de difusión. Con relación a la brecha digital esto quiere decir que aun cuando se adopte rápidamente Internet, la iniquidad aumentará con la adopción. Lo que nos lleva a plantear que en el futuro no será un problema entre quienes tienen y quienes no tienen acceso, sino entre aquellos que tienen toda la tecnología y aquellos que tienen alguna. ${ }^{11}$

Acceder a la tecnología de la información y de la comunicación significa contar con tecnología previa como electricidad, teléfono o sistemas de comunicación más complejos; tener la capacidad económica para adquirir una computadora con hardware y software apropiados para la cibernavegación así como una suscripción al servicio de Internet; poseer los conocimientos y habilidades para poder utilizar ambas tecnologías; poseer los conocimientos y habilidades necesarias para encontrar y evaluar la información disponible para hacer de ella un uso óptimo.

El acceso es un reflejo de las condiciones económicas, políticas y sociales de la comunidad, e incluso factor de marginación. La TIC tiene un papel específico e ideal en la sociedad actual, que se relaciona con la disponibilidad y uso de información para ampliar y diversificar las oportunidades de desarrollo humano. Este papel, desde la perspectiva meramente pragmática, ha contribuido a la apropiación social de la TIC.

\section{Apropiación social de la tecnología}

Es importante considerar que existen al menos dos aspectos significativos en la forma de ver la tecnología, aunque con frecuencia esos

10 Gartner Group, The digital divide and American Society citado por Rowena Cullen, 249. Disponible http:///www.emeraldinsight.com/0264-0473.htm; doi 101108/02640470310480506

11 Kuttan y Peters, 68. 
puntos de vista se encuentran enfrentados. En un bando están quienes piensan que la utilización de las tecnologías será suficiente para resolver todos los problemas; este grupo tiene una visión optimista del uso de la tecnología en la que hay más buenos deseos que objetividad con respecto a la solución de los problemas existentes; por el otro lado están quienes se resisten al uso de la tecnología, este grupo piensa que la tecnología no soluciona los problemas, al contrario, los complica, pues es costosa, confusa y difícil de manejar. Es importante que el papel que juega la tecnología sea apreciado correctamente como elemento importante en el desarrollo de la civilización. Cullen aborda este tema y nos ofrece dos postulados que pretenden sintetizar cuál es la realidad en el uso de las tecnologías:

(1) La tecnología por sí misma no resuelve las contradicciones sociales y económicas que existen dentro de las sociedades, y puede frecuentemente exacerbarlas.

(2) Las nuevas tecnologías no siempre remplazan a las antiguas. Ellas pueden coexistir y al hacerlo enriquecen la experiencia humana, sin que necesariamente disminuya la experiencia de aquellos que no utilizan la tecnología, prefiriendo tecnologías antiguas para obtener los mismos resultados. 12

La tecnología, como casi todo lo que el hombre produce, trae consecuencias que afectan de diferente forma a una parte o a la sociedad en su conjunto. Muchas personas sostienen que la tecnología es neutral y que beneficia por igual a todas las personas. Light sostiene lo contrario, ella nos dice que la tecnología no es un instrumento neutral con efectos universales, más bien es un medio que tiene consecuencias que son determinadas por el contexto histórico, social y cultural en el que se usa. ${ }^{13}$

O como ha dicho Paul Johnson en su trabajo sobre las iniciativas para reducir la brecha en la Asociación de Países del Sureste Asiático: para algunas personas la tecnología trae la promesa de inclusión, las

12 Cullen, 248.

13 Light, 710. 
oportunidades y la riqueza; para otras una mayor marginación y el aumento de la pobreza. ${ }^{14}$

Estas reflexiones nos presentan una visión más objetiva de la realidad tecnológica, porque como todos los productos humanos, la tecnología no tiene sólo efectos positivos o efectos negativos. La tecnología ha logrado avances en muchos terrenos, pero en el caso de la tecnología de la información, al menos por el momento, ha producido una brecha que margina y excluye del desarrollo vanguardista, de la cultura, de la educación y de la ciencia.

Algunas personas se conectan a Internet para hacer uso del correo electrónico, y otras más la utilizan para navegar en la red, buscar información, buscar juegos o jugar. La búsqueda de información incluye la utilización de bancos de datos especializados y/o publicaciones periódicas en texto completo e incluso la realización de experimentos mediante el uso de computadoras de alta velocidad de procesamiento y gran capacidad como las supercomputadoras.

La posibilidad de que las personas usen una computadora y el acceso a la red no debe ser visto como un objetivo en sí mismo. El uso de las computadoras y el ingreso a Internet sólo es valioso en cuanto le es útil a una persona para enfrentar los retos que se le presentan diariamente en su educación, su trabajo y en su vida social y familiar. Por ello es necesario no ser tan optimistas como aquellos que piensan que con el solo acceso a Internet los problemas de información se resolverán y que por tanto la sociedad y sus miembros podrán hacer frente a todos los retos que enfrentan.

Además de la disposición de TIC, también es necesario pensar en la necesidad de una capacitación que forme usuarios directos, e incluso antes que éstos, la formación de profesores y tutores que a su vez formen usuarios hábiles y diestros en el uso de las computadoras y de Internet. Esto cobra significado cuando se observa que un hábil

14 Paul Johnson, "Narrowing the digital divide: initiatives undertaken by the Association of South-East Asian Nations (ASEAN)", Program: Electronic Library and Information Systems 36, 1 (2002), 13. Disponible http://www.emeraldinsight. com/0033-0337.htm; doi 10.1108/00330330210426085. 
buscador de información se beneficia mayormente de los recursos que ofrece la red, que aquel que sólo realiza búsquedas elementales o bien que no sabe cómo buscar del todo. La frustración en el uso de la tecnología es una de las causas de su abandono.

Aceptar y utilizar una tecnología más moderna facilita el acceso a la información, pero estos no son los únicos elementos que deben ser considerados para una adecuada utilización de los recursos informáticos y un uso fructífero de la red; también es necesario contar con una adecuada educación, un fluido manejo del idioma en que se encuentra la información y un eficiente adiestramiento en el manejo de los instrumentos y los recursos.

El acceso a Internet ha sido muy acelerado y la incorporación de grandes grupos sociales ha provocado por una parte que aumente su uso, pero también que aquellos que no la están usando queden marginados. Internet tenía en 1994 aproximadamente tres millones de usuarios a escala mundial, seis años después el número de personas conectadas había crecido en forma dramática llegando a los $400 \mathrm{mi}$ llones de usuarios. Si bien el número de usuarios era todavía muy pequeño, en algunos lugares la mayoría de la población hacía uso de la red, la velocidad con la que las personas se incorporaban parecía incrementarse cada año. ${ }^{15}$

En la medida en que más personas usan la red, mayor utilidad tiene ésta. Afortunadamente el crecimiento no ha provocado que la red se vea afectada o que se congestione, las nuevas tecnologías de cómputo y telecomunicaciones permiten establecer que a mayor uso, mayor utilidad de la red.

Algunos datos sobre el uso de Internet son interesantes pues establecen pautas de comportamiento novedoso en lo social. El hecho de que cada vez más usuarios ingresen a la red desde sus casas indica un cambio en los patrones de las actividades domésticas. Además, que un número creciente de personas considere que Internet es una fuente de información quiere decir que las otras formas de obtener

15 Norris, Digital divide, 5. 
información se ven complementadas por Internet en la mayoría de los casos, aunque en algunos otros sean desplazadas.

Es posible que con la tecnología de la información suceda algo similar a lo ocurrido con la radio, el teléfono, la televisión y el cable. Con la aplicación de estas tecnologías muchas personas pensaron que las diferencias en la sociedad serían eliminadas o al menos disminuidas. No ocurrió así. Se han agregado ahora las tecnologías de la información y las expectativas son idénticas; la realidad es que mientras no se modifiquen las condiciones sociales, educativas y económicas de la sociedad, podemos esperar bien poco de las nuevas tecnologías. No se pretende decir que el uso de esos equipos e instrumentos no modificará la realidad, pero nuevas brechas surgirán sin que hayan desaparecido aquellas que ya existían previamente.

A menudo se comparan las tecnologías de la información con otras tecnologías como el teléfono, la radio, la televisión y la electricidad, y si bien es cierto que todas ellas se necesitan para tener acceso a Internet, no todas se relacionan, o lo hacen marginalmente, con la información. Muchas son las semejanzas y también las diferencias que hay entre esas tecnologías; posiblemente la mayor diferencia es que en la utilización de Internet se requiere de una participación activa de quien la emplea, mientras que en la radio y la televisión las personas sólo reciben información de manera pasiva. Y por último, en el teléfono se tiene una actitud proactiva, pero la información está limitada a dos personas.

La comparación entre la socialización del teléfono y la televisión nos permite observar que aunque el primero es medio siglo más antiguo que la segunda, esta última tiene mayor penetración. Para realizar tal comparación se seleccionaron cinco países, de distintas partes del mundo, y los resultados se presentan agregados en tres columnas en la figura 4 bajo las siguientes categorías: los países de ingreso alto, los países de ingreso medio y los países de ingreso bajo. En todos los casos la televisión tuvo mayor cobertura que el teléfono, tal vez debido a que el uso de aquella no requiere de instalaciones especiales en el hogar más allá de una antena que tiene un costo relativamente bajo, y que incluso puede ser instalada por el usuario que tenga un mínimo de habilidad manual. En los países de ingreso alto la brecha 
Figura 4

Líneas telefónicas y televisiones por cada 1000 personas, 2000

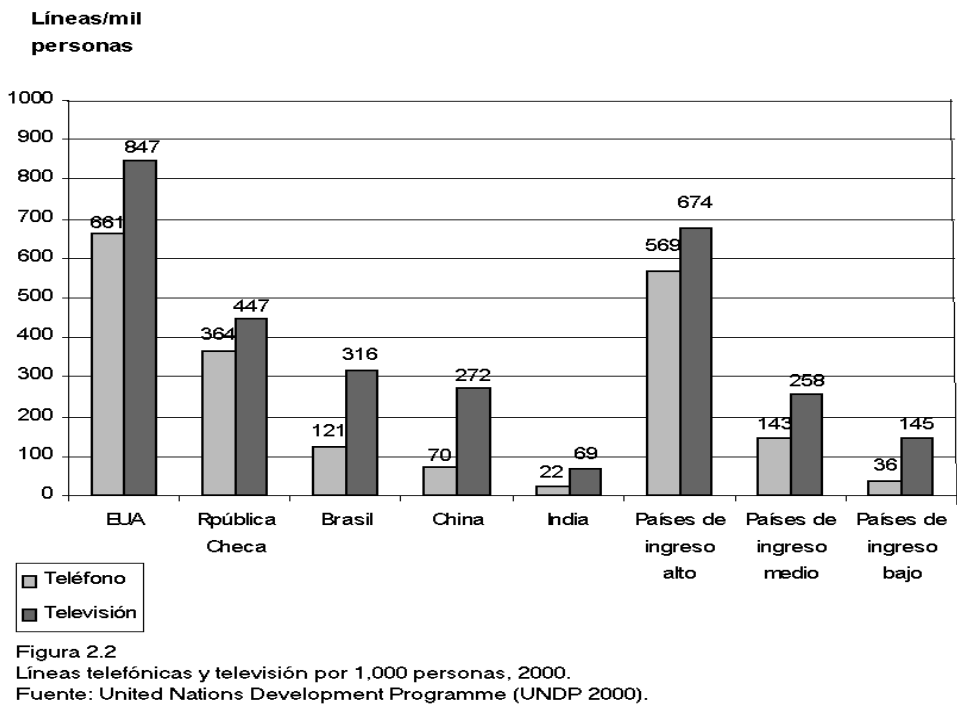

Tomado de Mark Warschauer, Technology and social inclusion: rethinking the digital divide

(Cambridge, Mass.: MIT Press, 2003), 37.

entre el uso del teléfono y la televisión no es tan grande como en el caso de los países de bajo ingreso, en los que el uso de la televisión es varias veces el uso del teléfono. Se podría pensar que los pobres no han sentido la necesidad de tener teléfono y por eso el desarrollo de esta tecnología es menor o bien que es muy difícil y caro de conseguir, como sucedía en México hasta la década de los años 90.

La figura 5 concentra información por región sobre diversos instrumentos de tecnología de la información y proporciona datos sobre diferentes herramientas: radio, computadoras personales, televisores, diarios, teléfonos fijos y móviles, y obtiene un índice del promedio de todos los nuevos elementos tecnológicos. Evidentemente los países escandinavos, América del Norte y Europa Occidental son las áreas más desarrolladas, la diferencia con el resto de las zonas geográficas es muy grande, lo que prácticamente divide al 


\section{mundo en dos. Los países de Europa Central y Oriental, así como los del Asia y el Pacífico, el Oriente Medio, América del Sur y África se en- cuentran en el lado negativo de la brecha, aunque algunos están en peor situación que otros.}

Figura 5

Proporción 01 de la población que utiliza nuevos y viejos medios

\begin{tabular}{|c|c|c|c|c|c|c|c|c|c|}
\hline \multicolumn{10}{|c|}{ Tabla 3.2. Proporción 01 de la población que utiliza nuevos y viejos medios } \\
\hline & \multicolumn{4}{|c|}{ Nuevos medios } & \multicolumn{5}{|c|}{ Viejos medios } \\
\hline & $\begin{array}{l}\text { Población en } \\
\text { línea }\end{array}$ & Servidores & PCs & Radios & Televisores & Diarios & $\begin{array}{l}\text { Teléfonos } \\
\text { fijos }\end{array}$ & $\begin{array}{l}\text { Teléfonos } \\
\text { móviles }\end{array}$ & $\begin{array}{l}\text { Índice } \\
\text { Soc-Info }\end{array}$ \\
\hline Región & 2000 & 2000 & 1998 & 1997 & 1998 & 1996 & 1998 & 1998 & \\
\hline Escandinavia & 35 & 11 & 36 & 112 & 58 & 45 & 64 & 47 & 80 \\
\hline América del Norte & 27 & 10 & 28 & 118 & 61 & 16 & 47 & 15 & 63 \\
\hline Europa Occidental & 12 & 3 & 27 & 79 & 53 & 21 & 53 & 24 & 52 \\
\hline $\begin{array}{l}\text { Europa Central y } \\
\text { Oriental }\end{array}$ & 3 & 0.3 & 6 & 45 & 32 & 13 & 21 & 4 & 30 \\
\hline Asia-Pacífico & 5 & 1 & 8 & 35 & 19 & 11 & 13 & 8 & 27 \\
\hline Medio Oriente & 3 & 0.2 & 6 & 39 & 25 & 11 & 19 & 8 & 22 \\
\hline América del Sur & 1 & 0.1 & 5 & 38 & 22 & 8 & 15 & 3 & 18 \\
\hline África & 0.3 & 0.1 & 1 & 17 & 5 & 1 & 3 & 0.5 & 6 \\
\hline \multicolumn{10}{|l|}{ Desarrollo } \\
\hline Alto & 14 & 4 & 23 & 83 & 49 & 26 & 46 & 23 & 53 \\
\hline Medio & 1 & 0.1 & 3 & 32 & 21 & 6 & 11 & 2 & 15 \\
\hline Bajo & 0.02 & 0.03 & 0.3 & 14 & 3 & 1 & 1 & 0.1 & 4 \\
\hline Total & 4 & 1 & 9 & 40 & 24 & 10 & 18 & 7 & 38 \\
\hline Número de naciones & 169 & 179 & 125 & 140 & 139 & 133 & 179 & 139 & 101 \\
\hline \multicolumn{10}{|c|}{$\begin{array}{l}\text { Notas: Todas las figuras se expresan como porcentaje de la población. Para mayores detalles véase la tabla 3.1. Porcentaje de radios (1997), } \\
\text { televisiones (1998), teléfonos móviles (1998) y PCS (1998) del World Development Indicators 2000, Banco Mundial. El nivel de desarrollo está } \\
\text { clasificado de acuerdo al UNDP (1999). Los } 100 \text { puntos del índice de la Soc-Info están calculados mediante la combinación de todos los indica- } \\
\text { dores en una escala estandarizada. }\end{array}$} \\
\hline
\end{tabular}

Tomado de Pippa Norris, Digital divide: civic engagement, information poverty, and the Internet worldwide (Cambridge: Cambridge University Press), 52. 
Se puede decir que la apropiación social de la TIC suele estar relacionada con la utilidad que las personas encuentran en ella. Más allá de los calificativos que pueda recibir, la TIC es aceptada y utilizada por los individuos cuando éstos determinan que es lo suficientemente valiosa para modificar sus patrones de actividad. Los niveles de apropiación social varían significativamente entre los países y regiones del globo en función del desarrollo económico, social, político y cultural de los mismos.

\section{El uso de la tecnología de la información y comunicación}

El uso que se hace de la red y de la información contenida en ella es el aspecto fundamental de todo este asunto y variará dependiendo de distintas causas aunque en el fondo todo uso tiene una connotación social. La brecha digital es una división que se presenta tanto en el plano social como en el tecnológico; se relaciona con quién hace uso de Internet, con qué propósito, bajo qué circunstancias, y cómo esto afecta las condiciones económicas y sociales del individuo y de la comunidad. Además es afín a temas como la inclusión, la exclusión y la prosperidad.

El uso de Internet ha creado nuevas prácticas sociales de comunicación; al utilizar la red, el usuario mantiene una dinámica nueva en su forma de comunicación con amigos y familiares. El correo electrónico y el messenger son formas de comunicación que se utilizan cada vez más y que permiten que personas que se encuentran distantes unas de otras se comuniquen con mayor facilidad y que en cuestión de minutos reciban noticias que antes de Internet podían tomar días y en ocasiones semanas. Estas nuevas formas de comunicación hacen que la separación física sea menos dura al permitir la transmisión de mensajes profundos o de comentarios banales que complementan el diálogo. En varios países se han realizado estudios sobre el uso de Internet y se ha encontrado que en la mayoría de ellos el correo electrónico y la búsqueda de información en la red son las principales aplicaciones. 
Las formas de comunicación mediante el uso de cualquiera de los servicios del messenger permiten la comunicación personal o colectiva y la transmisión de voz, datos e imágenes. Estas formas, que hace tan sólo unos 15 años no existían, son totalmente novedosas para la comunicación familiar, social y laboral.

Un aspecto que se ha destacado sobre el uso de la red es el relacionado con los individuos que usan Internet desde sus domicilios para trabajar y que sufren una especie de aislamiento que tiene un impacto importante en el comportamiento individual y colectivo. El aislamiento marca al individuo que se encuentra alejado de toda relación laboral y social, y por otra parte, el trabajo solitario impide que los individuos se organicen en asociaciones laborales del tipo de los sindicatos para defender sus derechos. ${ }^{16}$

A la fecha Internet tiene 60000 puestos de trabajo más que el ramo de los seguros y está cerca de duplicar el de los bienes raíces. Por lo tanto, cerrar el acceso a este segmento de la economía a las personas es tanto como darles con la puerta en la cara. ${ }^{17}$

El profesor del MIT David Gelemer dice que demandar el acceso a todos los estudiantes a Internet es como demandar que todos los niños tengan un equipo de buceo cuando no saben nadar [...] otorgarles ese equipo es no sólo innecesario, sino peligroso, se pueden ahogar. 18

También es necesario tener habilidades en el manejo de la tecnología para poder encontrar empleos adecuados. Al respecto Bolt y Crawford señalan:

La mayoría de nosotros está convencido de que para bien o para mal una persona debe tener un cierto nivel de aptitudes tecnológicas para ser de gran valor en su lugar de trabajo. La habilidad para manejar las computadoras y la conectividad tecnológica es un juego de habilidades que un patrón busca en sus futuros trabajadores y eso incluye una

16 Katz y Rice, 6.

17 Kuttan y Peters, 12.

18 Ibíd., 13. 
visión similar para posibles estudiantes. La falta de conocimientos de estas tecnologías puede ser un obstáculo para entrar al mundo de estas actividades. 19

Se observan además diferencias en el acceso y uso de la red entre los grupos étnicos de los diferentes países. Normalmente son los grupos dominantes quienes imponen sus rasgos culturales y las minorías tienen que seguirlos o quedar marginados de la corriente cultural, social y económica mayoritaria. En los países en desarrollo se conoce que estos fenómenos de exclusión existen pero no se han documentado lo suficiente, por lo que su solución no se puede lograr plenamente. En los países desarrollados se conocen con exactitud los datos, por ejemplo en Estados Unidos, en algunos otros no es fácil obtener cifras debido a que no existe una división tan tajante en su estructura social, en tanto que para otros el estudio de la información estadística ha permitido conocer el fenómeno y diseñar una política para resolver la situación.

En el caso estadounidense, sobre las minorías sabemos que las personas de origen asiático están conectadas en un 63 por ciento, incluso por encima de los blancos, que sólo lo están en 55 por ciento, mientras que la comunidad afroamericana cuenta con un porcentaje de conexión de 30 por ciento y en último lugar en conexión a Internet están los hispanos, que tienen el 28 por ciento. Las cifras nos dicen que las comunidades no están conectadas a Internet en función de su importancia poblacional, de ser así, los hispanos debían ocupar el segundo lugar entre las comunidades conectadas, para que después lo fueran los afroamericanos y en el último lugar estuvieran los asiáticoamericanos. Habría que buscar la explicación en otra parte, posiblemente en los niveles educativos y en el ingreso económico.

Por otro lado, existe un importante grupo de personas que han usado la red y que lo han dejado de hacer, las razones son varias y las analizaremos a continuación. Por ejemplo, en los Estados Unidos, donde el porcentaje de la población que usa la Internet llegó a 60\%,

19 Bolt y Crawford, 33. 
ahora aumenta mucho más el número de quienes la abandonan que el de nuevos usuarios, es tal el caso que las deserciones son más que las nuevas incorporaciones. ${ }^{20}$

El abandono de la red puede explicarse por motivos económicos ya que algunos usuarios han considerado que Internet es muy costosa con relación a los beneficios que obtienen de ella y terminan por cancelar su suscripción. Los usuarios aplican los adjetivos costoso o económico a Internet según el uso y la utilidad o beneficio que obtienen de ella. Si piensan que no obtienen suficiente información y servicios por su dinero, sin lugar a dudas la abandonarán. Katz y Rice, al analizar diversos documentos, muestran que se realizaron varias encuestas en los años de 1995, 1996, 1997 y 2000 y encuentran una disminución constante de alrededor de una quinta parte de aquellos que usaban Internet. Muchos de quienes abandonan el uso de la red han sido usuarios por periodos cortos; aunque no se trata de la única razón, sí es la más común. ${ }^{21}$

Las características de aquellos que abandonan la red pueden ser definidas por el conjunto de las siguientes variables:

- Se identifican como "novatos" en el uso de Internet, en contraposición con otros criterios como el tener una habilidad promedio o por encima del promedio o ser expertos

- No son diferentes de las personas que trabajan tiempo completo

- Principalmente son menores de 40 años de edad

- Pocas posibilidades de haberse graduado de la universidad

- Con un ingreso familiar menor a 35 mil dólares anuales

- Posiblemente es un persona afroamericana

- Posiblemente nunca se ha casado o es divorciado/viudo, que tenga una pareja u otra característica similar

- Con altas posibilidades de ser mujer

- Tiene una opinión satisfactoria de su vida. ${ }^{22}$

20 Chen y Wellman, 7.

21 Katz y Rice, 68-69.

22 Ibid., 69, 74. 
Las razones citadas con mayor frecuencia para abandonar la red son las siguientes: pérdida del acceso, 22.9 por ciento; costo, 15.7 por ciento; muy difícil y muy complejo, 14.9 por ciento; no tiene interés, 12.2 por ciento, y toma mucho tiempo, 7.5 por ciento. ${ }^{23}$

Una característica importante en los estudios que se han realizado sobre la brecha digital es que la mayoría de ellos se concentran en estudiar los diferentes aspectos del uso de las tecnologías de la información y muy pocos dedican suficiente esfuerzo a tratar de comprender por qué no se usan; el no uso de la TIC es visto exclusivamente como una deficiencia; sin embargo, es necesario que se dedique tiempo y espacio también al estudio de las causas por las que no están siendo usadas esas tecnologías.

Muchas personas dejan de usar la computadora al primer problema técnico que se les presenta, en ocasiones esta interrupción puede ser permanente y en otras sólo temporal.

De acuerdo con los datos de una encuesta que se realizó en abril de 2002 por la National Statistical Omnibus Survey, entre el 38 por ciento de los adultos británicos que nunca habían tenido acceso a Internet, el 37 por ciento no estaban interesados o bien consideraban que no tenían necesidad de usarla. En Estados Unidos, en una encuesta similar se probó que la mitad de la población adulta no había usado Internet nunca y el $57 \%$ no tenían interés en usarla. ${ }^{24}$

Por eso es importante tener en cuenta la iniciativa Gates para enfrentar la brecha digital, la cual no solamente se preocupa por ofrecer una computadora y acceso a Internet, sino que brinda capacitación para el uso de la computadora, de algunos paquetes y apoyo técnico.

23 Ibid., 75.

24 George Kuk, "The digital divide and the quality of electronic service delivery in local government in the United Kingdom”, Government Information Quarterly 20, 4 (2002), 355, disponible Elsevier ScienceDirect doi 10.1016/j.giq.2003. 08. 004 . 
Para atacar la brecha digital se han establecido computadoras en las bibliotecas, porque en ese ambiente es donde mejor pueden ser utilizadas, ya que éste propicia la búsqueda de información; es por ello que las computadoras se instalan en la biblioteca y no en los bancos o centros comerciales pues en estos últimos lugares las computadoras se encontrarían aisladas. A la biblioteca los usuarios asisten a buscar información, sea ésta en las formas tradicionales de papel o bien con la utilización de tecnología de la información.

De las personas no conectadas el 36 por ciento dice que la Internet es confusa y difícil, para ellos la brecha digital es un problema de uso que no puede ser cerrado a menos que las computadoras e Internet sean más fáciles de usar. ${ }^{25}$

Entre quienes son un tanto renuentes a usar Internet y aquellos que dicen que nunca se conectarán hay datos interesantes, pues presentan características especiales. Dentro de los primeros encontramos que 56 por ciento son mujeres, 64 por ciento tienen más de 50 años, 76 por ciento no han concluido la escuela secundaria o menos, y el 65 por ciento habita una casa en donde el ingreso anual es de 50 mil o menos dólares al año, mientras que entre quienes contestaron que nunca se conectarán, la situación es diferente, he aquí algunas de sus características: 57 por ciento son mujeres, 81 por ciento son mayores de 50 años, 82 por ciento tienen terminada la secundaria o menos y el 43 por ciento gana menos de 30 mil dólares anuales. ${ }^{26}$

Según el Gartner Group, ${ }^{27}$ hay cuatro barreras para el uso de Internet que están relacionadas con aspectos socioeconómicos, físicos, actitudes y contenidos:

25 Kuttan y Peters, 14.

26 Ibid., 63.

27 Gartner Group, The digital divide and American Society, citado por Rowena Cullen, 249-251. Disponible http:/www.emeraldinsight.com/0246-0473.htm; doi 10.1108/02640470310480506. 
1. Acceso físico a las tecnologías de la información y la comunicación. En algunos lugares hay una falta de acceso a la infraestructura de telecomunicaciones, inadecuada banda ancha para las conexiones de Internet y carencias económicas para cubrir los gastos de compra o renta de equipo, o bien para trasladarse a los lugares en donde pudiera hacerse uso de éste. En la actualidad las conexiones mediante la utilización de líneas telefónicas fijas son esenciales para acceder a Internet. Sin embargo, el uso de este tipo de teléfonos no es común en todos los países, habiendo lugares en que no se puede tener acceso a Internet por falta de la infraestructura telefónica. Unas de las zonas más afectadas son las áreas rurales, con todo, aun en las zonas agrícolas más ricas se da el fenómeno del aislamiento, la falta de banda ancha, conexiones no confiables e interferencias con algún equipo agrícola. La comunicación vía satélite ayuda a resolver parcialmente este problema, sin embargo no satisface todas las necesidades. Otra posibilidad es la conexión que brindan las compañías que ofrecen servicios de comunicación a través de cable, pero éste resulta muy caro y excluye a una parte importante de los usuarios potenciales; es posible, sin embargo, que en el futuro los costos tiendan a bajar y el servicio se haga más accesible.

El acceso a Internet también contempla proveer acceso a las personas con capacidades físicas diferentes, quienes presentan dificultades en la utilización del teclado, de la pantalla y de otros dispositivos (como los de voz y audio). Al respecto hay que agregar que "[...]la demanda de acceso a Internet para las personas discapacitadas se ha incrementado continuamente, al grado de que en algunos lugares es visto como un tema dentro de los derechos humanos." 28

28 Cullen, 250. 
2. Habilidades y apoyo para el uso de las tecnologías de la información y comunicación. En algunas sociedades el uso de la computación no es universal, y no se concibe como una necesidad de la sociedad que las personas tengan la capacidad de manejar las tecnologías de información y comunicación. Además, el apoyo que se presta al uso de los pocos equipos con que se cuenta es marginal.

3. Actitudes. En todas las sociedades existe una diferencia entre los géneros, tanto en la educación, en el empleo y en la utilización de los recursos tecnológicos de información y comunicación. Sin embargo, en los países en los que se encuentra un menor uso de Internet, como son los países en vías de desarrollo, la exclusión en el uso de Internet es mayor que en los países desarrollados. Tanto por actitudes respecto de las mujeres, como porque el uso de la tecnología se piensa que es exclusivo o al menos prioritario para utilización de los hombres.

4. Contenido. Algunas personas no utilizan Internet pues consideran que el contenido que les ofrece no es de calidad o no les resulta atractivo para sus actividades diarias. Otras piensan que lo único que ofrece Internet es material moralmente dañino para ellos o para sus hijos, y deciden no utilizarlo.

5. Lenguaje. También encontramos a las personas que ven restringido su acceso porque solamente manejan su lengua materna, la cual no es el inglés; en este idioma está la mayor parte de la información que se encuentra en la red. 



\section{La tecnología de la información y comunicación en el mundo}

escala mundial se ha observado un incremento en el número de quienes están en la red y por lo tanto hacen uso de los servicios y posibilidades que ésta ofrece. La ubicación geográfica en la que se encuentran los grupos humanos, así como los individuos, tiene una importancia relevante en relación con el acceso y uso de la TIC. Esto no es exclusivo del uso de la tecnología; tiene que ver también con el desarrollo industrial, la generación de oportunidades de empleo, la concentración de instituciones educativas en las zonas urbanas y otras circunstancias más que analizaremos en este capítulo.

A pesar del crecimiento exponencial que ha experimentado Internet en la última década, de casi un millón de usuarios en 1993 a más de 600 millones en 2002, sólo está conectada en línea el 10 por ciento de la población mundial. El 90 por ciento de los usuarios habitan en lo que consideramos países desarrollados, y casi un tercio de ellos viven en Estados Unidos. ${ }^{1}$ Desde esta perspectiva se observa que la mayoría de los usuarios de Internet se encuentran en las zonas urbanas de los países desarrollados. Las zonas agrícolas se hallan margi-

1 Moorhead, 2. 
nadas de las avanzadas tecnologías de información aun en los países que se caracterizan por tener la mayor conectividad a Internet. En muchas áreas rurales de países pobres se carece de la infraestructura más elemental y aun es necesario hacer esfuerzos para contar con electricidad y teléfonos antes de soñar en una comunicación vía Internet.

Se ha dicho que el 50 por ciento de la población mundial nunca ha hecho una llamada telefónica, por lo que la Internet para la mitad de la población es algo inaccesible, en especial para quienes habitan en los países en vías de desarrollo, en zonas rurales y en las zonas rurales de los países en desarrollo.

Cabe destacar que la tasa de crecimiento de los usuarios de Internet no guarda una constante, sino que en algunos momentos se acelera y en otros parece detenerse. En los países desarrollados parece ser más lenta, y esto se explica por la vieja ley de las utilidades marginales, en tanto que en los países en desarrollo pareciera que el crecimiento es más rápido, pero esto se debe a que el rezago es tan grande, que con mucha facilidad se logran porcentajes de crecimiento espectaculares, como el caso de Argentina, Brasil, Paraguay y Uruguay, donde el acceso a Internet se incrementó de enero de 1996 a enero de 1997 el 352 por ciento. ${ }^{2}$

Bowie, al responder a la pregunta “¿Cuántas personas están conectadas en línea?", nos permite conocer la concentración de usuarios de la TIC en los países desarrollados. De acuerdo con la encuesta realizada por NUA Internet Surveys en 2000, las estimaciones, aunque inexactas, rondaban los 332.73 millones de personas, de los cuales 147.48 vivían en Estados Unidos y Canadá, un 25 por ciento del total habitaba en Europa y menos del uno por ciento vivían en África. ${ }^{3}$ Respecto a la cantidad de usuarios de Internet, los últimos datos disponibles compilados por NUA Internet Surveys corresponden a septiembre de 2002, y

2 Murelli, 34.

3 Nolan A. Bowie, "The digital divide: making knowledge available in a global context", en Centre for Educational Research and Innovation [y] National Center on Adult Literacy, 43. 
el total mundial es de 605.60 millones de personas distribuidas, de acuerdo con la figura 6 , de la siguiente manera: ${ }^{4}$

Figura 6

Distribución mundial de los usuarios de Internet, 2002

\begin{tabular}{||l|c|c|}
\hline \multicolumn{1}{|c|}{ Área geográfica* } & Millones de personas & Porcentaje \\
\hline África & 6.31 & 1 \\
\hline Asia/Pacífico & 187.24 & 30.91 \\
\hline Europa & 190.91 & 31.52 \\
\hline Medio Oriente & 5.12 & .84 \\
\hline Canadá y Estados Unidos & 182.67 & 30.16 \\
\hline América Latina & 33.35 & 5.5 \\
\hline
\end{tabular}

* Para mayor detalle véase la desagregación geográfica en el sitio web de NUA Internet Surveys

Fuente: NUA Internet Surveys, How many online?, Jupitermedia Corporation, disponible http://www.nua.ie/surveys/how_many_online/index.html [Septiembre 1, 2005].

Por otra parte, se afirma que la isla de Manhattan cuenta con mayor número de conexiones a Internet que toda América Latina.

Kelley-Salinas asienta la diferencia entre los países más desarrollados y los menos desarrollados, que se manifiesta en el número de computadoras y servidores de Internet por cada 10 mil habitantes, según los datos del Banco Mundial. Así entonces, mientras los países menos desarrollados tienen 120 computadoras por cada 10 mil habitantes, los países más desarrollados poseen 2,690. Al mismo tiempo, mientras que los países menos desarrollados tienen tan sólo tres servidores de Internet por la misma cantidad de habitantes, los países desarrollados tienen 470.5

4 NUA Internet Surveys, How many online?, Jupitermedia Corporation, disponible http://www.nua.ie/surveys/how_many_online/index.html [Septiembre 1, 2005].

5 Kelley-Salinas, 25. 


\section{La brecha digital y sus determinantes}

Figura 7

Servidores de Internet por cada 10,000 personas en países de la OCDE, 1998

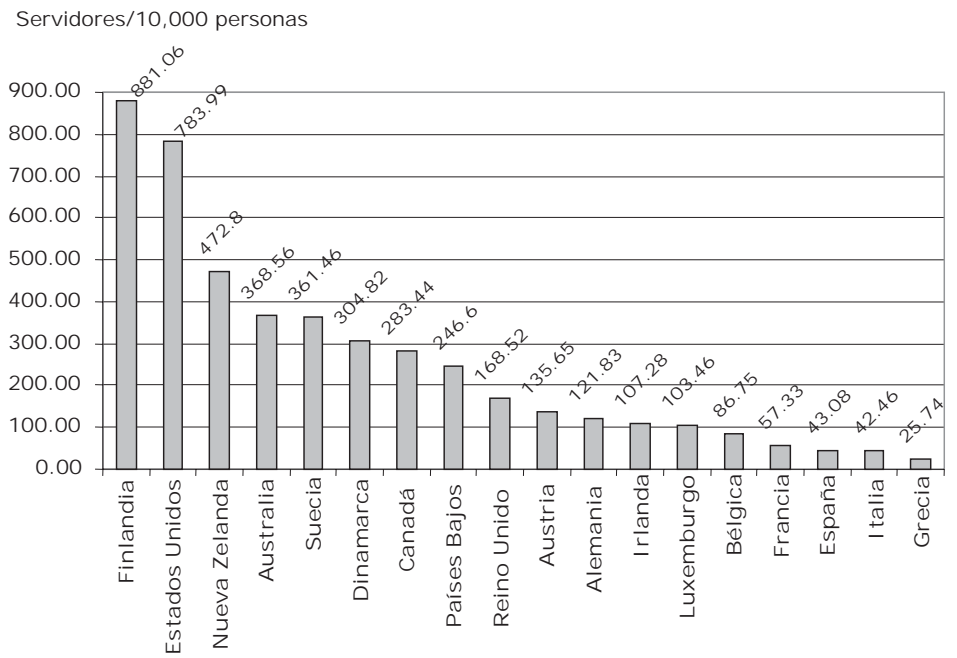

Figura 3.1.

Distribución de servidores de Internet en países de la OCDE seleccionados, 1998.

Fuente: Telecommunications Policy 23 (10-11). "Weaving the Western Web: Explaining Differences in Internet Connectivity among OECD Countries." by Eszter Hargittai, Copyright 1999. Usado con autorizaciòn de Elsevier Science.

Tomado de Mark Warschauer, Technology and social inclusion: rethinking the digitaldivide

(Cambridge, Mass.: MIT Press, 2003), 51.

Hargittai, citada por Warschauer, ${ }^{6}$ examinó la variación internacional de la conectividad entre 18 países miembros de la OCDE y encontró que a pesar de que todos ellos tienen un relativo desarrollo industrial, los rangos de penetración de Internet son impresionantes como se puede observar en la figura 7.

6 Eszter Hargittai, "Weaving the western web: explaining differences in Internet connectivity among OECD Countries", Telecommunications Policy 23 (10-11), citada por Mark Warschauer,Technology, 50. 
Figura 8

Los 12 países que no pertenecen a OCDE con más de 50 millones de habitantes y más de 1,000 servidores - Datos de Network Wizards, 1998

\begin{tabular}{||l|c|c||}
\hline \multicolumn{1}{|c|}{ Países } & Número de servidores & $\begin{array}{c}\text { \% de crecimiento entre } \\
\text { enero y julio de 1998 }\end{array}$ \\
\hline Brasil & 163.890 & $+39,8 \%$ \\
\hline Rusia & 150.466 & $+28,4 \%$ \\
\hline México & 83.949 & $+101,5 \%$ \\
\hline Turquía & 27.861 & $+12,4 \%$ \\
\hline Tailandia & 25.459 & $+77,1 \%$ \\
\hline China (sin Hong Kong) & 19.313 & $+18,3 \%$ \\
\hline Ucrania & 13.271 & $+44,6 \%$ \\
\hline Indonesia & 10.691 & $+11,3 \%$ \\
\hline India & 10.436 & $+45,8 \%$ \\
\hline Filipinas & 7.602 & $+76,3 \%$ \\
\hline Egipto & 2.043 & $+1,5 \%$ \\
\hline Pakistán & 1.923 & $+48,9 \%$ \\
\hline $\begin{array}{l}\text { Tabla 4: Los principales 12 países no miembros de la OCDE con más de 50 millones } \\
\text { de habitantes y más de 1,000 servidores - Datos elaborados por Network Wizards, } \\
\text { 1998. }\end{array}$ & & \\
\hline
\end{tabular}

Tomado de Elena Murelli, Breaking the digital divide: implications for developing countries, (S. I: Commonwealth Secretariat: SFI Pub., 2002), 35.

Por su parte Murelli elaboró la figura 8, con los datos de Network Wizards $^{7}$ de enero y julio de 1998, considerando a los 12 países que no pertenecen a la OCDE y que tienen más de 50 millones de habitantes, más de mil servidores de Internet, y que sin embargo tienen una baja densidad en el uso de la red.

Cabe señalar que México es miembro de la OCDE y por lo tanto, aunque se encuentra entre los países que cumplen con las caracterís-

7 Network Wizards, ISC Internet domain survey, 2004. Internet Systems Consortium, disponible http://www.isc.org/index.pl?/ops/ds/ [Agosto 18, 2005]. 
ticas definidas desde el punto de vista de servidores en la figura 8 , también podría no formar parte de ésta.

Murelli expone así los obstáculos para la expansión de Internet en los países en desarrollo:

La conclusión que se puede extraer del informe INET 98 es clara: los países en desarrollo tienen más problemas con respecto a la conectividad electrónica relacionada con la red. Se pueden ofrecer varias explicaciones a esta brecha aparente entre norte y sur.

- El primer problema es la pobreza de los países en desarrollo. Esto significa que los recursos necesarios para sobrevivir no están directamente disponibles y que Internet no es un objeto indispensable.

- El segundo factor es la falta de infraestructura necesaria para la información y la comunicación, lo que constituye tanto un obstáculo como un impulso, pues estos países tienen limitadas redes de telecomunicación y la existencia de Internet depende de condiciones mínimas de infraestructura de conectividad.

- El tercer factor está representado por la educación, el idioma y la cultura de esos países. Muchos de los usuarios de Internet son jóvenes, usualmente del tipo de los que están fascinados con la aplicación de las nuevas tecnologías. En 1995, el 17 por ciento de la población de los países en desarrollo tenía menos de 14 años de edad, en contraste con sólo el 9 por ciento en los países industrializados. El bajo nivel educativo en esos países no ayuda de manera importante a la introducción de la tecnología. En 1993 más de la mitad de la población de los países pobres no tenía la posibilidad de asistir a una escuela secundaria tanto por el bajo ingreso que recibía la familia como por la falta de escuelas. De acuerdo con ITU, la Unión Internacional de Comunicaciones (ITU 97), con excepción de la India y China el número de jóvenes que no podía asistir a una escuela secundaria se incrementó al 75 por ciento de esos países, en los países industrializados al contrario, el porcentaje de los jóvenes que asisten a la escuela secundaria es de 97 por ciento. 8

Tratando de determinar la posición que ocupa la sociedad estadounidense en materia de acceso y uso de Internet y de la tecnología de la comunicación, Servon estableció que del 2.5 por ciento de la

8 Murelli, 38. 
Figura 9

Usuarios de Internet: un enclave global

\begin{tabular}{||l|c|c||}
\hline \multicolumn{2}{||}{ Tabla 2.2 Usuarios de Internet: un enclave global } \\
\hline & $\begin{array}{c}\text { Población regional } \\
\text { (como \% de la po- } \\
\text { blación mundial) }\end{array}$ & $\begin{array}{c}\text { Usuarios de Internet } \\
\text { (como \% de la pobla- } \\
\text { ción regional) }\end{array}$ \\
\hline Estados Unidos & 4.7 & 26.3 \\
\hline OcDE (excluyendo a los EU) & 14.1 & 6.9 \\
\hline América Latina y el Caribe & 6.8 & 0.8 \\
\hline Asia Sudoriental y Asia Oriental del Pacífico & 8.6 & 0.5 \\
\hline Asia Oriental & 22.2 & 0.4 \\
\hline Europa Oriental y la Comunidad de Estados & 5.8 & 0.4 \\
\hline Independientes & 4.5 & 0.2 \\
\hline Estados árabes & 9.7 & 0.1 \\
\hline África Subsahariana & 23.5 & Menor al 0.1 \\
\hline Asia del Sur & 100.0 & 2.4 \\
\hline El mundo & & \\
\hline Fuente: Adaptado del United Nations Development Programme (1999). & \\
\hline
\end{tabular}

Tomado de Lisa J. Servon, Bridging the digital divide: technology, community and public policy

(Malden, Mass.: Blackwell Publishing, 2002), 42.

población mundial que se conectaba a Internet en 1998, aproximadamente un cuarto residía en Estados Unidos. Los datos correspondientes al resto del mundo, a excepción de los países miembros de la OCDE, fueron realmente marginales, en particular con relación a su población como se observa en la figura 9.

La difusión de Internet hoy en día presenta contrastes drásticos entre las diferentes regiones del globo, como lo muestra la figura 10. Mientras unos pocos países (29) tenían en el año 2000 casi 340 millones de usuarios en línea, los países no industrializados (150) tenían tan sólo 66 millones. 


\section{La brecha digital y sus determinantes}

Figura 10

Usuarios de Internet por región y tipo de sociedad, 2000

Tabla 3.1. Usuarios de Internet por región y tipo de sociedad, 2000

\begin{tabular}{||l|c|c|c|c|}
\hline & $\begin{array}{c}\text { Población total } \\
1997, \text { UNDP }\end{array}$ & $\begin{array}{c}\text { Total en línea } \\
2000\end{array}$ & $\begin{array}{c}\text { Total de servidores } \\
2000\end{array}$ & $\begin{array}{c}\text { Número de } \\
\text { naciones }\end{array}$ \\
\hline Industrializada & $1,098,620,000$ & $339,259,000$ & $65,785,669$ & 29 \\
\hline No industrializada & $4,672,773,000$ & $66,237,700$ & $2,161,528$ & 150 \\
\hline América del Norte & $369,400,000$ & $169,620,000$ & $46,123,871$ & 3 \\
\hline Asia-Pacífico & $3,270,250,000$ & $99,463,200$ & $5,950,661$ & 35 \\
\hline Europa Occidental & $362,960,000$ & $86,655,000$ & $11,318,161$ & 16 \\
\hline Europa Central y Oriental & $404,180,000$ & $16,310,500$ & 833,419 & 13 \\
\hline Escandinavia & $24,000,000$ & $12,354,000$ & $2,711,261$ & 5 \\
\hline América del Sur & $403,893,000$ & $13,710,000$ & 748,279 & 30 \\
\hline África & $685,020,000$ & $2,956,500$ & 21,608 & 52 \\
\hline Medio Oriente & $224,690,000$ & $4,427,500$ & 239,936 & 14 \\
\hline Desarrollo alto & $1,011,650,000$ & $340,810,500$ & $65,517,356$ & 43 \\
\hline Desarrollo medio & $4,102,603,000$ & $57,762,500$ & $1,819,652$ & 89 \\
\hline Desarrollo bajo & $583,250,000$ & 422,200 & 4,520 & 35 \\
\hline Total & $\mathbf{5 , 7 7 1 , 3 9 3 , 0 0 0}$ & $405,496,700$ & $67,947,197$ & 179 \\
\hline Notasy fun & & \\
\hline
\end{tabular}

Notas y fuentes: Población total 1997 del United Nations Development Report, 1999, Nueva York: UnDP/Oxford University Press; Total en línea en 2000 estimada de www.nua.ie, "How Many Online" y de International Telecommunications Union Basic Indicators 1998, www.itu.int; Total de servidores estimado por el International Consortium, enero 2000. LoS sitios .com, .net y .org fueron cargados según la localización del registro y su reasignación por nación según la metodología de la OCDE. Véase OCDE 1999, Communications Outlook 1999, París: OCDE, www.oecd.org. Nivel de desarrollo humano definido por el Human Development Index 1999, Human Development Report, 1999, Nueva York: UNDP/Oxford University Press.

Tomado de Pippa Norris, Digital divide: civic engagement, information poverty, and the Internet worldwide (Cambridge: Cambridge University Press), 46.

Estas diferencias son más dramáticas cuando las regiones geográficas se desagregan en los países que las componen, como se observa en la figura 11. 


\title{
La tecnología de la información y comunicación en el mundo
}

\author{
Figura 11
}

Porcentaje de la población en línea por nación, 2000

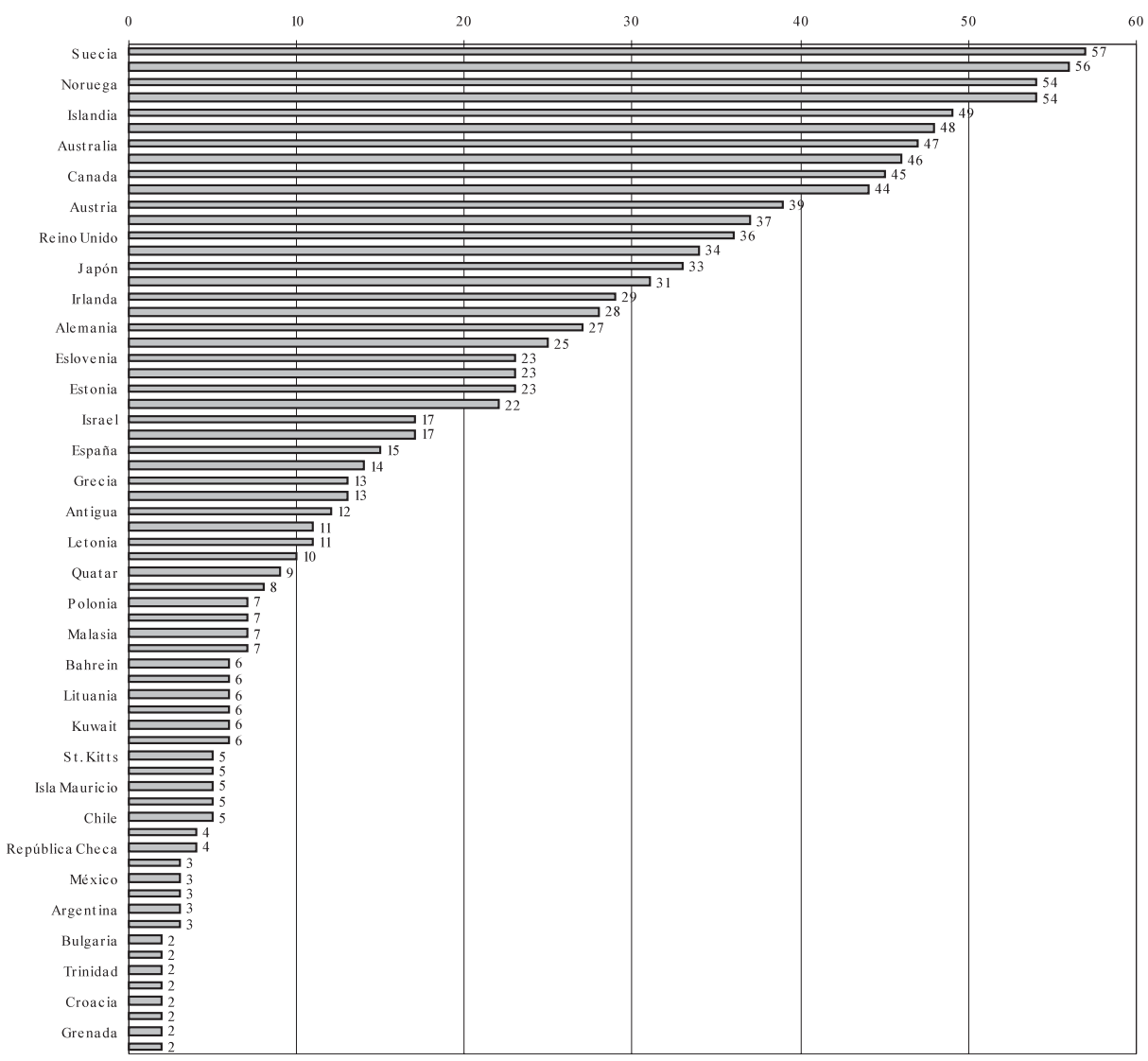

Figura 3.2. El porcentaje de población en línea por nación, 2000. Fuente: All the countries with more than 0.5 percent of the population online, "How many on line", www.nua.ie, noviembre 2000.

Tomado de Pippa Norris, Digital divide: civic engagement, information poverty, and the Internet worldwide

(Cambridge: Cambridge University Press), 48. 
Existen innumerables elementos que intervienen en la brecha digital, algunos de los cuales ya se han expuesto y otros que se irán desarrollando en los próximos capítulos. Pero la figura 12 nos ayudará a comprender la correlación entre esos aspectos y la expansión de la tecnología a escala mundial.

Figura 12

Explicando la expansión de la tecnología

\begin{tabular}{|c|c|c|c|c|}
\hline & \multirow{2}{*}{$\begin{array}{c}\text { Porcentaje en } \\
\text { línea }\end{array}$} & \multicolumn{2}{|c|}{$\begin{array}{c}\text { Índice de medios } \\
\text { nuevos }\end{array}$} & \multirow{2}{*}{$\begin{array}{l}\text { Índice de medios } \\
\text { viejos } \\
\text { Beta } \\
\text { (Sig.) }\end{array}$} \\
\hline & & $\begin{array}{l}\text { Beta } \\
\text { (Sig.) }\end{array}$ & $\begin{array}{l}\text { Beta } \\
\text { (Sig.) }\end{array}$ & \\
\hline \multicolumn{5}{|l|}{ Desarrollo económico } \\
\hline PIB per cápita & $.74^{\star \star}$ & $.37 * *$ & $.57^{\star *}$ & $.58^{\star *}$ \\
\hline Gasto en investigación y desarrollo (\%) & $.46^{\star \star}$ & $.32^{\star \star}$ & $.28^{\star \star}$ & $.32^{\star \star}$ \\
\hline \multicolumn{5}{|l|}{ Desarrollo social } \\
\hline Instrucción de adultos (\%) & $.40^{* *}$ & .03 & -.05 & .09 \\
\hline Educación secundaria (\%) & $.53^{\star \star}$ & .07 & .01 & .01 \\
\hline \multicolumn{5}{|l|}{ Desarrollo político } \\
\hline Nivel de democratización & $.55^{\star \star}$ & .08 & -.06 & .10 \\
\hline \multicolumn{5}{|l|}{ Región } \\
\hline Escandinavia & $.59^{\star *}$ & $.26^{\star *}$ & $.19^{\star \star}$ & .08 \\
\hline América del Norte & $.34^{\star *}$ & $.17^{\star *}$ & $.12^{\star \star}$ & .04 \\
\hline Europa Occidental & $.25^{\star *}$ & $.07^{\star}$ & .08 & -.06 \\
\hline Medio Oriente & -.04 & -.07 & -.11 & .01 \\
\hline Europa Central y Oriental & -.05 & -.06 & -.03 & .12 \\
\hline América del Sur & $-.29 * \star$ & -.11 & -.09 & .01 \\
\hline África & $-.29 * *$ & .01 & -.03 & .01 \\
\hline Ajuste R2 & & .80 & .57 & .91 \\
\hline \multicolumn{5}{|c|}{$\begin{array}{l}\text { Notas: Las variables dependientes incluyen la proporción de la población en línea (Primavera 2000), el índice de } \\
\text { medios nuevos (\% en línea, \% de PC, \% de servidores), y el índice de medios viejos (\% de diarios, \% de radios, \% } \\
\text { de televisiones, \% de teléfonos fijos y \% de teléfonos móviles) (véase tabla } 3.2 \text { para detalles). La figura represen- } \\
\text { ta los coeficientes de correlación (R) sin controles y coeficientes beta estandarizados de modelos OLs de análisis } \\
\text { de regresión multivariados. El descenso de la variable nominal Asia . * Sig.= -.01, **Sig.=.05. }\end{array}$} \\
\hline \multicolumn{5}{|c|}{ Fuentes: Véanse tablas previas en este capítulo para datos de las fuentes. } \\
\hline
\end{tabular}

Tomado de Pippa Norris, Digital divide: civic engagement, information poverty, and the Internet worldwide (Cambridge: Cambridge University Press), 62. 
La esperanza en que el uso de la tecnología ayude a cerrar la brecha que determina el uso de ciertos productos y servicios no es del todo cierta. En los años 1970 y 1980, por ejemplo, se pensó que la divulgación de las calculadoras portátiles reduciría la brecha relacionada con las habilidades matemáticas entre los estudiantes. Pero cuando la mayoría de los jóvenes tuvo una calculadora a la mano, debido al abaratamiento de los equipos y la facilidad para encontrarlas en casi todas partes, se redujo la brecha en la posesión de las calculadoras pero no necesariamente disminuyó la brecha en las habilidades matemáticas de los estudiantes. Cuando las calculadoras fueron accesibles y todos tuvieron una, sólo unos cuantos eran hábiles en su manejo debido a que sabían para qué podían utilizarlas.

La expectativa de que el uso de la tecnología borre todas las diferencias entre los individuos y los conduzca a una sociedad más justa en la que las desigualdades se vean disminuidas y tiendan a desaparecer, es tan sólo una utopía. La historia de la humanidad está llena de ejemplos en los que el uso de diferentes tecnologías ha creado la esperanza de producir una sociedad igualitaria, pero el uso de la tecnología por sí sola no ha tenido la fuerza suficiente para suprimir alguna de las diferencias. 9

La apropiación de la tecnología de la información creció rápidamente en algunos periodos y en otros pareció detenerse o al menos disminuir su ritmo de crecimiento; esto puede deberse a situaciones sociopolíticas especiales o a que las fuentes de donde se extrajo la información son variadas y cada una de ellas realiza sus cálculos de diferente forma. Esta es una muestra más de lo difícil que es conocer con exactitud el número de usuarios de Internet.

La información disponible permite determinar el ritmo en que se difundieron mundialmente la radio, la televisión e Internet. En la figura 13 se puede apreciar cómo el ritmo en la apropiación mundial no ha sido tan acelerado como el que se observa en Estados Unidos. El nivel global de penetración de la televisión, después de 50 años, es

9 Light, 724. 
Figura 13

Difusión mundial de la radio, televisión e Internet, 1950-2000

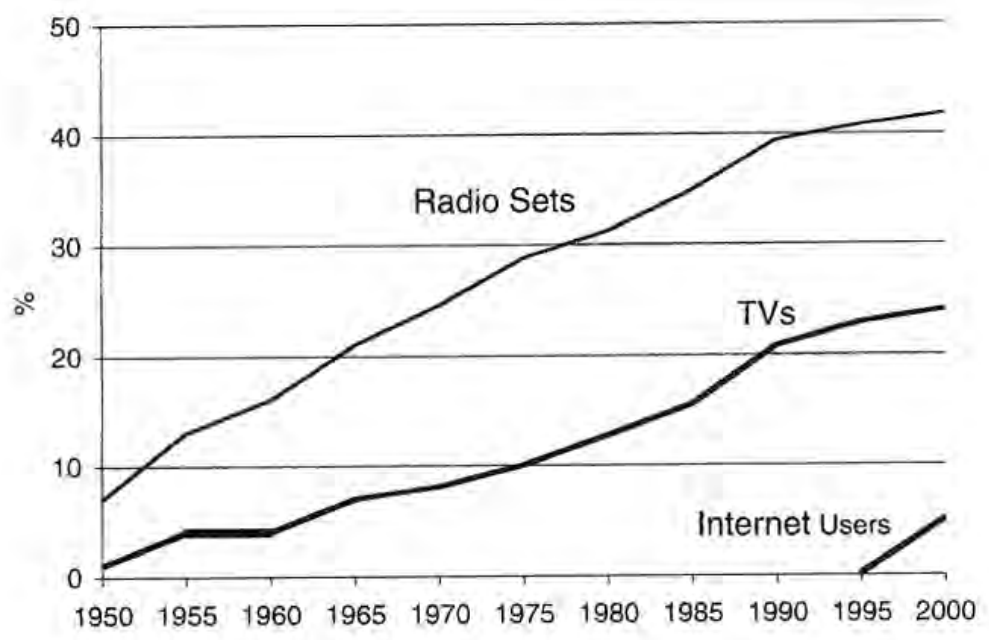

Figure 2.4. Worldwide Diffusion of Radio, Television, and the Internet, 1950-2000.

Sources: Television sets and radio receivers per household: annual UNESCO Statistical Yearbooks, UNESCO, Paris; estimates of the Internet population: "How Many Online?", 1, Www.NUA.ie

Tomado de Pippa Norris, Digital divide: civic engagement, information poverty, and the Internet worldwide (Cambridge: Cambridge University Press), 34.

de tan sólo el 25 por ciento, mientras que ese mismo nivel en Estados Unidos tomó cinco años. En general las cifras son muy bajas ya que al incluirse a los países en desarrollo, que tienen los niveles más bajos, las cifras generales se deprimen.

Una diferencia importante entre el acceso a la red y el empleo de otros medios de comunicación, como por ejemplo el teléfono y la televisión, es que en los instrumentos mencionados en segundo lugar la posibilidad de interactividad es menor que en Internet. A diferencia del usuario de la red, que puede preguntar, buscar más información, enriquecerla o confrontarla con otras fuentes, con la radio, el teléfono y la televisión se tiene acceso a información limitada en su 
Figura 14

Proporción en línea, EU-15, 1996-1999

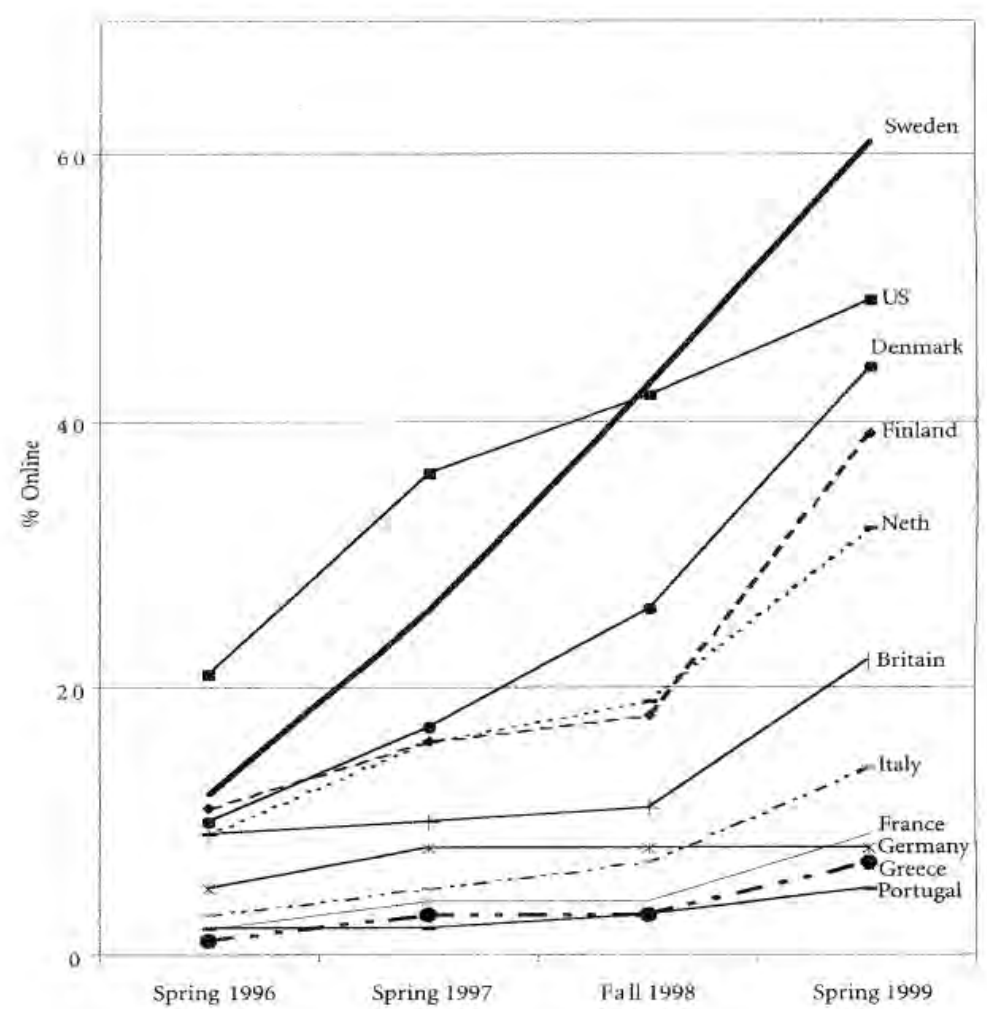

Figura 4.2. Porcentaje en línea, EU-15, 1996-99

Fuentes: Eurobarometers 1996-1999; Pew Surveys, United States

Tomado de Pippa Norris, Digital divide: civic engagement, information poverty, and the Internet worldwide (Cambridge: Cambridge University Press), 76.

cantidad y calidad y el receptor observa un comportamiento pasivo. Con las tecnologías menos interactivas el usuario requiere también menos conocimientos para operarlas correctamente y obtener provecho, en contraparte el acceso fructífero y exitoso a la red requiere de una adecuada capacitación. 
Figura 15

Población mundial conectada, 2002

\begin{tabular}{||l|l||}
\hline \hline Total mundial & 605.60 millones \\
\hline África & 6.31 millones \\
\hline Asia/Pacífico & 187.24 millones \\
\hline Europa & 190.91 millones \\
\hline Medio Oriente & 5.12 millones \\
\hline Canadá y EU & 182.67 millones \\
\hline América Latina & 33.35 millones \\
\hline
\end{tabular}

Tomado de: How many online?, Disponible en http://www.nua.com/surveys/how_many_online/ index.html [Agosto 10, 2005].

No todas las naciones han tenido el mismo ritmo de adición al uso de Internet. En algunos países, como Suecia, éste ha sido acelerado y en algunos otros, como Dinamarca, fue a partir de 1998 que la conexión se incrementó en forma explosiva, aunque antes ya había tenido un crecimiento importante. Sin embargo, otros países, como Gran Bretaña, han tenido un crecimiento lento y ha sido hasta 1998 que se ha acelerado, pero sin lograr los altos índices de conexión que tiene Suecia, que en muy poco tiempo alcanzó el 60 por ciento de conectividad. Hay cuatro países que muestran un crecimiento verdaderamente magro: Francia, Alemania, Grecia y Portugal, que registraban una conectividad de cinco por ciento según se observa en la figura 14.

La posibilidad de estimar cuántas personas están conectadas en línea en todo el mundo es inexacta, cuando mejor nos va, pero según un sondeo de la NUA Internet Surveys en 2002 existían 605.5 millones de usuarios de Internet en el mundo; véase la figura 15.

Tres son las zonas en las que se encuentra el mayor número de usuarios, aunque con relación a la población mundial esas regiones no necesariamente tienen la mayor proporción de habitantes. Así por ejemplo, Canadá y Estados Unidos tienen un elevado porcentaje de usuarios con relación al total de la población de esos dos países. La región de Asia y el Pacífico tiene un número de usuarios similar al de los países norteamericanos, pero la población de esa región supera varias veces la de los países americanos. 
Figura 16

Crecimiento mundial del número de usuarios de Internet, 1993-2002

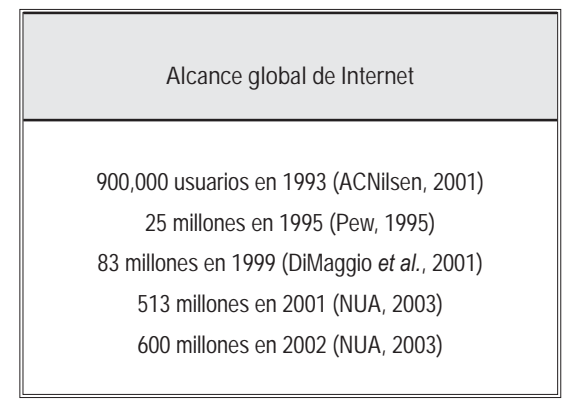

Elaborada con datos tomados de Wenhong Chen y Barry Wellman, Charting and bridging digital divides, comparing socio-economic, gender, life stage, and rural-urban Internet access and use in eight countries. Octubre 27, 2003, 2, disponible http://www.amd.com/us-en/assets/ content_type/DownloadableAssets/FINAL_REPORT_CHARTING_DIGI_DIVIDES.pdf [Agosto 6, 2004]

Europa cuenta con una cantidad de usuarios ligeramente superior a las dos regiones antes mencionadas, América Latina tiene una sexta parte de las tres regiones anteriores y en África y Medio Oriente sólo una pequeña fracción de la población tiene conexión.

Las cifras sobre el desarrollo de Internet y el número de sus usuarios son difíciles de establecer, pero existen estimaciones de cierto valor que demuestran que Internet ha crecido a una velocidad sin precedente. La figura 16 expone parcialmente ese ritmo de crecimiento.

Si bien es cierto que el empleo de Internet se ha adoptado en todo el mundo, también lo es que en los países desarrollados ello ha sido más rápido; esta situación es una muestra clara de que la brecha digital no solamente se encuentra dentro de una misma sociedad, sino que también debe ser estudiada y atacada en el mundo globalizado, donde las sociedades más desarrolladas tienen mayor acceso al mundo digital que los países en desarrollo. 
El Foro Económico Mundial de 2002 encontró que "aunque sólo un 10 por ciento de la población mundial estaba conectada a Internet en 2002, 88 por ciento de los usuarios de Internet residían en países industrializados". 10

En el lado equivocado de la brecha están quienes se encuentran al margen de la posibilidad de acceder a Internet; y aunque no tienen una sola característica sino muchas, que en la mayoría de los casos se combinan, en algunas circunstancias es una sola la que determina la marginación. Los rasgos de la marginación son los siguientes, según ha sintetizado Cullen:

Personas de bajos ingresos económicos, personas con bajas calificaciones educativas o con niveles bajos de alfabetización, los desempleados, los ancianos, personas aisladas o en áreas rurales, personas con discapacidades, padres solteros, mujeres y niñas. Debido a que ellas ya están en desventaja con relación a la educación, ingreso, salud y también por las profundas diferencias culturales, entre comunidades indígenas, migrantes y grupos étnicos minoritarios. 11

En el informe del secretario general del Consejo Económico y Social (ECOSOC, por sus siglas en inglés) se establece que la falta de infraestructura física en telecomunicaciones no es uno de los problemas principales en el mundo en desarrollo cuando la tecnología móvil está disponible y es utilizada adecuadamente. Para 2003 se calculaba que mil millones de personas tenían acceso a Internet a través de sus teléfonos móviles; sin embargo la telefonía móvil no garantiza el acceso a Internet, en especial en áreas remotas a los sistemas de transmisión convencionales. Hay que subrayar que la tecnología móvil necesita de la instalación de antenas para la recepción de las señales, o bien de sistemas de comunicación satelitales. Es difícil pensar que las grandes compañías de telecomunicaciones harán las inversiones necesarias para la conexión de áreas rurales si no están seguras de contar con el número de usuarios reales que paguen

10 Chen y Wellman, 2.

11 Cullen, 248. 
una cuota mensual. Además, aun con la tecnología móvil habría que tomar en cuenta que las baterías de los equipos requieren ser cargadas con electricidad y en muchas áreas rurales no se cuenta con ella.

Otros dos aspectos afectan la utilización de Internet; uno es que los pagos para la utilización de la red tienen que ser hechos en dólares y algunos países no cuentan con los recursos o bien les es muy difícil obtenerlos; el otro es el empleo del inglés como idioma principal en el uso de Internet, mucha de la información está en esa lengua aunque los autores hablen otra diferente, así, las más importantes publicaciones periódicas especializadas del mundo están en inglés y los científicos publican en ellas porque buscan que sus trabajos tengan mayor difusión entre los especialistas. No basta con utilizar otras lenguas, la lingua franca de Internet es el inglés y por lo tanto se seguirá empleando como herramienta común.

Una de las principales causas que han favorecido el crecimiento de Internet ha sido el decremento en el precio del equipo de cómputo. No todos los costos han disminuido, aún muchas personas consideran que la conexión a Internet es demasiado costosa, y esta es una de las razones por las que no están conectadas.

La figura 17 muestra la desproporción entre el acceso a Internet y la población de las diferentes partes del mundo. Mientras que Estados Unidos tiene una población semejante a la de América Latina, los estadounidenses cuentan con 75 por ciento del total de usuarios y Latinoamérica con tan pocos que no alcanza a ser representada en la gráfica. El resto del mundo, después de descontar a los Estados Unidos, el Reino Unido, Canadá y Australia, apenas consigue el 11 por ciento de los usuarios de la red, dejando en claro que Estados Unidos solo tiene casi seis veces más usuarios que el resto del mundo.

Otro ejemplo es África Subsahariana, que cuenta con 2.5 millones de usuarios de Internet, es decir menos del uno por ciento de la población mundial. Hay más usuarios en la rica Suecia que en todo el continente africano. ${ }^{12}$

12 Norris, The worldwide digital divide, 3. 
Figura 17

Usuarios de Internet por localización geográfica, 1995

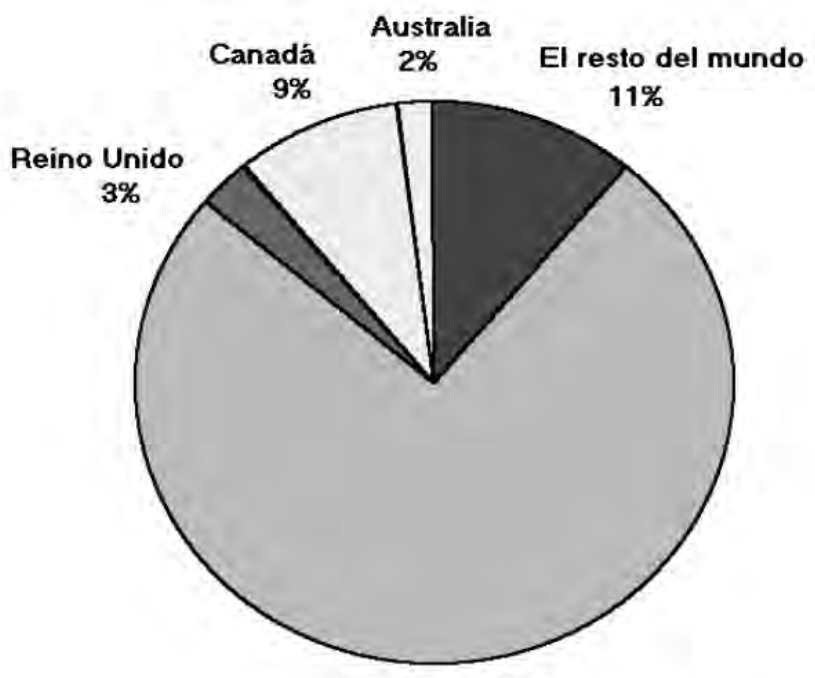

Estados Unidos

$75 \%$

Fuente: Yahoo/Jupiter

Tomado de NUA Internet Surveys, NUA Analysis, Internet users by geographic location, graphs and charts, disponible en http://www.nua.com/surveys/analysis/graphs_charts/1995graphs/ location.html [Enero 30, 2006].

Se puede decir que no hay una brecha digital con África, hay un abismo. Con 780 millones de personas o el 13 por ciento de la población mundial, tiene tantos servidores como Latvia, que tiene una población de 2.5 millones de habitantes.

África no se ha rezagado, ha sido superada por varias vueltas. En octubre de 1997 la brecha digital entre África y Norteamérica era un múltiplo de 267; en octubre de 2000, ésta había aumentado a un múltiplo de 540.13

13 Kuttan y Peters, 111. 


\section{La tecnología de la información y comunicación en el mundo}

Figura 18

Tasa de penetración de Internet por continente

\begin{tabular}{||l|c||}
\hline \hline \multicolumn{2}{||c|}{ Tabla 4.3. Tasa de penetración de Internet, por continente } \\
\hline Región & Tasa de penetración de Internet \\
\hline América del Norte & $41 \%$ \\
\hline Europa Occidental & $19 \%$ \\
\hline Europa Oriental & $3 \%$ \\
\hline América Latina & $3 \%$ \\
\hline Asia/Pacífico & $2 \%$ \\
\hline Medio Oriente & $1 \%$ \\
\hline África & Menos del $1 \%$ \\
\hline
\end{tabular}

Tomado de Appu Kuttan y Laurence Peters, From digital divide to digital opportunity (Lanham, Maryland: Scarecrow Press, 2003), 108.

Esta situación se debe en parte a que África carece de la infraestructura básica para tener acceso a la red. Según la Unión Internacional de Telecomunicaciones, en África más de treinta países tienen menos de una línea telefónica por cada 100 habitantes, comparada con el promedio mundial de 13 líneas por cada 100 personas. ${ }^{14}$

La figura 18 proporciona información sobre la penetración de Internet en las siete regiones en que Kuttan ha dividido el mundo. Como se observa, entre Estados Unidos (con un 40 por ciento) y Europa Occidental (el 19 por ciento) reúnen el 60 por ciento de todos los usuarios de Internet; en contraste, América Latina tiene tan sólo un tres por ciento y África el uno por ciento. Estas estadísticas revelan con toda claridad que la brecha entre regiones es enorme, y que si

14 International Telecommunication Union, Challenges to the network: telecommunications and Internet, Ginebra, citado por Nolan A. Bowie, "The digital divide: making knowledge available in a global context", en Centre for Educational Research and Innovation [y] National Center on Adult Literacy, 42. 
Figura 19

Tasa de penetración de Internet por continente (gráfico)

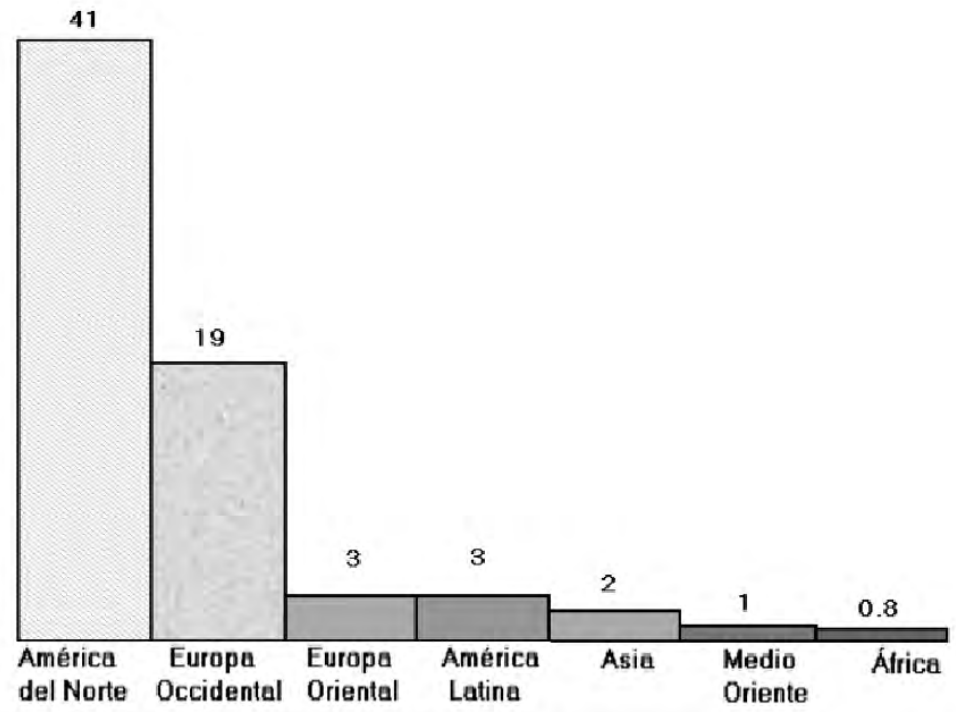

Figura 4.1. Tasa de penetración de Internet

Tomado de Appu Kuttan y Laurence Peters, From digital divide to digital opportunity (Lanham, Maryland: Scarecrow Press, 2003), 108.

bien en algunos casos, como entre Estados Unidos y Europa Occidental, la diferencia es de dos a uno, entre los extremos -Estados Unidos y África- es de 40 a uno.

Para facilitar la apreciación de las cifras anteriores obsérvese la figura 19. Pero no sólo es importante el nivel de penetración de Internet entre la población. Otros elementos nos hablan de la concentración no sólo de las computadoras personales, sino de las computadoras que se emplean como servidores y en las que se encuentran ubicados los bancos de información y de aquellas que controlan una muy importante parte del correo electrónico y de la información que proporciona la red. 
Figura 20

Número de servidores de Internet y usuarios, por continente

\begin{tabular}{||l|c|c||}
\hline \hline \multicolumn{3}{||c|}{ Tabla 4.4. Número de servidores de Internet y usuarios, por continente } \\
\hline & Número de servidores de Internet & Número de usuarios de Internet \\
\hline América del Norte & $80,299,100$ & $194,556,000$ \\
\hline Europa & $20,309,500$ & $89,066,300$ \\
\hline Asia & $8,929,770$ & $70,073,600$ \\
\hline Oceanía & $2,062,590$ & $17,227,800$ \\
\hline América del Sur & $1,264,850$ & $16,593,700$ \\
\hline América Central & 467,463 & $1,538,330$ \\
\hline África & 265,366 & $2,901,450$ \\
\hline
\end{tabular}

Tomado de Appu Kuttan y Laurence Peters, From digital divide to digital opportunity (Lanham, Maryland: Scarecrow Press, 2003), 109.

Así, mientras que en Norteamérica la relación entre los usuarios y los servidores en que se encuentra la información es de dos a uno, en América Latina es de 10.46 a uno y auque la brecha en África es similar a la de América Latina, el número de servidores en América Latina es seis y media veces mayor que en África de acuerdo con la figura 20.

La proporción de usuarios contra no usuarios se ve con claridad en la figura 21. El promedio mundial es de un usuario por 34 no usuarios, en tanto que Estados Unidos y Europa mantienen una relación de dos no usuarios por cada uno que sí lo es; el resto del mundo presenta variaciones muy importantes que nos ayudan a comprender el tamaño del problema. En los extremos están los países árabes, que guardan una relación de un usuario por cada 499 que no lo son, la diferencia más aguda está en los países del sur de Asia con un usuario por cada 2499 no usuarios. La brecha, según estos datos, parece casi imposible de ser resuelta a menos que se tomen medidas urgentes relacionadas con otros indicadores sociales, los cuales no pueden ser modificados mediante el uso exclusivo de la tecnología de la información. 


\section{La brecha digital y sus determinantes}

Figura 21

Proporción de usuarios y no usuarios de Internet

\begin{tabular}{||l|c||}
\hline \hline \multicolumn{2}{||}{ Tabla 4.5. Proporción de usuarios de Internet y no usuarios } \\
\hline Promedio norteamericano & 1 a 2 \\
\hline Promedio europeo & 1 a 2 \\
\hline Promedio latinoamericano y del Caribe & 1 a 124 \\
\hline Promedio del Sudeste Asiático y del Pacífico & 1 a 199 \\
\hline Promedio de Asia del Este & 1 a 249 \\
\hline Promedio africano & 1 a 249 \\
\hline Promedio de los estados árabes & 1 a 499 \\
\hline Promedio de Asia del Sur & 1 a 2499 \\
\hline Promedio mundial & 1 a 34 \\
\hline
\end{tabular}

Tomado de Appu Kuttan y Laurence Peters, From digital divide to digital opportunity (Lanham, Maryland: Scarecrow Press, 2003), 109.

Otra mirada a las cifras mundiales está representada en la figura 22 , en la que con cifras de 2001 se presentan y analizan dos elementos: el número de personas que estaban conectadas a Internet en millones y el porcentaje que representan en cada región.

Figura 22

Tasa de acceso a Internet, agosto de 2001

\begin{tabular}{||l|c|c||}
\hline \hline \multicolumn{1}{||c|}{ Tabla 3.1. Tasa de acceso a Internet, agosto de 2001 } \\
\hline & $\begin{array}{c}\text { No. de personas con ac- } \\
\text { ceso a Internet (millones) }\end{array}$ & $\begin{array}{c}\text { Porcentaje de población } \\
\text { con acceso a Internet }\end{array}$ \\
\hline Estados Unidos y Canadá & 181 & 57.2 \\
\hline Europa & 155 & 21.3 \\
\hline América Latina & 25 & 4.8 \\
\hline Asia & 144 & 3.9 \\
\hline Medio Oriente & 5 & 2.4 \\
\hline África & 4 & 0.5 \\
\hline El mundo & 513 & 8.4 \\
\hline Fuente: Adaptado de "How many online" (2001), Population Reference Bureau (2001) \\
\hline
\end{tabular}

Tomado de Mark Warschauer, Technology and social inclusion: rethinking the digital divide (Cambridge, Mass.: MIT Press, 2003), 50. 
El porcentaje más alto de personas conectadas está en Estados Unidos y Canadá, en donde el 57.2 por ciento de la población navega por la red; Europa con un 30 por ciento menos de población tiene el 21.3 por ciento, América Latina y Asia tienen porcentajes relativamente cercanos, aunque Asia tiene un 25 por ciento menos de personas conectadas a Internet. La gran diferencia está en que mientras América Latina tiene tan sólo 25 millones de personas conectadas, con el 4.8 por ciento de la población, Asia tiene 144 millones de personas, que representan el 3.9 por ciento de los asiáticos.

Llama la atención que el porcentaje global de personas que estaban conectadas en 2001 era de tan sólo el 8.4 por ciento. Esta situación nos lleva a pensar que mientras las regiones más atrasadas no logren su conexión a la red, los porcentajes generales serán muy bajos, no obstante que algunos de los países tengan cifras que rebasan el 70 por ciento de conectividad.

Ningún país en desarrollo tiene un sector de tecnología de la información y comunicación tan prominente como el de la India, aunque el acceso a Internet es verdaderamente reducido: sólo una fracción muy pequeña de la población de ese país puede hacer uso de la red. Por una parte, sólo en la ciudad de Bangalore se han instalado y funcionan más de 300 compañías de TIC, algunas de ellas líderes mundiales en su campo; por la otra, el 45 por ciento de la población no sabe leer y escribir, el 44 por ciento sobrevive con menos de un dólar al día y 370 mil poblaciones en el país carecen de conexiones telefónicas. ${ }^{15}$

Hay que decir que una infraestructura deficiente no es exclusiva de los países en desarrollo, aunque en éstos los problemas se agudizan más que en los países desarrollados. Según Servon, en Estados Unidos, aunque en general la penetración del teléfono alcanzaba en 1995 el 93.8 por ciento, en los hogares más pobres, que son aquellos que tienen un ingreso anual menor a los 10 mil dólares, el teléfono

15 E. Hanson, Globalization, inequity, and the Internet in India, ponencia presentada en la reunión anual de la International Studies Association, Chicago, y World Development Report 2000/2001: Attacking poverty, Washington, D.C., Banco Mundial, 2000; citados por Mark Warschauer, Technology, 60. 
Figura 23

Proporción de la población en línea por principales regiones, 2000

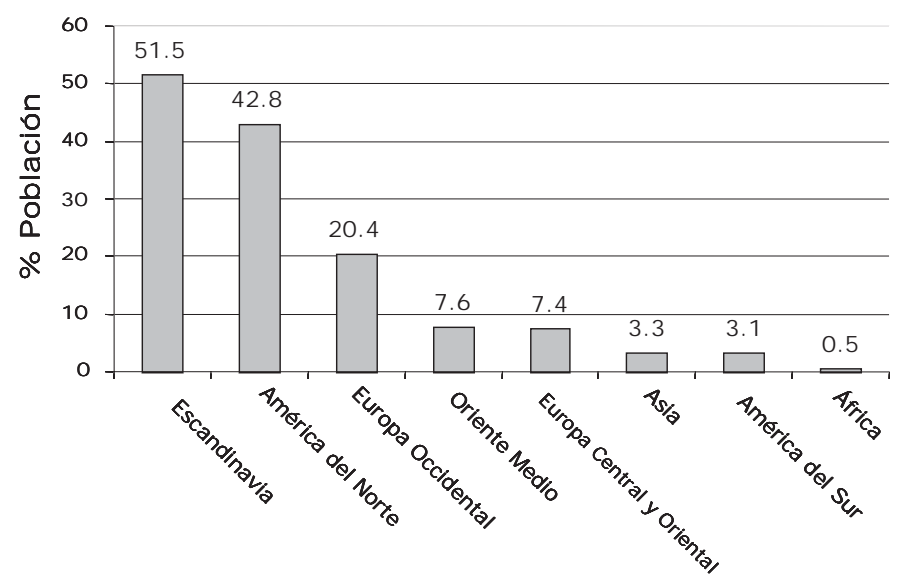

Figura 3.1. La proporción de la población en línea por las principales regiones, 2000.

Fuente: "How many online?"; www.NUA.er, noviembre 2000

Tomado de Pippa Norris, Digital divide: civic engagement, information poverty, and the Internet worldwide (Cambridge: Cambridge University Press, 2001), 47.

tenía la penetración más baja ya que sólo contaba con este servicio el 78.9 por ciento de los estadounidenses, lo que significaba que poco más del 20 por ciento de los hogares no tenían teléfono. ${ }^{16}$

En la región de África Subsahariana, por cada 100 habitantes hay 17 equipos de radio, cinco televisores y/o cinco teléfonos móviles.

La información que Norris ofrece sobre 2001 por regiones difiere de otras, por lo que es interesante incluirla en este análisis. Según la autora, es en los países escandinavos en donde se encuentra una mayor conectividad ya que su proporción es de $\mathbf{5 1 . 5}$ por ciento, mientras África tiene 0.5 por ciento, lo que la ubica en el otro extremo de la brecha, ${ }^{17}$ véase la figura 23.

16 Lisa J. Servon, Bridging the digital divide: technology, community and public policy (Malden, Mass.: Blackwell Publishing, 2002), 27.

17 Norris, Digital divide, 47. 


\section{La tecnología de la información y comunicación en el mundo}

Figura 24

Tendencias en el uso de Internet en Europa y

Estados Unidos, 1996-1999

\begin{tabular}{|c|c|c|c|c|c|}
\hline & $\begin{array}{c}\text { Primavera } \\
1996 \\
\end{array}$ & $\begin{array}{c}\text { Primavera } \\
1997 \\
\end{array}$ & $\begin{array}{r}\text { Otoño } \\
1998 \\
\end{array}$ & $\begin{array}{c}\text { Primavera } \\
1999 \\
\end{array}$ & $\begin{array}{l}\text { Incremento } \\
1996-1999\end{array}$ \\
\hline Suecia & 12 & 26 & 43 & 61 & +49 \\
\hline Estados Unidos a & 21 & 36 & 42 & 49 & +28 \\
\hline Dinamarca & 10 & 17 & 26 & 44 & +34 \\
\hline Finlandia & 11 & 16 & 18 & 39 & +28 \\
\hline Holanda & 9 & 16 & 19 & 32 & +23 \\
\hline Luxemburgo & 5 & 13 & 16 & 22 & +17 \\
\hline Gran Bretaña & 9 & 10 & 11 & 22 & +13 \\
\hline Irlanda del Norte & 4 & 8 & 10 & 10 & +16 \\
\hline Italia & 3 & 5 & 7 & 14 & +11 \\
\hline Irlanda & 4 & 5 & 9 & 14 & +10 \\
\hline Austria & 4 & 10 & 7 & 11 & +7 \\
\hline Bélgica & 3 & 6 & 8 & 11 & +8 \\
\hline Francia & 2 & 4 & 4 & 9 & +7 \\
\hline Alemania Occidental & 5 & 8 & 8 & 8 & +3 \\
\hline Alemania Oriental & 2 & 4 & 5 & 8 & +6 \\
\hline España & 2 & 2 & 5 & 8 & +6 \\
\hline Grecia & 1 & 3 & 3 & 7 & +6 \\
\hline Portugal & 2 & 2 & 3 & 5 & +3 \\
\hline UE15 & 5 & 9 & 12 & 20 & +15 \\
\hline \multicolumn{6}{|c|}{$\begin{array}{l}\text { a Estados Unidos: encuestas sucesivas del Pew Research Center for the People and the Press. Véase www. } \\
\text { peoplepress.org } \\
\text { Notas: La pregunta formulada por el Eurobarometer fue “¿Usted tiene acceso a, o usted utiliza la Internet o la World } \\
\text { Wide Web?" La pregunta formulada por el Pew fue "¿Usted siempre se conecta a Internet o a la World Wide Web o } \\
\text { envía y recibe correo electrónico?" }\end{array}$} \\
\hline \multicolumn{6}{|c|}{ Fuentes: Eurobarometer 44.2, primavera 1996; 47.0, primavera 1997; 50.1, otoño 1998; y 51.0, primavera 1999.} \\
\hline
\end{tabular}

Tomado de Pippa Norris, Digital divide: civic engagement, information poverty, and the Internet worldwide (Cambridge: Cambridge University Press, 2001), 74. 


\section{La brecha digital y sus determinantes}

Figura 25

Tendencias en el uso de computadora en Europa y

Estados Unidos, 1996-1999

\begin{tabular}{|c|c|c|c|c|}
\hline & $\begin{array}{l}\text { Primavera } \\
1996\end{array}$ & $\begin{array}{l}\text { Otoño } \\
1997\end{array}$ & $\begin{array}{c}\text { Primavera } \\
1999\end{array}$ & Incremento \\
\hline Suecia & 43 & 62 & 73 & +30 \\
\hline Estados Unidos a & 60 & 66 & 69 & +9 \\
\hline Dinamarca & 49 & 61 & 65 & +16 \\
\hline Holanda & 54 & 61 & 64 & +10 \\
\hline Finlandia & 36 & 43 & 52 & +16 \\
\hline Luxemburgo & 41 & 49 & 48 & +7 \\
\hline Gran Bretaña & 41 & 47 & 45 & +4 \\
\hline Irlanda del Norte & 25 & 34 & 39 & +14 \\
\hline Italia & 31 & 32 & 37 & +6 \\
\hline Bélgica & 28 & 32 & 37 & +9 \\
\hline Austria & 23 & 41 & 33 & +10 \\
\hline España & 25 & 29 & 33 & +8 \\
\hline Irlanda & 23 & 27 & 31 & +8 \\
\hline Francia & 25 & 34 & 30 & +5 \\
\hline Alemania Occidental & 31 & 32 & 29 & -2 \\
\hline Alemania Oriental & 27 & 32 & 27 & 0 \\
\hline Portugal & 21 & 20 & 22 & +1 \\
\hline Grecia & 12 & 19 & 17 & +5 \\
\hline UE15 & 31 & 38 & 40 & +9 \\
\hline \multicolumn{5}{|c|}{$\begin{array}{l}\text { a Estados Unidos: encuestas sucesivas del Pew Research Center for the People and } \\
\text { the Press. Véase www.peoplepress.org. }\end{array}$} \\
\hline \multicolumn{5}{|c|}{$\begin{array}{l}\text { Notas: La pregunta formulada por el Eurobarometer fue "¿Usted tiene acceso a, o us- } \\
\text { ted utiliza la Internet o la World Wide Web?". } 34 \text { La pregunta formulada por el Pew fue } \\
\text { "Usted utiliza una computadora en su lugar de trabajo, en la escuela, o en su casa por } \\
\text { lo menos de manera ocasional?" }\end{array}$} \\
\hline \multicolumn{5}{|c|}{$\begin{array}{l}\text { Fuentes: Eurobarometer 44.2, primavera 1996; 47.0, primavera } 1997 ; 50.1 \text {, otoño } \\
\text { 1998; y 51.0, primavera } 1999 .\end{array}$} \\
\hline
\end{tabular}

Tomado de Pippa Norris, Digital divide: civic engagement, information poverty, and the Internet worldwide (Cambridge: Cambridge University Press, 2001), 75. 
Las dos figuras anteriores ( 24 y 25 ) contienen datos sobre el uso de computadoras en varios países entre 1996 y 1999, e información sobre el uso de Internet en un grupo de países de diferentes continentes. La tendencia en el uso de Internet en Europa Occidental y Estados Unidos se presenta en la figura 24 que pone de manifiesto que al menos dos países europeos, Suecia y Dinamarca, tuvieron un mayor crecimiento que los Estados Unidos, que además experimentó el mismo crecimiento que Finlandia, seguidos de Holanda, Luxemburgo e Irlanda del Norte.

La serie de la figura 25, construida con cifras de 1996, 1997 y 1999, permite establecer que han sido Suecia, Finlandia, Dinamarca, Irlanda del Norte, Holanda y Austria las naciones que han presentado mayor crecimiento en el uso de las computadoras, aun por arriba de los Estados Unidos durante el mismo periodo.

Con las cifras anteriores se ha puesto de manifiesto que la brecha digital no sólo separa al mundo en dos, sino que a su vez separa continentes, sociedades y comunidades, por lo que a continuación se tratarán las características de la brecha digital por continentes y regiones.

\section{Estados Unidos}

Para Estados Unidos la brecha digital ha sido objeto de gran preocupación, así ha quedado de manifiesto a través de una década de trabajo en oficinas gubernamentales, instituciones académicas y organizaciones civiles. El enfoque estadounidense, en particular el reporte Falling Through the Net: Toward Digital Inclusion, se concentró en el acceso a las tecnologías, midiendo el grado de inclusión digital a través de los hogares e individuos que poseían una computadora y conexión a Internet. Otros estudios han relacionado los patrones de apropiación de las diversas tecnologías asociadas a la comunicación, las computadoras e Internet.

Debido a que las diversas tecnologías asociadas a la comunicación son un aspecto de suma importancia para dimensionar la brecha digital, se ha considerado oportuno iniciar la descripción de este fenó- 
Figura 26

Periodo en el que la tecnología ha sido adoptada por un tercio de los hogares estadounidenses

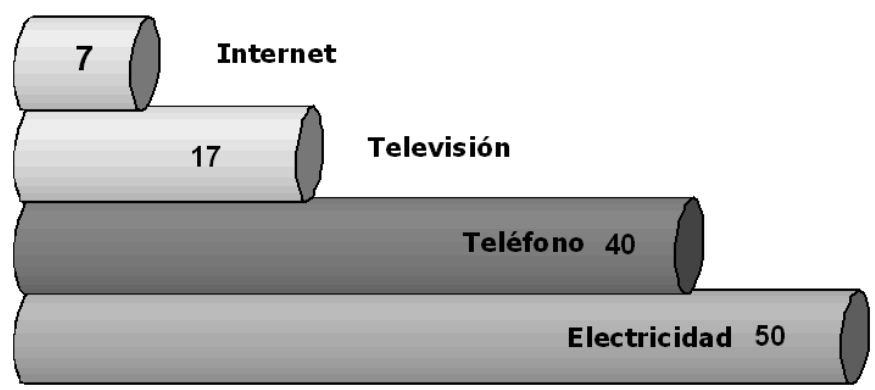

Figura 2.2. Periodo de tiempo empleado en alcanzar un tercio de los hogares estadounidenses

Tomado de Appu Kuttan y Laurence Peters, From digital divide to digital opportunity (Lanham, Maryland : Scarecrow Press, 2003), 60.

meno en la sociedad estadounidense a partir de la socialización de las tecnologías previas. Así, en la figura 26 se observan los años que han tardado cada una de las tecnologías en cubrir un tercio de la población norteamericana; mientras que la electricidad demoró 50 años en lograrlo, las otras tecnologías lo han hecho de forma más rápida hasta llegar a Internet, que lo ha logrado en tan sólo siete años. Esto nos indica dos cosas: que la sociedad se abre a novedades que considera importantes para su vida diaria, y que la situación económica de la sociedad ha permitido incorporar estos desarrollos, que si bien en un principio han sido caros, poco a poco han abatido sus costos. En los países en vías de desarrollo, la velocidad mostrada en esta figura parecería utópica.

En la figura 27 encontramos información sobre siete instrumentos tecnológicos, la gráfica indica el año de introducción en la sociedad norteamericana y el ritmo de crecimiento hasta 2000. El más antiguo es el teléfono y se introduce a principios del siglo XX, posteriormente se incorporará la radio, seguida de la televisión abierta y luego de la televisión de paga o por cable, en 1975 se introducen las computadoras personales, seguidas por la videocasetera y finalmente la red. 
Figura 27

Tecnología estadounidense, siglo XX

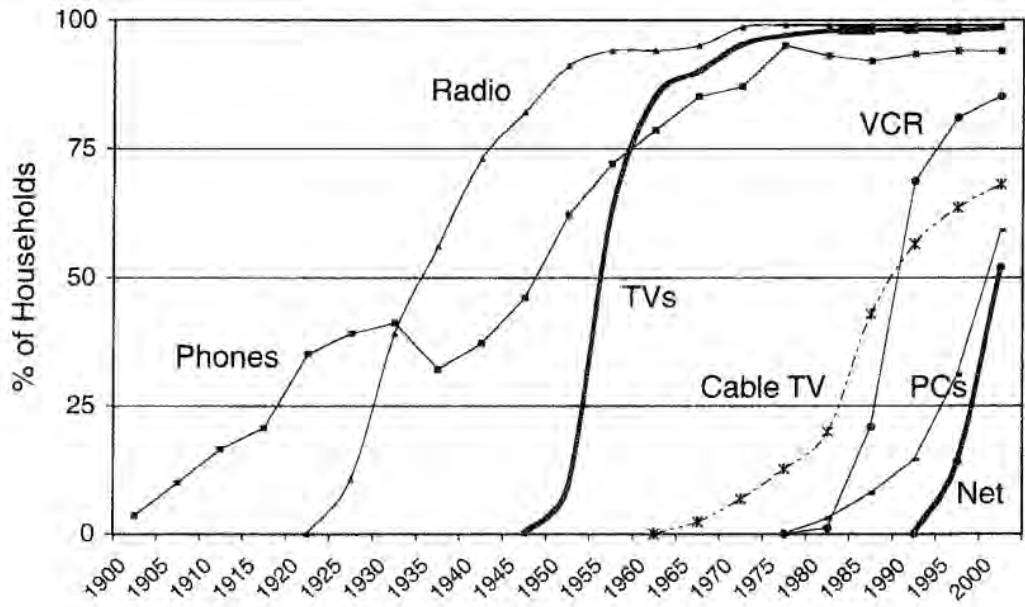

Figure 2.3. Twentieth-Century American Technology.

Sources: U.S. Census Bureau: Statistical Abstract of the U.S.,1999; Historical Statistics of the U.S.

Tomado de Pippa Norris, Digital divide: civic engagement, information poverty, and the Internet worldwide (Cambridge: Cambridge University Press), 33.

De la tecnología incluida en la figura 27, el teléfono ha sido el más lento en su inserción, ya que ha requerido de más tiempo para lograr una cobertura total; la red, desde su lanzamiento hace 10 años, ya cubre más del 50 por ciento de los hogares norteamericanos y aunque aún no ha logrado una cobertura total, su ritmo de adopción hace prever que en pocos años la alcanzará.

La naturaleza de la brecha digital y la peculiaridad de la sociedad estadounidense han conducido a que la brecha sea analizada, como se ha señalado anteriormente, mediante la cuantificación de hogares e individuos que poseen un computadora y acceso a Internet. La inclusión digital ha considerado diversas variables entre las que se encuentran la disponibilidad de teléfonos, la distribución geográfica, la raza, la educación y el ingreso económico, entre otras. 
Para lograr una idea clara sobre la brecha digital estadounidense, a continuación se reproducen algunos de los gráficos elaborados por el informe Falling Through the Net (1999), citados por Bolt y Crawford. ${ }^{18}$

La figura 28, con datos de 1998, nos brinda en primer lugar una apreciación general sobre la proporción de hogares estadounidenses que tienen teléfono, desagregada por regiones geográficas mayores (Noreste, la región del Oeste Medio, el Sur y el Oeste), y por zonas rurales, urbanas, y áreas centrales de las ciudades (inner). Nótese que las zonas centrales de las ciudades de los Estados Unidos son algunas de las áreas más pobres, y tienen menos teléfonos que las zonas rurales. Por la información disponible vemos que la mayor penetración está en el Noroeste, y la menor en el Sur; el Oeste Medio guarda la misma relación con respecto al Noreste en todos los casos.

En la figura 29 el porcentaje de los hogares estadounidenses que tienen teléfono se divide por zonas geográficas y raza u origen, según datos de 1998. La división geográfica es bajo el criterio de zonas rurales, urbanas y áreas centrales de las ciudades y el criterio racial es por blancos no hispanos, negros no hispanos, otros no hispanos e hispanos. De esta gráfica se deduce que los afroamericanos y los hispanoamericanos se encuentran al menos cinco puntos porcentuales por debajo de los otros dos grupos raciales en casi todas las regiones de ese país. Mientras que los blancos no hispanos parecen no tener una variación significativa derivada de las áreas geográficas en las que habitan, los otros grupos sí la presentan. Los negros no hispanos presentan varias diferencias aunque el contraste es significativo sólo en las áreas rurales. En el caso del grupo "otros no hispanos" se observa que en las zonas rurales hay un atraso considerable, y que en las otras zonas tienen mejores niveles que los grupos de negros no hispanos e hispanos. Estos últimos tienen una pequeña ventaja sobre los negros no hispanos.

18 Bolt y Crawford, 170-205. 
Figura 28

Porcentaje de hogares estadounidenses que tenían teléfono en 1998, apreciación general y división por zona rural, urbana y área central de las ciudades (inner)

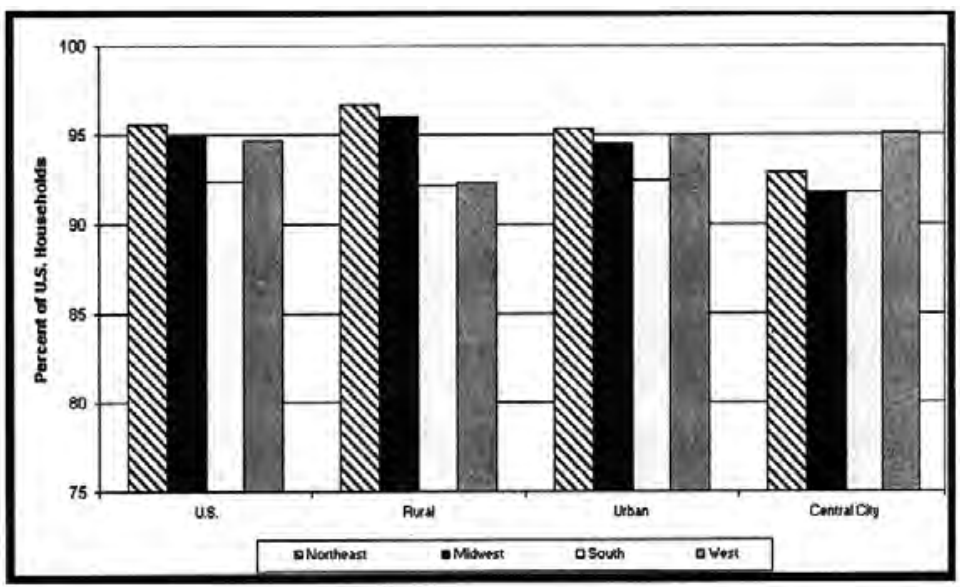

Tomado de David B. Bolt y Ray A. K. Crawford, Digital divide: computers and our children's future (Nueva York: TV Books, 2002), 170.

Figura 29

Porcentaje de hogares estadounidenses que tenían teléfono en 1998 dividido por zona rural, urbana y área central de las ciudades y por raza o antecedente racial

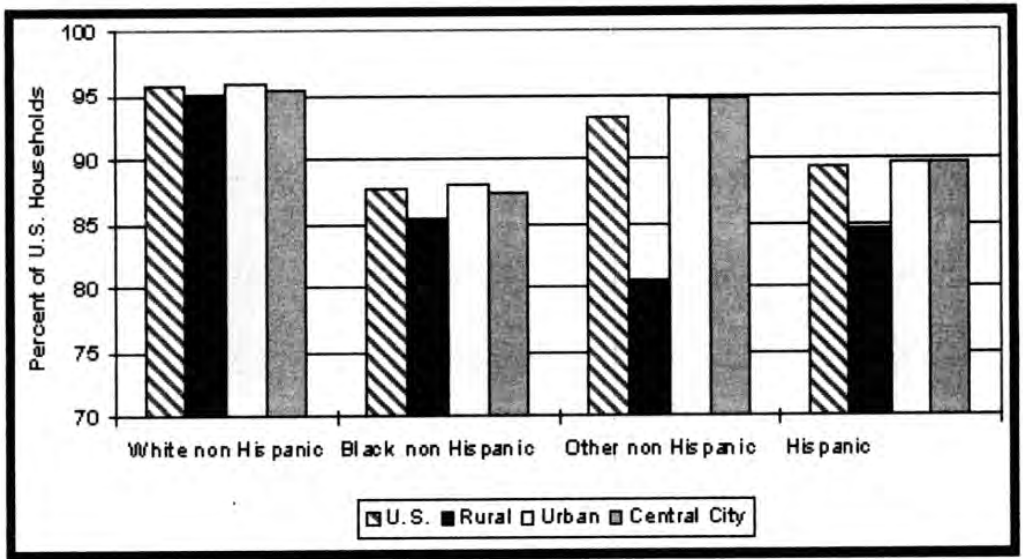

Tomado de David B. Bolt y Ray A. K. Crawford, Digital divide: computers and our children's future (Nueva York: TV Books, 2002), 171. 
Figura 30

Porcentaje de hogares estadounidenses que tenían teléfono en 1998, organizado por raza e ingreso económico

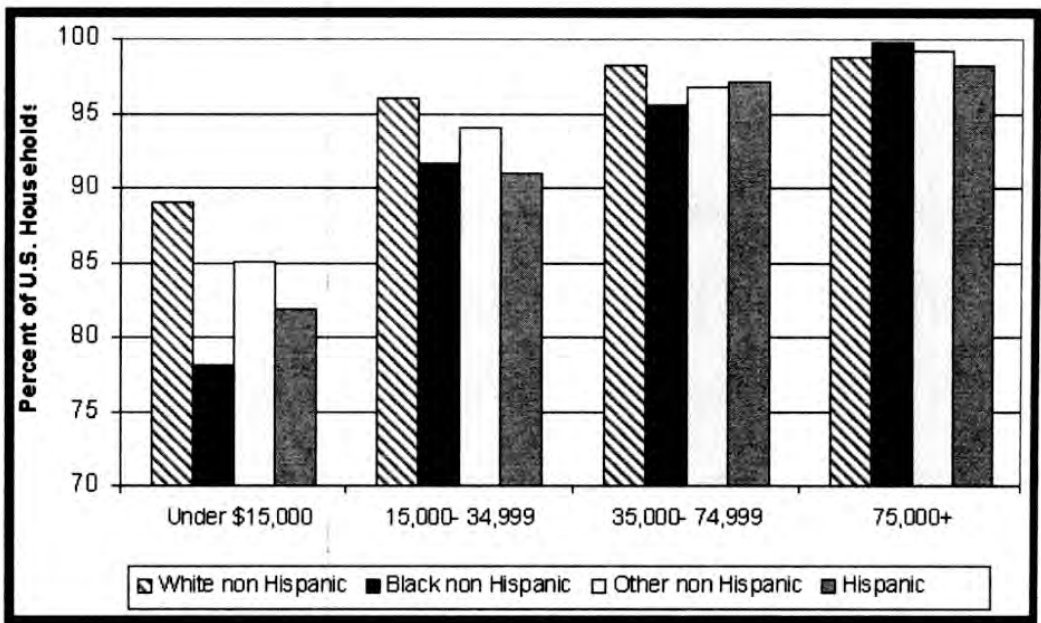

Tomado de David B. Bolt y Ray A. K. Crawford, Digital divide: computers and our children's future (Nueva York: TV Books, 2002), 172.

La figura 30 describe el porcentaje de hogares en los Estados Unidos que tenían teléfono en 1998, organizado por raza e ingreso económico. Como es de esperarse, a mayor ingreso, mayor posibilidad de que se posea un teléfono. Cuando se tiene un ingreso menor a $15 \mathrm{mil}$ dólares al año, los negros no hispanos son quienes tienen la menor proporción de teléfonos; pero cuando se trata de un ingreso superior a 75 mil dólares, este grupo es el que tiene un mayor porcentaje de hogares con teléfono. No hay una diferencia importante entre los distintos grupos raciales cuando el ingreso es superior a los 75 mil dólares. Las diferencias importantes se localizan en los sectores de más bajos recursos, lo que nos permite concluir que los niveles de separación más agudos en la brecha digital están en los grupos de bajo ingreso. En la medida en que la situación económica de una familia se mejora, las diferencias tienden a desaparecer. 
Figura 31

Porcentaje de hogares estadounidenses que tenían teléfono en 1998, dividido por zonas rural, urbana y central de las ciudades (inner) y por nivel educativo

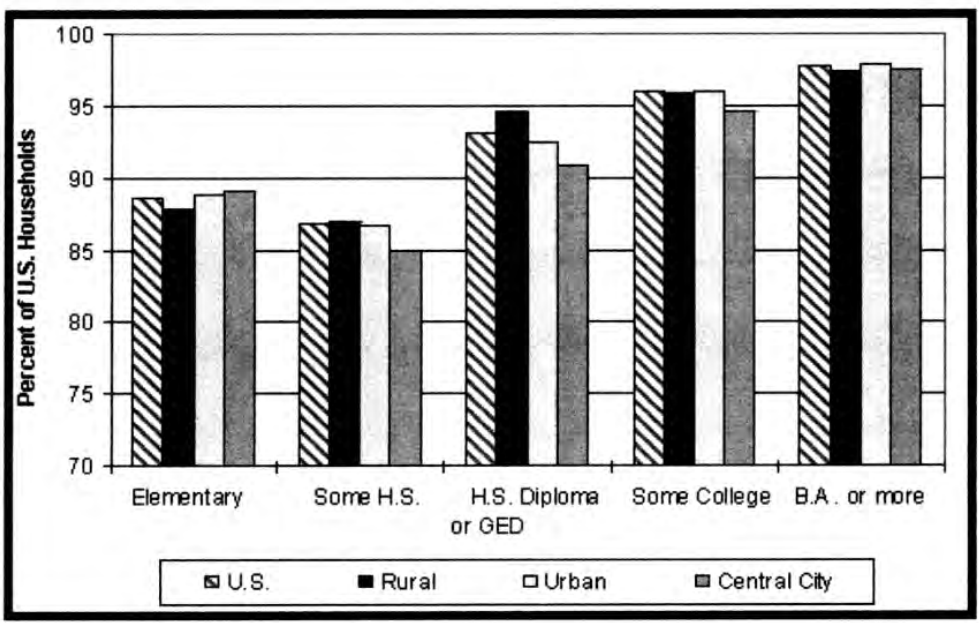

Tomado de David B. Bolt y Ray A. K. Crawford, Digital divide: computers and our children's future (Nueva York: TV Books, 2002), 173.

La figura 31 representa el porcentaje de hogares estadounidenses que tienen teléfono, dividido por zonas rural, urbana y área central de las ciudades (inner) y por niveles educativos en 1998. En ella se observa que hay un incremento en la posesión de teléfono, aun en las áreas centrales de las ciudades, relacionada con niveles de educación más altos. Esto puede ser un indicador de la relación entre ser propietario de un teléfono y el nivel económico y educativo. Es interesante que quienes cuentan con algunos estudios medios tienen menor acceso a un teléfono que quienes sólo tienen educación primaria; en la medida en que se incrementa el nivel educativo tienden a desaparecer las diferencias por zonas geográficas, de tal forma que quienes cuentan con educación universitaria o más tienen la misma proporción en todas las áreas. En las áreas rurales hay más teléfonos entre aquellos que tienen un diploma de educación media, pero a partir de que se tienen algunos estudios universitarios todas las áreas se equiparan en la posesión de teléfono. 
Figura 32

Porcentaje de hogares estadounidenses que tenían teléfono en 1998 dividido por zonas rural, urbana y central de las ciudades (inner) y por las características del jefe de familia

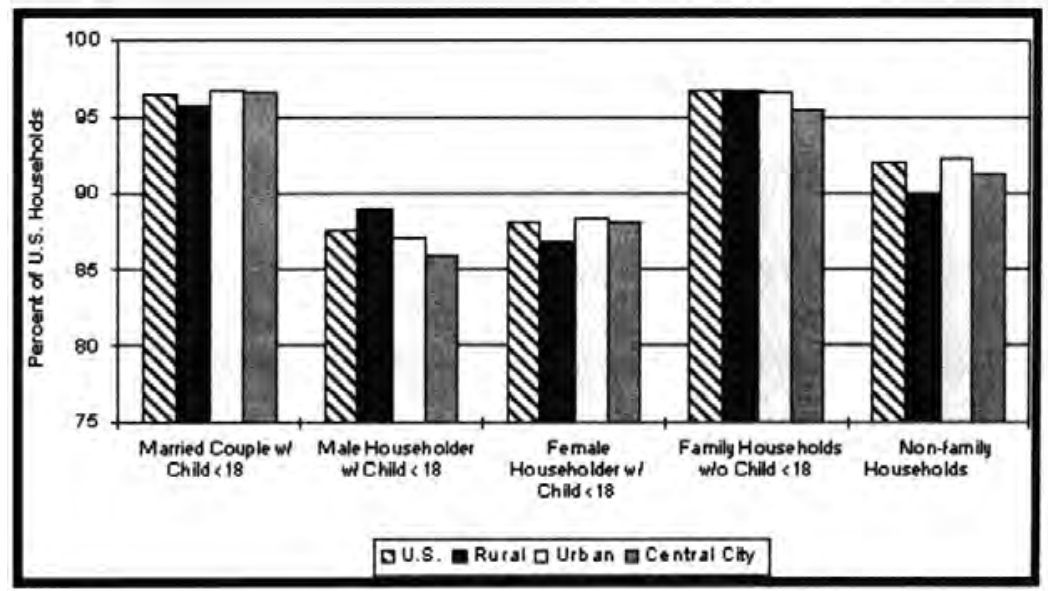

Tomado de David B. Bolt y Ray A. K. Crawford, Digital divide: computers and our children's future (Nueva York: TV Books, 2002), 174.

El porcentaje de hogares estadounidenses que tienen teléfono, dividido por zonas geográficas -rural, urbana y área central de las ciudades (inner) - y por las características del jefe de familia en 1998, se señala en la figura 32. Como se puede advertir, hay una brecha de casi 10 por ciento entre los hogares con padres solteros y los hogares con dos padres. Cuando hay dos padres, lo que se denomina hogar familiar, se tienen cifras similares, pero éstas decaen cuando sólo está el padre o la madre como cabeza del hogar. En cada uno de los grupos hay diferencias no muy grandes determinadas por el lugar en el que viven; pero en este caso, las diferencias significativas se dan en función de las características del jefe de familia.

En los Estados Unidos la brecha basada en elementos geográficos persiste, a pesar de todos los esfuerzos que se han hecho para contar con una mayor conectividad. Las personas que viven en áreas rurales tienen un mejor acceso a la red que aquellos que viven en áreas urbanas centrales. 
Figura 33

Porcentaje de hogares estadounidenses que tenían computadora en 1998, dividido por zonas rural, urbana y central de las ciudades (inner), agrupado por las cuatro regiones en que se divide el país

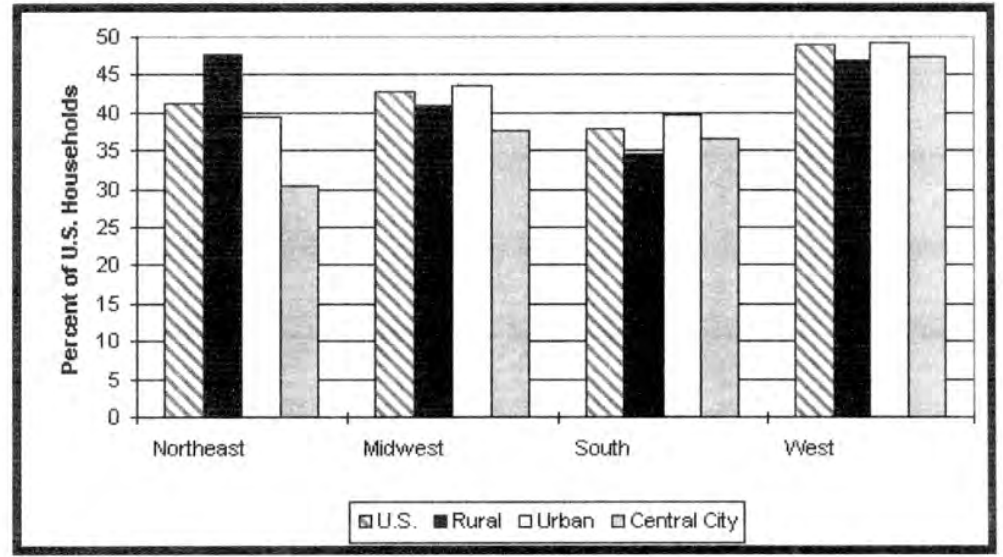

Tomado de David B. Bolt y Ray A. K. Crawford, Digital divide: computers and our children's future (Nueva York: TV Books, 2002), 178.

La brecha digital está determinada por las condiciones de la población que habita determinada zona geográfica. Así, por ejemplo, los estadounidenses que habitaban en zonas rurales y en las áreas centrales de las ciudades tenían menos acceso a Internet que aquellos que habitaban en las zonas suburbanas; 42 y 44 contra el 55 por ciento respectivamente. Para el año 2003 las cifras no habían cambiado de forma sustancial, pues el 63 por ciento de las personas de las áreas suburbanas usaban Internet, comparadas con menos de la mitad de quienes habitaban en las zonas rurales. ${ }^{19}$

19 A. Lenhard y otros, The ever-shifting Internet population: a new look at Internet access and the digital divide (Washington: Pew Internet and American Life Project, 2003), citado por Wenhong Chen y Barry Wellman, Charting and bridging digital divides, comparing socio-economic, gender, life stage, and rural-urban Internet access and use in eight countries. Octubre 27, 2003, 8, disponible http://www.amd.com/us-en/assets/content_type/DownloadableAssets/FINAL_ REPORT_CHARTING_DIGI_DIVIDES.pdf [Agosto 6, 2004]. 
Figura 34

Porcentaje de hogares estadounidenses que tenían computadora en 1998, dividido por zonas rural, urbana y central de las ciudades (inner) y por ingreso

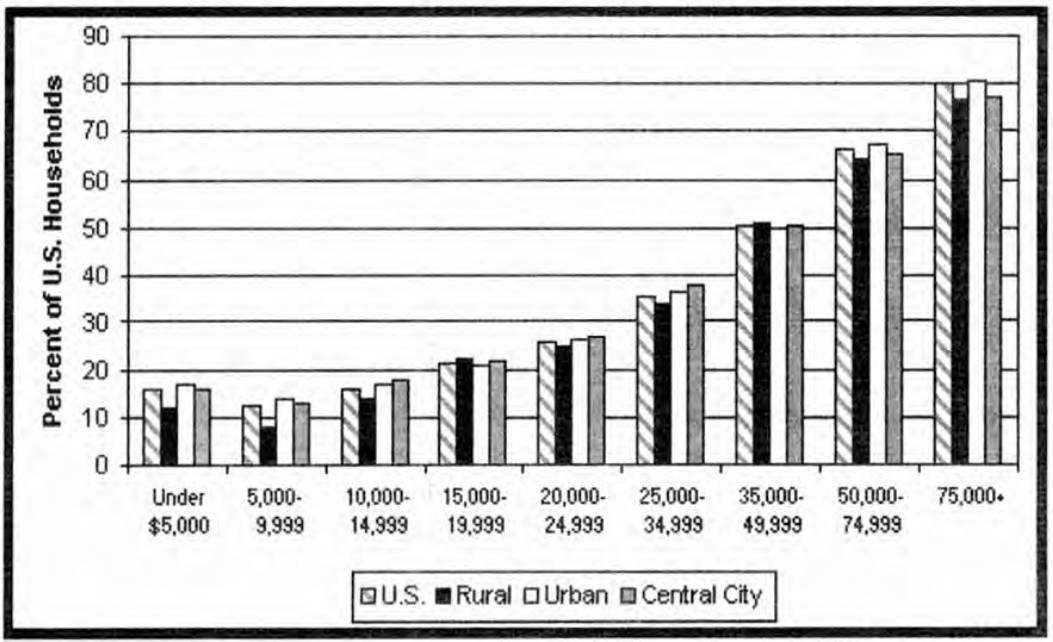

Tomado de David B. Bolt y Ray A. K. Crawford, Digital divide: computers and our children's future (Nueva York : TV Books, 2002), 183.

La figura 33 representa el porcentaje de hogares estadounidenses que en 1998 tenían computadora, divididos por zona rural, urbana y central de las ciudades (inner). Los datos están agrupados en las cuatro regiones geográficas en que se divide aquel país y proporcionan una imagen diferente de la que se refiere a la posesión de teléfono. Se puede observar que las zonas centrales son las que se encuentran más rezagadas y que el Occidente de los Estados Unidos es la región en donde hay más computadoras. El Oeste tiene la distribución más uniforme, mientras que en el Noroeste las diferencias son más marcadas.

El porcentaje de hogares estadounidenses que tenían computadora en 1998 ha sido dividido por zonas geográficas -rural, urbana y central de las ciudades (inner) - y por ingreso, en la figura 34. Esta figura muestra que la posesión de una computadora está más ligada al ingreso económico que a la zona geográfica en la que se habita. 
Figura 35

Porcentaje de hogares estadounidenses que tenían una computadora en 1998, dividido por zonas rural, urbana y central de las ciudades (inner) en las diferentes regiones que integran el país

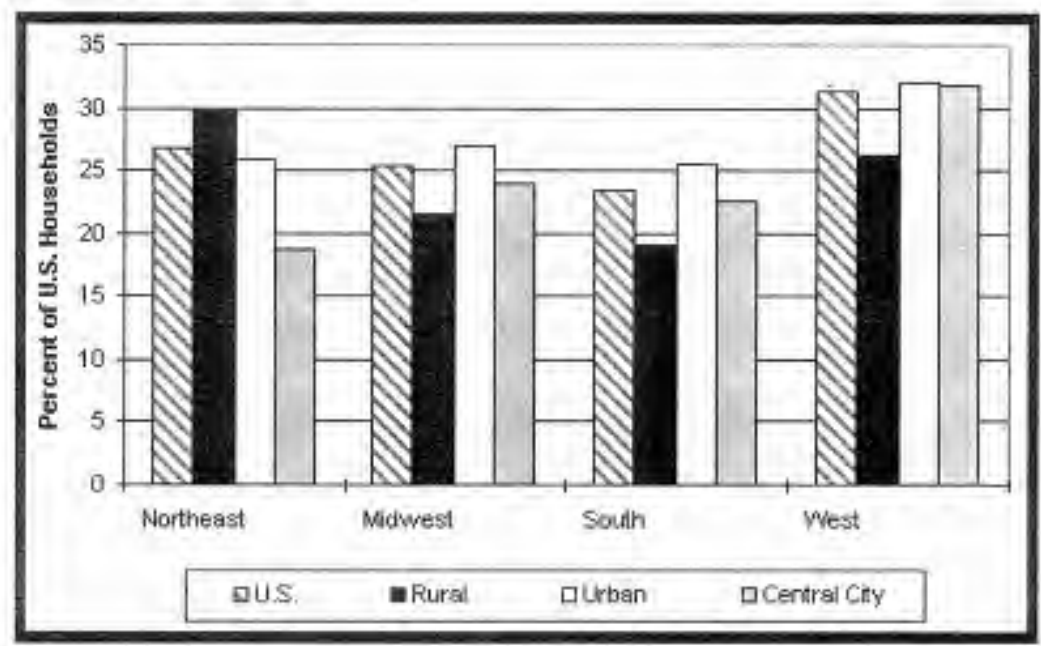

Tomado de David B. Bolt y Ray A. K. Crawford, Digital divide: computers and our children's future (Nueva York: TV Books, 2002), 186.

Mientras que en los niveles más bajos, hasta 9999 dólares, hay marcadas diferencias entre las zonas, las discrepancias desaparecen al incrementarse el ingreso.

El porcentaje de hogares estadounidenses que poseían una computadora en 1998, ha sido dividido en zonas geográficas, rural, urbana y central de las ciudades (inner) y por diferentes regiones en la figura 35. En esta gráfica se nota que en la posesión de computadoras el Oeste va a la vanguardia. Es interesante que las zonas centrales de las ciudades vayan adelante de las zonas rurales, en todas partes, con excepción del Noreste, donde los niveles de uso de Internet están por debajo del Sur rural. 
Figura 36

Distribución geográfica de los usuarios de Internet en Estados Unidos, subdividida de acuerdo con su origen étnico

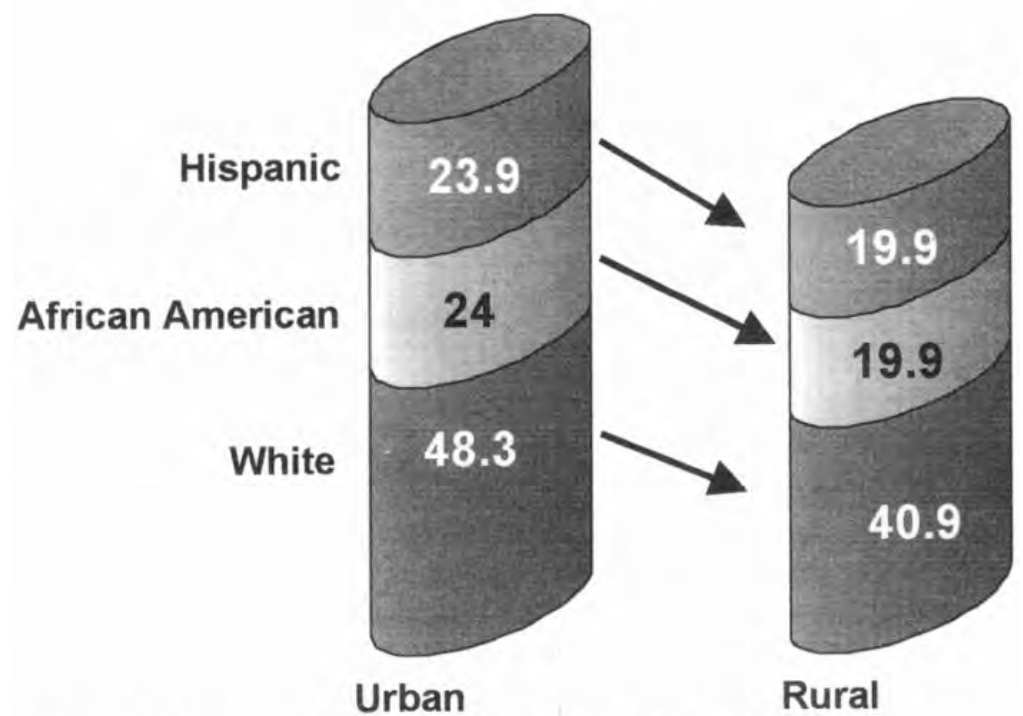

Figure 1.5. Urban vs. rural Internet penetration rates, by group.

Tomado de Appu Kuttan y Laurence Peters, From digital divide to digital opportunity (Lanham, Maryland: Scarecrow Press, 2003), 31.

En la figura 36 se observa la distribución de usuarios de Internet en Estados Unidos, con dos variables: la ubicación geográfica donde se encuentran los usuarios, ya sea en las zonas urbanas o bien en las rurales; la otra variable es el grupo racial al que pertenecen. Así, nos damos cuenta de que hay una mayor penetración en los habitantes de las zonas urbanas que en los que se encuentran en las zonas rurales. Pero la proporción de las personas de acuerdo al grupo racial no parece modificarse sustantivamente, pues en ambos casos la relación es la misma.

El porcentaje de ciudadanos estadounidenses que emplearon Internet fuera de casa durante 1998 se dividió por el lugar desde donde se llevó a cabo la conexión, como se ilustra en la figura 37 . Es 
Figura 37

Porcentaje de estadounidenses que usaban Internet fuera de casa en 1998, dividido por lugar de conexión

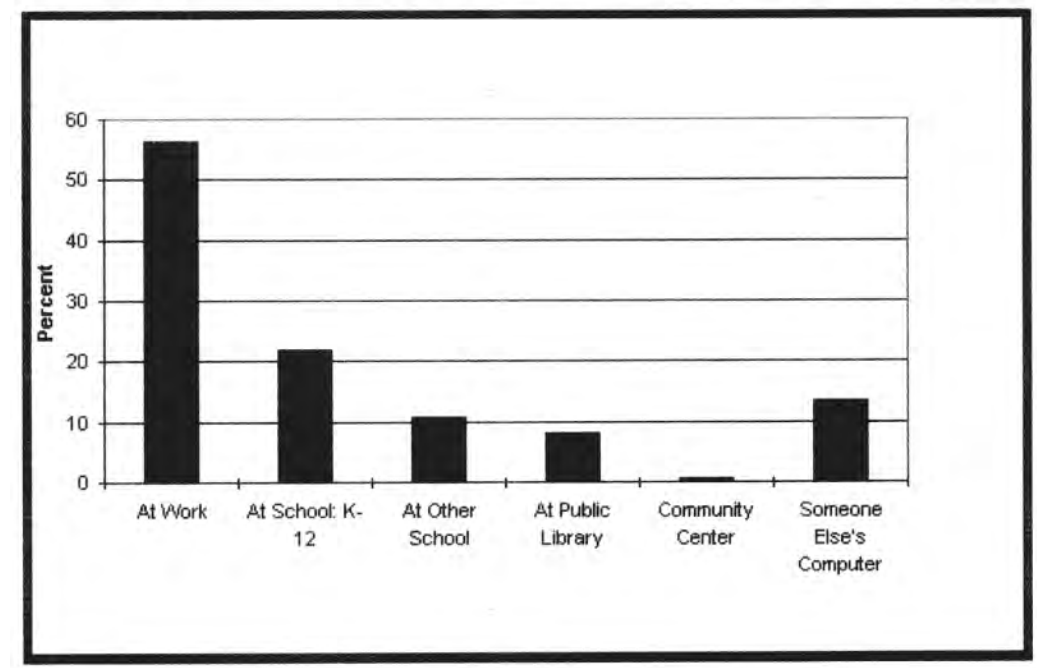

Tomado de David B. Bolt y Ray A. K. Crawford, Digital divide: computers and our children's future (Nueva York: TV Books, 2002), 196.

interesante que la conexión desde los centros comunitarios de tecnología representa una fracción muy pequeña del acceso a Internet. La mayoría de los estadounidenses consultan Internet en el trabajo y aunque el uso de Internet en la biblioteca pública es importante, todavía es exiguo. Mientras que la consulta desde la oficina era del 55 por ciento, en la biblioteca pública llegaba al ocho, y en la escuela media superior al 21 por ciento.

Warschauer realizó una comparación, con ayuda de la figura 38, entre los datos disponibles de 1998 y 2000 relacionados con el acceso a Internet en los hogares estadounidenses, empleando como criterios: etnia, ingreso económico, nivel educativo y área geográfica en que habitan los usuarios de Internet. 


\section{La brecha digital y sus determinantes}

Figura 38

Porcentaje de hogares estadounidenses con acceso a

Internet, 1998 y 2000

\begin{tabular}{|c|c|c|c|c|}
\hline \multicolumn{5}{|c|}{$\begin{array}{l}\text { Tabla } 3.2 \\
\text { Porcentaje de hogares estadounidenses con acceso a Internet, } 1998 \text { y } 2000\end{array}$} \\
\hline & \multicolumn{2}{|c|}{ Hogares (\%) } & \multirow[b]{2}{*}{$\begin{array}{l}\text { Diferencia en puntos } \\
\text { porcentuales }\end{array}$} & \multirow[b]{2}{*}{$\begin{array}{l}\text { Tasa de } \\
\text { crecimiento }\end{array}$} \\
\hline & Diciembre 1998 & Agosto 2000 & & \\
\hline \multicolumn{5}{|l|}{ Grupo étnico } \\
\hline Todos & 26.2 & 41.5 & 15.3 & 58.4 \\
\hline Negros no hispanos & 11.2 & 23.5 & 12.3 & $109.8^{a}$ \\
\hline Hispanos & 12.6 & 23.6 & 11.0 & $87.3^{\mathrm{a}}$ \\
\hline Blancos no hispanos & 29.8 & 46.1 & 16.3 & 54.7 \\
\hline $\begin{array}{l}\text { Asiáticoamericanos e } \\
\text { isleños del Pacífico }\end{array}$ & 36.0 & 56.8 & 20.8 & 57.8 \\
\hline \multicolumn{5}{|l|}{ Ingreso } \\
\hline Menos de $\$ 15,000$ & 7.1 & 12.7 & 5.6 & $78.9^{a}$ \\
\hline$\$ 15,000-\$ 24,999$ & 11.0 & 21.3 & 10.3 & $93.6^{a}$ \\
\hline$\$ 25,000-\$ 34,999$ & 19.1 & 34.0 & 14.9 & $78.0^{\mathrm{a}}$ \\
\hline$\$ 35,000-\$ 49,999$ & 29.5 & 46.1 & 16.6 & 56.3 \\
\hline$\$ 50,000-\$ 74,999$ & 43.9 & 60.9 & 17.0 & 38.7 \\
\hline$\$ 75,000$ y más & 60.3 & 77.7 & 17.4 & 28.9 \\
\hline \multicolumn{5}{|l|}{ Educación } \\
\hline Menos que preparatoria & 5.0 & 11.7 & 6.7 & $134.0^{\mathrm{a}}$ \\
\hline Graduados de preparatoria & 16.3 & 29.9 & 13.6 & $83.4^{a}$ \\
\hline Estudios superiores & 30.2 & 49.0 & 18.8 & $62.3^{a}$ \\
\hline Graduados universitarios & 46.8 & 64.0 & 17.2 & 36.8 \\
\hline Posgraduados & 53.0 & 69.9 & 16.9 & 31.9 \\
\hline \multicolumn{5}{|l|}{ Ubicación geográfica } \\
\hline Rural & 22.2 & 39.8 & 16.7 & $75.2^{\mathrm{a}}$ \\
\hline Urbano & 27.5 & 42.3 & 14.8 & 53.8 \\
\hline Ciudades centrales & 24.5 & 37.7 & 13.2 & 53.9 \\
\hline
\end{tabular}

Tomado de Mark Warschauer, Technology and social inclusion: rethinking the digital divide

(Cambridge, Mass.: MIT Press, 2003), 56. 
En la primera parte de la figura se advierte que los estadounidenses de origen asiático y provenientes de las islas del Pacífico tienen los índices más altos de acceso a Internet. Es conveniente señalar que el mayor incremento entre un año y otro correspondió a los negros no hispanos, con una tasa de crecimiento del 109.8 por ciento; pero a pesar de tal aumento, este sector aún se encuentra muy rezagado, ya que el incremento tan espectacular sólo alcanzó para que llegaran al 23.5 por ciento de sus hogares con acceso a Internet debido a que en 1998 tenían una tasa del 11.2 por ciento.

Desde el punto de vista de los ingresos económicos, quienes reciben menos, tienen los niveles más bajos de conexión a la red, sin embargo el ritmo de crecimiento disminuye en la medida en que los ingresos son mayores. La explicación es que el sector social con el nivel más bajo de ingresos es el que se encuentra más rezagado y tiene que hacer un mayor esfuerzo para incrementar su acceso. Los sectores de ingresos más altos tienen que cubrir un segmento menor de personas que no disfrutan de acceso y eso hace que su crecimiento parezca más lento.

El acceso a Internet desde la perspectiva del nivel educativo se comporta de manera similar que en cuanto al ingreso económico; la tasa de expansión es mayor entre quienes tienen educación básica que entre quienes tienen estudios superiores, lo que no significa que los primeros tengan mayor posibilidad de acceso que los segundos ya que por lo general es a la inversa. Podríamos decir que el acceso suele ser inversamente proporcional a las tasas de crecimiento en la conectividad.

Para establecer una idea clara respecto de la apropiación social de la TIC en Estados Unidos, nos auxiliaremos de la figura 39 en la que se observa el porcentaje de hogares estadounidenses que poseían computadoras o computadoras e Internet en 1994, 1997, 1998 y 2000. 


\section{La brecha digital y sus determinantes}

Figura 39

Porcentaje de hogares estadounidenses con acceso a computadora e Internet

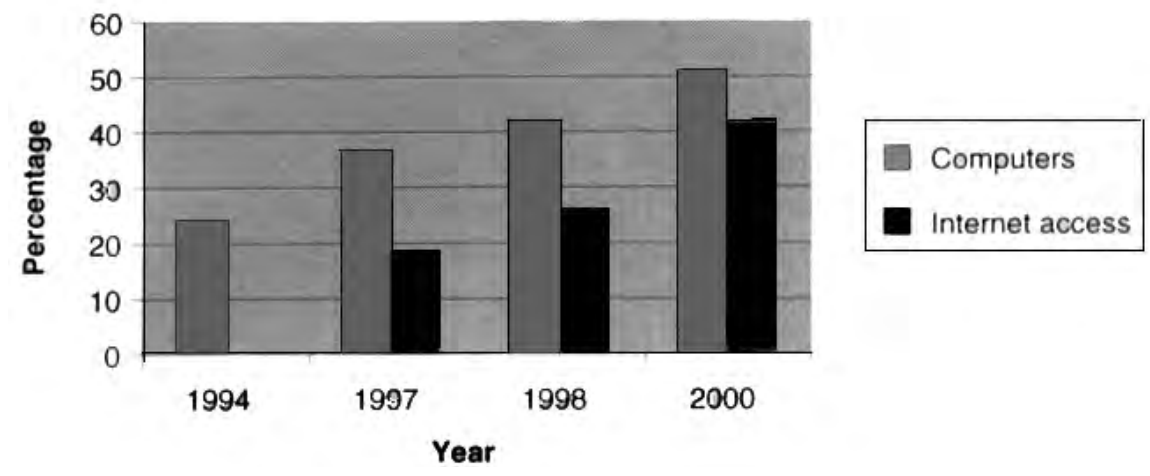

figure 2.1 Percent of US households with computer and Internet access Source: US Department of Commerce (2000a)

Tomado de Lisa J. Servon, Bridging the digital divide: technology, community and public policy (Malden, Mass.: Blackwell Publishing, 2002), 28.

De acuerdo con la figura anterior, la socialización de las computadoras e Internet ha crecido significativamente en menos de siete años. Hacia 1994 poco más del 20 por ciento de los estadounidenses tenían computadora pero no Internet; en 1997 la posesión de computadoras se había incrementado por arriba del 30 por ciento e Internet rondaba el 20 por ciento; en 1998 más del 40 por ciento de los hogares estadounidenses tenían computadora pero menos del 30 por ciento Internet. Finalmente, en 2000 poco más del 50 por ciento de los hogares estadounidenses tenían computadora y el 40 por ciento Internet.

Según los datos del Banco de la Reserva Federal de San Francisco, en Estados Unidos el acceso a Internet está muy generalizado, conforme a lo cual:

[El] 54.5 por ciento de la población mayor de tres años usa computadora en casa, el mismo porcentaje de trabajadores las utilizan en el trabajo y 84.8 por ciento de los jóvenes menores de 17 años (que asisten a la escuela) usan este tipo de equipos en la escuela (FRBSF, p. 1). En 
un estudio reciente de Sax y asociados encontraron que los jóvenes afroamericanos que cursan el primer año de formación universitaria usan menos la Internet. Así, por ejemplo, mientras que el 90.2 por ciento de los estudiantes del primer año usan Internet para investigación, sólo 77.6 por ciento de los estudiantes que ingresan a un colegio público de afroamericanos lo hacen. De igual forma, mientras que el 80.1 de los alumnos de primer año usan el correo electrónico regularmente, sólo 41.4 por ciento de los estudiantes inscritos en un colegio público de afroamericanos lo hace (Sax, Hoffman, 4). Esto es una muestra clara de cómo los blancos tienen mayor acceso que los negros en Estados Unidos. En el informe del Departamento de Comercio Falling through the Net II concluyen que la brecha entre 1994 y 1997 se amplía entre blancos, negros e hispanos. 20

Aunque es difícil hacer una estimación exacta, se piensa que para el año de 2005 más de la mitad de los norteamericanos estarán conectados en línea y casi tres cuartas partes de los usuarios tendrán aplicaciones en la red para obtener información. 21

En 2002 los usuarios estadounidenses de Internet destinaban, en promedio, 11 horas a la semana a su conexión. Cerca del 60 por ciento de los usuarios utilizan Internet desde sus casas, en 1995 lo hacían un 20 por ciento. El 61 por ciento de los usuarios consideran que Internet es una fuente importante de información. ${ }^{22}$

La situación en Estados Unidos ha cambiado rápidamente, en 1998 el 70 por ciento de la población no era usuaria de Internet, el 22 por ciento de quienes sí eran usuarios se conectaban desde el hogar, el 18 por ciento fuera de casa y el 32 por ciento desde cualquier

20 Hoffman, Novak y Schlosser, "The evolution of the digital divide", 5.

21 Norris, Digital divide, 28.

22 UCLA, Center for Communication Policy, The UCLA Internet report: surveying the digital future year three (Los Ángeles: UCLA, Center for Communication Policy, 2003). Citado por Wenhong Chen y Barry Wellman, Charting and bridging digital divides: comparing socio-economic, gender, life stage, and rural-urban Internet access and use in eight countries, disponible http:www.amd.com/us-en/assets/ content_type/DownloadableAssets/FINAL_REPORT_CHARTING_DIGI_DIVIDES.pdf [Agosto 6, 2004], 9. 
Figura 40

Porcentaje de estadounidenses usuarios de Internet, por lugar de conexión, 1998

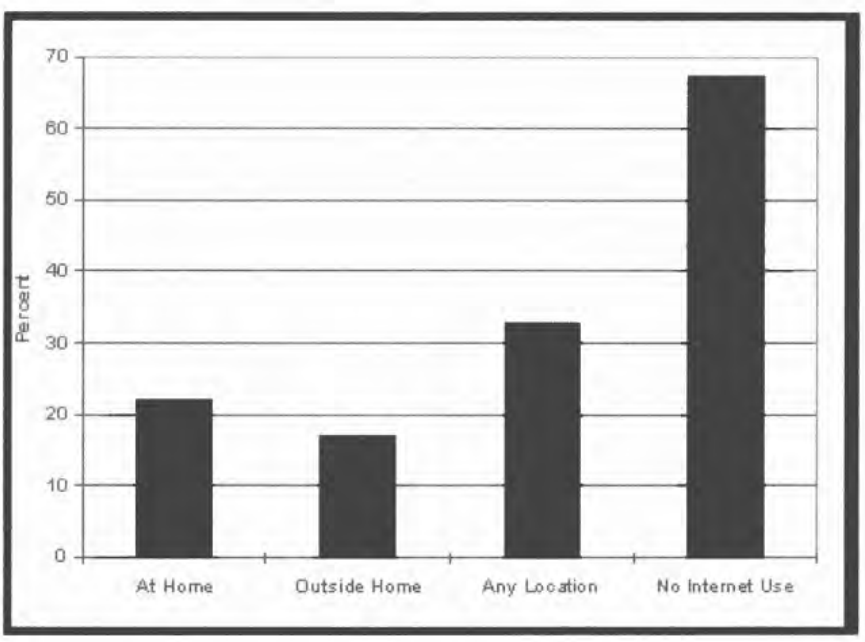

Tomado de David B. Bolt y Ray A. K. Crawford, Digital divide: computers and our children's future (Nueva York: TV Books, 2002), 194.

lugar de acuerdo con la figura 40. Esta situación ha cambiado considerablemente y en la actualidad casi el 60 por ciento de los norteamericanos están conectados a la red.

También conviene señalar que las actividades para las que se usaba Internet en 1998, han cambiado de manera significativa. Alrededor del 78 por ciento de las personas que se conectaban desde su casa en ese año usaban el correo electrónico, y el 60 por ciento empleaba Internet en la búsqueda de información. El entretenimiento era la opción menos frecuente de las posibilidades que se mencionaron en la encuesta. Es importante señalar que el comercio electrónico tenía una importancia marginal con solamente el 23 por ciento de los usuarios, aunque superior a la búsqueda de trabajo según se aprecia en la figura 41. 
Figura 41

Porcentaje de estadounidenses que usan Internet en sus casas desagregado por tipo de uso, 1998

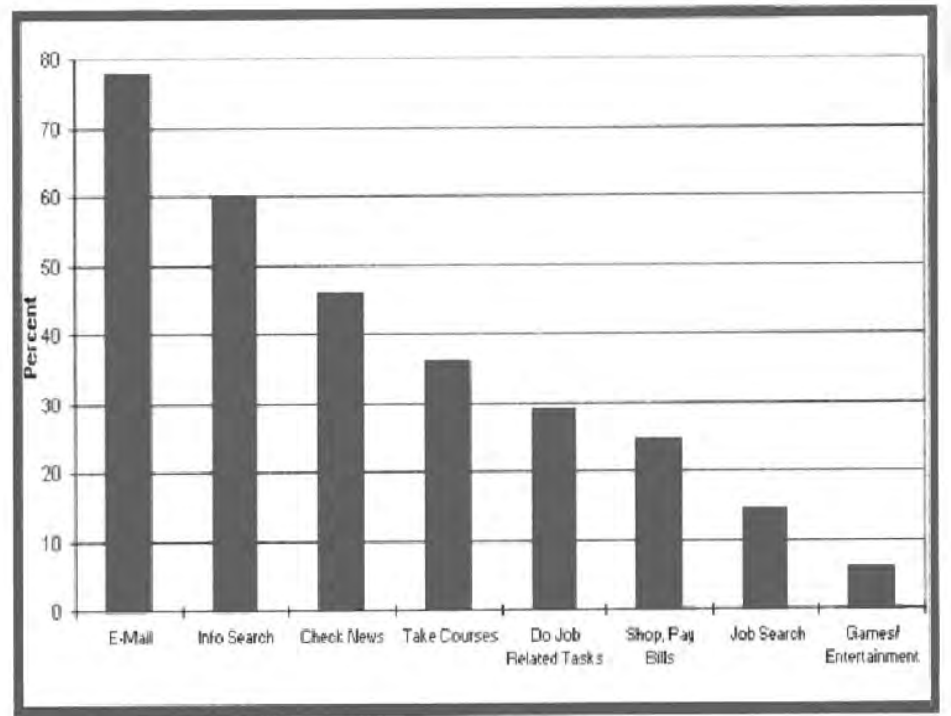

Tomado de David B. Bolt y Ray A. K. Crawford, Digital divide: computers and our children's future (Nueva York: TV Books, 2002), 195.

\section{América Latina y el Caribe}

América Latina y el Caribe son extremadamente diversos en desarrollo económico, social y tecnológico. Esta situación se refleja en la expectativa de vida de la población, en la educación, en el ingreso económico y en la infraestructura. Como es de esperarse, Argentina, Chile, Uruguay, México y Venezuela, pese a todos sus problemas, se ubican por arriba de otras naciones latinoamericanas y caribeñas. ${ }^{23}$

23 Gregory F. Traventon y Lee Mizell, eds. The future of the information revolution in Latin America: proceedings of a International Conference (S. 1.: RAND, 2001), 5. Disponible http://www.rand.org/publications/CF/CF166.1/ [Agosto 10, 2004]. 
Figura 42

América Latina mira al sur

\begin{tabular}{|c|c|c|c|c|}
\hline & Población & $\begin{array}{l}\text { Usuarios de } \\
\text { Internet }\end{array}$ & $\begin{array}{l}\text { Tasa de penetra- } \\
\text { ción de Internet * }\end{array}$ & $\begin{array}{c}\text { Computadoras } \\
\text { por } 100 \text { personas }\end{array}$ \\
\hline Bolivia & $8,330,000$ & 35,000 & $0.42 \%$ & 1.23 \\
\hline Brasil & $170,120,000$ & $3,500,000$ & $2 \%$ & 3.63 \\
\hline Colombia & $42,320,000$ & 600,000 & $1.4 \%$ & 3.37 \\
\hline Cuba & $11,200,000$ & 50,000 & $0.44 \%$ & 0.72 \\
\hline Ecuador & $12,200,000$ & 50,000 & $0.44 \%$ & 0.72 \\
\hline Guatemala & $11,390,000$ & 65,000 & $0.57 \%$ & 0.99 \\
\hline Honduras & $6,490,000$ & 20,000 & $0.3 \%$ & 0.95 \\
\hline México & $98,880,000$ & $2,500,000$ & $2.5 \%$ & 4.42 \\
\hline Nicaragua & $5,070,000$ & 20,000 & $0.39 \%$ & 0.81 \\
\hline Paraguay & $5,500,000$ & 20,000 & $0.36 \%$ & 1.12 \\
\hline Perú & $25,660,000$ & 400,000 & $1.5 \%$ & 1.98 \\
\hline Venezuela & $24,170,000$ & 400,000 & $1.6 \%$ & 4.22 \\
\hline \multicolumn{5}{|l|}{ Cono Sur } \\
\hline Argentina & $37,030,000$ & 900,000 & $2.4 \%$ & 4.92 \\
\hline Chile & $15,210,000$ & 625,000 & $4.1 \%$ & 6.66 \\
\hline Uruguay & $3,340,000$ & 300,000 & $8.9 \%$ & 9.96 \\
\hline
\end{tabular}

Tomado de Appu Kuttan y Laurence Peters, From digital divide to digital opportunity (Lanham, Maryland: Scarecrow Press, 2003), 125.

Por la información recopilada por Kuttan, figura 42, vemos que son tres los países del sur del continente los que tienen la mayor penetración de Internet junto con México: Uruguay, Chile y Argentina registran las cifras más altas en este renglón. Todos estos países encabezan tanto la penetración como la relación de computadoras por cada 100 habitantes. Sin embargo, el caso de Venezuela es interesante toda vez que tiene el mayor número de computadoras por cada 100 habitantes pero con un índice de penetración de Internet menor que Brasil, por ejemplo. Cabe destacar que de los quince países, sólo cinco tienen índices de penetración mayores o iguales al dos por ciento; y que los de algunos otros no sobrepasan el uno por ciento, 
lo que prácticamente los deja fuera de la red de información mundial y lejos de incorporarse a la información científica y humanística de calidad que allí se encuentra.

La participación de América Latina y el Caribe en el ciberespacio difiere según la fuente consultada, pero de acuerdo con NUA Internet Surveys esta área tenía 33.35 millones de usuarios en 2002. En la figura 43 se desglosa el número de usuarios por nación y como puede observarse, la información procede de diferentes fuentes, las cuales se indican en la columna de la derecha, normalmente con siglas. Con los datos de América Latina se puede apreciar la variedad de fuentes de información, así como las tendencias de crecimiento en la conectividad de los usuarios por país.

Figura 43

Distribución de usuarios de Internet en América Latina ${ }^{24}$

\begin{tabular}{|c|c|c|c|c|}
\hline País & Fecha & Número & \% Población & Fuente \\
\hline \multicolumn{5}{|c|}{ Antigua y Barbuda } \\
\hline & $\begin{array}{c}\text { Diciembre } \\
2000\end{array}$ & 5,000 & 7.52 & UIT \\
\hline & $\begin{array}{c}\text { Diciembre } \\
1999 \\
\end{array}$ & 4,000 & 5.5 & UIT \\
\hline \multicolumn{5}{|c|}{ Antillas Holandesas } \\
\hline & $\begin{array}{c}\text { Diciembre } \\
1999 \\
\end{array}$ & 2,000 & 0.95 & UIT \\
\hline \multicolumn{5}{|l|}{ Argentina } \\
\hline & Julio 2001 & 3.88 millones & 10.38 & Nielsen NetRatings \\
\hline & $\begin{array}{c}\text { Diciembre } \\
2000 \\
\end{array}$ & 2.5 millones & 6.76 & UIT \\
\hline & Febrero 2000 & 800,000 & 2.18 & Jupiter Communications \\
\hline & $\begin{array}{c}\text { Diciembre } \\
1999 \\
\end{array}$ & 500,000 & 1.36 & UIT \\
\hline & Agosto 1999 & 348,000 & 0.95 & Prince \& Cooke \\
\hline & Abril 1999 & 250,000 & 0.65 & IABIN \\
\hline
\end{tabular}

24 NUA Internet Surveys incluye bajo el rubro América Latina a las naciones del Caribe. 


\section{La brecha digital y sus determinantes}

\section{Figura 43}

(Cont.)

Distribución de usuarios de Internet en América Latina

\begin{tabular}{|c|c|c|c|c|}
\hline País & Fecha & Número & \% Población & Fuente \\
\hline \multicolumn{5}{|c|}{ Argentina (Cont.) } \\
\hline & Diciembre 1998 & 330,000 & 0.85 & IDC \\
\hline & Junio 1997 & 170,000 & 0.49 & $\begin{array}{l}\text { CommerceNet } \\
\text { Research }\end{array}$ \\
\hline \multicolumn{5}{|l|}{ Aruba } \\
\hline & Diciembre 2001 & 24,000 & 34.07 & UIT \\
\hline & Diciembre 1999 & 4,000 & 5.75 & UIT \\
\hline \multicolumn{5}{|l|}{ Bahamas } \\
\hline & Diciembre 2001 & 16,900 & 5.62 & UIT \\
\hline & Diciembre 2000 & 13,100 & 4.44 & UIT \\
\hline & Diciembre 1999 & 11,300 & 3.98 & UIT \\
\hline \multicolumn{5}{|l|}{ Barbados } \\
\hline & Diciembre 1999 & 6,000 & 2.19 & UIT \\
\hline \multicolumn{5}{|l|}{ Belice } \\
\hline & Diciembre 2001 & 18,000 & 6.84 & UIT \\
\hline & Diciembre 1999 & 15,000 & 6.02 & UIT \\
\hline & Diciembre 1999 & 10,000 & 2.54 & UIT \\
\hline \multicolumn{5}{|l|}{ Bolivia } \\
\hline & Diciembre 1999 & 78,000 & 0.98 & UIT \\
\hline & Octubre 1997 & 8,000 & 0.11 & UIT/Siemens \\
\hline \multicolumn{5}{|l|}{ Brasil } \\
\hline & Septiembre 2002 & 13.98 millones & 7.77 & $\begin{array}{l}\text { Nielsen } \\
\text { NetRatings }\end{array}$ \\
\hline & Mayo 2002 & 13.62 millones & 7.74 & $\begin{array}{l}\text { Nielsen } \\
\text { NetRatings }\end{array}$ \\
\hline & Julio 2001 & 11.94 millones & 6.84 & $\begin{array}{l}\text { Nielsen } \\
\text { NetRatings }\end{array}$ \\
\hline & Junio 2001 & 10.4 millones & 5.96 & $\begin{array}{l}\text { Nielsen } \\
\text { NetRatings }\end{array}$ \\
\hline & Noviembre 2000 & 9.84 millones & 5.7 & $\begin{array}{l}\text { Nielsen } \\
\text { NetRatings }\end{array}$ \\
\hline & Septiembre 2000 & 8.65 millones & 5.0 & Media Metrix \\
\hline & Diciembre 1999 & 6.79 millones & 3.95 & $\begin{array}{l}\text { Computer Industry } \\
\text { Almanac }\end{array}$ \\
\hline & Julio 1999 & 3.1 millones & 1.8 & ISC Brasileña \\
\hline & Diciembre 1998 & 2.35 millones & 1.4 & IDC \\
\hline
\end{tabular}


Figura 43

(Cont.)

Distribución de usuarios de Internet en América Latina

\begin{tabular}{|c|c|c|c|c|}
\hline País & Fecha & Número & \% Población & Fuente \\
\hline \multicolumn{5}{|l|}{ Brasil (Cont.) } \\
\hline & Noviembre 1998 & 3.5 millones & 2.1 & ISC Brasileña \\
\hline & Octubre 1998 & 3.4 millones & 2 & IBOPE \\
\hline & Mayo 1998 & 1.3 millones & 0.8 & ISC Brasileña \\
\hline & Marzo 1998 & 2.5 millones & 1.5 & IBOPE \\
\hline & Diciembre 1997 & 1.3 millones & 0.64 & ISC Brasileña \\
\hline & Noviembre 1997 & 1 millón & 0.61 & IBOPE \\
\hline & Octubre 1997 & 764,000 & 0.47 & UIT/Siemens \\
\hline & Julio 1997 & 1.15 millones & 0.6 & ISC Brasileña \\
\hline & Junio 1997 & 475,000 & 0.29 & CommerceNet Research \\
\hline & Diciembre 1996 & 740,458 & 0.45 & ISC Brasileña \\
\hline & Diciembre 1996 & 500,000 & 0.3 & ZDNet \\
\hline & Julio 1996 & 500,746 & 0.3 & ISC Brasileña \\
\hline & Enero 1996 & 170,429 & 0.1 & ISC Brasileña \\
\hline \multicolumn{5}{|l|}{ Chile } \\
\hline & Diciembre 2001 & 3.1 millón & 20.02 & UIT \\
\hline & Diciembre 2000 & 1.75 millones & 11.6 & UIT \\
\hline & Diciembre 1999 & 625,000 & 4.12 & UIT \\
\hline & Abril 1999 & 150,000 & 1 & IABIN \\
\hline & Junio 1997 & 200,000 & 1.30 & CommerceNet Research \\
\hline \multicolumn{5}{|l|}{ Colombia } \\
\hline & Diciembre 2001 & 1.15 millones & 2.81 & UIT \\
\hline & Diciembre 2000 & 878,000 & 2.21 & UIT \\
\hline & Diciembre 1999 & 664,000 & 1.69 & UIT \\
\hline & Abril 1999 & 350,000 & .95 & IDC \\
\hline & Abril 1999 & 90,000 & 0.24 & IABIN \\
\hline & Junio 1997 & 120,000 & 0.32 & CommerceNet Research \\
\hline \multicolumn{5}{|l|}{ Costa Rica } \\
\hline & Diciembre 2001 & 384,000 & 10.01 & UIT \\
\hline & Diciembre 2000 & 250,000 & 6.74 & UIT \\
\hline & Diciembre 1999 & 150,000 & 4.04 & UIT \\
\hline & Abril 1999 & 30,000 & 3.4 & IABIN \\
\hline & Junio 1997 & 50,000 & 5.78 & CommerceNet Research \\
\hline
\end{tabular}




\section{La brecha digital y sus determinantes}

Figura 43

(Cont.)

Distribución de usuarios de Internet en América Latina

\begin{tabular}{|c|c|c|c|c|}
\hline País & Fecha & Número & \% Población & Fuente \\
\hline \multicolumn{5}{|l|}{ Cuba } \\
\hline & Diciembre 2001 & 120,000 & 1.07 & UIT \\
\hline & Diciembre 2000 & 60,000 & 0.54 & UIT \\
\hline & Diciembre 1999 & 34,800 & 0.31 & UIT \\
\hline \multicolumn{5}{|l|}{ Dominica } \\
\hline & Diciembre 1999 & 2,000 & 2.8 & UIT \\
\hline \multicolumn{5}{|l|}{ Ecuador } \\
\hline & Diciembre 2001 & 328,000 & 2.44 & UIT \\
\hline & Diciembre 2000 & 180,000 & 1.39 & UIT \\
\hline & Diciembre 1999 & 100,000 & 0.8 & UIT \\
\hline & Octubre 1997 & 5,000 & 0.04 & UIT/Siemens \\
\hline \multicolumn{5}{|l|}{ El Salvador } \\
\hline & Diciembre 1999 & 40,000 & 0.65 & UIT \\
\hline \multicolumn{5}{|l|}{ Granada } \\
\hline & Diciembre 2001 & 5,200 & 5.83 & UIT \\
\hline & Diciembre 2000 & 4,100 & 4.59 & UIT \\
\hline & Diciembre 1999 & 2,500 & 2.8 & UIT \\
\hline \multicolumn{5}{|l|}{ Guadalupe } \\
\hline & Diciembre 1999 & 4,000 & 0.94 & UIT \\
\hline \multicolumn{5}{|l|}{ Guatemala } \\
\hline & Diciembre 2001 & 200,000 & 1.5 & UIT \\
\hline & Diciembre 1999 & 65,000 & 0.51 & UIT \\
\hline \multicolumn{5}{|l|}{ Guayana } \\
\hline & Diciembre 2001 & 95,000 & 13.61 & UIT \\
\hline & Diciembre 1999 & 3,000 & 0.43 & UIT \\
\hline \multicolumn{5}{|c|}{ Guayana Francesa } \\
\hline & Diciembre 1999 & 2,000 & 1.16 & UIT \\
\hline \multicolumn{5}{|l|}{ Haití } \\
\hline & Diciembre 2001 & 30,000 & 0.42 & UIT \\
\hline & Diciembre 1999 & 6,000 & 0.09 & UIT \\
\hline & Julio 1998 & 2,000 & - & News.com \\
\hline \multicolumn{5}{|l|}{ Honduras } \\
\hline & Diciembre 1999 & 40,000 & 0.64 & UIT \\
\hline & Diciembre 1999 & 20,000 & 0.33 & UIT \\
\hline
\end{tabular}




\section{La tecnología de la información y comunicación en el mundo}

Figura 43

(Cont.)

Distribución de usuarios de Internet en América Latina

\begin{tabular}{|c|c|c|c|c|}
\hline País & Fecha & Número & \% Población & Fuente \\
\hline \multicolumn{5}{|l|}{ Islas Vírgenes } \\
\hline & Diciembre 1999 & 12,000 & 9.92 & UIT \\
\hline \multicolumn{5}{|l|}{ Jamaica } \\
\hline & Diciembre 2001 & 100,000 & 3.73 & UIT \\
\hline & Diciembre 1999 & 60,000 & 2.26 & UIT \\
\hline \multicolumn{5}{|l|}{ Martinica } \\
\hline & Diciembre 1999 & 5,000 & 1.21 & UIT \\
\hline \multicolumn{5}{|l|}{ México } \\
\hline & Diciembre 2001 & 3.5 millones & 3.38 & UIT \\
\hline & Julio 2001 & 3.42 millones & 3.36 & UIT \\
\hline & Diciembre 2000 & 2.71 millones & 2.7 & UIT \\
\hline & Febrero 2000 & 1.3 millones & 1.3 & Jupiter Communications \\
\hline & Diciembre 1999 & 1.82 millones & 1.81 & UIT \\
\hline & Septiembre 1999 & 900,000 & 0.9 & Visa México \\
\hline & Abril 1999 & 600,000 & 0.6 & IABIN \\
\hline & Diciembre 1998 & 713,000 & 0.7 & IDC \\
\hline & Diciembre 1998 & 504,900 & 0.5 & Mori de México \\
\hline & Noviembre 1997 & 370,000 & 0.38 & CommerceNet Research \\
\hline \multicolumn{5}{|l|}{ Nicaragua } \\
\hline & Diciembre 1999 & 20,000 & 0.42 & UIT \\
\hline \multicolumn{5}{|l|}{ Panamá } \\
\hline & Diciembre 1999 & 45,000 & 1.6 & UIT \\
\hline \multicolumn{5}{|l|}{ Paraguay } \\
\hline & Diciembre 1999 & 20,000 & 0.36 & UIT \\
\hline & Octubre 1997 & 1,000 & 0.01 & UIT/Siemens \\
\hline \multicolumn{5}{|l|}{ Perú } \\
\hline & Diciembre 2001 & 3 millones & 10.73 & UIT \\
\hline & Febrero 2000 & 400,000 & 1.5 & Jupiter Communications \\
\hline & Abril 1999 & 20,000 & 0.08 & IABIN \\
\hline & Octubre 1997 & 31,000 & 0.12 & UIT/Siemens \\
\hline & Junio 1997 & 65,000 & 0.26 & CommerceNet Research \\
\hline \multicolumn{5}{|l|}{ Puerto Rico } \\
\hline & Diciembre 2001 & 600,000 & 15.61 & UIT \\
\hline & Abril 2000 & 200,000 & 5.14 & UIT \\
\hline
\end{tabular}




\section{La brecha digital y sus determinantes}

\section{Figura 43}

(Cont.)

Distribución de usuarios de Internet en América Latina

\begin{tabular}{|c|c|c|c|c|}
\hline País & Fecha & Número & \% Población & Fuente \\
\hline \multicolumn{5}{|c|}{ República Dominicana } \\
\hline & Diciembre 2001 & 186,000 & 2.13 & UIT \\
\hline & Abril 1999 & 25,000 & -- & IABIN \\
\hline \multicolumn{5}{|c|}{ St Kitts y Nevis } \\
\hline & Diciembre 1999 & 2,000 & 5.15 & UIT \\
\hline \multicolumn{5}{|l|}{ San Vicente } \\
\hline & Diciembre 2000 & 35,000 & 3.03 & UIT \\
\hline & Diciembre 1999 & 3,000 & 2.6 & UIT \\
\hline \multicolumn{5}{|l|}{ Santa Lucía } \\
\hline & Diciembre 1999 & 3,000 & 1.92 & UIT \\
\hline \multicolumn{5}{|l|}{ Surinam } \\
\hline & Diciembre 2001 & 14,500 & 3.32 & UIT \\
\hline & Diciembre 2000 & 11,700 & 2.71 & UIT \\
\hline & Diciembre 1999 & 8,700 & 2 & UIT \\
\hline \multicolumn{5}{|c|}{ Trinidad y Tobago } \\
\hline & Diciembre 2001 & 120,000 & 10.31 & UIT \\
\hline & Diciembre 2000 & 42,800 & 3.64 & UIT \\
\hline & Diciembre 1999 & 30,000 & 2.55 & UIT \\
\hline \multicolumn{5}{|l|}{ Uruguay } \\
\hline & Diciembre 2001 & 400,000 & 13.61 & UIT \\
\hline & Diciembre 2000 & 370,000 & 11.1 & UIT \\
\hline & Diciembre 1999 & 330,000 & 9.97 & UIT \\
\hline & Abril 1999 & 90,000 & 2.7 & IABIN \\
\hline & Octubre 1997 & 9,000 & 0.27 & UIT/Siemens \\
\hline \multicolumn{5}{|l|}{ Venezuela } \\
\hline & Diciembre 2001 & 1.3 millones & 5.35 & UIT \\
\hline & Diciembre 2000 & 950,000 & 4.04 & UIT \\
\hline & Diciembre 1999 & 525,000 & 2.26 & UIT \\
\hline & Abril 1999 & 80,000 & 0.34 & IABIN \\
\hline & Octubre 1997 & 12,000 & 0.05 & UIT/Siemens \\
\hline & Junio 1997 & 35,000 & 1.20 & CommerceNet Research \\
\hline
\end{tabular}

Tomado de: How many online?, Latin America, disponible en http://www.nua.ie/surveys/how_many_ online/s_america.html [Agosto 10, 2005]. 
De la información anterior De Munster destaca sólo algunos países latinoamericanos:

[...] podemos encontrar un marcado crecimiento en la conexión y el uso de Internet en los últimos años tal como lo publica NUA Internet Surveys en sus páginas dedicadas a cada país:(4)

Tan sólo mencionaremos algunos ejemplos:

Argentina: de $0.85 \%$ (330 mil) de la población en diciembre de 1998 a $10.38 \%$ (3.88 millones) de su población en julio de 2001

Brasil: 1.4\% (2.35 millones) de la población en diciembre de 1998 a 6.84\% (11.94 millones) de su población en julio de 2001

Chile: $1.30 \%$ (200 mil) en junio de 1997 a 20.02\% (3.1 millones) de su población en diciembre de 2001

México: 0.38 (370 mil) de la población en noviembre de 1997 a 3.36\% (3.42 millones) de su población en julio de 2001

Perú: $0.12 \%$ en octubre de 1997 a 10.73\% (3 millones) en diciembre de 2001

Uruguay: $0.27 \%$ (9 mil) de la población en octubre de 1997 a 13.61\% de su población (400 mil) en diciembre de 2001.25

Sobre la misma región geográfica, Hilbert ha elaborado la figura 44, donde expone gráficamente la proporción de usuarios de Internet en siete países latinoamericanos durante 2000 y hace una estimación para 2003. En virtud de que los datos sobre el acceso a Internet son relativos, Hilbert modifica la primera serie de países al eliminar al Perú de entre los estados con mayor número de usuarios en las dos gráficas complementarias y agrupa a las naciones con menor presencia en la red en un solo rubro; de este modo señala datos sobre Brasil, México, Argentina, Chile, Colombia, Venezuela y "el resto" de América Latina.

25 Irene L. de Munster, "La brecha informativa en Latinoamérica: un caso de estudio", World Library and Information Congress: 70th IFLA General Conference and Council, 22-27 August 2004, Buenos Aires, Argentina, 3, disponible http:/www. ifla.org/IV/ifla70/papers/031s-Munster.pdf [Agosto 8, 2004]. 


\section{La brecha digital y sus determinantes}

Figura 44

Acceso a Internet en América Latina

Percentage of inhabitants connected 2000 ,

(with estimates for 2003)
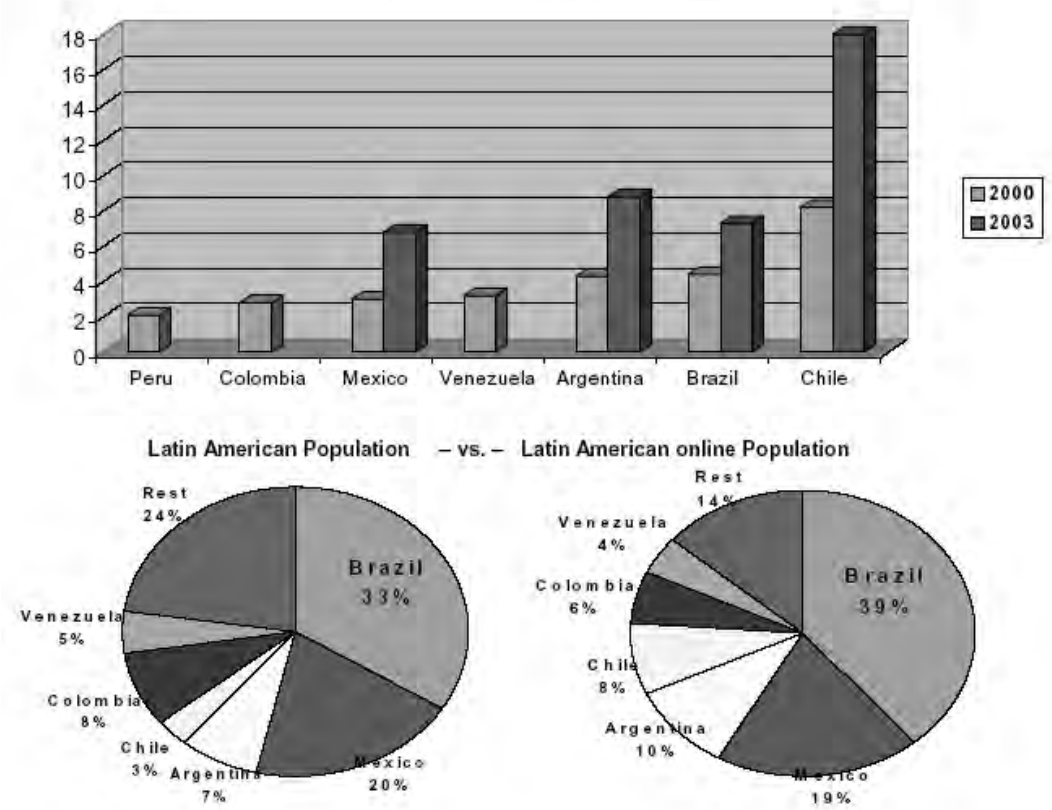

Tomado de Martin R. Hilbert, Latin America on its path into the digital age: where are we?

(Santiago, Chile: Naciones Unidas, 2001), 40, disponible http://www.eclac.org/publicaciones/

DesarrolloProductiva/5/LCL1555P/Lc/1555.pdf [Septiembre 25, 2005].

Latinoamérica tiene muy pocos usuarios de Internet, especialmente cuando se le compara con otras regiones y países. Por poner un ejemplo que resulta muy ilustrativo, digamos que Finlandia, con tan sólo cinco millones de habitantes, tiene más servidores conectados con Internet que toda América Latina con sus más de 250 millones de habitantes. ${ }^{26}$

26 Chen y Wellman, 21. 


\section{México}

En México el Instituto Nacional de Estadística, Geografía e Informática (INEGI) ha realizado cuatro encuestas nacionales sobre tecnologías de la información: la Encuesta Nacional sobre Disponibilidad y Uso de las Tecnologías de la Información en los Hogares (ENDUTIH 2004 y 2005), Encuesta sobre Disponibilidad y Uso de Tecnología de Información en los Hogares (EDUTIH, 2002) y Módulo Nacional de Computación (MONACO, 2001). Pero al igual que en otros países, los sectores civil y académico han iniciado el análisis de la brecha digital, obteniendo incluso resultados divergentes.

Los datos del INEGI para el año 2005 señalan que el 18.4 por ciento de los hogares mexicanos cuentan con una computadora y el 9 por ciento con conexión a Internet; ${ }^{27}$ a pesar de que durante los últimos años la cantidad de hogares con computadora se ha incrementado, aún es marginal con relación a la población general.

Con base en los datos anteriores se puede decir que en México hay más personas que poseen una computadora que aquellas que tienen acceso a Internet en su hogar, aunque los datos sobre la cantidad de mexicanos usuarios de la red varían según la fuente. Chen, apoyado en datos de Servicios de Telecomunicaciones, ${ }^{28}$ al referirse a la población mexicana que disponía de computadora en su hogar y que además se conectaba desde ese lugar a Internet, señaló que en 2002

27 INEGI, Hogares con equipamiento de tecnología de información y comunicaciones por tipo de equipo, 2001 a 2005, disponible http://www.inegi.gob.mx/est/

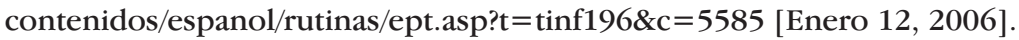

28 Servicios de Telecomunicaciones, Usuarios estimados de Internet en México (2003). http://www.cofetel.gob.mx/html/5_est/Graf_Internet/estiminternet_01.html, citado por Wenhong Chen y Barry Wellman, Charting and bridging digital divides: comparing socio-economic, gender, life stage, and rural-urban Internet access and use in eight countries, disponible http://www.amd.com/us-en/assets/content_type/ DownloadableAssets/FINAL_REPORT_CHARTING_DIGI_DIVIDES.pdf [Agosto 6, 2004], 21. 
había 4.7 millones de usuarios, en tanto que el INEGI contabilizó 3.9 millones en el mismo periodo según se observa en la figura $45 .{ }^{29}$

Es conveniente realizar algunos comentarios sobre la figura 45 a fin de facilitar su entendimiento; los términos "Con computadora en el hogar" y "Sin computadora en el hogar" se refieren a la disponibilidad del equipo, en tanto que "En el hogar" y "Fuera del hogar" se refiere al espacio físico desde donde se accede a Internet. En esta figura vale la pena resaltar la correlación entre la posesión de equipo de cómputo y acceso a Internet; nótese que el número de usuarios de Internet que se conecta desde fuera de su hogar porque no cuenta con equipo de cómputo es superior a quienes tienen computadora en casa pero no Internet; adicionalmente puede advertirse que la cantidad de usuarios que se conectan a Internet fuera de casa es mayor con relación a aquellos usuarios que se conectan usando equipo propio desde sus domicilios.

Teniendo en cuenta los datos de la figura 45 se puede concluir que en México alrededor del 42 por ciento de los usuarios de Internet no disponen de equipo de cómputo en sus hogares.

Bajo este esquema se puede observar que la variación porcentual en el número de usuarios de Internet entre 2001 y 2002 fue del 52.75 por ciento, y que la variación porcentual entre 2002 y 2004 correspondió al 16.84 por ciento; es decir, que el número de usuarios de Internet no mantuvo el mismo ritmo de crecimiento.

Sobresalen los datos correspondientes al año 2002, en donde se observa un incremento significativo prácticamente en todos los rubros del gráfico a excepción de aquel que se refiere a la disponibilidad de computadora y acceso a Internet en los hogares. Para mayor detalle, véase la figura 46.

29 Comisión Federal de Telecomunicaciones, Usuarios de Internet por disponibilidad de computadora en el hogar, según lugar de acceso 2000-2004, disponible en http://www.cofetel.gob.mx/wb2/COFETEL/COFE_Usuarios_estimados_de_ internet_en_Mexico [24Octubre 4, 2005]. 


\section{La tecnología de la información y comunicación en el mundo}

Figura 45

Usuarios mexicanos de Internet por disponibilidad de computadora en el hogar, según lugar de acceso 2000-2004

\begin{tabular}{|c|c|c|c|c|}
\hline Año & Concepto & Total & En el hogar & Fuera del hogar \\
\hline \multirow{3}{*}{$2000 / e$} & Estados Unidos Mexicanos & 5057533 & 2568783 & 2488750 \\
\hline & Con computadora en el hogar & 2863021 & 2568783 & 294238 \\
\hline & Sin computadora en el hogar & 2194512 & n.a. & 2194512 \\
\hline \multirow[t]{3}{*}{2001} & Estados Unidos Mexicanos & 7047172 & 3194638 & 3852534 \\
\hline & Con computadora en el hogar & 4094680 & 3194638 & 900042 \\
\hline & Sin computadora en el hogar & 2952492 & n.a. & 2952492 \\
\hline \multirow{3}{*}{2002} & Estados Unidos Mexicanos & 10764715 & 3934434 & 6830281 \\
\hline & Con computadora en el hogar & 5932887 & 3934434 & 1998453 \\
\hline & Sin computadora en el hogar & 4831828 & n.a. & 4831828 \\
\hline \multirow{3}{*}{ 2003/e } & Estados Unidos Mexicanos & 12218830 & 4632062 & 7586768 \\
\hline & Con computadora en el hogar & 6920910 & 4632062 & 2288848 \\
\hline & Sin computadora en el hogar & 5297920 & n.a. & 5297920 \\
\hline \multirow{3}{*}{$2004 / p$} & Estados Unidos Mexicanos & 12945888 & 4985418 & 7960470 \\
\hline & Con computadora en el hogar & 7414922 & 4985418 & 2429504 \\
\hline & Sin computadora en el hogar & 5530966 & n.a. & 5530966 \\
\hline \multirow{3}{*}{$2004 / e$} & Estados Unidos Mexicanos & 14036475 & 5521128 & 8515347 \\
\hline & Con computadora en el hogar & 8155940 & 5521128 & 2634812 \\
\hline & Sin computadora en el hogar & 5880535 & n.a. & 5880535 \\
\hline $\begin{array}{l}\text { Fuente: } \\
\text { Notas: }\end{array}$ & \multicolumn{4}{|c|}{$\begin{array}{l}\text { Dirección General de Tarifas e Integración Estadística, Cofetel, con información del INEGI. } \\
\text { n.a.; no aplica } \\
\text { Ip; Cifra preliminar al mes de junio. } \\
\text { le; Cifras estimadas por Cofetel, con base en información del INEGI y de reportes de las } \\
\quad \text { empresas que proporcionan el servicio de acceso a Internet. } \\
\text { 2001; INEGI-Módulo Nacional de Computación. } \\
\text { 2002; Encuesta sobre Disponibilidad y Uso de Tecnología de Información en los Hogares. } \\
\text { 2004; INEGI-Encuesta Nacional sobre Disponibilidad y Uso de Tecnología de la Información en } \\
\text { los Hogares. }\end{array}$} \\
\hline
\end{tabular}

Tomado de Comisión Federal de Telecomunicaciones, Usuarios de Internet por disponibilidad de computadora en el hogar, según lugar de acceso 2000-2004, Disponible en http://www.cofetel. gob.mx/wb2/COFETEL/COFE_Usuarios_estimados_de_internet_en_Mexico_2 [Octubre 4, 2005]. 
Figura 46

Variación porcentual anual de los usuarios mexicanos de Internet según la disponibilidad de computadora e Internet

\begin{tabular}{|c|c|c|c|c|c|c|}
\hline & \multicolumn{2}{|c|}{ Usuarios de Internet } & \multicolumn{2}{|c|}{$\begin{array}{c}\text { Usuarios con computadora } \\
\text { en el hogar }\end{array}$} & \multicolumn{2}{|c|}{$\begin{array}{c}\text { Usuarios sin computadora } \\
\text { en el hogar }\end{array}$} \\
\hline & Total & Variación \% & Total & Variación \% & Total & Variación \% \\
\hline 2001 & 7047172 & & 4094680 & & 2952492 & \\
\hline 2002 & 10764715 & 52.7 & 5932887 & 44.89 & 4831828 & 63.65 \\
\hline \multirow[t]{3}{*}{2004} & 12945888 & 16.84 & 7414922 & 24.97 & 5530966 & 14.46 \\
\hline & \multicolumn{2}{|c|}{$\begin{array}{c}\text { Usuarios con computadora } \\
\text { e Internet en el hogar }\end{array}$} & \multicolumn{2}{|c|}{$\begin{array}{l}\text { Usuarios con computadora } \\
\text { y sin Internet en el hogar }\end{array}$} & \multicolumn{2}{|c|}{$\begin{array}{c}\text { Usuarios sin computadora e } \\
\text { Internet en el hogar }\end{array}$} \\
\hline & Total & Variación \% & Total & Variación \% & Total & Variación \% \\
\hline 2001 & 3194638 & & 900042 & & 2952492 & \\
\hline 2002 & 3934434 & 23.15 & 1198453 & 122.03 & 4831828 & 63.65 \\
\hline 2004 & 4985418 & 26.17 & 2429504 & 21.56 & 5530966 & 14.46 \\
\hline \multicolumn{7}{|c|}{$\begin{array}{l}\text { Adaptado de Comisión Federal de Telecomunicaciones, Usuarios de Internet por disponibilidad de computadora en el } \\
\text { hogar, según lugar de acceso 2000-2004, disponible en http://www.cofetel.gob.mx/ wb2/COFETEL/COFE_Usuarios_es- } \\
\text { timados_de_internet_en_Mexico_2 [Octubre 4, 2005]. }\end{array}$} \\
\hline
\end{tabular}

La baja penetración de Internet se atribuye a la pobreza generalizada de la población y a una deficiente red de telecomunicaciones.

Chen y Wellman señalan que México tenía la penetración más baja en líneas telefónicas, con 12 por ciento de los hogares mexicanos en 2000, comparada con países de su mismo nivel de desarrollo. ${ }^{30}$ Chen parece haber incurrido en un error conceptual, ya que la proporción a que se refiere corresponde a la teledensidad, es decir a la proporción de líneas telefónicas fijas por cada 100 habitantes.

La teledensidad en México, de acuerdo con la Comisión Federal de Telecomunicaciones, determinada por el criterio arriba señalado, fue en 2000 del 12.4, en 2001 de 13.7, en 2002 de 14.7, en 2003 de 15.8 y

30 Chen y Wellman, 21. 
las cifras preliminares para 2004 de 17.1. ${ }^{31}$ La proporción de hogares mexicanos con teléfono fijo según cifras del INEGI fue del 36.2 por ciento en 2000, y la proporción de habitantes en esos hogares del 34.8 por ciento. 32

La Comisión Federal de Telecomunicaciones ha elaborado un comparativo internacional de penetración de computadoras, con datos de la Unión Internacional de Telecomunicaciones, de donde se han rescatado los datos sobre México. Cabe mencionar que el nivel de penetración se mide proporcionalmente, tomando como referente 100 habitantes; de esta manera el nivel de penetración de las computadoras en México ha guardado la siguiente proporción: en 1999, 4.4 ; en 2000, 5.8; en 2001, 6.9; en 2002, 8.2.33

Zenker indica que el 53 por ciento de los usuarios de Internet utilizan su propia computadora, 35 por ciento emplean la computadora de la oficina, 15 por ciento utilizan las computadoras de un cibercafé, ocho por ciento hace uso de las computadoras de la escuela, y un porcentaje similar utilizan una computadora prestada. ${ }^{34}$ Estos datos sugieren que el uso social, aunque limitado, se está basando en los recursos propios y que es poco el impacto que los programas de dotación de computadoras a las bibliotecas y otros espacios públicos tienen en la población en general.

31 Comisión Federal de Telecomunicaciones, Densidad de líneas telefónicas fijas en servicio por entidad federativa, líneas por cada cien habitantes 1990-2005, disponible en http://www.cofetel.gob.mx/wb2/COFETEL/COFE_Densidad_de_ lineas_telefonicas_fijas_en_serv[Octubre 4, 2005].

32 INEGI, Disponibilidad de bienes seleccionados en viviendas y sus ocupantes, 2000, disponible http://www.inegi.gob.mx/est/contenidos/espanol/rutinas/ept. asp?t $=$ tinf031\&c=3455 [Agosto 2, 2005]

33 Comisión Federal de Telecomunicaciones, Comparativo internacional de penetración de computadoras, computadoras por cada 100 babitantes, disponible en http://www.cofetel.gob.mx/wb2/COFETEL/COFE_Comparativo_Internacional_ de_Penetracion_de_2 [Octubre 4, 2005].

34 Alejandro Zenker, "Navegan más las mujeres". Reforma, mayo 10 (2004): Cultura, 2C. 
Sin embargo, estas cifras difieren de las oficiales. De acuerdo con los datos del INEGI empleados en la elaboración de la figura 45, la tasa de usuarios de Internet que emplean equipo propio no rebasa el 50 por ciento e incluso se observa una tendencia a la baja. La proporción de usuarios que utilizaban su computadora para conectarse a Internet en 2001 fue del 45.3 por ciento, para 2002 disminuyó al 36.5 por ciento y en 2004 fue del 38.5 por ciento. En este caso, se podría decir que el incremento en el número de mexicanos que usan Internet no depende de la posesión de equipo de cómputo.

Cuauhtémoc Valdiosera, en un artículo publicado por el diario $R e$ forma en abril de 2003, señaló que de la población mexicana sólo estaba conectada un cuatro por ciento, y comparó esta tasa con la de algunos países desarrollados, por ejemplo los países nórdicos, donde el 78 por ciento de la población está conectada a Internet. Valdiosera además suministra algunas ideas sobre para qué se conectan los mexicanos a Internet.

¿Pero para qué se conectan a la Red estos internautas? Muchos han dejado de ver noticias, por lo que ha descendido dicho porcentaje, mientras las transferencias en la Red han aumentado, pero esto tal vez por el uso de la banca electrónica y del obligado pago de impuestos electrónicos establecido el año pasado. Las compras siguen brillando por su ausencia, cuando sólo una minoría de 10 por ciento afirma haberlas hecho y una dramática mayoría, 77 por ciento, dice que nunca las hará. A su vez predomina la consulta de información con un 87 por ciento, pero no se dice cuál tipo de información, ni para qué fines se ha hecho. 35

El autor señala que el uso del correo electrónico ha crecido enormemente entre quienes tienen la posibilidad de usar la red, pasando de 11 por ciento en 2000, al 52 por ciento en 2003.

Para Valdiosera resulta frustrante que sólo el tres por ciento de la población se conecte desde casa, cifra que está muy por debajo de los números oficiales. Esto nos habla de que una parte muy pequeña de

35 Cuauhtémoc Valdiosera R., "Crece uso del correo electrónico”, Reforma, abril 2, 2003. Disponible http:///www.reforma.com/articulo/281680/default.htm [Abril 2, 2003]. 
la población mexicana tiene el privilegio de tener la conexión en su domicilio; y la causa de este problema se encuentra, como se ha mencionado con anterioridad, en los bajos ingresos económicos de la población en general. Pero también nos habla de que quienes tienen mayores recursos económicos, que son minoría, tienen una ventaja para el uso de correo electrónico, búsqueda de la información y en general para propósitos educativos. Aquellos que carecen de ingresos suficientes que les permitan adquirir una computadora y cubrir los gastos asociados a la conexión a Internet son los que se encuentran en la otra ribera de la brecha y son la mayoría.

En el mismo diario Reforma, un mes y medio después María Osterroth presentó datos un tanto diferentes. Ella nos informa que los usuarios de Internet en México ya superan los 10 millones y que era posible que a finales de ese año se registraran 12 millones. ${ }^{36}$ De haber sido ciertos esos datos, México tendría casi un 10 por ciento de la población conectada.

Las cifras que se han expuesto a lo largo de los párrafos anteriores son un buen ejemplo de lo difícil que es trabajar con las estadísticas que se publican, las cuales son en la mayoría de las veces especulaciones y cálculos sin fundamento.

En algunos países, como el caso de México, se presentan fenómenos raros en los que el uso de Internet aumenta o disminuye de tiempo en tiempo. Así, por ejemplo, Zenker en su artículo periodístico presenta información que nos permite ver el cambio al que se ha hecho referencia. En el año 2000 había una brecha entre las personas que usaban la Internet a diario o varias veces a la semana, el 29 por ciento, mientras que el 57 por ciento lo hacía rara vez o nunca. En el 2001 quienes la usaban a diario o frecuentemente habían aumentado a 49 por ciento y los otros habían disminuido a 39 por ciento; en 2002 las cifras se mantenían prácticamente sin cambio, existía un in-

36 María Osterroth, “Aumentan usuarios de Internet en México," Reforma, mayo 20, 2003, disponible http:/www.reforma.com/parseo/printage.asp?pagetoprint:. ./economiayfinanzas/articulo [Mayo 21, 2003]. 
cremento de un punto porcentual en aquellos que la usaban frecuentemente, y quienes no la usaban se mantenían con el mismo porcentaje. En 2003, quienes la usaban frecuentemente eran el 52 por ciento y quienes la usaban esporádicamente habían descendido a 29 por ciento. En 2004 hay un cambio de tendencia y quienes la usan frecuentemente han descendido seis puntos para llegar a 46 por ciento, mientras que aquellos que no la usan frecuentemente aumentaron ocho puntos, alcanzando el 37 por ciento. Como se observa por las cifras anteriores, hay un cambio de orientación de los usuarios. Sin embargo el autor no nos ofrece una explicación del cambio, y nosotros no estamos en posibilidad de hacerlo, pues no tenemos la información de las personas encuestadas, por lo que no se puede repetir la medición y buscar la explicación que justifique este comportamiento errático.

Hay que tomar con mucho cuidado estos datos y determinar si las tendencias se mantienen o cambian, porque no existe una explicación de este cambio en las tendencias.

Otro aspecto vinculado a la brecha digital en México es el que se refiere a la cantidad de servidores de Internet:

México ha quedado rezagado de la difusión de Internet con relación a los otros países de la OCDE ya que sólo había cinco servidores por cada 1000 habitantes en 2001, en contraste con el promedio de los países de la OCDE, de 101 servidores por 1000 personas (OCDE, 2002). Aun comparada con otros de los más grandes países de América Latina, la penetración de Internet entre la población de México era más baja que la de Argentina (ocho por ciento) y Brasil (cinco por ciento) (E_Marketer, 2002). 37

Una vez más los indicadores internacionales aplicables a la apropiación de TIC ponen de manifiesto el retraso de México en esta materia. Son muchos los aspectos que deben ser analizados respecto a la brecha digital en México, algunos de los cuales han sido tratados en Tecnologías de la información y brecha digital en México, 2001-

37 Chen y Wellman, 21. 
2005, publicado en 2006 por el Centro Universitario de Investigaciones Bibliotecológicas.

Los usuarios mexicanos están concentrados en las grandes zonas urbanas, como la ciudad de México y su área metropolitana, la ciudad de Guadalajara, Toluca, Puebla, Monterrey, Tijuana y León, entre otras.

Mientras que en Chiapas hay 3.5 líneas telefónicas por cada 100 habitantes, en la ciudad de México hay 33 por cada 100 habitantes; como puede observarse, la distribución por zonas geográficas es muy desigual. 38

\section{Europa}

Hacia el año 2000 el Pan European Internet Monitor (PEIM) señaló que 107.8 millones de europeos, o el 34 por ciento de la población total, tenían acceso a Internet; ${ }^{39}$ y que la región con mayor penetración era Escandinavia. Para el año 2002 los resultados del NUA Internet Surveys indicaron que Europa había alcanzado 190.91 millones de usuarios de Internet y que, como en otras partes del mundo, el grado de penetración de Internet variaba ampliamente de país en país. De estos datos se deduce que el número de usuarios de Internet de 2000 a 2002 creció en 83.11 millones de personas.

Más adelante, Nielsen NetRatings informaba que Estados Unidos tenía el 29 por ciento del total de usuarios de Internet, seguido por Europa con el 23 por ciento, Asia-Pacífico con 13 por ciento y América Latina con el dos por ciento. ${ }^{40}$

Cuando hablamos de quienes tienen acceso al mundo tecnológico, se asume que Europa Occidental tiene las mismas características que Estados Unidos. Sin embargo, mientras que la penetración de Internet

38 Ibid., 22.

39 Pro Active, Digital divide still apparent in Europe, 2000, disponible http://www. nua.com/surveys/?f=VS\&art_id=905355714\&rel=true [Septiembre 30, 2005].

40 Nielsen NetRatings, Global Net population increases (2003), disponible http:// www.nua.com/surveys/index.cgi?f=VS\&art_id $=905358729 \&$ rel $=$ true $[$ Septiembre 30, 2005]. 
en Estados Unidos es de $\mathbf{4 1 . 5}$ por ciento, en Europa Occidental es de tan sólo el 19 por ciento. Pero si vemos los datos con más detalle, hay países que tienen índices superiores a los Estados Unidos, como es el caso de Islandia con 53.57 por ciento, Noruega, 44.95, mientras que hay países como España que tiene tan sólo el 6.9 por ciento. ${ }^{41}$

De acuerdo con los resultados obtenidos por Nielsen NetRatings, Alemania, Reino Unido e Italia tienen la población más grande de usuarios de Internet en el hogar, en tanto que Suecia, Hong Kong, los Países Bajos y Austria tienen los mercados en Internet más maduros.

La tasa de penetración de Internet en algunos estados europeos durante 2000 fue la siguiente: Suecia, 53 por ciento; Reino Unido, Países Bajos, Suiza y Austria, el 33 por ciento. En ese mismo año, la penetración de Internet en Francia, Italia, Bélgica y Alemania estaba por abajo del promedio europeo. El caso alemán merece especial mención ya que su nivel se ve debilitado por la baja tasa de penetración en la antigua Alemania del Este; si se considerara solamente a la antigua República Federal Alemana, el nivel subiría hasta el del Reino Unido. ${ }^{42}$

En la figura 47, que se refiere a Europa Occidental, se observa que los países nórdicos cuentan con una mayor conectividad que los países del sur de Europa. Mientras que los primeros tienen índices de penetración cercanos o superiores al 30 por ciento, los países del sur -Turquía, Grecia y Portugal entre otros- no llegan al ocho por ciento.

En el Reino Unido, como en casi todos los países, hay diferencias importantes en las conexiones a la red. La zona más rica cubre Londres, y el este y sur de Inglaterra es el área que cuenta con mejores conexiones. Más de la mitad de las casas de esa zona están conectadas. ${ }^{43}$

41 Kuttan y Peters, 121.

42 Pro Active, Digital divide still apparent in Europe, 2000.

43 UK Cabinet Office, UK online annual report 2002, disponible http://archive.cabinetoffice.gov.uk/e-envoy/reports-annrep-2002/\$file/indexpage.htm, citado por Wenhong Chen y Barry Wellman, Charting and bridging digital divides: comparing socio-economic, gender, life stage, and rural-urban Internet access and use in eight countries. Octubre 27, 2003, 11, disponible: http://www.amd.com/us-en /assets/content_type/DownloadableAssets/FINAL_REPORT_CHARTING_DIGI_ DIVIDES.pdf [Agosto 6, 2004]. 
Figura 47

De sur a norte a lo largo de la brecha digital en

Europa Occidental

\begin{tabular}{|l|c|c|c|c|}
\hline \multicolumn{7}{|l|}{ Tabla 4.11 De sur a norte a lo largo de la brecha digital europea } \\
\hline & Población & $\begin{array}{c}\text { Usuarios de } \\
\text { Internet }\end{array}$ & $\begin{array}{c}\text { Tasa de penetración } \\
\text { de Internet * }\end{array}$ & $\begin{array}{c}\text { PCs por } 100 \\
\text { personas }\end{array}$ \\
\hline Turquía & $65,700,000$ & $1,500,000$ & $2.2 \%$ & 3.23 \\
\hline Grecia & $10,650,000$ & 750,000 & $7 \%$ & 6.02 \\
\hline Portugal & $10,020,000$ & 700,000 & $6.9 \%$ & 9.32 \\
\hline España & $40,600,000$ & $2,830,000$ & $6.9 \%$ & 12.18 \\
\hline Italia & $57,300,000$ & $5,000,000$ & $8.7 \%$ & 19.18 \\
\hline Francia & $58,800,000$ & $5,660,000$ & $9.6 \%$ & 22.08 \\
\hline Austria & $8,210,000$ & 850,000 & $10.3 \%$ & 25.68 \\
\hline Suiza & $7,160,000$ & $1,761,000$ & $24.5 \%$ & 46.19 \\
\hline Alemania & $82,180,000$ & $15,900,000$ & $19.3 \%$ & 29.69 \\
\hline Bélgica & $10,160,000$ & $1,400,000$ & $13.7 \%$ & 31.52 \\
\hline Holanda & $15,960,000$ & $3,000,000$ & $18.8 \%$ & 35.97 \\
\hline Irlanda & $3,730,000$ & 440,000 & $11.7 \%$ & 32.39 \\
\hline Reino Unido & $59,770,000$ & $12,500,000$ & $29.9 \%$ & 30.64 \\
\hline Dinamarca & $5,330,000$ & $1,500,000$ & $28.1 \%$ & 41.4 \\
\hline Noruega & $4,449,000$ & $2,000,000$ & $44.95 \%$ & 44.99 \\
\hline Suecia & $8,880,000$ & $3,666,000$ & $41.28 \%$ & 35.16 \\
\hline Finlandia & $5,180,000$ & $1,667,000$ & $32.18 \%$ & 53.9 \\
\hline Islandia & 280,000 & 150,000 & $57 \%$ & \\
\hline * Usuarios de Internet/Población & & & \\
\hline
\end{tabular}

Tomado de Appu Kuttan y Laurence Peters, From digital divide to digital opportunity (Lanham, Maryland: Scarecrow Press, 2003), 123.

Alemania, que tiene una tasa de penetración de Internet del 19.3 por ciento, cuenta con el mayor número de computadoras por cada 100 habitantes al tener el 46 por ciento. Con esta información y la que se ofrece sobre otras latitudes es posible concluir, aunque no de manera terminante, que es posible tener una alta penetración con pocas computadoras por persona y con una muy limitada posesión de teléfonos. 
En Alemania el incremento en el número de usuarios había sido lento. Además, no todos los usuarios de equipos de cómputo tenían acceso a Internet, pero en los últimos años el número de usuarios se ha incrementado en forma significativa:

La tasa de penetración de Internet ha aumentado dramáticamente en Alemania desde mediados de los años 1990. Entre la población alemana de 14 años o más, el siete por ciento usaba Internet en 1997, 10 por ciento en 1998 y 18 por ciento en 1999 (Van Esmeren et al., 2002). Al contrario de Norteamérica, en Alemania hubo una brecha sustancial entre posesión de computadoras y uso de Internet; hacia 1999, cuando el 45 por ciento de los hogares alemanes tenían una computadora, sólo alrededor de un cuarto de ellos (11 por ciento) estaban conectados a Internet (ITU, 2002 ${ }^{\mathrm{a}}$; Welling y Kubrik, 2000). La difusión de Internet se ha acelerado, desde entonces 29 por ciento de la población alemana estaba conectada en 2000,39 por ciento en 2001 y 44 por ciento en 2002.44

Para la mayoría de los alemanes el uso de Internet tiene fines de comunicación y de búsqueda de información. Por ello es que las principales actividades que se realizan con Internet son la comunicación por medio del correo electrónico, 81 por ciento, y la búsqueda de información, 55 por ciento. No son exclusivas, pero son las más importantes; Internet también es utilizada para realizar operaciones bancarias, 32 por ciento, conversaciones individuales o de grupo, 23 por ciento, juegos en la red, 15 por ciento, y otras actividades con un menor uso. ${ }^{45}$

En Alemania los habitantes de la antigua zona occidental tienen mayor experiencia en el uso de Internet que los alemanes de la antigua Alemania Oriental. ${ }^{46}$ Esto se debe posiblemente a que la red telefónica occidental era mejor y estaba más difundida entre la población. En la antigua Alemania Oriental se tenían mayores limitaciones para acceder a una línea telefónica.

44 Chen y Wellman, 11.

45 Ibid., 13.

46 Ibid., 12. 
Otro caso que vale la pena comentar es el italiano, que aunque continúa por debajo de los países más desarrollados, ha demostrado una expansión en el nivel de penetración de Internet durante los últimos años.

En Italia el acceso a Internet es uno de los más bajos de Europa y su crecimiento ha sido muy lento. En 1998 sólo el cinco por ciento de los hogares italianos estaban conectados a la red. Esto sin lugar a dudas está asociado a que los italianos tienen un bajo índice de posesión de computadoras. Sin embargo la situación parece haberse modificado y el ritmo de conectividad se ha acelerado en los últimos años, aunque todavía mantiene un nivel bajo. En el año 2000, el 31 por ciento de los hogares poseían una computadora y de ellos el 60 por ciento tenían contactos con Internet, es decir, sólo el 20 por ciento de la población estaba conectada a la red. Debe observarse la diferencia tan grande entre poseer una computadora (60 por ciento) y estar conectado con Internet (20 por ciento), que es de cuarenta puntos. Esta diferencia se explica porque los equipos de cómputo son utilizados para realizar programas propios de los negocios o bien para utilizarlos como procesadores de palabra. 47

En Italia la brecha digital existe entre el norte y el sur del país, el primero es el más desarrollado, en tanto que en el sur todos los indicadores económicos y sociales muestran un menor desarrollo. El norte aventaja al sur por 16 puntos porcentuales, tanto en la posesión de computadoras como en acceso a Internet. ${ }^{48}$

España y Portugal también se encuentran por abajo del promedio europeo, y son las naciones del Sureste Europeo que presentan menores logros en la incorporación de Internet a sus sociedades.

Con ayuda de la figura 48 podemos ejemplificar la diferencia en las tasas de penetración de Internet entre el norte y el sur de Europa Occidental. La naturaleza y magnitud de la brecha digital y de las diferencias propias de cada nación están determinadas por la geopolítica.

47 Ibid., 13.

48 Ibid., 14. 
Figura 48

Tasa de penetración de Internet en algunas naciones de Europa Occidental

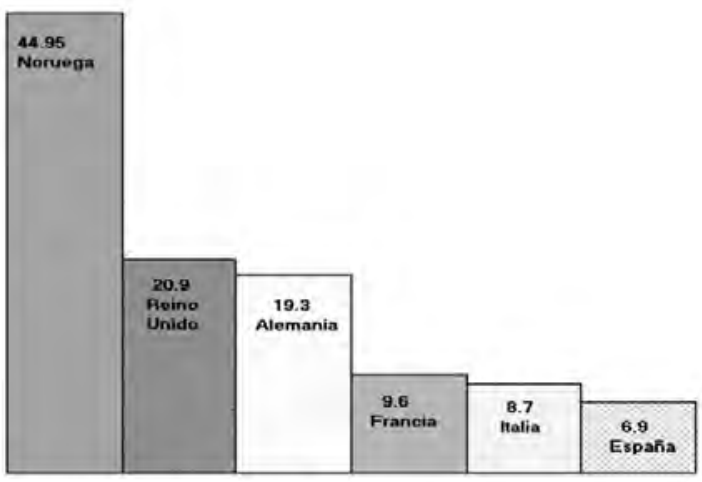

Figura 4.8. Tasa de penetración de Internet en naciones de Europa Occidental

Tomado de Appu Kuttan y Laurence Peters, From digital divide to digital opportunity (Lanham, Maryland: Scarecrow Press, 2003), 121.

Para determinar la situación de Europa Oriental se ha recurrido al análisis de Yugoslavia y algunos países del antiguo bloque soviético, que nos muestra que la apropiación de la TIC ha sido heterogéneo. Es muy difícil encontrar las explicaciones que justifiquen tal desequilibrio dado que todos los países formaban parte de un gran bloque; sin embargo podríamos suponer que la unidad no fue del todo equitativa entre las diferentes naciones que componían la antigua URSS; que tal vez las diferencias en el nivel de desarrollo son el resultado de la desintegración de la Unión Soviética y del consecuente cambio en las políticas públicas y en los intereses relacionados con el acceso a la información; o simplemente que cuando se desmiembra la Unión Soviética, Internet estaba en sus etapas iniciales.

Cualquiera que haya sido la causa de esta diferencia en el desarrollo de los países de Europa Oriental, en la figura 49 se muestran los datos que corresponden al número de usuarios de Internet, de teléfonos por cada 100 habitantes y el número de computadoras por el mismo número de personas en esta área geográfica. 
Figura 49

Lo mejor y el resto de Europa Oriental

\begin{tabular}{|c|c|c|c|c|c|}
\hline & Población & $\begin{array}{c}\text { Usuarios } \\
\text { de Internet }\end{array}$ & $\begin{array}{l}\text { Tasa de penetra- } \\
\text { ción de Internet* }\end{array}$ & $\begin{array}{l}\text { Líneas telefónicas } \\
\text { por } 100 \text { personas }\end{array}$ & $\begin{array}{l}\text { Computadoras } \\
\text { por } 100 \text { personas }\end{array}$ \\
\hline \multicolumn{6}{|l|}{ Lo mejor } \\
\hline Estonia & $1,440,000$ & 200,000 & $13.8 \%$ & 35.74 & 13.49 \\
\hline República Eslovaca & $5,410,000$ & 700,000 & $12.9 \%$ & 30.67 & 7.43 \\
\hline Eslovenia & $1,990,000$ & 250,000 & $12.5 \%$ & 37.8 & 25.14 \\
\hline \multicolumn{6}{|l|}{ Lo mejor del resto } \\
\hline República Checa & $10,240,000$ & 700,000 & $6.8 \%$ & 37.09 & 10.72 \\
\hline Polonia & $38,770,000$ & $2,100,000$ & $5.4 \%$ & 26.27 & 6.2 \\
\hline Hungría & $10,230,000$ & 600,000 & $5.8 \%$ & 37.09 & 7.35 \\
\hline Latvia & $2,380,000$ & 105,000 & $4.4 \%$ & 29.99 & 8.2 \\
\hline Croacia & $4,470,000$ & 200,000 & $4.47 \%$ & 36.43 & 6.7 \\
\hline \multicolumn{6}{|l|}{ El resto } \\
\hline Albania & $3,910,000$ & 2,500 & $0.06 \%$ & 3.65 & 0.52 \\
\hline Bielorrusia & $10,240,000$ & 10,000 & $0.09 \%$ & 25.68 & ND \\
\hline Bulgaria & $8,220,000$ & 200,000 & $2.4 \%$ & 35.43 & 2.66 \\
\hline Lituania & $3,700,000$ & 103,000 & $2.7 \%$ & 31.16 & 5.94 \\
\hline Moldavia & $4,380,000$ & 15,000 & $0.3 \%$ & 12.68 & 0.8 \\
\hline Rumania & $22,330,000$ & 600,000 & $2.6 \%$ & 16.7 & 2.68 \\
\hline Rusia & $146,930,000$ & $2,700,000$ & $1.8 \%$ & 21.03 & 3.74 \\
\hline Ucrania & $50,460,000$ & 200,000 & $0.3 \%$ & 19.89 & 1.58 \\
\hline Yugoslavia & $10,640,000$ & 80,000 & $0.75 \%$ & 21.44 & 2.07 \\
\hline
\end{tabular}

Tomado de Appu Kuttan y Laurence Peters, From digital divide to digital opportunity (Lanham, Maryland: Scarecrow Press, 2003), 120.

Así, Estonia es la nación que tiene una mayor penetración en la red, con casi 14 por ciento, seguida muy de cerca por la República Eslovaca y Eslovenia. Con menos de la mitad de la tasa de esas dos naciones se encuentran la República Checa, Polonia y Hungría, para concluir con Rusia y Yugoslavia, que tiene muy escasa penetración. 
Figura 50

Tasa de penetración de Internet en algunos países de Europa Oriental

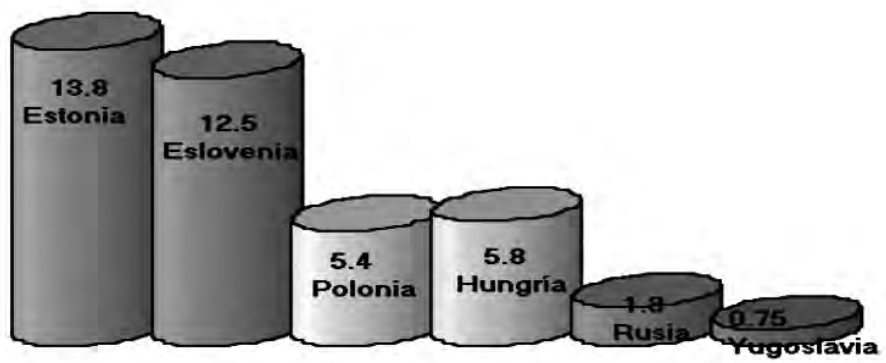

Figura 4.7. Tasa de penetración de Internet en países de Europa Oriental

Tomado de Appu Kuttan y Laurence Peters, From digital divide to digital opportunity (Lanham, Maryland: Scarecrow Press, 2003), 119.

La figura 50 nos proporciona una idea más clara sobre el nivel de apropiación de Internet en las naciones de Europa Oriental, ya que va de la nación con la tasa más alta, al país con la tasa más baja de penetración, y al comparar las figuras 48 y 50 es evidente la diferencia en el desarrollo que existe entre Europa Occidental y Europa Oriental respecto a la apropiación de la TIC.

Llama la atención que la República Eslovaca, con un bajo número de computadoras por persona, tenga un nivel tan elevado de penetración de Internet y un número igualmente alto de usuarios de Internet. Si comparamos el número de personas por línea telefónica, así como el número de computadoras con que cuenta la República Checa, que son mayores que las de Eslovaquia, no se comprende cómo puede este país tener un nivel tan bajo en la penetración de Internet.

El conjunto de países de Europa del Este no rebasan el 14 por ciento en la penetración de Internet, lo cual los deja en desventaja con relación al resto de Europa, que tiene niveles más altos de conectividad y uso. 
En los países que integran esta región también se observa el efecto de la carencia de una infraestructura en servicios de comunicación entre las áreas rural y urbana, lo que es señalado por Kuttan y Peters:

- 60 por ciento de los usuarios de Internet en Rumania viven en la capital, Bucarest;

- Casi 80 por ciento de los usuarios de Bielorrusia viven en la capital, Minsk;

- Hay 20 líneas telefónicas en la parte urbana de Rusia contra 8 en las zonas rurales. 49

\section{Región Asia-Pacífico}

La región Asia-Pacífico, a septiembre de 2002, era la segunda área con más usuarios de Internet según NUA Internet Surveys, quien había contabilizado 187.27 millones de usuarios. De las naciones que integran esta región, quienes tenían las tasas más altas de usuarios de Internet fueron Australia, Hong Kong, Japón, Nueva Zelanda, Singapur, Corea del Sur y Taiwán. Una mención especial es necesaria para China, ya que a pesar de tener $\mathbf{4 5 . 8}$ millones de usuarios de Internet, con motivo del total de su población, esta cifra sólo representa al 3.58 por ciento de aquella.

La proporción de población usuaria de Internet en los países señalados durante el año 2002, de acuerdo con la fuente indicada, fue la siguiente: Australia, 54.38 por ciento (10.63 millones de personas); Hong Kong, 59.58 por ciento (4.35 millones de personas), Japón, 44.1 por ciento (56 millones de personas); Nueva Zelanda, 52.7 por ciento (2.06 millones de personas); Singapur, 51.84 (2.35 millones de personas); Corea del Sur, 53.8 por ciento ( 53.8 millones de personas); y Taiwán, 51.85 por ciento (11.6 millones de personas).

49 Kuttan y Peters, 120-121. 
En Japón el porcentaje de hogares con acceso a Internet disminuye según el tamaño de la ciudad: las ciudades más grandes tienen mayor utilización de la red, mientras que las pequeñas utilizan menos este recurso, seguidas por pequeñas villas y pueblos. ${ }^{50}$

La brecha digital en Corea no tiene las mismas características que se observan en otros países desarrollados. Este es un país de mediano desarrollo, con amplio uso de computadoras y conexión a Internet y no obstante que su desarrollo no sea equiparable al de Italia, por poner un ejemplo, su cobertura en el uso de tecnología de cómputo y acceso a la red es mayor.

De 1998 a 1999 el número de usuarios de Internet en Corea (definidos como usuarios mayores de siete años y que usan Internet al menos una vez al mes) aumentó tres veces, saltando de tres millones a $11 \mathrm{mi}$ llones. Para 2001, el 57 por ciento de los coreanos mayores de siete años (24 millones) estaban conectados (Soe, 2002). El número de usuarios de Internet ha continuado creciendo y ha llegado a 26 millones en junio de 2002, casi nueve veces la cantidad de usuarios que se tenía cinco años antes. 51

En Corea la mayor concentración de usuarios se encuentra en la capital, Seúl, entre las posibilidades de uso en esta zona y el resto del país hay al menos 10 puntos porcentuales de diferencia. Sin embargo, el gobierno ha estado haciendo esfuerzos por homogeneizar las regiones y la diferencia existente entre las provincias tenderá a desaparecer en el futuro. ${ }^{52}$ No es casual que Corea posea el liderazgo en el número de usuarios que utilizan los servicios de banda ancha, con 14 suscriptores de servicios de banda ancha por cada 100 habitantes en junio de 2002 .

Hay una brecha por zonas en China que es interesante destacar. Entre Pekín y las ciudades de Shanghái y Cantón reúnen más del 20 por ciento de la cobertura total. Sin embargo:

50 Chen y Wellman, 16.

51 Ibid., 17.

52 Ibid., 18. 
Hay una enorme brecha entre zonas urbanas y rurales. Los campesinos que son, aproximadamente, el 80 por ciento de la población, sólo representan el uno por ciento de los usuarios de Internet en el país. 53

En China el uso de las computadoras y de Internet se inició relativamente tarde, por lo cual tiene una baja penetración porcentual de usuarios, pero como la población es tan grande, un bajo porcentaje significa muchos millones de usuarios. En 1997 sólo había 620 mil usuarios, en 2001 se había incrementado a 22.5 millones y en 2003 a 60 millones. Como se puede ver por las cifras anteriores, el aumento en la cantidad de usuarios es muy grande; aunque no lo parezca, sí se relaciona con el total de la población. ${ }^{54}$

Los chinos usan los equipos de cómputo y las conexiones a Internet desde lugares públicos debido a que la infraestructura de telecomunicaciones no es lo suficientemente amplia y por la estructura social y de satisfactores que caracterizó a la sociedad china bajo anteriores gobiernos.

Por otro lado, en la India hay sólo 2.2 líneas telefónicas por cada 100 habitantes, sólo 26 millones de personas tienen un teléfono. Además las conexiones son muy lentas, el ancho de banda de la India es tan sólo de 350 megabytes, comparada con la china, que tiene 40 gigabytes, y la de Estados Unidos, de 200 gigabytes. Hay 0.3 personas con computadora por cada 100 habitantes y sólo dos millones de usuarios de Internet, lo que significa un 0.19 por ciento de los usuarios de Internet a escala mundial. 55

53 CNNIC, Semiannual survey report on the development of China's Internet, http://www.cnnic.org.cn, citada por Wenhong Chen y Barry Wellman, Charting and bridging digital divides: comparing socio-economic, gender, life stage, and rural-urban Internet access and use in eight countries. Octubre 27, 2003, 20, disponible http://www.amd.com/us-en/assets/content_type/DownloadableAssets/ FINAL_REPORT_CHARTING_DIGI_DIVIDES.pdf [Agosto 6, 2004].

54 Chen y Wellman, 19.

55 Kuttan y Peters, 117. 


\section{El Medio Oriente}

En el Medio Oriente se encuentra la tasa más baja de penetración de Internet del mundo. Hay sólo 1.9 millones de usuarios de Internet en el mundo árabe, lo cual representa el 0.7 por ciento del total de los usuarios de Internet.

En esta zona geográfica, el país más desarrollado en los aspectos relacionados con la tecnología de la información es Israel, que no obstante que tiene una población relativamente pequeña, posee la tasa más alta de usuarios de Internet. Un millón de israelitas son usuarios de Internet, cifra que representa en términos porcentuales el 15.9 por ciento de la población, además Israel ocupa el primer lugar en computadoras por cada 100 habitantes con $47.13 .{ }^{56} \mathrm{En}$ el otro lado de la brecha se encuentra Yemen, que con casi tres veces la población de Israel (17 millones 479 mil habitantes), tiene sólo $12 \mathrm{mil}$ usuarios de Internet y una tasa de penetración del 0.06 por ciento y 0.17 computadoras por cada 100 habitantes.

En la figura 51 se pueden observar las bajas tasas de penetración de Internet en esta parte del mundo. Para explicar este fenómeno podemos considerar al menos dos elementos: el primero es la falta de democracia, que conlleva reprimir el uso de Internet como medida para evitar la propagación de ideas peligrosas; y el segundo es la marginación social, política y cultural de que son objeto las mujeres en esas naciones. En el último caso se segrega a más de la mitad de la población pero no sólo del uso de la tecnología de la información sino inclusive de la lectura y la educación. Otro dato interesante de observar en la figura es la información relativa a los Emiratos Árabes Unidos, país que tiene un mayor porcentaje de penetración de Internet que Israel pero cuenta con menos computadoras por cada 100 habitantes.

56 Ibíd. 
Figura 51

Penetración de Internet en

Medio Oriente

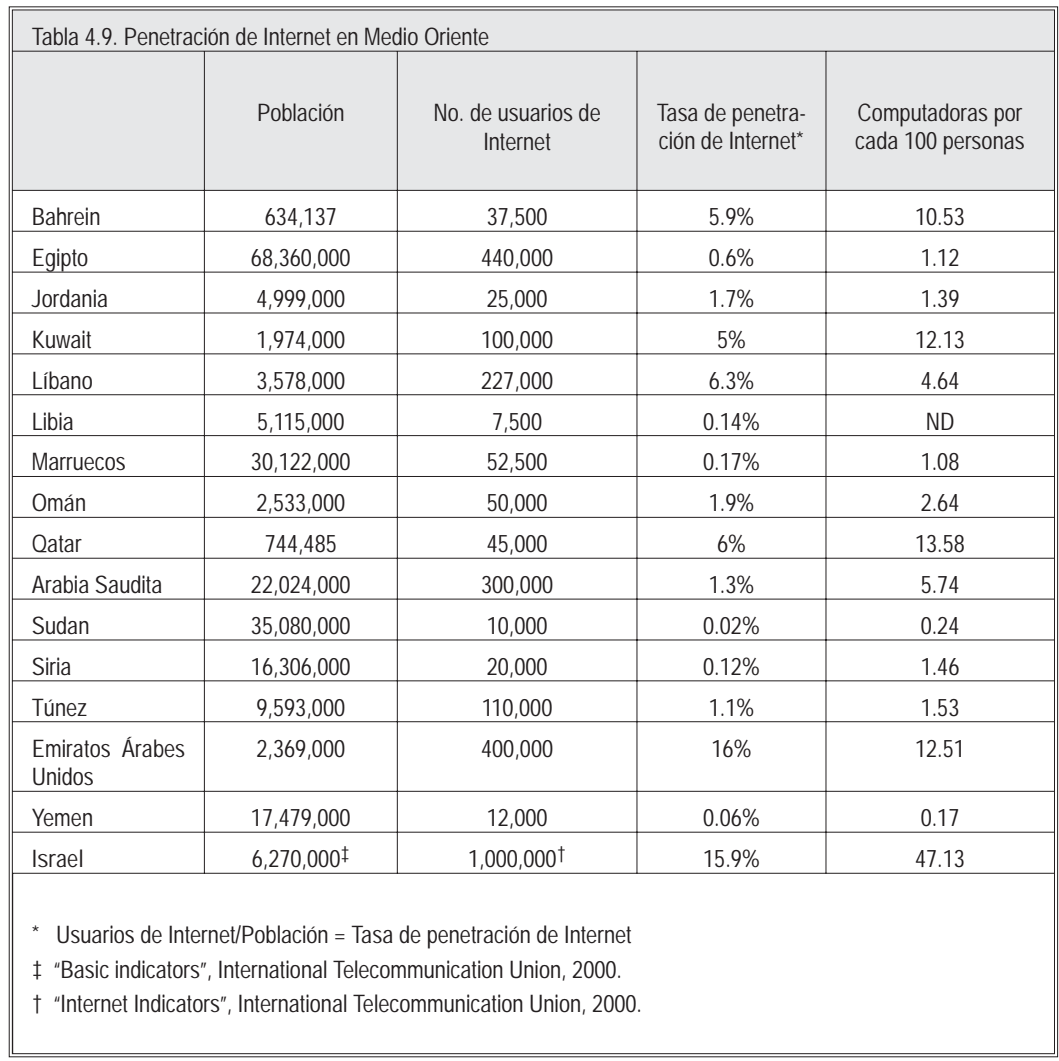

Tomado de Appu Kuttan y Laurence Peters, From digital divide to digital opportunity (Lanham, Maryland: Scarecrow Press, 2003), 118. 


\section{África}

El caso africano es quizá el más dramático, los países que obtuvieron su independencia primero, al final de la segunda guerra mundial, son los más atrasados. En los años de 1960 países como Kenya, Nigeria y Senegal eran los líderes políticos y encabezaban el movimiento cultural y educativo de África; sin embargo, los países que se liberaron en forma tardía, como es el caso de los países del sur, son actualmente los más desarrollados en todos los aspectos: líneas telefónicas por habitante, usuarios de Internet, rango de penetración de computadoras por habitante, Internet por cada 100 personas y servidores por cada 10 mil personas.

Las cifras sobre la brecha digital africana se aprecian en la figura 52, y hablan de que aun entre las áreas que se encuentran en los niveles más desprotegidos, desde el punto de vista de la penetración de Internet en la sociedad, se presentan diferencias importantes.

La figura 52 pone de manifiesto la carencia de una infraestructura en telecomunicaciones que, sin embargo, es el problema menos grave de aquellos que enfrentan naciones que luchan contra el hambre, la pobreza, la desnutrición y el sida en un contexto que puede incluir inestabilidad política.

De los 17 países africanos que componen la figura anterior, sólo dos tienen una tasa de penetración de computadoras superior al uno por ciento: Túnez y Sudáfrica, con el 1.1 y 4.16 por ciento respectivamente.

El uso de las tecnologías de la información es más extenso en Sudáfrica que en la mayoría de los países del continente, no sólo en cuanto a acceso a Internet, sino en otros aspectos que están relacionados como el número de líneas telefónicas con relación a la población total del país y los servidores que están disponibles en el mercado.

Si bien Sudáfrica tiene una baja penetración en comparación con naciones de otros continentes -sólo el 4.16 por ciento de la población con acceso a Internet-, hay países como Nigeria cuya participación es meramente simbólica, ya que tiene una penetración de 0.08 por ciento, es decir, no llega al uno por ciento de su población. Una vez más, con ayuda de la figura 53, podemos observar las características de la brecha digital para el continente africano. 


\section{La tecnología de la información y comunicación en el mundo}

Figura 52

Una visión sobre las diferencias entre

el norte y el sur de África

\begin{tabular}{|c|c|c|c|c|c|c|}
\hline & Población & $\begin{array}{l}\text { Líneas telefó- } \\
\text { nicas por } 100 \\
\text { personas }\end{array}$ & $\begin{array}{l}\text { Usuarios } \\
\text { de Internet }\end{array}$ & $\begin{array}{l}\text { Tasa de pene- } \\
\text { tración, com- } \\
\text { putadoras* }\end{array}$ & $\begin{array}{l}\text { Internet por } \\
\text { cada } 100 \text { per- } \\
\text { sonas }\end{array}$ & $\begin{array}{c}\text { Servidores de } \\
\text { Internet por } \\
10,000 \text { personas }\end{array}$ \\
\hline \multicolumn{7}{|l|}{$\begin{array}{l}\text { África del } \\
\text { Norte }\end{array}$} \\
\hline Egipto & $68,360,000^{\dagger}$ & 8.08 & $400,000^{\ddagger}$ & $0.6 \%$ & 1.12 & 0.35 \\
\hline Marruecos & $30,122,000^{\dagger}$ & 5.06 & $52,500^{\ddagger}$ & $0.17 \%$ & 1.08 & 0.73 \\
\hline Túnez & $9,593,000^{\dagger}$ & 8.99 & $110,000^{\ddagger}$ & $1.1 \%$ & 1.53 & 0.03 \\
\hline \multicolumn{7}{|l|}{ Áfricas } \\
\hline Burkina Faso & $11,940,000$ & 0.41 & 4,000 & $0.03 \%$ & 0.10 & 0.18 \\
\hline Camerún & $15,090,000$ & 0.64 & 20,000 & $0.13 \%$ & 0.27 & ND \\
\hline Congo & $2,940,000$ & 0.77 & 500 & $0.017 \%$ & 0.35 & 0.01 \\
\hline Guinea & $7,900,000$ & 0.59 & 5,000 & $0.63 \%$ & 0.38 & $\mathrm{ND}$ \\
\hline Kenia & $30,670,000$ & 1.03 & 35,000 & $0.11 \%$ & 0.42 & 0.2 \\
\hline Malí & $11,230,000$ & 0.25 & 10,000 & $0.08 \%$ & 0.10 & 0.01 \\
\hline Nigeria & $113,860,000$ & 0.43 & 100,000 & $0.08 \%$ & 0.64 & 0.01 \\
\hline Senegal & $9,480,000$ & 2.18 & 30,000 & $0.31 \%$ & 1.52 & 0.33 \\
\hline \multicolumn{7}{|l|}{$\begin{array}{l}\text { África } \\
\text { Meridional }\end{array}$} \\
\hline Bostwana & $1,620,000$ & 7.69 & 12,000 & $0.7 \%$ & 3.13 & 13.94 \\
\hline Namibia & $1,760,000$ & 6.38 & 6,000 & $0.34 \%$ & 2.95 & 12.06 \\
\hline Swazilandia & $1,010,000$ & 3.12 & 3,000 & $0.29 \%$ & ND & 6.75 \\
\hline Zimbabwe & $12,630,000$ & 2.07 & 20,000 & $0.15 \%$ & 1.30 & 1.80 \\
\hline $\begin{array}{l}\text { República de } \\
\text { Sudáfrica }\end{array}$ & $43,690,000$ & 12.53 & $1,820,000$ & $4.16 \%$ & 6.01 & 42.01 \\
\hline \multicolumn{7}{|c|}{$\begin{array}{l}\text { * Usuarios de Internet/Población = Tasa de penetración de Internet } \\
\text { † IDB Summary of Demographic Data, U.S. Census Bureau, Mayo 20, } 2000 . \\
\text { † Fawaz Jarrah, "Number of Internet Users in Arab Countries Edges towards Two Million”, DITnet, Marzo 7, } 2000 . \\
\S \text { Existen } 54 \text { naciones en África, pero debido a razones de espacio, no pudieron ser listadas todas. }\end{array}$} \\
\hline
\end{tabular}

Tomado de Appu Kuttan y Laurence Peters, From digital divide to digital opportunity (Lanham, Maryland: Scarecrow Press, 2003), 112. 


\section{La brecha digital y sus determinantes}

Figura 53

Penetración de Internet: comparación entre la República de Sudáfrica y otras naciones africanas

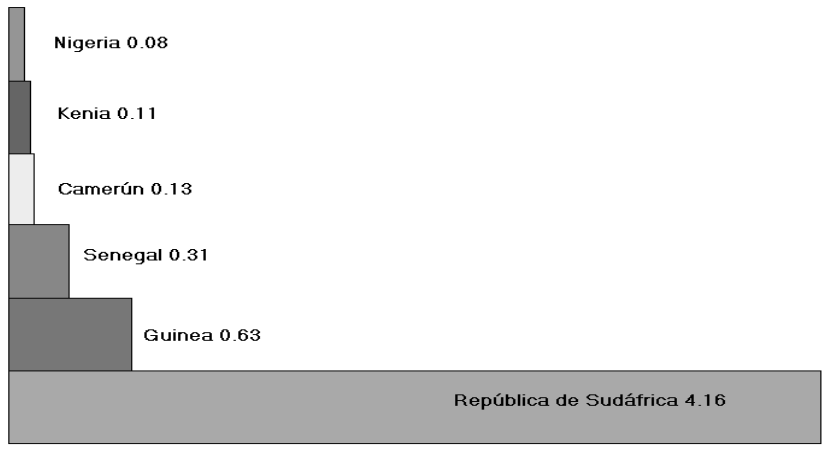

Figura 4.3. Penetración de Internet: comparación entre la Reública de Sudáfrica y otras naciones africanas

Tomado de Appu Kuttan y Laurence Peters, From digital divide to digital opportunity (Lanham, Maryland: Scarecrow Press, 2003), 112. 


\title{
Determinantes económicos de la brecha digital
}

\begin{abstract}
1 acceso a la información y a las tecnologías de la comunicación se ha convertido en un aspecto importante en la agenda del desarro- llo social y económico de la sociedad, enfatizando la disminución de la pobreza. Las tecnologías de la comunicación impactan la reducción de la pobreza mediante tres mecanismos principales: 1. al incrementar la eficiencia y la competitividad de la economía a escala mundial con impacto positivo en el crecimiento y en el desarrollo; 2 . al permitir que los servicios públicos, como los de salud y educación, lleguen a un número mayor de personas; y 3. al crear nuevas formas de ingreso y empleo en las poblaciones de menores recursos. ${ }^{1}$

Esta visión es importante ya que muchas de las acciones del Banco Mundial se basan en esos tres aspectos e impulsan el uso de recursos de comunicación e información cuando alguno de ellos se ve beneficiado. El Banco está especialmente interesado en lograr que los proyectos de incorporación de TIC tengan un impacto importante en la reducción de la pobreza mediante el acceso a la información y mediante la utilización de mecanismos variados, entre los que se encuentran:
\end{abstract}

1 Juan Navas-Sabater, Andrew Dymond, Niina Juntunen. Telecommunications and information services for the poor: toward a strategy for universal access (Washington, D. C.: Banco Mundial, 2002), ix. 
- Promover la integración al permitir terminar con el aislamiento de algunas comunidades, aislamiento que les impide incorporarse a la economía global;

- Promover la ganancia, la eficiencia y el crecimiento;

- Facilitar que los servicios públicos lleguen a las comunidades más alejadas y aisladas de los países ya que son especialmente importantes para romper el aislamiento de las comunidades rurales y promover su integración a las comunidades urbanas más desarrolladas. 2

Los aspectos económicos son relevantes en el estudio de la brecha digital, dado que constituyen o limitan la posibilidad de que las personas logren acceder a la TIC. Por otro lado, la habilidad en el uso de las computadoras e Internet contribuye a que quienes las utilizan puedan tener acceso a mejores empleos debido a su capacidad para trabajar con nuevas tecnologías.

\section{El ingreso económico como factor determinante de la brecha digital}

El ingreso económico es tal vez uno de los aspectos más importantes en la propagación de Internet. La Unión Internacional de Telecomunicación sostiene que en los países la iniquidad en el acceso y uso de Internet es probablemente dos veces mayor que la iniquidad en el ingreso económico, ${ }^{3}$ situación lastimera cuando se reconoce que una gran parte de la población mundial se alimenta, viste, educa y mantiene su salud con menos de un dólar al día.

2 Ibíd., 1-3.

3 International Telecommunication Union, Final report DRAFT (Ginebra: World telecommunication/ICT Indicators Meeting, 2003), citado por Wenhong Chen y Barry Wellman, Charting and bridging digital divides: comparing socio-economic, gender, life stage, and rural-urban Internet access and use in eight countries. Octubre 27, 2003, 4, disponible http://www.amd.com/us-en/assets/content _type/DownloadableAssets/FINAL_REPORT_CHARTING_DIGI_DIVIDES.pdf [Agosto 6, 2004]. 
Muchos países que carecen de los avances técnicos, de infraestructura y de capacidad institucional, se han visto rezagados del resto del mundo, el problema no es simplemente que la tecnología beneficia a los ricos sino que además impone más limites y penurias a los pobres. La brecha digital es la más reciente manifestación de la brecha tecnológica relacionada con la falta de acceso a las telecomunicaciones y la informática; en este sentido se puede decir que su antecedente es la brecha analógica que surge con la invención del teléfono y con los beneficios y privilegios que esta tecnología aporta a quien la posee. Para medir la brecha analógica se ha empleado como indicador la teledensidad, es decir la cantidad de teléfonos por cada 100 habitantes, e incluso se ha encontrado evidencia sobre la interrelación entre ésta y el producto interno de un país.

En la figura 54 se puede observar esta tendencia por continente. África, por ejemplo, con un PIB de 823 dólares, tiene 2.45 líneas telefónicas y .88 computadoras por cada 100 habitantes, mientras que Oceanía, con un PIB de 14, 336 dólares, tiene 40.29 líneas telefónicas y 42.71 computadoras por cada 100 personas según se aprecia.

Reddick y Boucher han señalado la relación que existe entre el acceso a Internet y los ingresos que recibe una persona. ${ }^{4}$ Esta relación nos indica que a mayor ingreso, es más factible ser usuario de la red; y a nivel general, mientras más alto es el promedio de ingresos de una sociedad, más usuarios tiene y, por lo tanto, al disminuir los ingresos, el número de usuarios decrece significativamente.

James, en su trabajo sobre cómo cerrar la brecha utilizando tecnología de la información de bajo costo, o bien con equipos que sean reciclados, ha observado la relación que existe entre ingreso económico y acceso a Internet. ${ }^{5}$ Con ayuda de la figura 55 se puede apreciar con toda claridad que a mayor ingreso, mayor cantidad de

4 A. Reddick y C. Boucher, Tracking the dual digital divide (Ekos Research Associates, 2002).

5 Jeffrey James, "Bridging the digital divide with low-cost information technologies", Journal of Information Science, 27, 4 (2001): 211-217. 
servidores de Internet, y que la población mundial está distribuida de manera inversamente proporcional al ingreso.

A diferencia de la figura 54, en que la división geográfica se hace por continente, James muestra la disponibilidad tecnológica de los países clasificándolos sobre la base de sus ingresos. Esta información, aunque corresponde a 1998, revela la enorme disparidad que existe entre los países pobres y los ricos no sólo con relación a los servidores de Internet sino en cuanto a población.

Figura 54

Comparación entre el PIB, líneas telefónicas y computadoras por continente

\begin{tabular}{|c|c|c|c|}
\hline & $\begin{array}{c}\text { PIB per cápita } \\
\text { (\$US) }\end{array}$ & $\begin{array}{l}\text { Líneas telefónicas por } \\
\text { cada } 100 \text { personas }\end{array}$ & $\begin{array}{l}\text { Computadoras por } \\
\text { cada } 100 \text { personas }\end{array}$ \\
\hline África & 823 & 2.45 & .88 \\
\hline Asia & 2,144 & 8.32 & 2.52 \\
\hline América & 14,178 & 33.13 & 21.34 \\
\hline Europa & 12,109 & 38.48 & 14.63 \\
\hline Oceanía & 14,336 & 40.29 & 42.71 \\
\hline
\end{tabular}

Tomado de Appu Kuttan y Laurence Peters, From digital divide to digital opportunity (Lanham, Maryland: Scarecrow Press, 2003), 107.

Figura 55

La brecha digital, 1998

\begin{tabular}{||l|c|c||}
\hline & $\begin{array}{c}\text { Servidores de internet } \\
\text { por 10,000 personas }\end{array}$ & $\begin{array}{c}\text { Porcentaje de la } \\
\text { población mundial }\end{array}$ \\
\hline Países de bajos ingresos & 0.1 & 31 \\
\hline Países de ingresos medios & 4.0 & 50 \\
\hline Países de ingresos altos & 739.0 & 19 \\
\hline
\end{tabular}

Tomado de Jeffrey James, "Bridging the digital divide with low-cost information technologies", Journal of Information Science, 27, 4 (2001): 211. 
Por otra parte, el Banco Mundial también ha contribuido con cifras sobre la concentración de los equipos de cómputo y las conexiones a Internet en países pobres y en países ricos, así, en su informe del año 1999 reportaba las cifras de la figura 56.

La figura 56 confirma una vez más la interrelación entre las condiciones económicas de los países y la disponibilidad de TIC, que a su vez inciden en el desarrollo económico de las naciones.

Evidentemente los países que integran una región geográfica presentan diferentes niveles de desarrollo económico, así en cada continente podemos identificar a las naciones con el más alto y el más bajo PIB, para después establecer su teledensidad y la disponibilidad de computadoras como ocurre en la figura 57.

La figura 57 manifiesta la enorme disparidad que existe entre el ingreso económico de las naciones dentro de un mismo continente; cualquiera que sea el PIB de la nación más "rica”, la nación más "pobre" está por debajo de la primera en promedio un 90 por ciento. Las cifras relacionadas con la teledensidad también denotan un atraso significativo en las naciones pobres, pero la diferencia se hace aún más evidente cuando se analiza la disponibilidad de computadoras ya que si comparamos a los países ricos con los pobres, estos últimos están por debajo de los primeros hasta en un 95 por ciento.

Las diferencias a que nos hemos referido no sólo son observables entre continentes y países, también lo son entre los distintos estratos sociales que integran una nación. En Estados Unidos, por ejemplo, en el año 2000 más del 60 por ciento de los hogares que tenían un ingreso anual superior a los 35 mil dólares estaban conectados a la red, mientras sólo un 42 por ciento de los hogares con ingresos de $15 \mathrm{mil}$ dólares lo estaban. ${ }^{6}$ Esto es una diferencia de 18 puntos porcentuales, como se aprecia en la figura 58.

6 Chen y Wellman, 8. 


\section{La brecha digital y sus determinantes}

Figura 56

Distribución de computadoras y servidores por cada 1000 habitantes

\begin{tabular}{||l|c|c||}
\hline & Regiones menos desarrolladas & Regiones más desarrolladas \\
\hline Computadoras & 12.3 & 269.4 \\
\hline Servidores de Internet & 3.08 & 470.12 \\
\hline
\end{tabular}

Adaptado de Banco Mundial, Entering the 21st century: world development report 1999/2000: changing the world (Washington, D.C.: Oxford University Press, 1999) p, 267.

Figura 57

Líneas telefónicas y computadoras a nivel regional, naciones industrializadas vs. naciones en desarrollo

\begin{tabular}{|c|c|c|c|}
\hline & $\begin{array}{l}\text { PIB per cápita } \\
\text { (\$US) }\end{array}$ & $\begin{array}{l}\text { Líneas telefónicas por cada } \\
100 \text { personas }\end{array}$ & $\begin{array}{c}\text { Computadoras por cada } 100 \\
\text { personas }\end{array}$ \\
\hline \multicolumn{4}{|l|}{ África } \\
\hline Sudáfrica* & 3,107 & 13.77 & 6.01 \\
\hline Camerún & 664 & 0.66 & 0.27 \\
\hline \multicolumn{4}{|l|}{ Asia } \\
\hline Japón & 30,105 & 55.75 & 28.69 \\
\hline Filipinas & 898 & 3.88 & 1.64 \\
\hline \multicolumn{4}{|l|}{ América } \\
\hline Estados Unidos & 32,198 & 66.4 & 51.05 \\
\hline El Salvador & 1,984 & 7.61 & 2.01 \\
\hline \multicolumn{4}{|l|}{ Europa } \\
\hline Alemania & 26,214 & 58.79 & 29.69 \\
\hline Moldavia & 430 & 12.68 & 0.8 \\
\hline \multicolumn{4}{|l|}{ Oceanía } \\
\hline Australia & 18,879 & 51.97 & 47.06 \\
\hline Fiji & 2,002 & 10.11 & 5 \\
\hline
\end{tabular}

Tomado de Appu Kuttan y Laurence Peters, From digital divide to digital opportunity (Lanham, Maryland: Scarecrow Press, 2003), 107. 
Figura 58

Proporción de hogares estadounidenses con acceso a Internet por nivel de ingreso económico

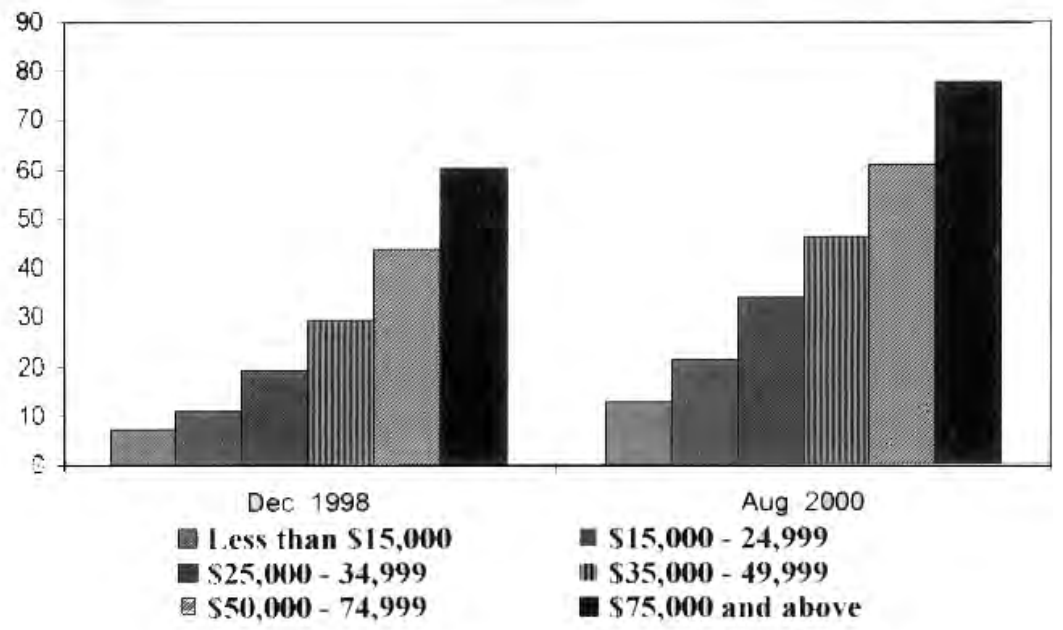

Figure 1.3. Percent of households with Internet access, by income level.

Tomado de Appu Kuttan y Laurence Peters, From digital divide to digital opportunity (Lanham, Maryland: Scarecrow Press, 2003), 25.

Esta pauta parece ser uniforme en todas las sociedades. Las clases más adineradas tienen acceso a Internet, especialmente desde la casa. Los de menores ingresos tienen que recibir los servicios que proporcionan las escuelas y las bibliotecas públicas, para tener acceso.

El Banco de la Reserva Federal de San Francisco encontró también una relación entre el uso de las computadoras y los salarios. En aquellos lugares donde el uso de las tecnologías de la información es mayor, los habitantes tienen ingresos mayores $^{7}$ como lo demuestra la figura 59.

7 Banco de la Reserva Federal de San Francisco, "Is there a digital divide?", FRBSF Economic Letter, 38, diciembre 26, 2003, disponible http://www.frbsf.org/publications/economics/letter/2003/el2003-38.html [Agosto 30, 2005]. 
Figura 59

Proporción del uso de computadoras en el hogar.

B. Por ingreso familiar

B. By family income (s)

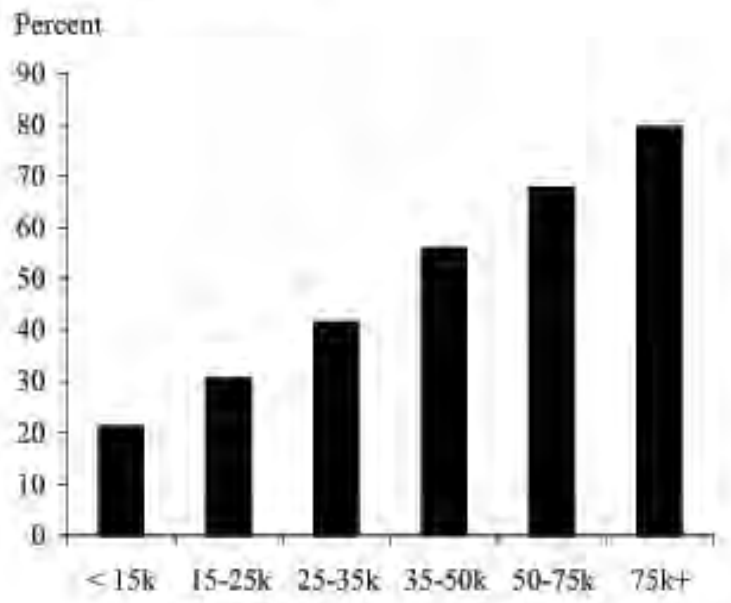

Tomado de Banco de la Reserva Federal de San Francisco, "Is there a digital divide?", FRBSF Economic Letter, 38, diciembre 26, 2003, disponible http://www.frbsf.org/publications/ economics/letter/2003/el2003-38.html [Agosto 30, 2005].

Los datos indican que el empleo de computadoras en Estados Unidos está bastante extendido, con el $\mathbf{5 4 . 5}$ por ciento de la población de tres años y más que usa computadora en casa; el mismo porcentaje de trabajadores la usa en el trabajo y el 84.8 por ciento de los jóvenes de 17 años y menores que asisten a la escuela usa computadora en ese recinto. La encuesta arrojó como resultado global que el 76.5 por ciento de los estadounidenses usan computadora en uno o más lugares; esta cifra aumentó, ya que en 1998 fue del 42 por ciento. Las cifras correspondientes a 2002 que presenta el Banco de la Reserva Federal de San Francisco difieren de las del Departamento de Comercio debido a la forma en que se recolectó la información. ${ }^{8}$

8 Ibíd., 1-2. 
El ingreso económico es un factor importante en la brecha digital en el Reino Unido. En ese país, por ejemplo, la brecha digital entre quienes tienen mayores ingresos y aquellos que tienen menores no ha desaparecido, al contrario, se ha incrementado:

La brecha en el uso de Internet entre los grupos que tienen los más altos ingresos y los que tienen los ingresos más bajos ha aumentado en los últimos años. En 1999 la diferencia era de 29 puntos, para 2000 había aumentado a 42, en 2001 se incrementó a 64 y el último dato con que se cuenta nos indica que en 2002 era de 69 puntos. 9

La información anterior es preocupante porque pareciera que en el Reino Unido, no obstante todos los esfuerzos que se hacen para dotar a los ciudadanos de nuevas posibilidades para usar la red, y con ello lograr la disminución de la brecha, ésta no sólo no se cierra, sino que parece ensancharse.

En Alemania las características de quienes se conectan a Internet siguen una pauta similar a la de otros lugares; en particular, los primeros usuarios fueron quienes tenían un nivel más alto de educación, así como un mayor ingreso.

En Italia la posesión de computadoras y el acceso a Internet establece una diferencia muy importante entre las personas que tienen una mejor educación y mayor nivel económico. En 2000, el 62 por ciento de los hogares italianos donde la cabeza de familia poseía educación universitaria tenía una computadora y de ellos el 59 por ciento utilizaba la Internet. Sin embargo, la diferencia entre quienes no tienen esos niveles es dramática: de aquellos que poseen el nivel primario de educación sólo el siete por ciento posee computadora y apenas el cuatro por ciento tiene acceso a la red. Aunque la diferen-

9 UK Cabinet Office, UK online annual report 2002, disponible http://archive.cabinetoffice.gov.uk/e-envoy/reports-annrep-2002/\$file/indexpage.htm. Citado por Wenhong Chen y Barry Wellman, Charting and bridging digital divides: comparing socio-economic, gender, life stage, and rural-urban Internet access and use in eight countries, octubre 27, 2003, 10, disponible http://www.amd.com/us-en/ assets/content_type/DownloadableAssets/FINAL_REPORT_CHARTING_DIGI_DIVIDES .pdf [Agosto 6, 2004]. 
cia es presentada en términos educativos, está asociada con el ingreso, la riqueza, el estatus laboral y los niveles de ocupación. ${ }^{10}$

$\mathrm{Al}$ referirse al caso asiático, Kuttan y Peters optan por dividir al continente en tres segmentos según su nivel de desarrollo (figura 60 ): el primero corresponde a las naciones desarrolladas que poseen una sólida infraestructura en telecomunicaciones (tigres); el segundo corresponde a naciones de mediano desarrollo (gatos), y el tercero a las naciones en desarrollo (gatitos).

En Japón, como en casi todos los países, entre mayor es el ingreso económico, mayor es el acceso a Internet. En 2001, cerca del 50 por ciento de los hogares que tenían un ingreso de ocho millones de yenes (aproximadamente 70 mil dólares) o más, tenían acceso a la red, mientras que la cuarta parte de quienes tenían un ingreso de dos millones (aproximadamente 17,500 dólares) estaban conectados, observándose una brecha de 25 puntos porcentuales. ${ }^{11}$

Entre quienes más ganan en Corea, es decir, aquellos que al menos obtienen dos mil dólares mensuales y quienes no, existe una diferencia importante. El 70 por ciento de quienes ganan dos mil dólares mensuales tienen conexión a Internet, mientras que de aquellos que ganan 1 250, sólo están conectados el 37 por ciento. ${ }^{12}$ En este país, que tiene uno de los crecimientos más acelerados en acceso a Internet, el mayor problema es la falta de habilidades para hacer usos efectivos de Internet. De acuerdo con la Oficina Nacional de Estadística de Corea, el 60 por ciento de los habitantes de ese país eran analfabetos computacionales en 1997. En otra encuesta que se realizó en 2000, se encontró que el 46 por ciento de los coreanos carecen de conocimientos sobre computadoras y de cómo navegar en la red.

En general, la población en China tiene ingresos económicos muy bajos pero a pesar de ello esta situación no ha tenido un impacto catastrófico en el acceso a Internet debido a que los chinos emplean

10 Chen y Wellman, 14.

11 Ibid., 15-16.

12 Ibid., 18. 
Figura 60

Tigres asiáticos de Internet... y gatos... y gatitos

\begin{tabular}{|c|c|c|c|c|c|}
\hline & Población & $\begin{array}{l}\text { PIB per } \\
\text { cápita }\end{array}$ & $\begin{array}{l}\text { Usuarios } \\
\text { de Internet }\end{array}$ & $\begin{array}{c}\text { Tasa de pe- } \\
\text { netración de } \\
\text { Internet* }^{*}\end{array}$ & $\begin{array}{c}\text { Computado- } \\
\text { ras por } 100 \\
\text { personas }\end{array}$ \\
\hline \multicolumn{6}{|l|}{ Tigres } \\
\hline Hong Kong & $6,800,000$ & 23,593 & $1,734,000$ & $25.5 \%$ & 29.05 \\
\hline Japón & $126,920,000$ & 34,377 & $18,300,000$ & $14.4 \%$ & 28.69 \\
\hline Corea del Sur & $47,300,000$ & 8,685 & $6,823,000$ & $14.4 \%$ & 18.29 \\
\hline Taiwán & $22,260,000$ & 13,392 & $4,540,000$ & $20.3 \%$ & 18.07 \\
\hline \multicolumn{6}{|l|}{ Gatos } \\
\hline China & $1,278,000,000$ & 782 & $8,900,000$ & $0.6 \%$ & 1.22 \\
\hline Malasia & $23,260,000$ & 3,607 & $1,500,000$ & $6.4 \%$ & 6.87 \\
\hline Tailandia & $60,620,000$ & 2,038 & 800,000 & $1.3 \%$ & 2.27 \\
\hline Filipinas & $75,330,000$ & 1,030 & 500,000 & $0.66 \%$ & 1.69 \\
\hline \multicolumn{6}{|l|}{ Gatitos } \\
\hline Indonesia & $212,090,000$ & 675 & 400,000 & $0.18 \%$ & 0.91 \\
\hline Camboya & $13,100,000$ & 196 & 4,000 & $0.03 \%$ & 0.12 \\
\hline Laos & $5,430,000$ & 276 & 2,000 & $0.03 \%$ & 0.23 \\
\hline Myanmar & $47,750,000$ & 5,504 & 500 & $0.001 \%$ & 0.11 \\
\hline Vietnam & $79,830,000$ & 363 & 100,000 & $0.12 \%$ & 0.89 \\
\hline
\end{tabular}

Tomado de Appu Kuttan y Laurence Peters, From digital divide to digital opportunity (Lanham, Maryland: Scarecrow Press, 2003), 114.

equipo y recursos públicos para acceder a ésta. El 44 por ciento de los usuarios de Internet tienen un ingreso mensual menor a los 1000 yuanes (125 dólares) y un 17 por ciento adicional no tiene ingreso. Sin embargo, la importancia del ingreso económico en el acceso a Internet está distorsionada ya que el 28 por ciento de los usuarios de Internet son a menudo estudiantes de bajos recursos que acceden a la red en laboratorios de cómputo, universidades y escuelas.

Pero Asia también incluye otras naciones que están por debajo de lo que puede decirse es el "nivel regular del continente", como puede observarse en la figura 61. 
Figura 61

Países asiáticos por debajo del nivel regular del continente

\begin{tabular}{||l|c|c|c|c|c||}
\hline \hline & Pablación & PIB per cápita & $\begin{array}{c}\text { Usuarios de } \\
\text { Internet }\end{array}$ & $\begin{array}{c}\text { Tasa de penetra- } \\
\text { ción de Internet* }\end{array}$ & $\begin{array}{c}\text { Computadoras } \\
\text { por } 100 \text { personas }\end{array}$ \\
\hline Bangladesh & $137,440,000$ & 279 & 30,000 & $0.02 \%$ & 0.1 \\
\hline Bután & 680,000 & 624 & 500 & $0.07 \%$ & 0.46 \\
\hline India & $1,012,400,000$ & 435 & $2,000,000$ & $0.19 \%$ & 0.33 \\
\hline Nepal & $23,040,000$ & 222 & 35,000 & $0.15 \%$ & 0.26 \\
\hline Pakistán & $141,260,000$ & 458 & 80,000 & $0.05 \%$ & 0.43 \\
\hline Sri Lanka & $18,920,000$ & 846 & 65,000 & $0.34 \%$ & 0.56 \\
\hline * Usuarios de Internet/Población = tasa de penetración de Internet & & \\
\hline
\end{tabular}

Tomado de Appu Kuttan y Laurence Peters, From digital divide to digital opportunity (Lanham, Maryland: Scarecrow Press, 2003), 116.

Por otra parte, en Egipto, con un ingreso per cápita de 120 dólares por mes, pocas familias pueden pagar el costo de la computadora, que es de un poco más de 500 dólares americanos, y mucho menos gastar 15 dólares de acceso mensual a Internet. Como puede verse, en estas circunstancias el acceso a la TIC es difícil y la situación de Egipto no es única. Si se desea contar con un correo electrónico, aunque hay algunos de capacidad reducida disponibles de manera gratuita, es necesario pagar para disponer de un mayor espacio, y si además incluimos el costo de un antivirus, se puede concluir que las condiciones de ingreso económico, como factor en la brecha digital, son importantes.

En 1998 se dieron a conocer los siguientes datos: en Sudáfrica, los usuarios de Internet tenían un ingreso económico siete veces superior al ingreso promedio nacional; en Bangladesh una persona tenía que gastar el ingreso total de ocho años para poder comprar una computadora, comparado con el ingreso promedio de un mes que se necesitaba en Estados Unidos. ${ }^{13}$

13 Servon, 43. 
No hay información sobre las características económicas de los usuarios de Internet en México, pero se puede suponer que éstos se encuentran localizados entre las capas de mayores ingresos. El porcentaje de usuarios de Internet es muy bajo y según las fuentes utilizadas varía, pero de acuerdo con el Instituto Nacional de Estadística, Geografía e Informática (INEGI), en el 2004 el 14.1 por ciento de la población de seis años y más utilizaba Internet. ${ }^{14}$

Respecto al ingreso económico de los mexicanos que utilizan computadora, se dispone de las cifras correspondientes a 1996, 1998, 2000 y 2002, según las cuales la relación entre ingresos y hogares con computadora es la que se ilustra en la figura 62.

Como se puede observar, en todos los años que integran la gráfica, los hogares con ingresos de cero a cuatro salarios mínimos son quienes tienen menos computadoras. Posiblemente hablar en términos de salarios mínimos no sea tan significativo como hablar en pesos y centavos, así entonces conviene decir que en 1996 el ingreso anual correspondiente a cuatro salarios mínimos fue de 33203 pesos, en 1998 llegó a los 46540 pesos, en 2000 a 54576 pesos y en 2002 a 60696 pesos (aproximadamente 6277 dólares); pero no se debe olvidar que hablamos de un rango de cero a cuatro salarios mínimos, así que con seguridad hubo hogares que percibieron mucho menos que las cantidades indicadas.

En el extremo contrario está el estrato de los 32.01 salarios mínimos y más, que durante 1996 y 2000 fue el que más computadoras tuvo, el 20.2 y el 20.06 por ciento respectivamente, retrocede un poco en 1998 y de manera sensible en 2002, llegando al 16.1 y 9 por ciento cada uno. La diferencia en las percepciones es enorme, ya que se estima que 32.01 salarios mínimos en 1996 fueron 265734 , en 1998, 372 442, en 2000, 436744 y en 2002, 485719 pesos.

14 INEGI, Población de seis años y más usuaria de las tecnologías de la información, 2001, 2002 y 2004, disponible http://www.inegi.gob.mx/est/contenidos/ espanol/rutinas/ept.asp?t $=\operatorname{tinf} 204 \& \mathrm{c}=5577$ [Agosto 2, 2005]. 
Figura 62

Hogares mexicanos con computadora por

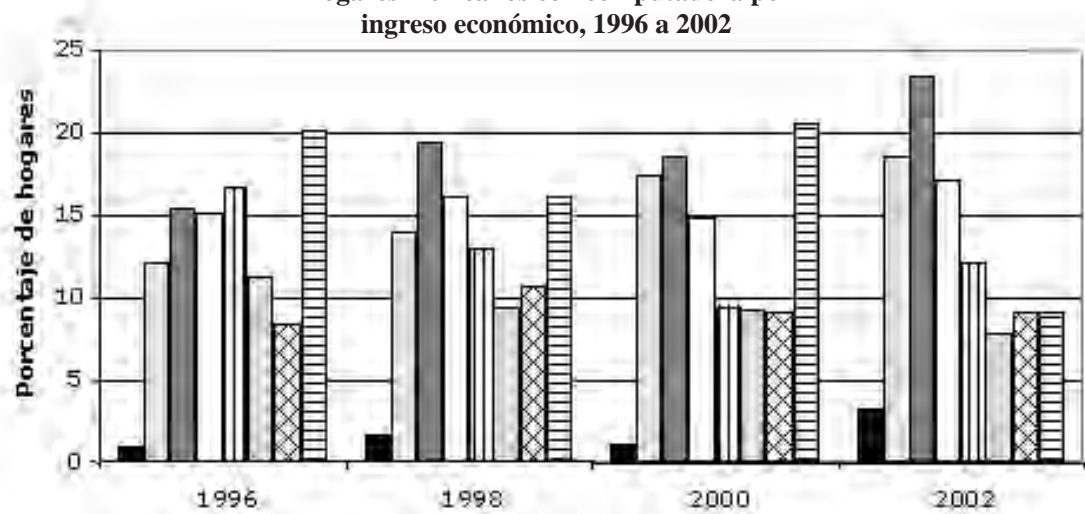

Salarias Mínimos

- De 00,00 a 04,00 $\square$ De 04,01 a 0800 a De 08,01 a 12,00 $\square$ De 12,01 a 16,00 MDe 16,01 a 20,00 पDe 20,01 a 24,00 四 De 24,01 a 32,00 日 De 32, 01 y más

Adaptada de INEGI, Hogares con computadora por estrato de ingreso, 1996 a 2002, disponible en http://www.inegi.gob.mx/est/contenidos/espanol/rutinas/ept.asp?t=tinf038\&c=3462 [Enero 10, 2006].

Nótese además que son tres los grupos que han mostrado cierta continuidad en su crecimiento a lo largo de los años que componen la serie. Estos grupos se ubican entre 4.01 y 20 salarios mínimos, aunque el de mayor crecimiento es aquel de 8.01 a 12 salarios mínimos (de los 12 a los 18 mil dólares aproximadamente en 2002).

\section{El costo de la computadora y la suscripción a Internet}

El problema económico no se relaciona sólo con el costo de la computadora. El ejemplo de lo extendido que está el uso de la televisión entre pobres y ricos nos lleva a pensar que con el ingreso a la red pueda suceder algo parecido. En el uso de la televisión el mayor costo es el aparato mismo, posteriormente tiene un cargo si se selecciona recibir el servicio de la televisión por cable y el pago por evento. Pero la televisión abierta proporciona productos similares a la televi- 
sión de paga: programas de diversión, noticiarios, películas, telenovelas, espectáculos, eventos deportivos, entre otros, sin gastos adicionales. En el caso de Internet, tener acceso a una computadora no es suficiente, hay que agregar el costo de conexión y los gastos que han de hacerse en mantenimiento, equipo periférico, paquetes de programación (software), administración, planeación y en entrenamiento (éste último, posiblemente el más importante). ${ }^{15}$ Además se debe considerar el corto periodo de vigencia de los equipos y el alto grado de obsolescencia de los programas, lo que no sucede con otras tecnologías como es el caso de la televisión.

En los medios de información y comunicación convencionales, como la radio y la televisión, bastaba con que el usuario realizara el pago por el dispositivo de acuerdo con las características del mismo y un esquema de precios que fijaba por lo general el productor; no era indispensable la adquisición de equipo adicional para operar los aparatos ni para recibir información, con excepción del servicio de televisión por cable. En este último caso, quien deseaba obtener el servicio de televisión cerrada, además del costo del aparato receptor, debía considerar el precio de la suscripción al servicio.

Sin embargo, el empleo de la tecnología de información y comunicación incluye diversos costos, entre los que se encuentran: a) el costo del equipo de cómputo, que dependerá de su grado de sofisticación y de los dispositivos periféricos; b) los costos relacionados con la disponibilidad de una línea telefónica que vinculada con un módem constituyan la infraestructura para lograr una conexión a la red, o en su defecto el empleo de banda ancha, que permite realizar la conexión y mantener disponible al mismo tiempo la línea telefónica; c) los costos de la suscripción a Internet, que varían según el proveedor del servicio; y d) los costos de la producción de la información y su incorporación a un formato digital. Los costos del teléfono y de la suscripción a Internet son mensuales y permanentes hasta que se les cancela, se haga o no uso de ellos.

15 Warschauer, Technology, 7. 
Figura 63

Disminución del precio de la computadora “modelo básico”

\begin{tabular}{||c|c|c||}
\hline & Precio & Cambio anual \\
\hline 1996 & $\$ 1,747.00$ & \\
\hline 1997 & $\$ 1,434.00$ & $\$ 313.00$ \\
\hline 1998 & $\$ 1,139.00$ & $\$ 295.00$ \\
\hline 1999 & $\$ 916.00$ & $\$ 223.00$ \\
\hline \multicolumn{2}{|l|}{ Fuente: PC Data, Inc, 2000. } \\
\hline
\end{tabular}

Tomado de Adam D. Thierer, "How free computers are filling the digital divide", The Heritage Backgrounder, disponible en http://www.heritage.org/ResearchandTechnology/BG1361.cfm [Diciembre 13, 2005].

En un principio, el costo de las computadoras era el elemento que limitaba el acceso a la red, pero a pesar de que durante los últimos años ha disminuido y ahora es considerado "bajo", sólo un grupo pequeño de personas están en condiciones de adquirir un equipo de cómputo. El decremento en el costo de las computadoras que se continúa experimentando abre la posibilidad de que en un futuro más y más personas puedan navegar en la red.

Así, por ejemplo, Thierer ${ }^{16}$ nos ofrece la figura 63 con información sobre la disminución del precio de la computadora "modelo básico" sin especificar cuáles son las características técnicas de ese equipo, que además pueden variar en forma significativa ya que como él mismo señala, según la Ley de Moore, el poder de los microprocesadores se duplica cada 18 meses.

Mientras que las primeras computadoras costaban miles de dólares, incluso millones, en la actualidad se puede obtener una computadora personal de gran rapidez, velocidad de proceso y capacidad de almacenamiento, que no se pensó pudiera existir hace 10 años. El precio de estos nuevos equipos de cómputo es de unos cuantos cien-

16 Adam D. Thierer, "How free computers are filling the digital divide", The Heritage Backgrounder 1361 (Abril 20, 2000). 
Figura 64

Precio promedio de una computadora personal, modelo básico, en Estados Unidos, 1996-2002

\begin{tabular}{|c|c|c||}
\hline \hline \multicolumn{3}{|l|}{$\begin{array}{l}\text { Tabla 3.4 } \\
\text { Precio promedio de una computadora personal, modelo básico, en } \\
\text { los Estados Unidos, 1996-2002 }\end{array}$} \\
\hline Año & Precio (USD) & $\begin{array}{c}\text { Decremento } \\
\text { anual (USD) }\end{array}$ \\
\hline 1996 & $\$ 1,747$ & -- \\
\hline 1997 & $\$ 1,434$ & $-\$ 313$ \\
\hline 1998 & $\$ 1,139$ & $-\$ 295$ \\
\hline 1999 & $\$ 916$ & $-\$ 223$ \\
\hline 2002 (estimado) & $\$ 577$ & \\
\hline Fuente: Adaptado de Thierer (2001). \\
\hline
\end{tabular}

Tomado de Mark Warschauer, Technology and social inclusion: rethinking the digital divide

(Cambridge, Mass.: MIT Press, 2003), 62.

tos de dólares y se pueden optimizar con un costo aproximado a los mil dólares americanos, adquiriéndose un equipo de gran capacidad para los estándares de $1990 .{ }^{17}$

En muy poco tiempo los precios pasaron de más de mil 500 dólares a una tercera parte de esa cantidad; en la figura 64 que se presenta arriba, podemos ver cómo en 1996 el costo era de mil 747 dólares y que en el año 2002 se estimaba en 577 dólares. Los precios se han mantenido a la baja, ampliando la posibilidad de encontrar computadoras y equipos periféricos mucho más económicos. Aunque los precios han descendido en los países en desarrollo, no lo han hecho en la misma proporción que en los países desarrollados.

Hoy en día una persona puede encontrar un equipo de cómputo razonablemente bueno por casi 450 dólares. Cuando se comparan los recursos que es necesario invertir en la adquisición de un equipo de cómputo y aquellos para adquirir un televisor, podemos observar

17 Kuttan y Peters, 61. 
que ambos se han reducido, pero los precios de las computadoras han descendido en forma más rápida y por tanto la diferencia entre uno y otro es cada vez menor.

El descenso en el costo de los equipos de cómputo ha sido inversamente proporcional a la capacidad de los equipos. En 1980 un gigabyte de almacenamiento costaba varios cientos de miles de dólares y ocupaba una habitación. En la actualidad cabe en una tarjeta de crédito y cuesta una fracción del precio que se tenía que pagar hace veinte años. ${ }^{18}$

De la misma forma, el costo del acceso a Internet ha descendido, reduciendo con ello la restricción económica de la conexión, e incluso se han abierto algunas posibilidades de acceso gratuito. Por acceso gratuito no nos referimos a la disponibilidad de equipos de cómputo e Internet en lugares públicos como universidades, bibliotecas públicas, oficinas, sino a proveedores de acceso gratuito como Address.com, AltaVista o BlueLight, mencionados por Thierer. ${ }^{19}$

En un principio el uso de Internet fue casi gratuito:

El uso de Internet solía ser un poco como la comuna de HaightAshbury, en donde todo lo esencial era gratuito, nos dice Charles Ardai, ejecutivo principal de Juno Online Services. En la actualidad se está convirtiendo cada vez más en el Manhattan de 2001, en donde se tiene que pagar por las cosas que más se desean.20

Y los usuarios que no pueden pagar por los servicios, caen inmediatamente en el lado negativo de la brecha.

Sólo el 25 por ciento de las familias que ganan menos de 30 mil dólares al año tienen una computadora, en contraste con el 80 por ciento de los hogares que tienen una computadora y un ingreso superior a los 100 mil dólares anuales.

18 Norris, Digital divide, 8.

19 Thierer, "How free computers are filling the digital divide".

20 Kuttan y Peters, 21. 
Sólo 22 por ciento de los niños cuyas familias tienen un ingreso de menos de 20 mil dólares al año tienen una computadora en su casa, comparado con 91 por ciento de los niños cuyas familias ganan más de 75 mil dólares anuales. 21

Las naciones ricas como Norteamérica y Europa abruman a las regiones pobres como África y Asia del Sur en relación al acceso a Internet. Las estadísticas prueban que las naciones como Estados Unidos y Japón, que tienen solamente el 20 por ciento de la población total del mundo, disfrutan del 86 por ciento del ingreso de la población mundial y tienen el 91 por ciento de los usuarios de Internet. En el lado opuesto, el 20 por ciento de la población mundial vive en las naciones más pobres, como Etiopía y Laos y tienen tan sólo el uno por ciento del ingreso y del uso de Internet.22

Hablar de la disminución de costos implica cierta relatividad determinada por la capacidad de los bolsillos, por ello muchas personas aún consideran que la conexión a Internet es demasiado costosa y por esta razón no poseen una. El Pew Internet Project y la Kaiser Foundation realizaron una encuesta y encontraron que el 39 por ciento de las personas sostienen que el precio de Internet es demasiado elevado. ${ }^{23}$

- Los países con ingresos económicos elevados tienen el 16 por ciento de la población mundial y el 90 por ciento de los servidores de Internet.

- La ciudad de Nueva York tiene más líneas telefónicas que todo el continente africano.

- Hay casi 30 computadoras por cada 100 personas en el Reino Unido; en Malawi hay una computadora por cada 10,000 personas. 24

En una cita que se ha repetido muchas veces, Bill Gates, poniendo en perspectiva la brecha digital, afirmó que la mayoría de la población mundial nunca ha usado un teléfono, ya no digamos Internet, y que el 80 por ciento de las personas que habitan el planeta viven con menos

21 Ibíd., 25.

22 Ibid., 109.

23 Ibíd., 61.

24 Ibid., 106. 
de un dólar al día. ¿Tienen los norteamericanos una idea de lo que significa vivir con menos de un dólar al día?25

Por poner un ejemplo de los costos que pueden estar asociados a la posesión de la computadora, diremos que el precio del sistema operativo dominante (Windows) y del paquete de trabajo también más popular (Office), están por arriba del ingreso anual de muchos de los habitantes de los países en desarrollo. ${ }^{26}$

Los costos varían grandemente de un país a otro y muchas veces los más bajos no se encuentran en los países más pobres sino al contrario, son más elevados; así, por ejemplo Warschauer hace referencia a datos de la OCDE según los cuales el paquete de acceso a Internet, que consiste de una línea telefónica, cuarenta horas de uso durante horas pico y una cuenta de Internet, tiene una variación tan grande que mientras en Estados Unidos cuesta 25 dólares, en la República Checa cuesta $175 .^{27}$

McNair sostiene que es necesaria la intervención del Estado para que el uso de las tecnologías de la información no produzca una división social mayor que la que ya existe. Si el Estado se mantiene al margen de la política de las tecnologías de la información, el acceso sencillo para los ricos les permitirá que cada vez sean más ricos y que en el futuro puedan incorporar nuevas tecnologías a sus actividades diarias. Tal es el caso de quienes cuentan con una buena educación y se benefician en mayor medida de las oportunidades de educación continua que ofrece la sociedad, y por lo tanto son ellos los que tienen mayores oportunidades de ascender en la escala social.

25 Manny Frischberg, "Gates: poor need meds, not PCs”, Wired News, Octubre 19, 2000, citado por Appu Kuttan y Laurence Peters, From digital divide to digital opportunity (Lanham, Maryland: Scarecrow Press, 2003), 115.

26 Warschauer, Technology, 64.

27 Ibid., 70. 
En suma, aquellos que cuentan con las posibilidades de mayor información, son cada vez más ricos en estas posibilidades, mientras que los que no cuentan con esa educación informacional son cada vez más pobres. 28

El costo de conexión es un elemento importante para enlazarse a la red. Los costos varían de un país a otro y pueden representar una parte pequeña del ingreso mensual o llegar a significar un porcentaje tan alto que resulte prohibitivo. En este caso, para poder conectarse a Internet se tendría que dedicar una parte importante del ingreso mensual o incluso el de varios meses para cubrir el costo de suscripción. En Estados Unidos el costo de un mes de conexión es del 1.2 por ciento del ingreso mensual, en Bután se eleva al 80 por ciento del ingreso promedio de cada mes y en Nepal se requiere el 278 por ciento, esto es, casi tres meses del ingreso promedio mensual. ${ }^{29}$

Norris sugiere que el desarrollo económico es el factor principal que impulsa el acceso a las tecnologías digitales, así que Internet refleja y refuerza las iniquidades tradicionales entre las sociedades ricas y pobres. 30

El desarrollo económico explica en gran medida el acceso a Internet entre los distintos estratos sociales, los países y los continentes, pero no puede ser considerado como el único ni el más importante de los factores que determinan la brecha digital. La brecha digital también debe ser considerada en función del desarrollo del capital humano o social vinculado con los niveles educativos, la participación ciudadana y los derechos humanos. Norris ha tratado de explicar la forma en que la tecnología se ha esparcido, estableciendo la correlación entre estos aspectos mediante la figura 65.

28 McNair, 10.

29 Servon, 43.

30 Norris, Digital divide, 15. 
Internet ha transformado a la sociedad de múltiples modos, por ejemplo, en 1998 el Correo de los Estados Unidos repartió solamente 101 billones de piezas mientras los estadounidenses enviaron un estimado de 4 trillones de correos electrónicos en el mismo periodo. El correo electrónico se ha convertido en un medio de comunicación fundamental, con un total de 42 por ciento de personas usándolo diariamente. Más aún, la mitad de las llamadas telefónicas que se hacen en Estados Unidos se realizan usando Internet. ${ }^{31}$

\section{El caso de los Estados Unidos}

El uso de los recursos digitales en Estados Unidos es posiblemente el más conocido y difundido, y aunque no nos explica el comportamiento de éste en un ambiente diferente, sí nos ayuda a comprender el fenómeno; la causa es que desde que se inició el uso de la red, los estadounidenses se dieron a la tarea de recopilar información. El camino andado por Estados Unidos ha sido de interés para algunos países que han seguido este modelo para recolectar información en tanto que otros han decidido hacerlo de diferente manera. Actualmente la diversidad de las formas empleadas en la extracción de los datos relativos a la brecha digital, hace muy difícil que éstos puedan ser comparados debido a su falta de normalización.

El gobierno de los Estados Unidos ha dividido en dos grupos a los ciudadanos respecto del uso que hacen de Internet: el primero se compone de aquellos que tienen acceso a la red, y el segundo de aquellos que no tienen acceso. En este país, dada la forma en que se integra la sociedad, es difícil hacer una generalización sobre la población usuaria de Internet ya que las etnias juegan un papel muy importante. A diferencia de Estados Unidos, en sociedades más homogéneas el planteamiento no se basa tanto en las etnias como en

31 Kuttan y Peters, 11. 
las clases sociales a las que se pertenece o a los niveles de ingreso económico. ${ }^{32}$

A marzo de 2003, más de la mitad de la población de los Estados Unidos estaba en línea, un crecimiento de 26 millones de usuarios en 13 meses permitió llegar a la mitad de la población, y si bien es cierto que el número de usuarios ha aumentado, también lo es que muchos de los usuarios no estaban conectados por distintas razones, pero la capacidad económica no era el principal impedimento. ${ }^{33}$

Debido al volumen de información sobre la brecha digital estadounidense y su detalle de descripción, se ha considerado conveniente, a fines de ejemplificar la influencia del factor económico, incluir los datos estadísticos que permiten observar con mayor claridad la correlación entre ingreso económico y uso de TIC.

En la figura 66 se presenta el porcentaje de hogares norteamericanos que disfrutaban de computadora en 1998, dividido por raza e ingreso económico. La figura muestra una clara correlación entre el nivel de ingreso y la posesión de una computadora, con tendencia al cierre de la brecha entre grupos étnicos en el nivel de ingresos más alto. En contraste, los afroamericanos y los hispanos de menores ingresos son quienes menos computadoras poseen con relación a los blancos y otros grupos no hispanos.

El porcentaje de hogares estadounidenses que usaban Internet en 1998 se divide por raza y por ingreso en la figura 67, y en este caso, como en algunos otros, se observa una estrecha relación entre el nivel de ingreso y el uso de Internet. En esta figura se exhiben las mismas características que se observaron entre los propietarios de una computadora, es decir la brecha cerrándose en los niveles de ingresos más altos. Independientemente del nivel de ingresos, los hispanos y los afroamericanos presentan el índice más bajo en el uso de Internet, aunque en los grupos con menores ingresos la diferencia es impresionante.

32 Simon Applebaum, "Facing the digital divide", News Multichannel, disponible en http://www.multichannel.com/index.asp?layout $=$ article \&display $=$ Archives $\&$ articleid=CA59445 [Diciembre 13, 2005].

33 Arrison, "What digital divide?", p 1. 
Figura 66

Porcentaje de hogares norteamericanos que tenían computadoras en 1998, dividido por raza e ingreso económico

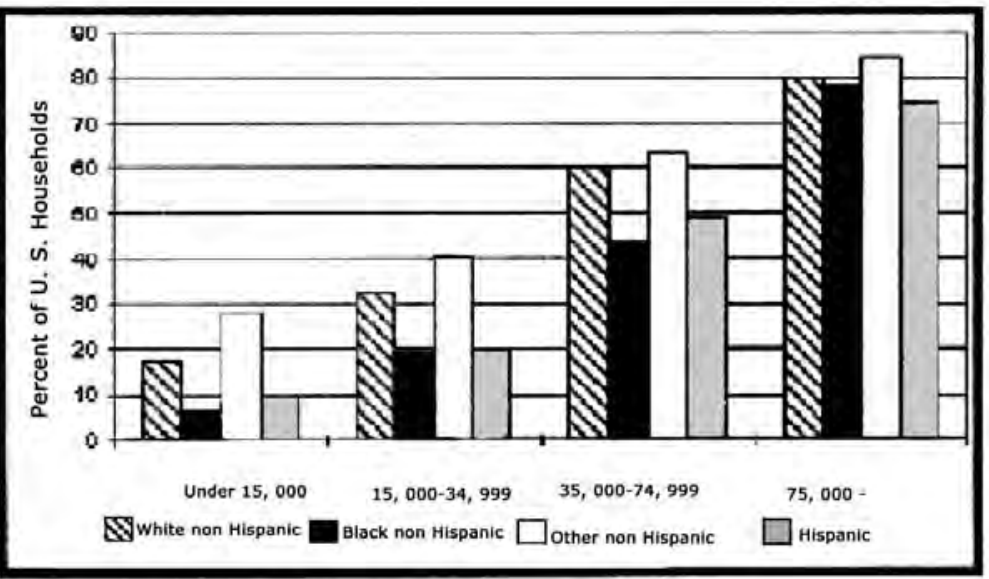

Tomado de David B. Bolt y Ray A. K. Crawford, Digital divide: computers and our children's future (Nueva York: TV Books, 2002), 180.

Figura 67

Porcentaje de hogares estadounidenses que usaban Internet en 1998, organizado por etnia e ingreso económico

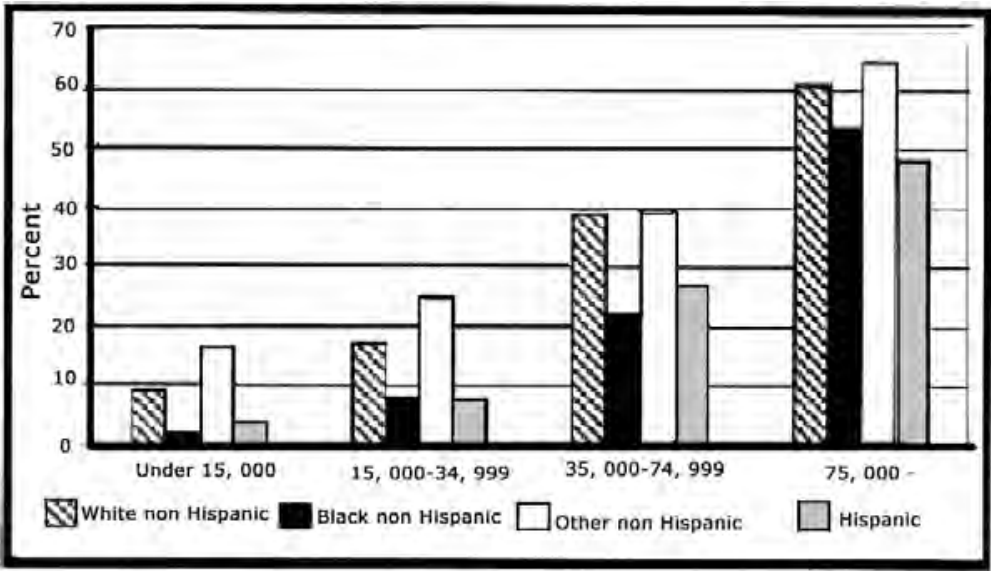

Tomado de David B. Bolt y Ray A. K. Crawford, Digital divide: computers and our children's future (Nueva York: TV Books, 2002), 188. 
Figura 68

Porcentaje de hogares estadounidenses con computadora y acceso a Internet por ingreso económico 1998, 1999

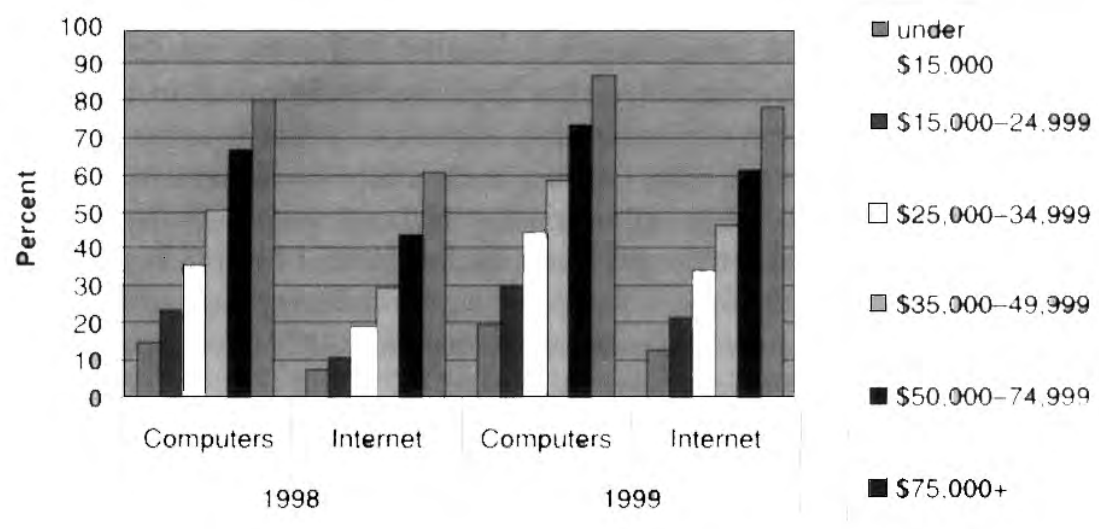

Figura 2.3 Porcentaje de hogares estadounidenses con computadora y acceso a Internet por ingreso económico. Fuente: us Departament of Commerce (2000a)

Tomado de Lisa J. Servon, Bridging the digital divide: technology, community and public policy (Malden, Mass.: Blackwell Publishing, 2002), 34.

La tendencia descrita por las figuras 66 y 67 continúa sin cambio durante 1999, es decir, los grupos con mayor ingreso económico tienen altos índices en la posesión de computadoras y acceso a Internet mientras que quienes tienen los más bajos ingresos tienen también los índices más bajos en posesión de computadora y acceso a Internet.

La figura 68 permite comparar la posesión de computadoras y el acceso a Internet con base en el ingreso económico durante 1998 y 1999 en la sociedad estadounidense. De esta figura vale la pena destacar que durante 1998 los segmentos de la población con ingresos económicos bajos (de menos de 15 mil a 34999 dólares) tenían menos computadoras que los segmentos de ingresos altos (de $35 \mathrm{mil} \mathrm{a}$ más de 75 mil dólares), pero que los primeros contaban con mayor acceso a Internet que los segundos de acuerdo con su proporción. Si se observa cuidadosamente la gráfica se verá que durante 1998 la diferencia entre los hogares de bajos ingresos que contaban con computadora y aquellos con acceso a Internet era menor que entre los 
Figura 69

Porcentaje de hogares estadounidenses que usaban Internet en 1998, organizado por zonas rural, urbana y central de las ciudades (inner) y por ingreso económico

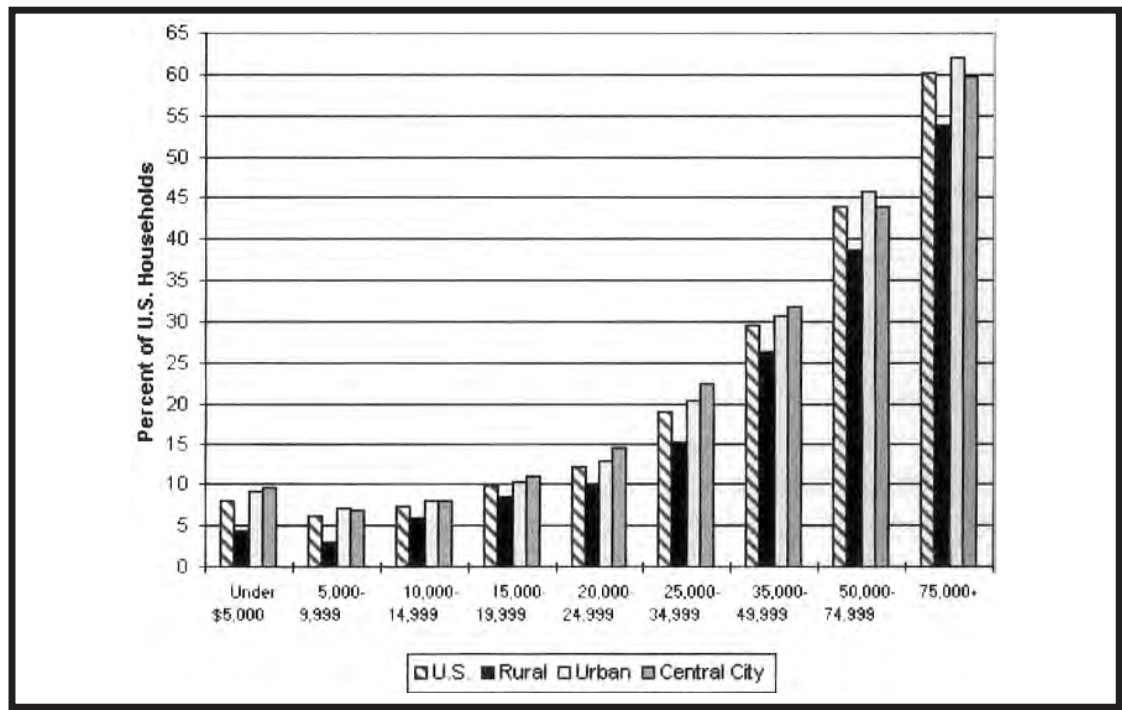

Tomado de David B. Bolt y Ray A. K. Crawford, Digital divide: computers and our children's future (Nueva York: TV Books, 2002), 191.

hogares de mayor ingreso, en el primer caso podemos calcular la diferencia entre 10 y 15 puntos porcentuales, en tanto que en el segundo la diferencia es del orden del 20 por ciento. Sin embargo, en 1999 esta situación cambia y la diferencia entre quienes cuentan con computadora y acceso a Internet es de aproximadamente el 10 por ciento en todas las categorías de ingreso.

En la figura 69 se observa el porcentaje de hogares norteamericanos que usaban Internet, dividido por zonas rural, urbana y central de las ciudades (inner) y por ingreso durante 1998. Como puede verse, aquellos con mayores recursos están más conectados que los de bajos ingresos. Adicionalmente, quienes habitan las zonas rurales, de no importa qué segmento de ingreso, son los que tienen las menores conexiones, aunque quienes viven en zonas rurales y cuentan con in- 
Figura 70

Porcentaje de estadounidenses que usaban Internet en 1998, organizado por ingreso y lugar de conexión

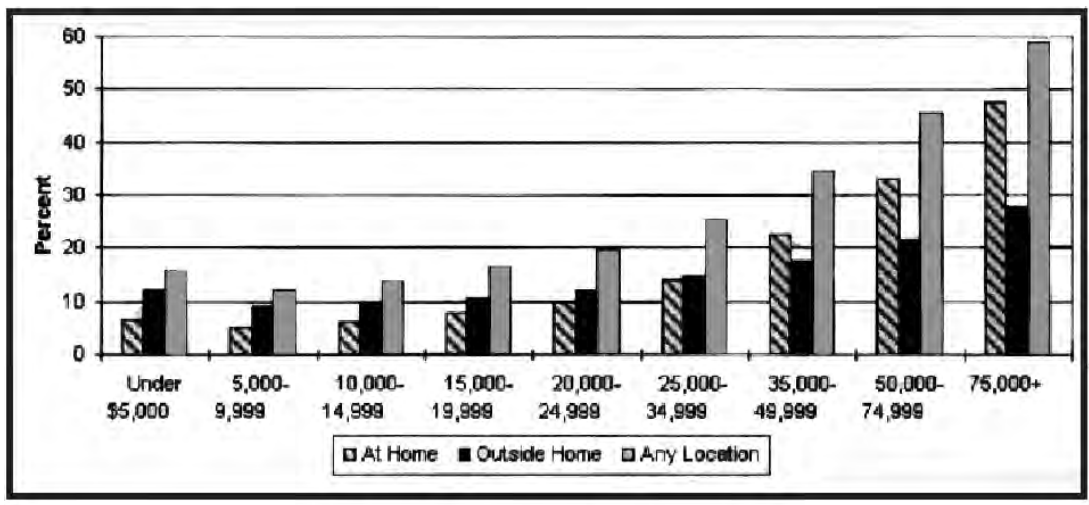

Tomado de David B. Bolt y Ray A. K. Crawford, Digital divide: computers and our children's future (Nueva York: TV Books, 2002), 197.

gresos altos tienen mayor conectividad que quienes tienen menores ingresos, sin importar la zona en que habitan.

Parece existir un patrón de uso similar, sin importar de qué área se trate. Evidentemente, entre mayor es el ingreso, aumenta el uso, de forma muy semejante en todas las zonas de las cuales se proporciona información.

En la figura 70 se observan las cifras relacionadas con la proporción de ciudadanos estadounidenses que usaban Internet en 1998, dividida por ingreso y lugar en que se establecía la conexión. Los ciudadanos de menores recursos solían usar Internet principalmente desde lo que se ha calificado como cualquier lugar; el uso desde la casa está en tercer lugar. Sin embargo, cuando se percibe un salario de 25 mil dólares anuales, la consulta en el domicilio se incrementa llegando a representar un porcentaje importante, en especial en la medida en que aumentan los ingresos. 
Figura 71

Porcentaje de ciudadanos de los Estados Unidos que usaban Internet en 1998, dividido por el estatus en cuanto a su trabajo y si trabajan en casa o fuera de ella

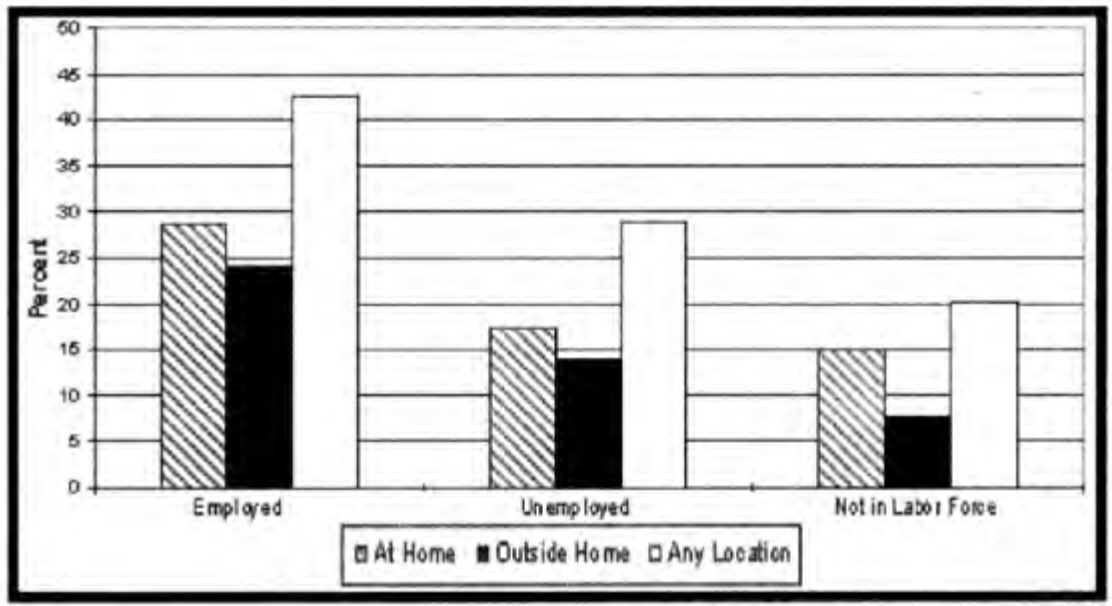

Tomado de David B. Bolt y Ray A. K. Crawford, Digital divide: computers and our children's future (Nueva York: TV Books, 2002), 198.

La figura 71 representa el porcentaje de ciudadanos de los Estados Unidos que usaban Internet en 1998, dividido por el estatus en cuanto a su trabajo y si trabajan en casa o fuera de ella. Dado que mucha gente indica que se conecta a Internet desde el trabajo, es lógico que los no empleados tengan una caída tan fuerte en el acceso.

En este contexto resulta interesante determinar el motivo por el cual las personas no tienen una computadora ni acceso a la red y para ello nos apoyaremos en la figura 72. La razón principal por la que los estadounidenses no tienen una computadora en casa es porque la consideran muy costosa; la siguiente razón es que no la necesitan y en tercer lugar que no están familiarizados con ella; se ofrecen al menos una docena más de motivos, pero la proporción de respuestas es marginal en comparación con las anteriores. La sumatoria de todas las respuestas no es 100, pues era posible dar más de una razón en una pregunta de opción múltiple. 


\section{La brecha digital y sus determinantes}

Figura 72

Motivos para no tener una computadora en casa

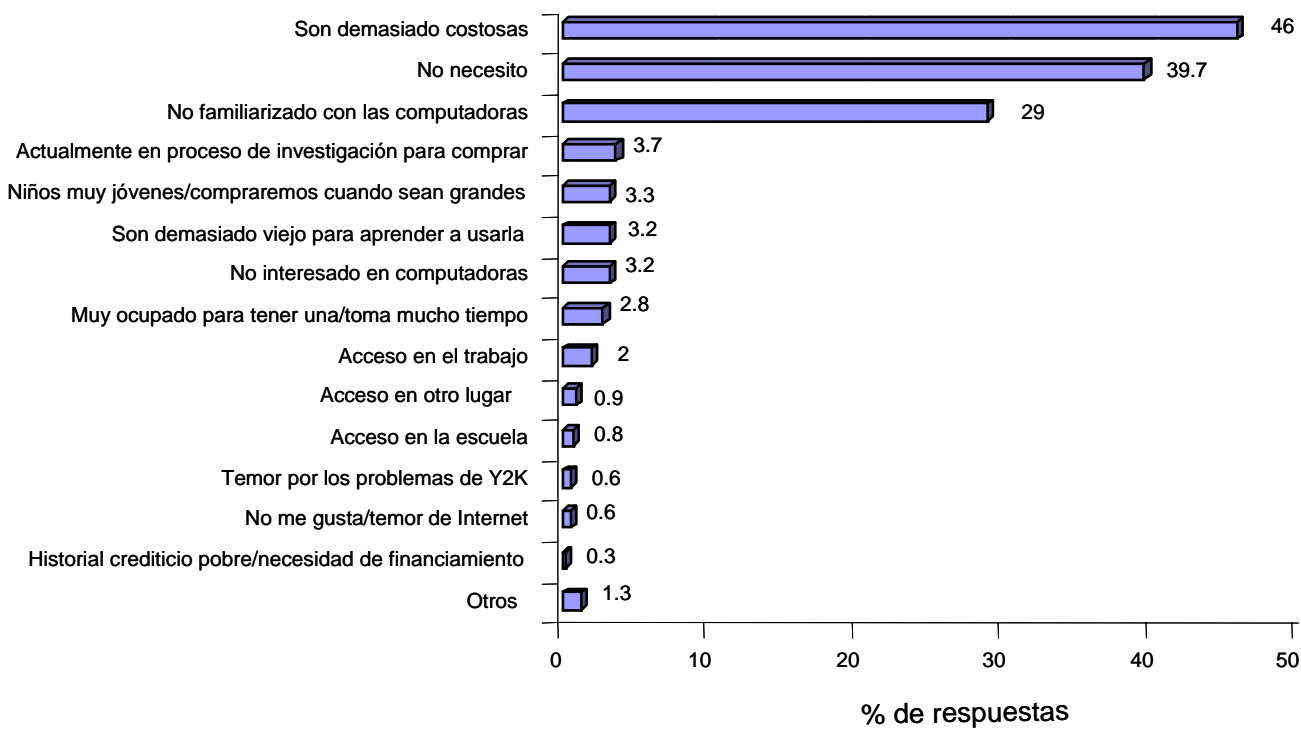

Tomado de Cheskin Research, "The digital world of hispanics in the United States", en Benjamin M. Compaine (ed.) The digital divide: facing a crisis o creating a myth? (Cambridge, Mass.: MIT Press, 2001), 274.

Como acertadamente han señalado Bolt y Crawford:

La falta de contacto con la tecnología, en casa y en el salón de clase, envía a una gran cantidad de jóvenes norteamericanos a tener empleos mal pagados, trabajos inseguros y marginales de la economía. 34

La mayoría de las escuelas carecen o bien de equipos de cómputo o bien de las facilidades en telecomunicaciones necesarias para estar conectadas a la red. Pero no es suficiente llevar un grupo de computadoras a la escuela y ya; es necesario que toda la escuela y el distrito escolar o zona escolar estén conectados, entrenar a los profesores

34 Bolt y Crawford, 19. 
Figura 73

Porcentaje de estadounidenses que usaban Internet fuera de casa en 1998, dividido por la ubicación en que la usan y el ingreso de la familia

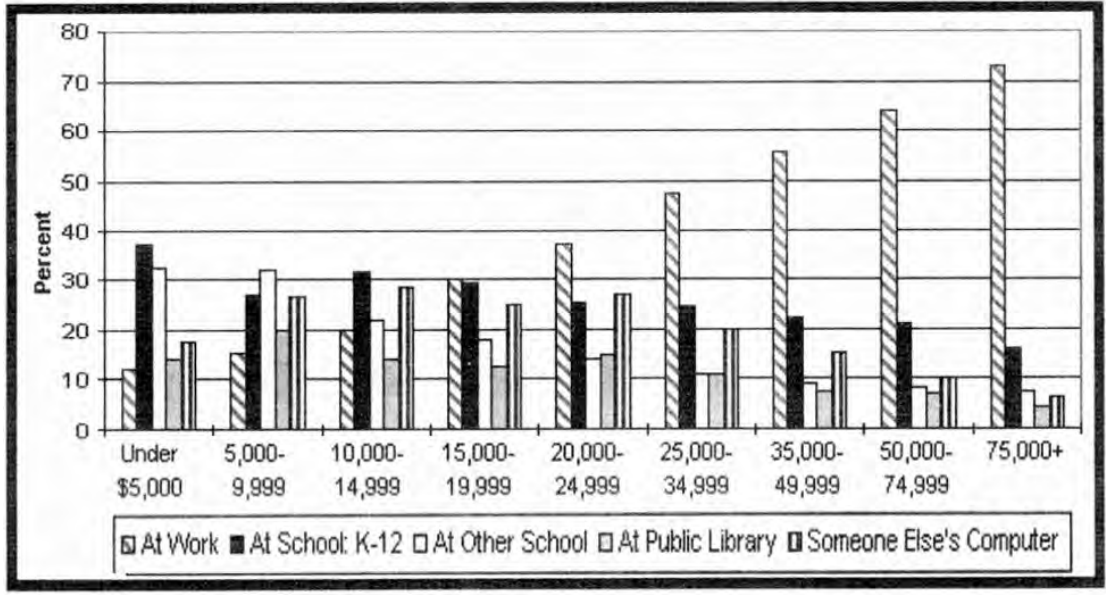

Tomado de David B. Bolt y Ray A. K. Crawford, Digital divide: computers and our children's future (Nueva York: TV Books, 2002), 199.

para que sean capaces de instruir a los alumnos, y hacer que los estudiantes se comprometan con el uso de las computadoras y demás recursos tecnológicos en el desarrollo de los planes y programas de estudio. ${ }^{35}$

En la figura 73 se encuentra información sobre el uso de Internet fuera de casa. Resulta especialmente revelador que entre menos ingresos económicos se tienen, el uso de la red en las escuelas es mayor. Pero a partir de un ingreso de 20 mil dólares al año, el uso de la red en el trabajo se incrementa de manera espectacular llegando al 70 por ciento para las personas que obtienen un ingreso de $70 \mathrm{mil} \mathrm{o}$ más dólares anuales. Aun en las personas de mayores recursos que consultan Internet en el trabajo, la escuela es la segunda opción.

35 Ibíd., 30. 


\section{La brecha digital y sus determinantes}

Figura 74

Relación entre ingresos económicos y nivel educativo de los hogares estadounidenses que usaban Internet en 2000

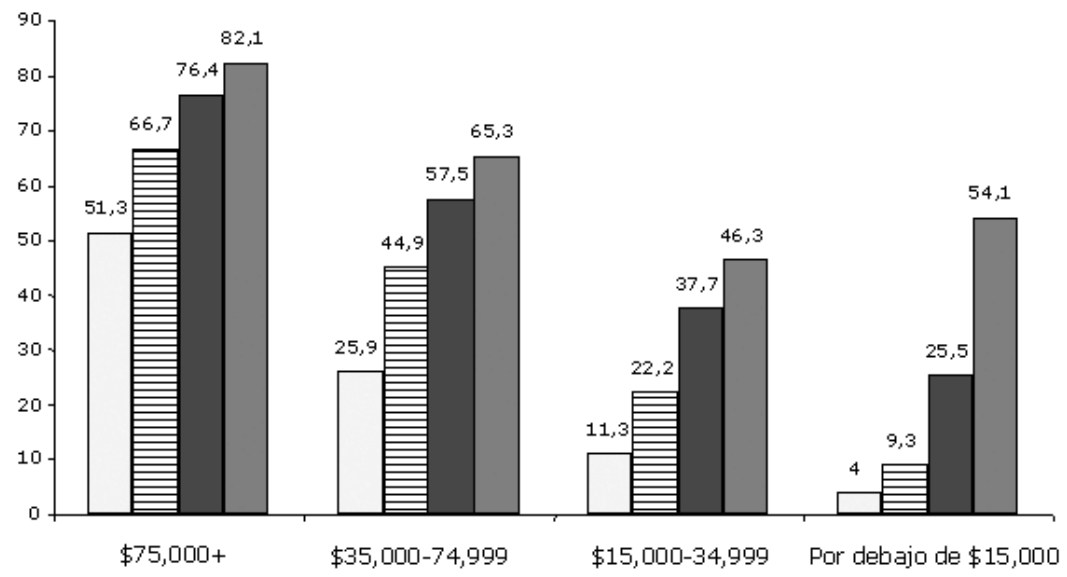

$\square$ Por debajo de la educación secundaria 日Educación secundaria

$\square$ Estudios superiores incompletos

$\square$ Titulo universitario o más

Figura 3.3 Porcentaje de hogares estadounidenses con acceso a Internet, por ingreso económico y educación, 2000 Fuente: National Telecommunication and Information Administration (NTIA 2000). Usado con permiso.

Tomado de Mark Warschauer, Technology and social inclusion: rethinking the digital divide (Cambridge, Mass.: MIT Press, 2003), 54.

El nivel educativo es un elemento importante en el uso de la red, que además está vinculado con el nivel de ingresos. Si tomamos en consideración la figura 74 , vemos que en todos los casos quien más utiliza la red es el grupo de personas que tiene mayor nivel educativo. Ahora bien, si comparamos los niveles educativos entre quienes tienen un ingreso de 75 mil dólares al año, podemos decir que la brecha entre ellos no es tan amplia como ocurre en los niveles de bajos ingresos, como es el caso de las personas que reciben menos de 15 mil dólares anualmente. Es decir, entre quienes tienen un título universitario o más y quienes no tienen completos sus estudios secunda- 
rios y perciben 75 mil dólares, la diferencia es del 62 por ciento, en tanto que entre quienes tienen un título universitario o más y quienes no tienen completos sus estudios secundarios y perciben $15 \mathrm{mil}$ dólares anuales, la diferencia es del orden de 88 por ciento.

En síntesis podemos concluir que en Estados Unidos las características principales de quienes se encuentran conectados a la red son las siguientes:

Un hogar de altos ingresos económicos, localizado en una zona urbana, tiene veinte veces más posibilidades de tener acceso a Internet que un hogar con un bajo ingreso económico y ubicado en una zona rural.

Un niño que pertenece a una familia blanca de bajos ingresos tiene tres veces más posibilidades de tener acceso a Internet que un niño comparable de raza negra y cuatro veces más que un niño de familia hispana.

Un hogar de asiáticos ricos y de isleños del Pacífico tiene trece veces más posibilidades de poseer una computadora que una casa de negros y treinta y cinco veces más de tener acceso a Internet. 36

36 Compaine, 18. 



\title{
Determinantes demográficos de la brecha digital
}

\begin{abstract}
os elementos que nos permiten describir un grupo humano, una comunidad o una sociedad en su conjunto son de diferente naturaleza, y pueden ser entre otros su medio ambiente natural, su economía, su demografía, su cultura y su forma de gobierno. En los capítulos "La tecnología de la información y comunicación en el mundo" y "Determinantes económicos de la brecha digital" se analizó la brecha digital desde la perspectiva de su distribución geográfica y de los aspectos económicos que influyen en ella; en este capítulo trataremos de identificar algunos de los aspectos demográficos que definen su naturaleza y magnitud al analizar el género, la edad y la etnia de los usuarios de la TIC.
\end{abstract}

\section{El género, factor de distinción en la brecha digital}

Existe una gran diferencia entre hombres y mujeres cuando se les considera como usuarios de Internet. Es bien sabido que la sociedad establece roles que los niños deben jugar, así por ejemplo las niñas juegan con muñecas y utensilios de cocina mientras los niños reciben juguetes como coches, trenes y otros más que conllevan los aspectos tecnológicos en sí mismos. Así la educación familiar y social condiciona a las niñas a que la tecnología les sea ajena. Esto explica en parte por qué menos mujeres usan las tecnologías de la información que los varones; se dice que lo expresa parcialmente pues no es 
Figura 75

Usuarios de Internet por género, 1995

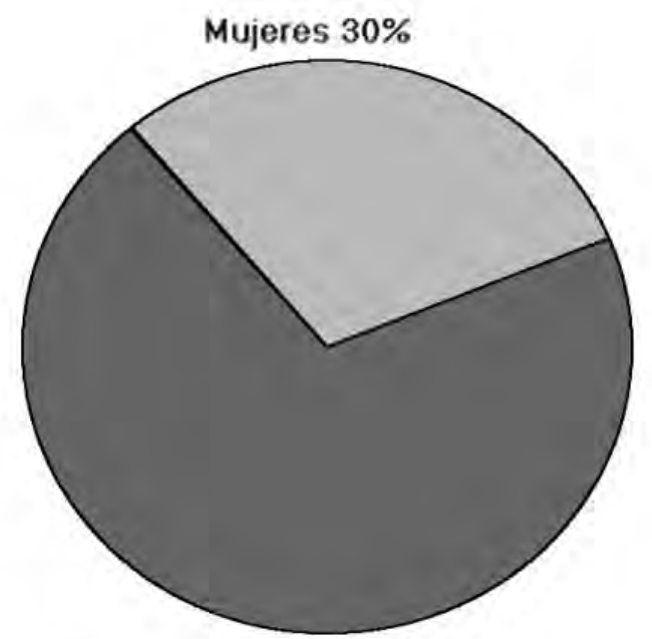

Fuente: Varias

Hombres $70 \%$

Tomado de NUA Internet Surveys, NUA analysis, Internet users by gender [1995], graphs and charts, disponible en http://www.nua.com/surveys/analysis/graphs_charts/1995graphs/ gender.html [Enero 30, 2006].

la única causa a la que se puede atribuir la brecha digital por género, como veremos a continuación.

En algunas culturas y zonas geográficas, la brecha digital determinada por el género se está cerrando o es muy pequeña; en algunas otras -en especial aquellas donde la mujer es objeto de marginación- las brechas digital, social, económica y cultural son de grandes proporciones. En las sociedades donde la discriminación y marginación son culturalmente aceptadas, las mujeres no tienen acceso a Internet o en el mejor de los casos tienen una mínima posibilidad de utilizar la red y recibir información. De acuerdo con la figura 75, en 1995 el 30 por ciento de los usuarios de Internet eran mujeres en contraste con 70 por ciento de usuarios varones, lo que significaba que de 10 usuarios de Internet, sólo tres eran mujeres. 
Figura 76

Usuarios de Internet por género, 1996

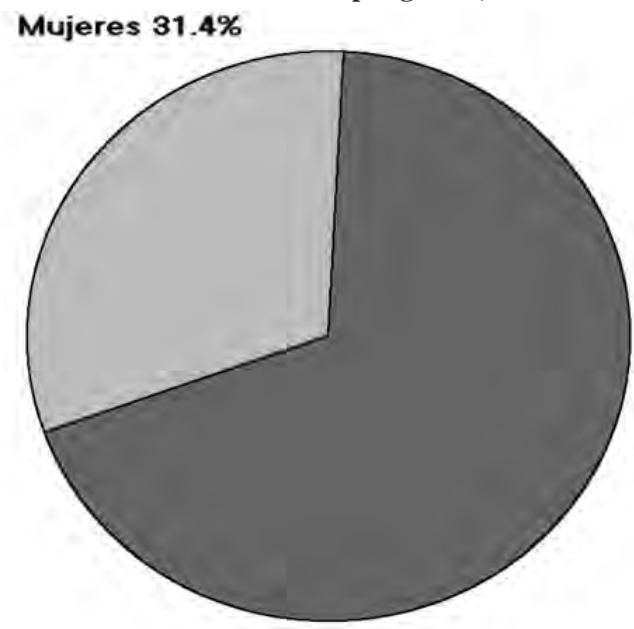

Hombres 68.6\%

Tomado de NUA Internet Surveys, NUA analysis, Internet users by gender [1996,] graphs and charts, disponible en http://www.nua.com/surveys/analysis/graphs_charts/1996graphs/ gender.html [Enero 30, 2006].

Con ayuda de la figura 76 se observa que un año más tarde, en 1996, la brecha entre géneros desciende un uno por ciento con respecto a 1995. Esta diferencia, aunque mínima, nos muestra que no en todas las regiones los cambios son espectaculares y que de un año a otro no se pueden modificar drásticamente las causas de la brecha.

La proporción de uso por género se mantiene, en general las mujeres están conectadas a Internet a razón de tres a siete, aumentando su proporción ligeramente en cuanto se separan por edades. A mayor edad de las mujeres más amplia es la brecha con relación a los varones, como indica la figura 77. 
Figura 77

Categorías de edad analizadas por género, 1996

Categorías de edad analizadas por género

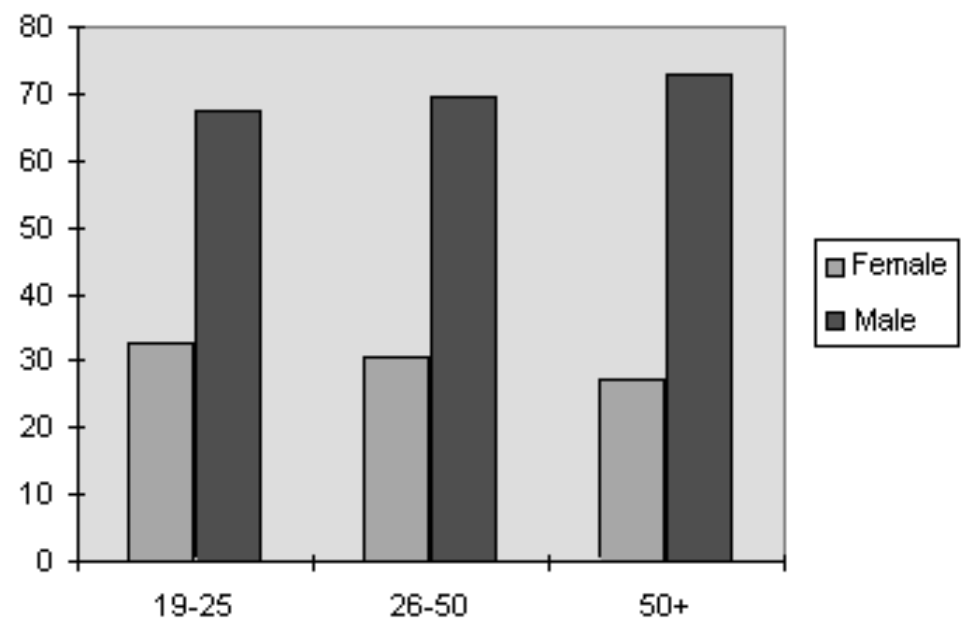

Tomado de NUA Internet Surveys, NUA analysis, age groups broken by gender [1996], graphs and charts, disponible en http://www.nua.com/surveys/analysis/graphs_charts/1996graphs/ genderage. html [Enero 30, 2006].

A pesar de que Estados Unidos y Europa forman parte del mundo desarrollado, en 1997 se identificó una diferencia importante determinada por el género de los usuarios de Internet entre ambas regiones. Según la figura 78 , mientras que en Estados Unidos la diferencia entre hombres y mujeres era de casi 19 puntos porcentuales, en Europa ésta era de 56 puntos. Si hacemos la comparación entre los usuarios varones estadounidenses y europeos, encontramos que había más hombres conectados en Europa que en Estados Unidos, la diferencia fue de 18.5 puntos porcentuales. Pero si comparamos el acceso de las mujeres estadounidenses y europeas, la posición se invierte, es decir, las mujeres europeas usuarias de Internet son alrededor de la mitad de las mujeres que están conectadas en Estados Unidos, la diferencia en el uso es mayor a los 18.58 puntos porcentuales. 
Figura 78

Usuarios de Internet por género, 1997

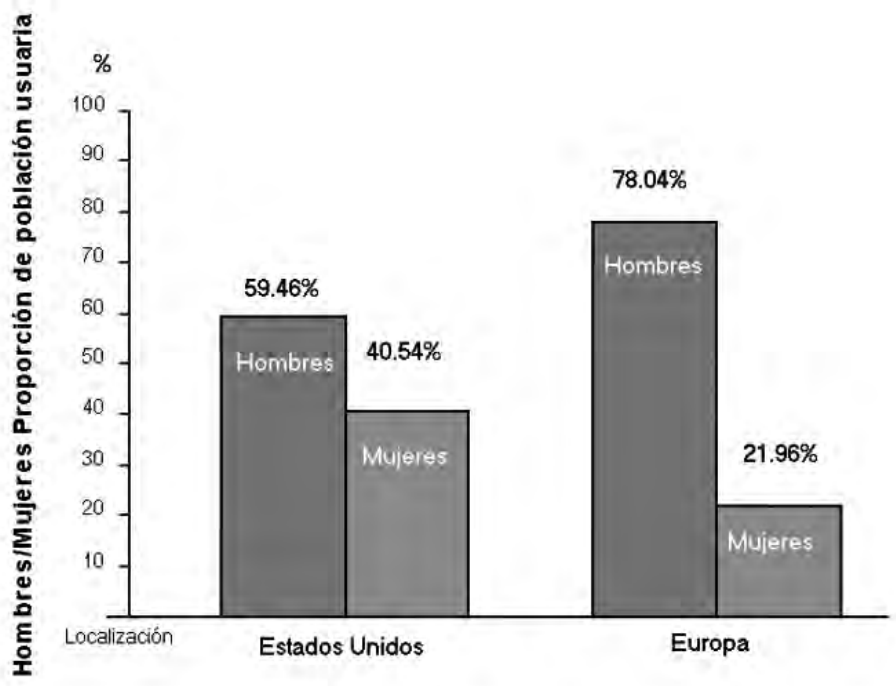

Fuente: GVU User Surveys.

Tomado de NUA Internet Surveys, NUA analysis, Internet users by gender 1997, graphs and charts, disponible en http://www.nua.com/surveys/analysis/graphs_charts/1997graphs/ gender.html [Enero 30, 2006].

Las cifras anteriores demuestran la existencia de la brecha basada en el género; aun entre los países desarrollados que, podríamos suponer, cuentan con características similares.

La cifra de mujeres usuarias de Internet varía de región en región, de año en año y de fuente en fuente, aunque siempre su proporción es menor que la de los hombres. En los datos correspondientes a 1998 que ilustra la figura 79, se puede observar que pese a la variación porcentual, la razón entre hombres y mujeres usuarios de Internet en Estados Unidos y Europa se mantuvo, y que para el resto del mundo ésta continúa siendo de tres mujeres usuarias por siete varones usuarios.

En 1998, según Servon, solamente el 25 por ciento de las mujeres brasileñas eran usuarias de la red; en Japón y Sudáfrica este número disminuía a 17 por ciento, casi la misma proporción se encuentra en 
Figura 79

Usuarios de Internet por género, 1998

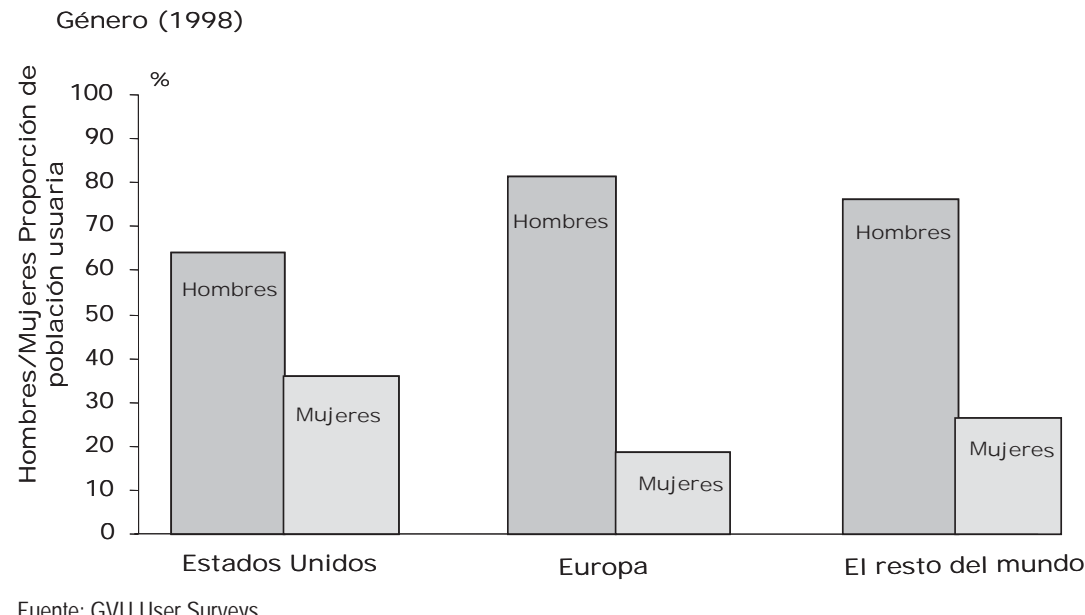

Tomado de NUA Internet Surveys, NUA Analysis, Internet users by gender-1998, graphs and charts, disponible en http://www.nua.com/surveys/analysis/graphs_charts/1998graphs/ gender.html [Enero 30, 2006].

Rusia con 16 por ciento. Los niveles más bajos se encuentran en África con siete, y tan sólo el cuatro por ciento en los países árabes. ${ }^{1}$

Estas cifras varían cuando se analizan por nación y por periodo, así, el 37 por ciento en Japón, el 43 por ciento en Taiwán y el 50 por ciento en China de los usuarios son mujeres, ${ }^{2}$ mientras que el 77 por ciento de los hindúes que usan Internet son hombres. ${ }^{3}$

1 Servon, 43.

2 Kuttan y Peters, 114.

3 Ibid., 117. 
Figura 80

Usuarias de Internet como proporción del total de usuarios, 2002

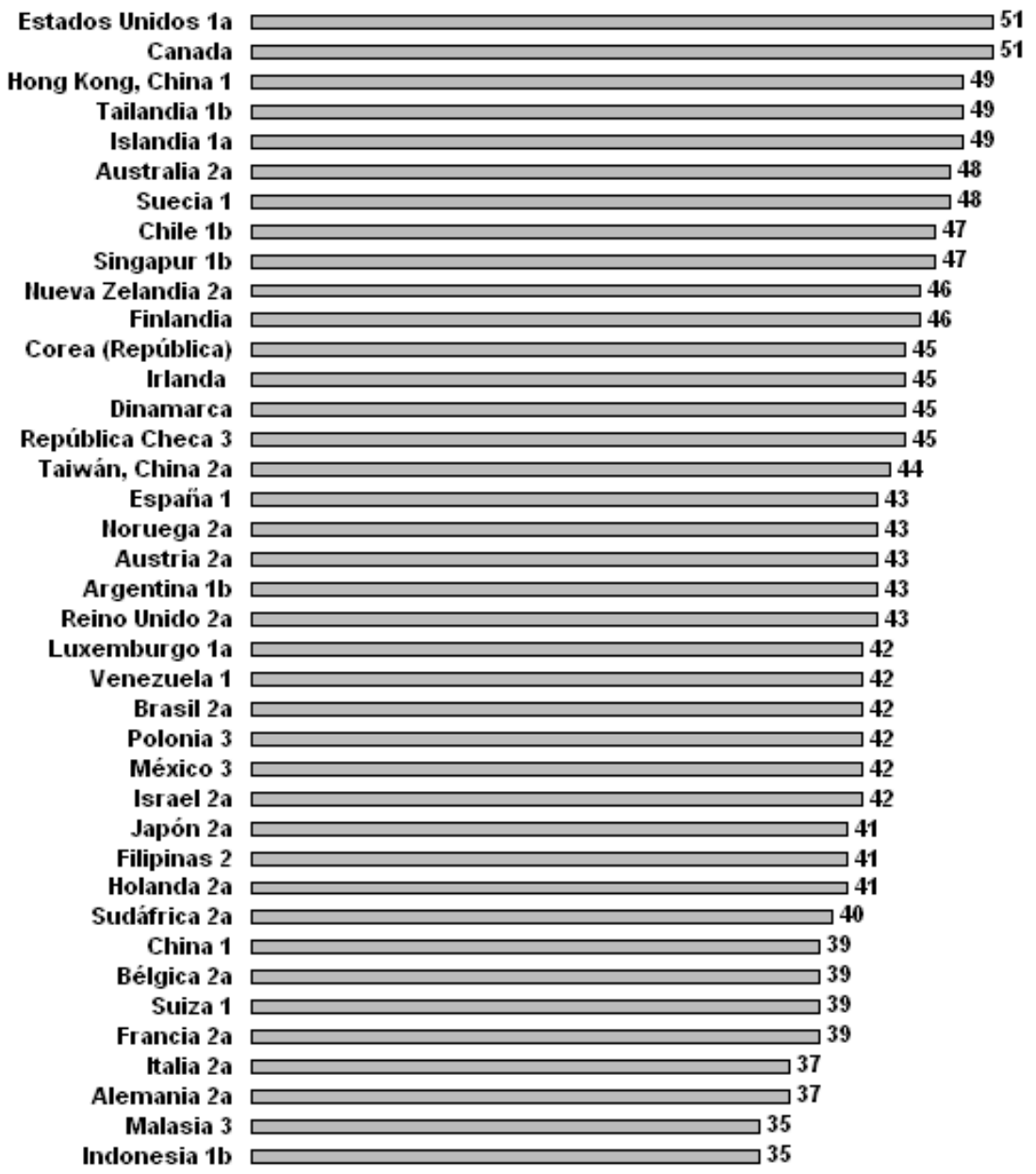

Ilota: 1=Fuente nacional. 2=Ilielsen/lletRatings. $3=$ TIIS. a=2001. $b=2000$.

Tomado de International Telecommunication Union, Female Internet users as \% of total Internet users, 2002, disponible http://www.itu.int/ITU-D/ict/statistics/at_glance/f_inet.html [Agosto 31, 2005]. 
Para el año 2002 los datos anteriores se habían modificado de la siguiente manera: Japón pasó del 37 al 41 por ciento, Taiwán del 43 al 44 y China del 50 al 39, según las cifras de la figura 80 . En la misma figura sobresalen Estados Unidos y Canadá con el 51 por ciento de usuarios femeninos de Internet, en tanto que Malasia e Indonesia se situaron en el rango inferior con el 35 por ciento.

No se puede dejar de comentar el caso mexicano, que de acuerdo con la información que proporciona la figura que nos ocupa, en 2002 tuvo el 42 por ciento de usuarias de Internet.

Chen y Wellman también señalan que en México el 42 por ciento de los usuarios de Internet en 2002 eran mujeres, ${ }^{4}$ mientras que en una encuesta publicada por el periódico Reforma de la ciudad de México se encuentran datos que son por demás interesantes. Estos datos indican que quienes utilizan una computadora son en 60 por ciento hombres y 46 por ciento mujeres (aunque si se suman da más del 100 por ciento) y que de éstos 84 por ciento de los hombres y el 83 por ciento de las mujeres utilizan Internet. ${ }^{5}$

Las cifras anteriores difieren de las que proporcionan la Asociación Mexicana de Internet (AMIPCI) y el Instituto Nacional de Estadística, Geografía e Informática (INEGI).

AMIPCI ha realizado cinco encuestas con el objetivo de profundizar en el conocimiento de los usuarios mexicanos de Internet respecto de sus usos y características sociodemográficas. ${ }^{6}$ Según la primera encuesta, realizada en 2000 , el 30 por ciento de los usuarios de Internet eran mujeres y el 70 por ciento hombres; en 2002 la información sobre género no se incluyó en el resumen ejecutivo; en 2003 la proporción del sexo femenino se había incrementado hasta llegar al 33 por ciento en tanto que los varones se ubicaron en el 67 por ciento;

4 Chen y Wellman, 22.

5 Zenker, "Navegan más las mujeres", 2C.

6 El resumen ejecutivo de cada encuesta se encuentra disponible en el sitio web de la Asociación, http://www.amipci.org.mx/contenidos/estudios.html. 
en 2004 nuevamente hay un incremento en el número de usuarias al alcanzar el 47 por ciento y los varones el 53 por ciento; finalmente en 2005 se observa un retroceso cuando el porcentaje de usuarios mujeres pierde seis puntos porcentuales y se ubica en el 41 por ciento.

Pero las cifras anteriores tampoco coinciden con aquellas que integran las estadísticas elaboradas por el INEGI. Según este organismo, el 46.4 por ciento de los mexicanos que usaban computadora en 2001 eran mujeres y el 53.6 por ciento hombres, en 2002 los porcentajes habían cambiado a 49.2 por ciento de mujeres y 50.8 por ciento de hombres, y el último dato que se conoce es el de 2004 en donde las mujeres ocupan el 48.2 por ciento y los hombres el 51.8 por ciento. ${ }^{7}$ Estos datos sugieren que la brecha relacionada con el uso de computadoras entre mexicanos y mexicanas tiende a reducirse, y que esta situación debe influir positivamente en la equidad en el acceso y uso de Internet.

Respecto de las cifras sobre el uso de Internet, el INEGI señala lo siguiente: en 2001 el 45.4 por ciento de los usuarios de Internet eran mujeres y el 54.6 por ciento hombres; en 2002 el 48 por ciento eran usuarias de Internet en tanto que el 52 por ciento eran varones; en 2004 los porcentajes fueron 47 por ciento mujeres y 53 por ciento hombres; y en 2005 el 47.1 por ciento mujeres y el 52.9 por ciento hombres. ${ }^{8}$ De todas estas cifras podemos concluir que determinar la proporción de hombres y mujeres mexicanos usuarios de Internet es un asunto complicado dada la inconsistencia de los números; empero, de acuerdo con los datos anteriores la brecha digital determinada por el género tiende a reducirse en México.

En el Reino Unido la brecha entre géneros se ha venido estrechando; por un informe del año 2002 se sabe que el 61 por ciento de los

7 INEGI, Población de seis años y más que utiliza computadora por sexo, 2001, 2002 y 2004, disponible http://www.inegi.gob.mx/est/contenidos/espanol/rutinas/ept.asp? $\mathrm{t}=\operatorname{tinf} 211 \& \mathrm{c}=5570$ [Julio 2, 2005].

8 INEGI, Usuarios de Internet por género, 2001 a 2005, disponible http://www. inegi.gob.mx/est/contenidos/espanol/rutinas/ept.asp?t $=\operatorname{tinf} 216 \& \mathrm{c}=5565$

[Noviembre 22, 2005]. 
hombres y el 55 por ciento de las mujeres tenían acceso a Internet en el señalado año. ${ }^{9}$

En Alemania se ha producido un fenómeno por demás interesante, mientras en 1997 la brecha era de siete puntos porcentuales (el 10 por ciento usuario con respecto a la población total eran varones y el tres por ciento mujeres), en el año 2001 el número de usuarios alemanes había aumentado y la brecha entre los géneros también. En ese año el 48 por ciento de los pobladores usuarios eran varones y el 30 por ciento mujeres, lo que significó que la brecha entre unos y otras se amplió en 18 puntos porcentuales. Finalmente, para el año 2002 el 53 por ciento eran usuarios varones en contraste con el 36 por ciento de usuarias, la brecha continuaba en 17 puntos porcentuales. ${ }^{10}$

En Italia ocurrió un fenómeno también interesante, en 1999 el 37 por ciento de las mujeres usaban Internet, para 2001 se encontró que sólo el 32 por ciento de ellas estaban utilizando la red según una nueva encuesta. No se han ofrecido explicaciones que nos aclaren el por qué de esta disminución que va en contra de todas las tendencias, incluidos los países en vías de desarrollo. ${ }^{11}$

En Rusia el 81 por ciento de los usuarios de Internet son hombres. ${ }^{12}$ Más del 82 por ciento de las personas conectadas con la red en Bielorrusia son hombres. El 60 por ciento de los croatas usuarios de Internet son hombres y en Bulgaria por cada dos hombres usuarios de la red hay una mujer que lo es. ${ }^{13}$

9 UK Cabinet Office, UK online annual report 2002, disponible http://archive.cabinetoffice.gov.uk/e-envoy/reports-annrep-2002/\$file/indexpage.htm. Citado por Wenhong Chen y Barry Wellman, Charting and bridging digital divides: comparing socio-economic, gender, life stage, and rural-urban Internet access and use in eight countries. Octubre 27, 2003, 10, disponible http://www.amd.com/us-en/ assets/content_type/DownloadableAssets/FINAL_REPORT_CHARTING_DIGI_DIVIDES.pdf [Agosto $6,2004]$.

10 Chen y Wellman, 12.

11 Ibid., 14.

12 Kuttan y Peters, 119.

13 Ibid. 
En Japón el 68 por ciento de los hombres y el 56 por ciento de las mujeres usaban Internet en 2002. Es interesante que entre los jóvenes japoneses de 19 a 24 años de edad las mujeres sean quienes usen más la Internet que los hombres. La razón de este extraño comportamiento es que más mujeres usan teléfonos móviles para acceder a Internet. ${ }^{14}$

Los hombres coreanos usan más Internet que las mujeres, mientras que el 50 por ciento de los varones estaban utilizando Internet a finales de 2000, sólo un 39 por ciento de las mujeres también lo hacía. En los últimos años se ha incrementado el número de mujeres con acceso a la red, pero la brecha de entre 12 y 14 puntos porcentuales se ha mantenido. ${ }^{15}$

El porcentaje de las mujeres que utilizan Internet se ha estado incrementando en China. En 1997 sólo el 13 por ciento de los usuarios eran mujeres, para 2001 el porcentaje había aumentado considerablemente y llegaba al 41 por ciento de los usuarios. ${ }^{16}$ Una cifra muy parecida proporciona Kuttan y Peters pues según sus fuentes el 40 por ciento de las mujeres usan la red en China. ${ }^{17}$

Sobre Asia contamos con algunos datos, por ejemplo, el 37 por ciento de los usuarios japoneses son mujeres, y 43 por ciento de los usuarios de Taiwán son mujeres. ${ }^{18}$

El 87 por ciento de los usuarios de Etiopía, el 83 por ciento de Senegal y el 64 por ciento de Zambia son hombres. ${ }^{19}$

14 World Internet Project Japan, Internet usage trends in Japan survey report (Tokyo: Institute of Socio-Information y Communication Studies, University of Tokyo, 2002), citado por Wenhong Chen y Barry Wellman, Charting and bridging digital divides: comparing socio-economic, gender, life stage, and rural-urban Internet access and use in eight countries, Octubre 27, 2003, 16, disponible http://www.amd.com/us-en/assets/content_type/DownloadableAssets/FINAL_ REPORT_CHARTING_DIGI_DIVIDES.pdf [Agosto 6, 2004].

15 Chen y Wellman, 18.

16 Ibid., 20.

17 Kuttan y Peters, 114.

18 Ibid.

19 Ibid., 113. 
La Iniciativa Educativa para las Niñas Africanas es un buen ejemplo que se realiza en 20 países y tiene programas específicos que permiten que las niñas aumenten su participación en la escuela y las provee de nueva información. Las niñas educadas de esta manera muestran un nuevo comportamiento, como por ejemplo un matrimonio a edad más tardía y tener menos hijos. ${ }^{20}$ En los países árabes sólo el seis por ciento de las mujeres utilizan Internet. ${ }^{21}$

La brecha entre géneros en los Estados Unidos es menor que en otros muchos lugares; Kuttan y Peters, haciendo uso de diferentes encuestas, señalan que en ese país el 55 por ciento de los hombres y el 52 por ciento de las mujeres están conectados a Internet, la diferencia es de tan sólo tres puntos porcentuales. Mientras tanto en otra zona desarrollada, como aquella que comprende a los países de Europa Occidental, la diferencia es del 14 por ciento, 34 por ciento de los hombres contra el 20 por ciento de las mujeres que están conectados a Internet. La diferencia es importante, ya que mientras el 52 por ciento de las mujeres estadounidenses están conectadas a Internet, sólo el 34 por ciento de las europeas también lo están. ${ }^{22}$

En 1998 sólo el 34 por ciento de las mujeres estadounidenses usaban Internet, y para el 2000 el 44 por ciento de ellas ya eran usuarias. En 2002 el 73 por ciento de los varones y 69 por ciento de las mujeres estadounidenses lo hacían. ${ }^{23}$ Como puede verse por los datos anteriores, la brecha entre hombres y mujeres es muy pequeña en Estados Unidos.

La figura 81 señala la proporción de ciudadanos estadounidenses que usaban Internet de acuerdo con su género y lugar de uso en 1998, a través de ella podemos identificar que las mujeres consultan en menor medida Internet que los hombres. Las variables de lugar que constituyen esta figura son muy generales e imprecisas (en casa, fuera de

20 Kelley-Salinas, 23.

21 Kuttan y Peters, 119.

22 Ibid., 122.

23 Chen y Wellman, 8. 
Figura 81

Proporción de estadounidenses que usaban Internet en 1998 de acuerdo con su género y lugar de uso

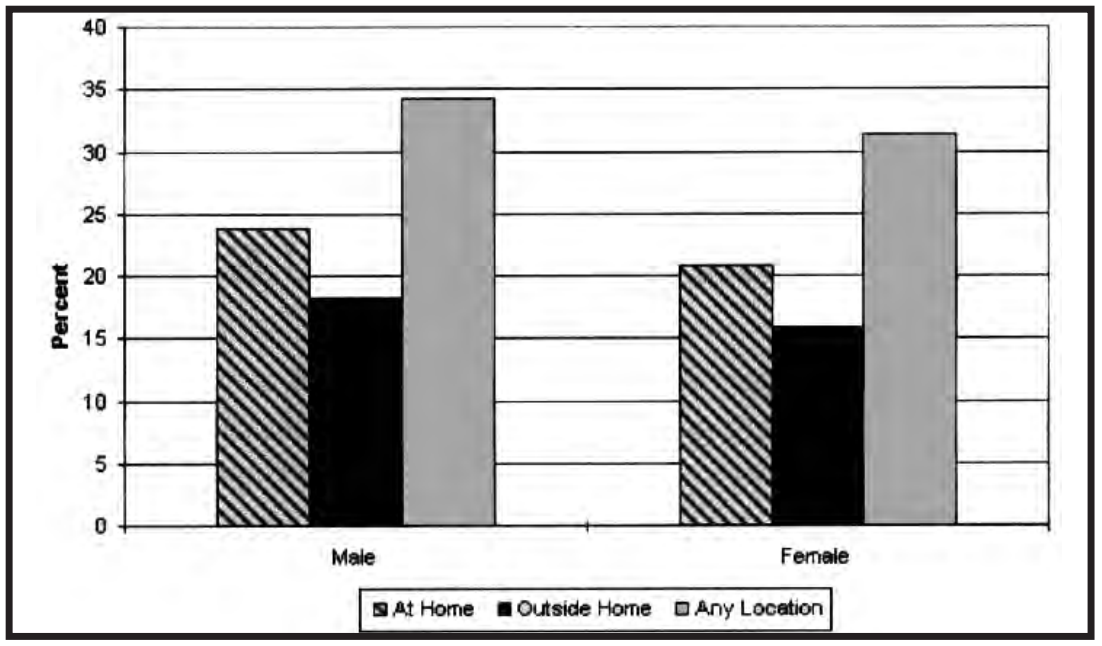

Tomado de David B. Bolt y Ray A. K. Crawford, Digital divide: computers and our children's future (Nueva York: TV Books, 2002), 202.

casa, en cualquier lugar), por lo que no es posible determinar si el lugar incide en la diferencia del comportamiento entre géneros.

Para complementar la información proporcionada por la figura anterior, analicemos ahora a través de la figura 82 el porcentaje de los ciudadanos estadounidenses que usaban Internet fuera de la casa en 1998, dividido por género y lugar. Los hombres usaban Internet principalmente en el trabajo, en tanto que las mujeres además de emplearla en el trabajo presentan un mayor índice de uso que los hombres en la escuela de educación media, en otras escuelas, en la biblioteca pública o en la computadora de alguien más.

Aunque en menor proporción, pero siguiendo una pauta semejante, los hombres y las mujeres consultan Internet fuera de casa en forma similar. El lugar preferido para conectarse a la red es el trabajo, seguido por la escuela y el uso de la computadora de otra persona, 
Figura 82

Porcentaje de estadounidenses que usaban Internet en 1998 fuera de casa, dividido por género y lugar de acceso

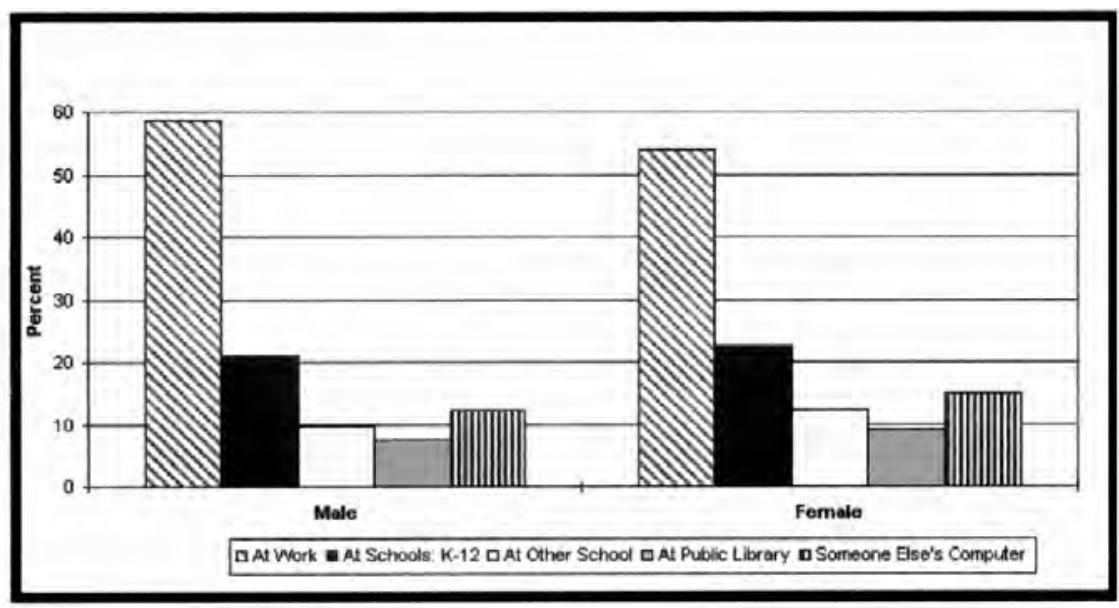

Tomado de David B. Bolt y Ray A. K. Crawford, Digital divide: computers and our children's future (Nueva York: TV Books, 2002), 204.

para hacer uso de la red en forma marginal desde la biblioteca pública y alguna otra escuela.

La proporción de ciudadanos estadounidenses que utilizan Internet en las bibliotecas fue dividida por género en la figura 83. En esta figura se observa que las mujeres hacen más uso de Internet en la biblioteca que los hombres. Una posible explicación es que las mujeres usan más Internet en la biblioteca porque los hombres lo hacen más en la escuela.

En la figura 83 encontramos que las mujeres y los hombres hacen uso de Internet en forma muy parecida cuando se conectan a la red en la biblioteca. Esto nos permite especular que es posible que la brecha entre hombres y mujeres en parte se deba a la falta de equipos de cómputo en casa y que esto afecta más a las mujeres que a los 
Figura 83

Proporción de estadounidenses que utilizan Internet en las bibliotecas por género

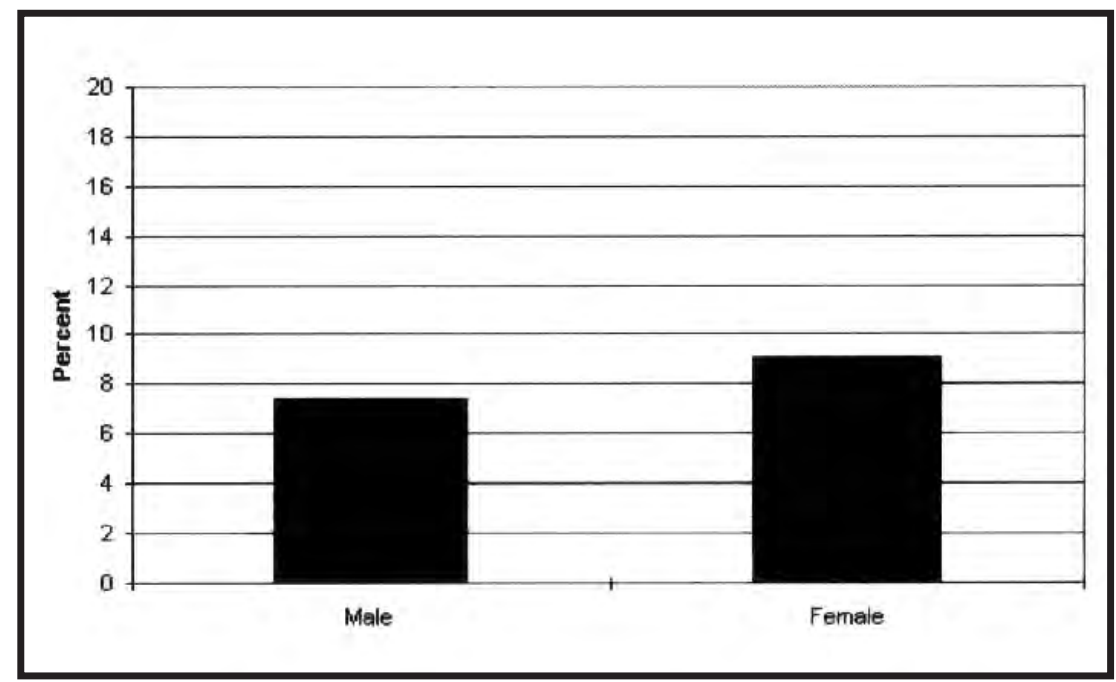

Tomado de David B. Bolt y Ray A. K. Crawford, Digital divide: computers and our children's future (Nueva York: TV Books, 2002), 205.

hombres, quienes la utilizan en las oficinas; o en su defecto, que el uso de la computadora es visto en la casa como algo primordialmente relacionado con los varones.

Resulta interesante poder determinar cuál es el uso que se le da a Internet bajo la perspectiva de género. En la figura 84 se presenta el porcentaje de ciudadanos estadounidenses que usaban Internet en casa dividido por género y tipo de uso en 1998. En esta figura podemos observar cómo es distinto el uso que hacían de Internet, en 1998 , los hombres y las mujeres. Mientras que las mujeres utilizaban la red para enviar y recibir correos electrónicos y para tomar cursos, los hombres hacían uso de Internet para buscar información, trabajos relacionados con su empleo y para buscar empleo. 
Figura 84

Porcentaje de estadounidenses que usaban Internet en 1998 en casa, dividido por género y tipo de uso

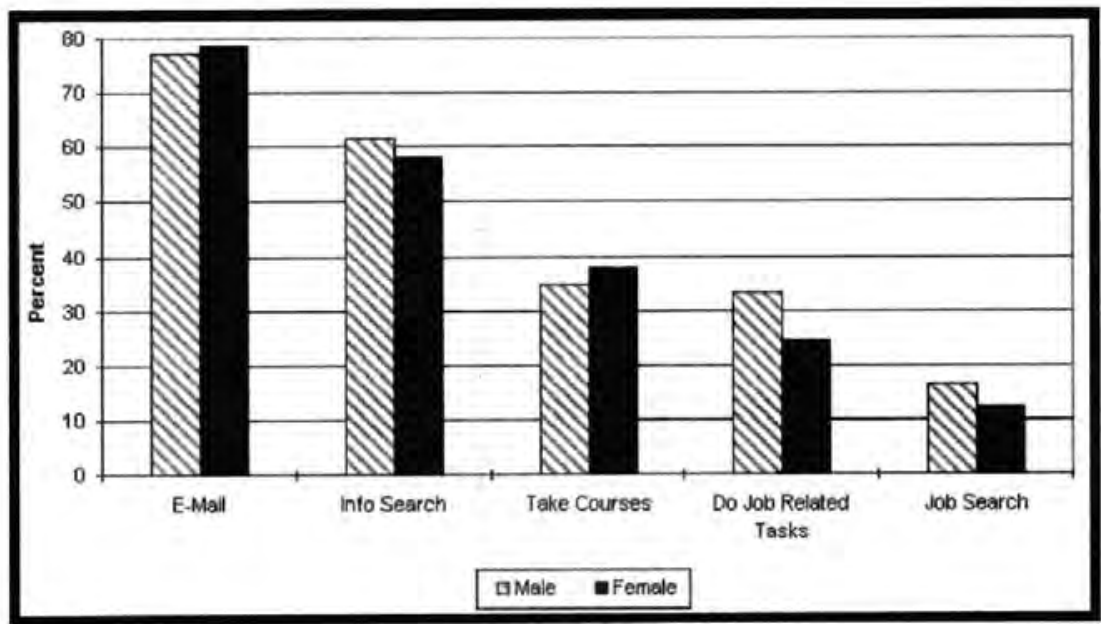

Tomado de David B. Bolt y Ray A. K. Crawford, Digital divide: computers and our children's future (Nueva York: TV Books, 2002), 203.

También debe notarse que las mujeres toman más cursos en línea que los hombres, posiblemente esto refleja las desventajas que representan para ellas los sistemas educativos presenciales.

Otra vertiente relacionada con el género, estudiada en la sociedad estadounidense, es aquella que se refiere a la integración familiar y el género de quien es el jefe de familia. En la figura 85 se presenta la proporción de hogares que usaban Internet, divididos por zonas rural, urbana y central de las ciudades (inner) y por tipo de integración familiar en 1998. En esta figura se observa una brecha consistente entre los hogares de un padre o madre solo y aquellos constituidos en pareja.

El uso de Internet aumenta en los hogares que se encuentran integrados por una pareja; en la medida en que los hogares son monoparentales, sea el varón o la madre, el índice de usuarios tiende a disminuir y varía según la zona. Es de destacar que casi no existe diferencia de uso 
Figura 85

Proporción de hogares que usaban Internet en 1998, dividido por zona rural, urbana y central de las ciudades (inner) y por tipo de integración familiar

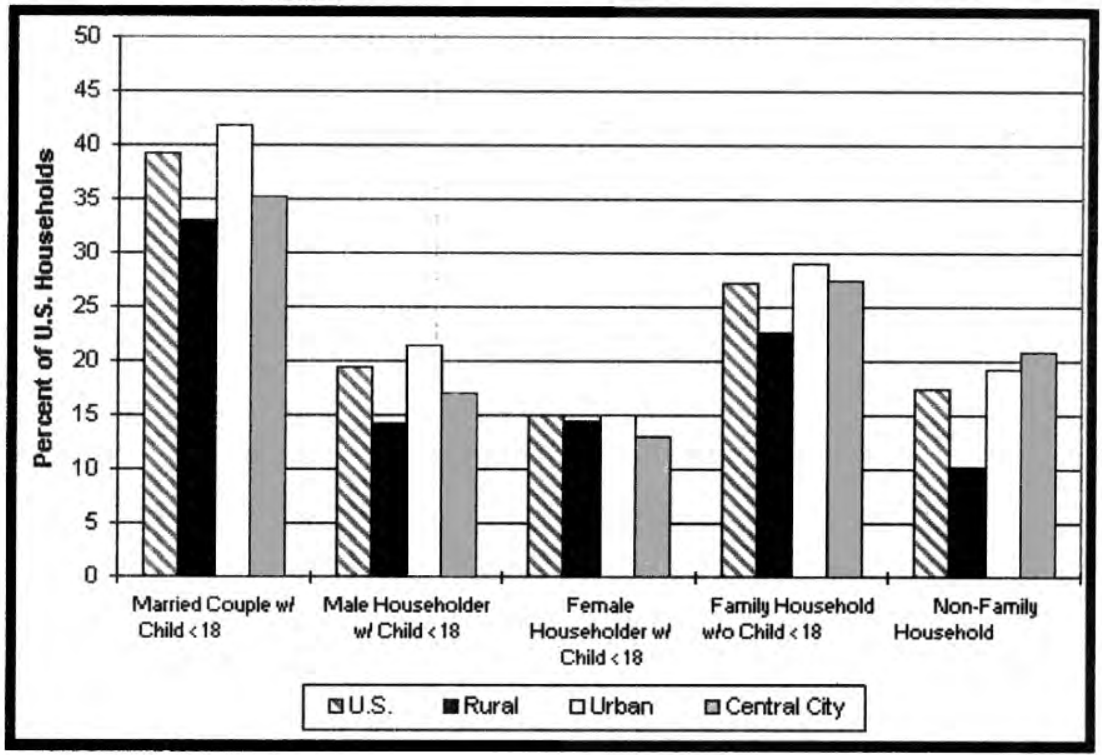

Tomado de David B. Bolt y Ray A. K. Crawford, Digital divide: computers and our children's future (Nueva York: TV Books, 2002), 198.

en las familias que están encabezadas por mujeres, sin importar si están en una zona rural, urbana o en el centro de una ciudad.

Las cifras de la figura 86 señalan el porcentaje de hogares que tenían computadora en 1998, dividido por zona rural, urbana y central de las ciudades (inner) y por tipo de hogar. La brecha entre padres solteros y parejas con hijos es más grande que la brecha en la propiedad de un teléfono, casi 30 por ciento en algún caso. El grupo más grande es el de parejas casadas con hijos; tienen los niveles más altos de cobertura, seguidos por los casos en que existe una familia y niños.

Si nos limitamos a los porcentajes globales del uso de Internet entre hombres y mujeres, en algunos casos la brecha se ha cerrado; sin embargo en otros la diferencia aún es muy grande y no se puede prever 
Figura 86

Porcentaje de hogares que tenían computadora en 1998, dividido por zona rural, urbana y central de las ciudades (inner) y por tipo de hogar

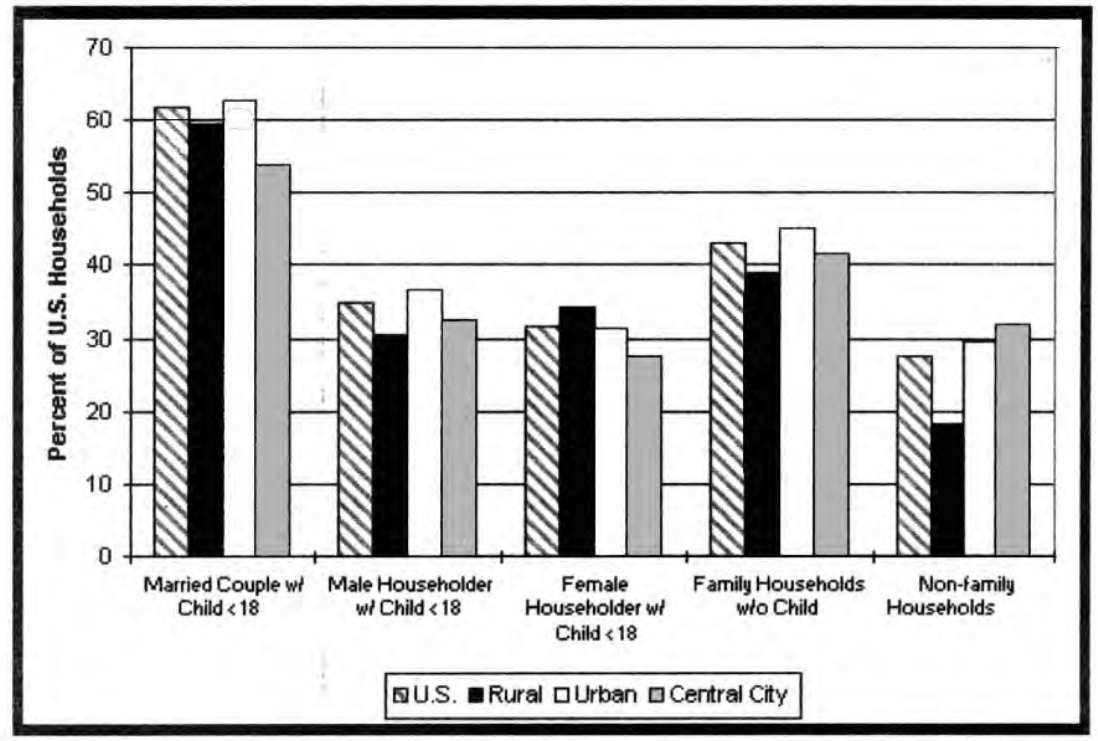

Tomado de David B. Bolt y Ray A. K. Crawford, Digital divide: computers and our children's future (Nueva York: TV Books, 2002), 182.

un pronto estrechamiento de la misma porque los problemas que lo impiden tienen sus fundamentos en concepciones religiosas o culturales muy difíciles de superar y que tienen que ver con el papel que juegan las mujeres en la sociedad.

Haciendo un breve resumen de la información presentada en este apartado, la brecha digital basada en el género existe y sus causas son múltiples. No se dice que es una cuestión meramente basada en la diferencia de género, sino en el uso que se hace de la red y en las posibilidades que cada género tiene para acceder a ella. 


\section{La edad también hace la diferencia}

La magnitud de la brecha digital no es uniforme pero en general se puede decir que las personas de mayor edad, aquellos que ya eran mayores cuando Internet entró en escena en la década de 1990, presentan mayor resistencia al uso de las tecnologías de la información.

Se tiende a decir que los jóvenes utilizan la red con gran facilidad y esto es cierto desde el momento en que los niños o jóvenes logran acceder a ella. Sin embargo hay que puntualizar que el problema que supone el acceso a Internet no es exclusivamente generacional, y que existen otros motivos relevantes para explicar la brecha, entre los que se encuentran los de tipo geográfico, económico, educativo e idiomático.

La directriz general establece que son los jóvenes quienes más usan Internet; la emplean para buscar información tanto como para oír música, chatear y jugar, entre otras cosas. Han manifestado mayor inclinación hacia la tecnología de la información y comunicación, adoptándola como parte de su cotidianeidad y como fuente de información y esparcimiento, y las tendencias nacionales y regionales, aunque con las variaciones propias de cada una de ellas, demuestran este hecho.

En el caso estadounidense, por ejemplo, la figura 87 nos permite determinar la proporción de usuarios de Internet de acuerdo con siete rangos de edad en 1995. De estos rangos sobresale el grupo de 35-44 años con el 25 por ciento de usuarios, seguido del 23 por ciento que corresponde a 18-24 años, el 17 por ciento de 25-29 años, y para 30-34 y 45-54 años, el 15 por ciento cada uno. A partir de los 55 años la proporción de usuarios disminuye sensiblemente. Otra lectura de la misma figura nos permite determinar que la mayor proporción de usuarios estadounidenses de Internet tienen entre 18 y 29 (el 40 por ciento) y 30 y 44 años ( 40 por ciento), y que esto obedece a las actividades que corresponden a cada segmento. Es decir, de los 18 a los 29 se encuentran en formación, en tanto que de los 30 a los 44 se está en alguna actividad económica. 
Figura 87

Usuarios estadounidenses de Internet por grupos de edad, 1995

Edad (Usuarios de Internet estadounidenses)

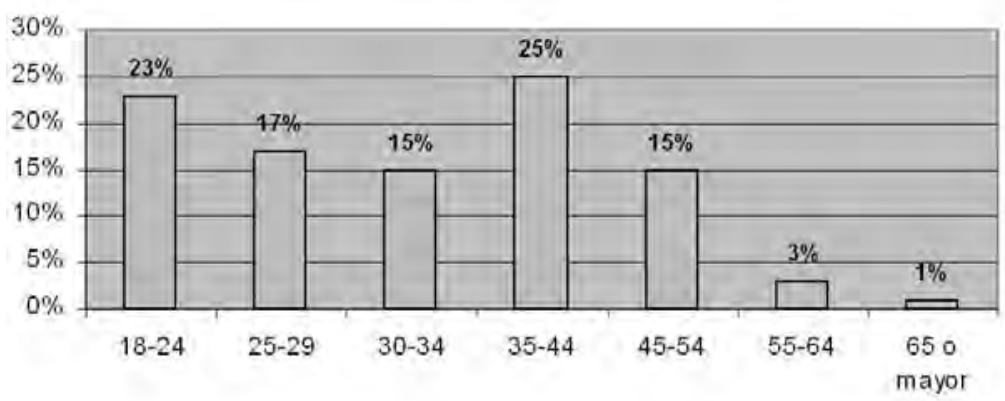

Fuente: O'Reilly and Associates.

Bajo otro criterio, Kuttan y Peters, con ayuda de la figura 88, nos permiten conocer con mayor detalle cuál es la proporción de usuarios de Internet estadounidenses con relación a su grupo de edad. Esta información es interesante toda vez que decir que los jóvenes usan más Internet, sin un referente de la proporción de éstos con relación a la población total de cada grupo, sería un error de interpretación que podría guiar a conclusiones apresuradas.

En la figura 88 la proporción de usuarios de Internet por grupo de edad guarda cierta similitud cuando se observan los datos que representan a los tres primeros segmentos (9-17, 18-24 y 25-49 años), en tanto que se percibe una diferencia de casi la mitad en el último grupo. El 53.4 por ciento de los estadounidenses que tienen de 9 a 17 años de edad, el 56.8 de quienes tienen entre 18 y 24 años y el 55.4 por ciento de quienes tienen entre 25 a 49 años, son usuarios de Internet; estas cifras contrastan con el 29.6 por ciento de usuarios que tienen más de 50 años. 
Figura 88

Proporción de usuarios estadounidenses de

Internet por grupos de edad

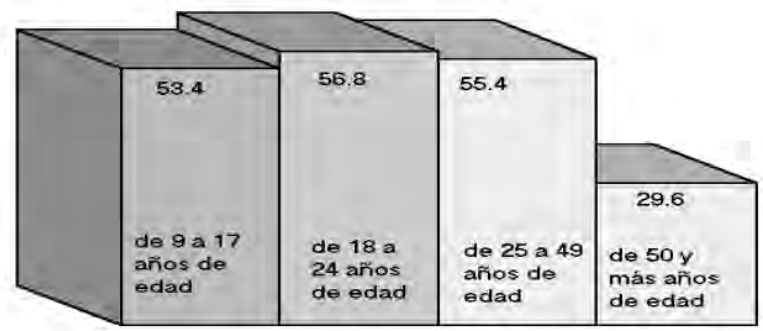

Figura 1.6. Proporción de usuarios de Internet, por grupos de edad

Tomado de Appu Kuttan y Laurence Peters, From digital divide to digital opportunity (Lanham, Maryland: Scarecrow Press, 2003), 34.

Al estratificar los grupos sociales por edad se ha encontrado que los usuarios más frecuentes de Internet son aquellos que están entre los 18 y los 49 años. El grupo de las personas mayores de 50 años tiene el menor índice de uso, y es lógico ya que cuando crecieron y fueron educados no había, tanto en la escuela como en casa, computadoras personales ni se tenía la posibilidad de conexión a Internet.

En 2002 los jóvenes estadounidenses de entre 12 y 35 años constituían el grupo que más utilizaba la red al representar el 80 por ciento de los usuarios; en contraste, sólo el 34 por ciento de las personas mayores de 65 años tenían conexión. ${ }^{24}$

En el Reino Unido la brecha por edad es considerable, el 89 por ciento de las personas entre 16 y 24 años de edad emplean Internet mientras que sólo el 14 por ciento de las personas con 65 años o más tienen una conexión a la red. ${ }^{25}$

24 Ibid., 8. 
La brecha digital por edad en Alemania es muy amplia y se ha mantenido así por varios años. Las personas mayores de 60 años hacen poco uso de Internet, ya que sólo el cinco por ciento de ellos tiene acceso a ésta; en oposición, el 73 por ciento de todos los usuarios alemanes eran jóvenes menores de 40 años. No obstante que ese porcentaje disminuyó a 65 por ciento en 2002, la brecha digital basada en la edad ha permanecido igual. En ese año, por ejemplo, sólo el cinco por ciento de las personas de 60 años o más tenían acceso a Internet. ${ }^{26}$

En Italia la brecha basada en la diferencia de edades existe y es enorme. Mientras que la proporción de personas mayores que tiene una computadora y acceso a Internet es casi marginal, los jóvenes poseen más equipo y tienen mayor acceso a la red.

Por ejemplo, en el año 2000 sólo el cinco por ciento de los hogares italianos cuyo jefe de familia era mayor de 65 años poseía una computadora y únicamente el tres por ciento tenía acceso a Internet. En contraste, 40 por ciento de los hogares cuyo jefe de familia tenía entre 31 y 50 años tenían una computadora y aproximadamente el 30 por ciento de tales cabezas de familia habían usado Internet en ese año. ${ }^{27}$

25 Ibid., 11.

26 B. van Eimeren, H. Gerhard y B. Frees, "ARD/ZDF-Online-Studie 2002 Entwicklung der Online-Nutzung in Deutschland: Mehr Routine, Wengier entdeckerfreude", Media Perspektiven, 8, 346-362, citado por Wenhong Chen y Barry Wellman, Charting and bridging digital divides: comparing socio-economic, gender, life stage, and rural-urban Internet access and use in eight countries. Octubre 27 , 2003, 12, disponible http://www.amd.com/us-en/assets/content_type/DownloadableAssets/FINAL_REPORT_CHARTING_DIGI_DIVIDES.pdf [Agosto 6, 2004].

27 L. Frey, "The digital divide by age groups in the countries involved in NESIS", documento presentado en la Statistical Information Systems Conference for Good Governance within the New Economy, Olimpia, Grecia, citado por Wenhong Chen y Barry Wellman, Charting and bridging digital divides: comparing socio-economic, gender, life stage, and rural-urban Internet access and use in eight countries. Octubre 27, 2003, 14, disponible http://www.amd.com/us-en/assets/content_type/DownloadableAssets/FINAL_REPORT_CHARTING_DIGI_DIVIDES. pdf [Agosto 6, 2004]. 
En Europa Oriental las personas entre 60 y 75 años de edad representan el 1.8 por ciento de los usuarios de Internet; menos de cinco por ciento de los jubilados tienen acceso a Internet en Eslovenia, $\mathbf{8 4 . 4}$ por ciento de los usuarios de Bielorrusia tiene menos de 30 años; sólo el ocho por ciento de las personas de entre 50 y 59 años y sólo un uno por ciento de aquellos que tienen entre 60 y 65 años tienen acceso a Internet en Estonia. ${ }^{28}$

La brecha entre jóvenes y personas mayores también se observa en Japón. Los jóvenes de 20 años tienen 30 veces más posibilidades de usar Internet que los mayores; mientras que las personas de alrededor de 20 años tienen acceso a Internet en un 80 por ciento -43 por ciento mediante el uso de computadoras y 53 por ciento mediante un teléfono móvil-, el 15 por ciento de las personas de 60 años que usan Internet, la mayoría de las veces se conectan mediante una computadora. ${ }^{29}$

Los jóvenes coreanos se han incorporado al uso de Internet en forma por demás vigorosa. Sin embargo el grupo de las personas mayores de 50 años usuarias de Internet se ha mantenido prácticamente igual, esto explica el que la brecha digital entre jóvenes y mayores se haya ampliado. Posiblemente este sea el país, de los cuales disponemos de datos, en el que la brecha generacional se manifiesta con una apertura tan marcada. La brecha digital que existe en la sociedad coreana entre quienes tienen de 7 a 19 años y el grupo de personas mayores de 50 se ha ampliado rápidamente de 40 puntos en 1999 a 70 puntos en 2000 y a 84 en 2001.30 Algo similar ha ocurrido entre los

28 Kuttan y Peters, 120.

29 Chen y Wellman, 16.

30 Y. Soe, The digital divide: an analysis of Korea's Internet diffusion, tesis inédita de maestría, Universidad Georgetown, Washington, citada por Wenhong Chen y Barry Wellman, Charting and bridging digital divides. comparing socio-economic, gender, life stage, and rural-urban Internet access and use in eight countries, Octubre 27, 2003, 18, disponible http:/www.amd.com/us-en/assets/ content_type/DownloadableAssets/FINAL_REPORT_CHARTING_DIGI_DIVIDES.pdf [Agosto 6, 2004]. 
estudiantes de nivel superior y quienes sólo tienen el equivalente a la escuela secundaria, la brecha en 1999 era de 28 puntos y en 2001 se había ampliado a 40 puntos porcentuales. Este es un magnífico ejemplo de cómo algunos factores lejos de cerrar la brecha la pueden ampliar. La educación demanda el uso de Internet, lo que requiere que los estudiantes de los niveles superiores tengan acceso a ella, mientras que en los niveles más bajos esta demanda no tiene las mismas características y entonces la brecha se amplía.

La mayoría de los usuarios de Internet en China son jóvenes, sólo el 3.7 por ciento de personas mayores de 50 años utiliza la red. Sin embargo, a medida que pasa el tiempo, el grupo de jóvenes cercanos a los 35 años que es usuario de Internet crece. ${ }^{31}$

Las personas de entre 15 y 29 años de edad representan un porcentaje muy alto de los usuarios de Internet, así por ejemplo, 57 por ciento de los usuarios en China, 45 por ciento de los usuarios en Hong Kong y 52 por ciento de los usuarios en Taiwán tienen esa edad, y sólo el 5.7 por ciento de los habitantes de Corea del Sur mayores de 50 años usan Internet. ${ }^{32}$

La mayoría de los usuarios de la red son personas que tienen una edad menor a los 30 tanto en China como en el Reino Unido. ${ }^{33}$

La edad como variable en el estudio del uso de la TIC en México ha tomado dos vertientes, la primera de ellas se refiere a la edad del jefe de familia de los hogares que tienen computadora y la segunda a la edad de los usuarios de las computadoras e Internet. El INEGI ha encontrado que la proporción más grande de los hogares con computadora (57.2 por ciento en $1996,70.6$ por ciento en $1998,70.1$ por ciento en 2000 y 62.5 por ciento en 2002) corresponde a los jefes de familia que tienen más de 40 años de edad, seguidos por aquellos

31 Chen y Wellman, 20.

32 Kuttan y Peters, 114.

33 Servon, 43. 
que tienen de 31 a 40 años (33.5 por ciento en 1996, 21 por ciento en $1998,21.1$ por ciento en 2000 y 27.6 por ciento en 2002). ${ }^{34}$

Respecto de los mexicanos que utilizan computadora, el INEGI ha determinado siete rangos de edad, entre los seis y hasta los 55 y más años. Bajo este esquema las categorías con mayor porcentaje de usuarios de computadora se ubican en la población de 12 a 17 y de 18 a 24 años de edad, que en su conjunto representaron en 2001 el 54 , en 2002 el 51.4 y en 2004 el 48.2 por ciento de usuarios. Los mexicanos de 25 a 34 y de 35 a 44 años son quienes, en número, ocupan el segundo lugar como usuarios de Internet. A partir de los 45 y más años de edad se reduce la cantidad de usuarios, que incluso es menor que entre la población de seis a 11 años de edad. Los niños de seis a 11 años de edad se están convirtiendo en usuarios de computadoras de forma lenta pero continua al pasar del 8 por ciento en 2001 al 10.7 por ciento en 2002 y al 13.1 por ciento en $2004 .{ }^{35}$

Del mismo modo, la proporción de usuarios de Internet se concentra entre la población de 12 a 17 y de 18 a 24 años de edad, ya que entre ambos grupos sumaron en 2001 el 55.8 por ciento, en 2002 el 53.9 por ciento, en 2004 el 51.7 por ciento y en 2005 el 53.8 por ciento de usuarios de la red, en tanto que los grupos de 25 a 34 y de 35 a 44 años en su conjunto tuvieron el 30.3 por ciento en 2001, el 33.4 por ciento en 2002 , el 34.6 por ciento en 2004 y el 29.8 por ciento en 2005. ${ }^{36}$ La discrepancia entre el uso de computadoras y el uso de Internet se encuentra en los segmentos de la población de seis a 11

34 INEGI, Hogares con computadora por edad y escolaridad del jefe de familia, 1996 a 2002, disponible http://www.inegi.gob.mx/est/contenidos/espanol/rutinas/ept.asp? $\mathrm{t}=$ tinf039\&c $=3463$ [Julio 13, 2005].

35 INEGI, Población de seis años y más que utiliza computadora por grupos de edad, 2001, 2002 y 2004, disponible http://www.inegi.gob.mx/est/contenidos/ espanol/rutinas/ept.asp?t $=$ tinf214\&c $=5567$ [Julio 13, 2005].

36 INEGI, Usuarios de Internet por grupos de edad, 2001 a 2005, disponible http:// www.inegi.gob.mx/est/contenidos/espanol/rutinas/ept.asp?t $=\operatorname{tinf} 214 \& \mathrm{c}=5567$ [Noviembre 22, 2005]. 
años y de 45 años o más, ya que es este último el que tiene más usuarios de Internet que el primero.

El 73 por ciento de los mexicanos varones de entre 16 y 30 años son quienes más emplean la computadora e Internet; les sigue el grupo de quienes tienen entre 31 y 49 años, que emplean la red en un 50 por ciento; y finalmente está el grupo de 50 años y más, que sólo se conecta en un 15 por ciento. Pero el comportamiento de las mujeres es totalmente diferente, aquellas que tienen entre 16 y 30 años usan estos recursos en un 88 por ciento, 15 puntos más que los hombres. El 78 por ciento de las mujeres de entre 31 y 49 usan Internet, esto es 28 puntos más que los hombres, y las mujeres de 50 o más años se conectan en un 80 por ciento, un 65 por ciento más que los hombres. Esta característica no se presenta en ningún otro país de los que poseemos información. ${ }^{37}$

El 77 por ciento de los usuarios árabes de Internet tiene entre 21 y 35 años de edad, en comparación con el 4.5 por ciento que son mayores de 40.38

Los jóvenes constituyen el grupo que mayor beneficio ha recibido de la tecnología debido a que hacen mayor uso de ella, aunque cabe señalar que quienes provienen de hogares de bajo ingreso económico han tenido su primer contacto con la TIC fuera de casa, en la escuela o en la biblioteca pública. Por ello es tan importante que la tecnología llegue al grupo de jóvenes pobres mediante la oferta de servicios en sitios públicos: bibliotecas, escuelas, centros cívicos e iglesias entre otros. ${ }^{39}$ Esta situación implica que los profesores y los bibliotecarios estén adecuadamente capacitados para entrenar a los usuarios de sus servicios. Como se ha dicho a lo largo de este trabajo, no basta con que se instalen computadoras y conexiones a Internet, es necesario que los usuarios sepan sacar el mayor provecho de las herramientas tecnológicas.

37 Zenker, "Navegan más las mujeres”, 2C.

38 Kuttan y Peters, 119.

39 Servon, 107-109. 
Como puede observarse por la información recopilada sobre las distintas naciones, la brecha digital es diferente en profundidad o amplitud entre los jóvenes y las personas mayores; pero independientemente de la sociedad que se analice, la brecha basada en la edad y el uso de Internet es un hecho.

Algunos países han hecho esfuerzos especiales para tratar de cerrar la brecha; en algunos de ellos la política tiende a fomentar el uso de la TIC por los jóvenes y se ha olvidado a las personas de mayor edad. En estos casos parecería que la política para cerrar la brecha consiste en esperar a que los usuarios mayores desaparezcan para terminar con el problema, pues raramente se realizan esfuerzos para adiestrar a los mayores en el uso de las tecnologías de la información. Con esto también se les margina de un mercado laboral que exige cada vez más, como elemento importante para el trabajo, el adecuado manejo de la TIC.

\section{Origen étnico y brecha digital: el caso estadounidense}

Debido a la forma en que se integra la sociedad estadounidense, ha sido difícil hacer generalizaciones respecto de la brecha digital, por lo que una de las variables tomadas en cuenta ha sido el origen étnico. En vista de ello se han tenido consideraciones especiales para conocer el funcionamiento, las necesidades y los problemas que enfrentan los diferentes grupos étnicos que la integran. A diferencia de esta nación, en las sociedades más homogéneas el planteamiento no se basa tanto en las etnias como en las clases sociales a las que se pertenece o a los niveles de ingreso económico. ${ }^{40}$

La figura 89 proporciona información sobre el porcentaje de hogares que en 1998 tenían una computadora, dividido por zona rural, urbana y central de las ciudades (inner), complementada por grupo racial u origen étnico. Como sucede con la posesión de teléfono, los

40 Applebaum, "Facing the digital divide", 1. 
Figura 89

Porcentaje de hogares estadounidenses que tenían una computadora en 1998, dividido por zona rural, urbana y central de las ciudades (inner)

y por grupo racial u origen étnico

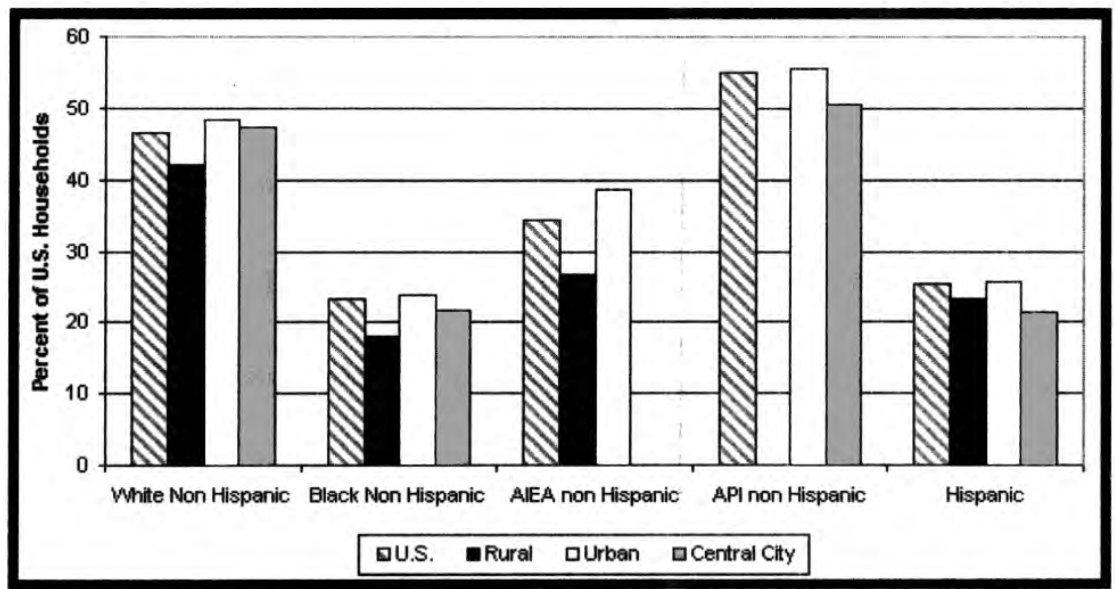

Notas: Los estándares para AIEA (por sus siglas en inglés), Indios americanos/Esquimales/Aleutianos, cuya barra sobre la penetración en la zona central de las ciudades falta, se observa en línea como el 35.6 por ciento; los estándares para API (por sus siglas en inglés), Isleños de Asia/Pacífico, cuya barra para la penetración en zona rural falta, se observa en línea como el 40.6 por ciento.

Tomado de David B. Bolt y Ray A. K. Crawford, Digital divide: computers and our children's future (Nueva York: TV Books, 2002), 179.

afroamericanos y los hispanos se encuentran rezagados en casi todas las zonas. El grupo con mayor rezago es el de los negros no hispanos, seguido por los hispanos.

En la figura 90 el porcentaje de hogares estadounidenses que tenían computadora en 1998, se ha dividido por zona rural, urbana y central de las ciudades (inner) y por raza/origen. Debe notarse que el uso de Internet entre los hispanos y afroamericanos en cualquier medio ambiente está por debajo de los blancos que habitan las zonas rurales y de otros grupos raciales que incluyen a los nativos americanos en reservaciones. 
Figura 90

Porcentaje de hogares estadounidenses que tenían una computadora en 1998, dividido por zona rural, urbana y central de las ciudades (inner)

y por raza/origen

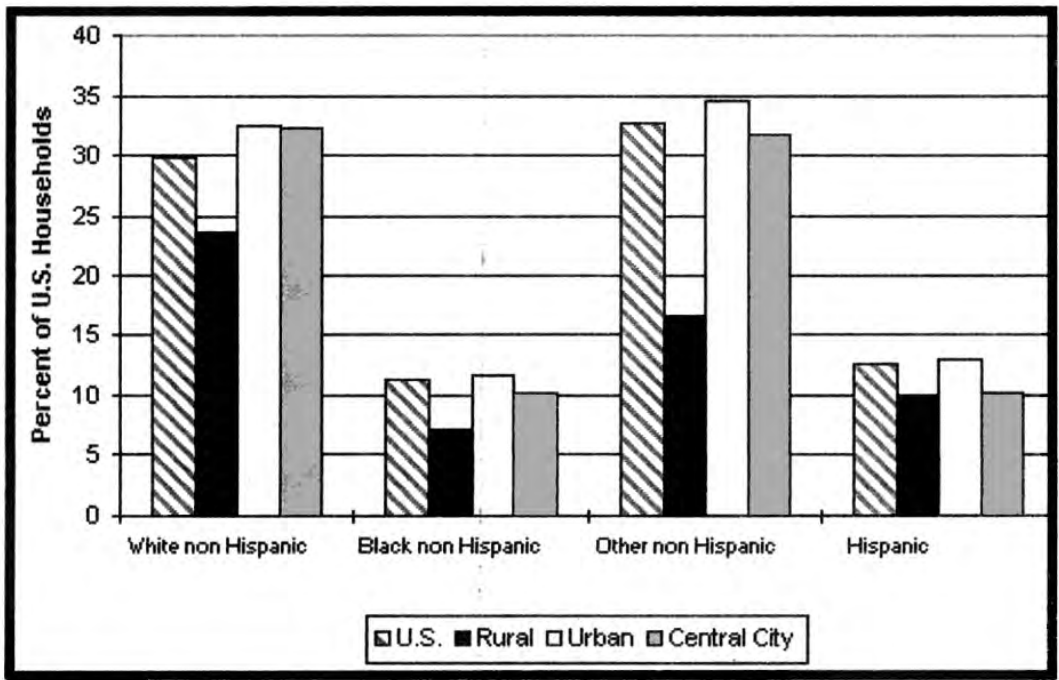

Tomado de David B. Bolt y Ray A. K. Crawford, Digital divide: computers and our children's future (Nueva York: TV Books, 2002), 187.

La figura 91 permite apreciar el comportamiento de la sociedad estadounidense respecto de la posesión de computadoras en 1994, 1997, 1998 y 1999. Se puede decir que durante los años que incluye la serie, se mantuvo la tendencia tanto en crecimiento como en la proporción de los distintos grupos étnicos.

En 2000 las cifras sobre la composición étnica de los estadounidenses que tenían acceso a Internet indicaban que los asiáticoamericanos superaban a las demás etnias, incluso a los blancos con 10.7 puntos porcentuales, y que los hispanos y los afroamericanos, aunque habían incrementado su acceso a la red, aún continuaban siendo los grupos más rezagados como puede apreciarse en la figura 92. 


\section{La brecha digital y sus determinantes}

Figura 91

Proporción de hogares estadounidenses con computadora por raza

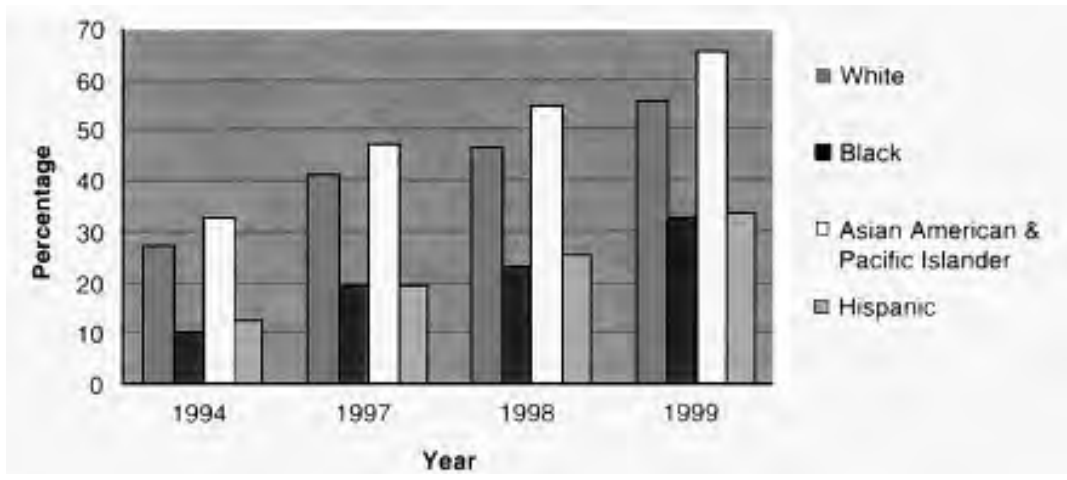

Figura 2.2. Porcentaje de hogares estadounidenses con computadora por raza.

Fuente: US Department of Commerce (2000a)

Tomado de Lisa J. Servon, Bridging the digital divide: technology, community, and public policy (Malden, Mass.: Blackwell Publishing, 2002), 29.

Figura 92

Proporción de hogares estadounidenses con acceso a Internet, basado en la raza y origen étnico

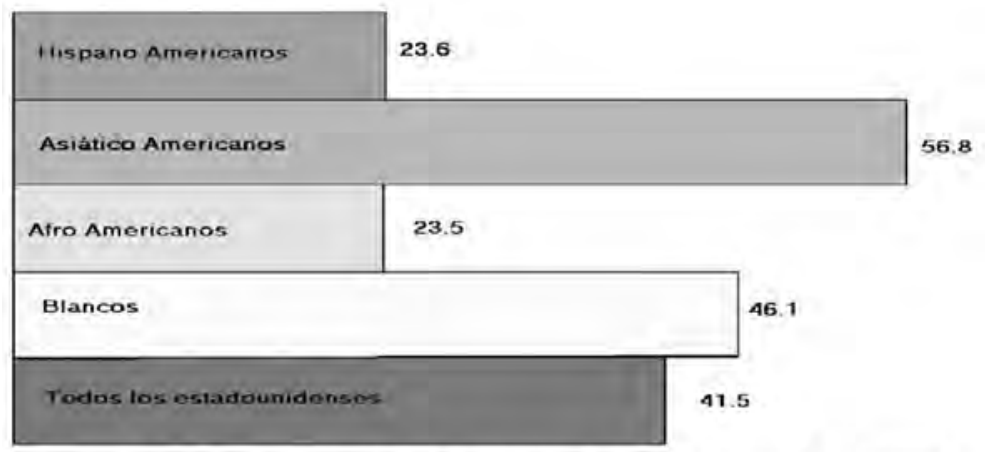

Figura 1.4. Proporción de hogares con acceso a Internet. basado en la raza y origen étnico

Tomado de Appu Kuttan y Laurence Peters, From digital divide to digital opportunity

(Lanham, Maryland: Scarecrow Press, 2003), 27. 
Figura 93

Diferencias demográficas sobre el acceso y uso de la red por blancos

\begin{tabular}{|c|c|c|c|c|c|c|c|c|c|}
\hline \multirow[t]{3}{*}{31} & ceso y & de la r & or blance & urante & iodos & nрo & & & \\
\hline & \multicolumn{3}{|c|}{ IDS 2} & \multicolumn{3}{|c|}{ IDS3 } & \multicolumn{3}{|c|}{ IDS4 } \\
\hline & $\begin{array}{c}\text { Sin } \\
\text { acceso }\end{array}$ & $\begin{array}{c}\text { Sólo } \\
\text { acceso }\end{array}$ & $\begin{array}{l}\text { Usuarios } \\
\text { Web }\end{array}$ & $\begin{array}{c}\operatorname{Sin} \\
\text { acceso }\end{array}$ & $\begin{array}{c}\text { Sólo } \\
\text { acceso }\end{array}$ & $\begin{array}{l}\text { Usuarios } \\
\text { Web }\end{array}$ & $\begin{array}{c}\text { Sin } \\
\text { acceso }\end{array}$ & $\begin{array}{c}\text { Sólo } \\
\text { acceso }\end{array}$ & $\begin{array}{l}\text { Usuarios } \\
\text { Web }\end{array}$ \\
\hline $\mathrm{N}$ & 2,825 & 569 & 1,365 & 3,185 & 569 & 2,227 & 1,63 & 285 & 1,522 \\
\hline \multicolumn{10}{|l|}{ Edad } \\
\hline$<25$ & 7,41 & 15,66 & 25,39 & 6,81 & 11,14 & 26,58 & 7,10 & 8,50 & 23,49 \\
\hline $25-45$ & 38,95 & 50,04 & 52,74 & 36,02 & 46,90 & 48,75 & 34,81 & 46,30 & 50,57 \\
\hline $46-64$ & 29,61 & 25,52 & 19,52 & 29,63 & 34,15 & 22,93 & 29,99 & 38,09 & 22,35 \\
\hline$>64$ & 24,02 & 8,78 & 2,35 & 27,54 & 7,81 & 1,74 & 28,10 & 7,11 & 3,59 \\
\hline Total & $100 \%$ & $100 \%$ & $100 \%$ & $100 \%$ & $100 \%$ & $100 \%$ & $100 \%$ & $100 \%$ & $100 \%$ \\
\hline \multicolumn{10}{|l|}{ Educación } \\
\hline Menor que preparatoria & 21,93 & 13,38 & 11,64 & 21,99 & 12,33 & 14,66 & 25,04 & 9,62 & 13,22 \\
\hline Preparatoria completa & 40,18 & 30,74 & 17,46 & 42,23 & 35,75 & 17,69 & 43,01 & 37,84 & 18,60 \\
\hline Educación superior incompleta & 23,68 & 30,79 & 31,58 & 22,37 & 30,18 & 30,13 & 21,39 & 38,78 & 29,77 \\
\hline Graduado universitario & 14,20 & 25,09 & 39,31 & 13,41 & 21,74 & 37,51 & 10,56 & 13,76 & 38,41 \\
\hline | Total & $100 \%$ & $100 \%$ & $100 \%$ & $100 \%$ & $100 \%$ & $100 \%$ & $100 \%$ & $100 \%$ & $100 \%$ \\
\hline \multicolumn{10}{|l|}{ Ocupación } \\
\hline Profesional & 12,28 & 22,33 & 26,33 & 11,33 & 17,51 & 26,24 & 11,00 & 17,67 & 27,64 \\
\hline Empleado de oficina & 28,51 & 38,76 & 39,16 & 27,16 & 38,27 & 38,95 & 23,76 & 37,82 & 38,40 \\
\hline Obrero & 13,68 & 9,64 & 5,63 & 15,16 & 15,14 & 7,04 & 16,65 & 15,96 & 7,34 \\
\hline Ama de casa & 13,92 & 9,32 & 3,80 & 13,94 & 11,16 & 4,47 & 16,43 & 9,38 & 4,29 \\
\hline Estudiante & 2,13 & 9,59 & 18,28 & 1,64 & 7,46 & 17,78 & 1,42 & 5,78 & 15,27 \\
\hline Retirado & 29,10 & 9,63 & 4,85 & 30,77 & 10,45 & 5,52 & 30,40 & 12,74 & 5,78 \\
\hline Total & $100 \%$ & $99,26 \%$ & $98,06 \%$ & $100 \%$ & $100 \%$ & $100 \%$ & $99,67 \%$ & $99,36 \%$ & $98,72 \%$ \\
\hline \multicolumn{10}{|l|}{ Ingreso familiar } \\
\hline$<\$ 10 K$ & 11,49 & 3,79 & 2,59 & 12,80 & 3,10 & 2,87 & 13,60 & 5,51 & 2,53 \\
\hline$\$ 10 K-\$ 19,9$ & 14,12 & 6,73 & 5,34 & 15,87 & 8,65 & 5,01 & 15,91 & 9,11 & 4,47 \\
\hline$\$ 20 K-\$ 29,9$ & 17,67 & 12,47 & 9,69 & 18,97 & 14,28 & 9,63 & 17,39 & 15,60 & 10,16 \\
\hline$\$ 30 K-\$ 39,9$ & 17,62 & 16,20 & 11,36 & 17,35 & 14,37 & 13,48 & 18,31 & 12,37 & 11,65 \\
\hline$\$ 40 K-\$ 59,9$ & 20,93 & 28,41 & 27,44 & 21,14 & 30,53 & 26,13 & 19,21 & 30,46 & 25,95 \\
\hline$\$ 60 \mathrm{~K}+$ & 18,17 & 32,39 & 43,57 & 13,87 & 29,07 & 42,88 & 15,58 & 26,95 & 45,24 \\
\hline | Total & $100 \%$ & $100 \%$ & $100 \%$ & $100 \%$ & $100 \%$ & $100 \%$ & $100 \%$ & $100 \%$ & $100 \%$ \\
\hline \multicolumn{10}{|l|}{ Género } \\
\hline Masculino & 43,65 & 48,22 & 60,68 & 44,96 & 44,51 & 54,66 & 44,71 & 54,37 & 55,40 \\
\hline Femenino & 56,35 & 51,78 & 39,32 & 55,04 & 55,49 & 45,34 & 55,29 & 54,63 & 44,60 \\
\hline |Total & $100 \%$ & $100 \%$ & $100 \%$ & $100 \%$ & $100 \%$ & $100 \%$ & $100 \%$ & $100 \%$ & $100 \%$ \\
\hline \multicolumn{10}{|l|}{$\%$ de quien... } \\
\hline \begin{tabular}{||l} 
Tiene PC \\
\end{tabular} & 26,52 & 63,43 & 81,86 & 23,61 & 54,51 & 77,57 & 21,63 & 51,28 & 77,57 \\
\hline \begin{tabular}{|l} 
Tiene acceso a una PC en \\
el trabajo
\end{tabular} & 23,39 & 58,43 & 68,16 & 26,32 & 58,18 & 64,48 & 23,75 & 54,89 & 63,05 \\
\hline
\end{tabular}

Tomado de Donna L. Hoffman, Thomas P. Novak y Ann E. Schlosser, "The evolution of the digital divide: examining the relationship of race to Internet access and usage over time", en Benjamin M. Compaine (ed.), The digital divide: facing a crisis or creating a myth? (Cambridge, Mass.: MIT Press, 2001), 52-53. 
Figura 94

Diferencias demográficas sobre el acceso y uso de la red por afroamericanos

\begin{tabular}{|c|c|c|c|c|c|c|c|c|c|}
\hline \multicolumn{10}{|c|}{$\begin{array}{l}\text { Tabla } 3.2 \\
\text { Diferencias demográficas sobre el acceso y uso de la red por afroamericanos durante tres periodos de tiempo }\end{array}$} \\
\hline & \multicolumn{3}{|c|}{ IDS 2} & \multicolumn{3}{|c|}{ IDS3 } & \multicolumn{3}{|c|}{ IDS4 } \\
\hline & $\begin{array}{c}\text { Sin } \\
\text { acceso }\end{array}$ & $\begin{array}{c}\text { Sólo } \\
\text { acceso }\end{array}$ & $\begin{array}{c}\text { Usuarios } \\
\text { Web }\end{array}$ & $\begin{array}{c}\text { Sin } \\
\text { acceso }\end{array}$ & $\begin{array}{c}\text { Sólo } \\
\text { acceso }\end{array}$ & $\begin{array}{l}\text { Usuarios } \\
\text { Web }\end{array}$ & $\begin{array}{c}\text { Sin } \\
\text { acceso }\end{array}$ & $\begin{array}{c}\text { Sólo } \\
\text { acceso }\end{array}$ & $\begin{array}{l}\text { Usuarios } \\
\text { Web }\end{array}$ \\
\hline $\mathrm{N}$ & 298 & 73 & 109 & 387 & 108 & 190 & 266 & 30 & 144 \\
\hline \multicolumn{10}{|l|}{ Edad } \\
\hline$<25$ & 16,20 & 21,25 & 46,30 & 13,00 & 17,53 & 38,51 & 10,78 & 5,46 & 49,47 \\
\hline $25-45$ & 37,23 & 53,43 & 39,13 & 46,72 & 51,82 & 50,12 & 38,40 & 47,24 & 41,76 \\
\hline $46-64$ & 22,76 & 21,04 & 14,10 & 22,02 & 22,96 & 11,01 & 28,68 & 46,46 & 8,31 \\
\hline$>64$ & 23,80 & 4,28 & 0,47 & 18,27 & 7,70 & 0,35 & 22,15 & 0,84 & 0,47 \\
\hline Total & $100 \%$ & $100 \%$ & $100 \%$ & $100 \%$ & $100 \%$ & $100 \%$ & $100 \%$ & $100 \%$ & $100 \%$ \\
\hline \multicolumn{10}{|l|}{ Educación } \\
\hline Menor que preparatoria & 40,52 & 16,09 & 29,45 & 36,57 & 25,39 & 16,37 & 41,57 & 38,27 & 30,63 \\
\hline Preparatoria completa & 29,75 & 33,70 & 14,21 & 35,35 & 24,71 & 11,57 & 33,00 & 32,20 & 17,14 \\
\hline Educación superior incompleta & 17,71 & 27,45 & 26,04 & 20,70 & 36,96 & 37,51 & 18,75 & 22,90 & 32,50 \\
\hline Graduado universitario & 12,03 & 25,58 & 30,30 & 7,37 & 12,94 & 34,54 & 6,67 & 6,63 & 19,74 \\
\hline Total & $100 \%$ & $100 \%$ & $100 \%$ & $100 \%$ & $100 \%$ & $100 \%$ & $100 \%$ & $100 \%$ & $100 \%$ \\
\hline \multicolumn{10}{|l|}{ Ocupación } \\
\hline Profesional & 11,32 & 24,02 & 28,59 & 12,36 & 25,23 & 26,55 & 11,84 & 15,60 & 18,95 \\
\hline Empleado de oficina & 23,13 & 35,66 & 28,56 & 25,80 & 39,60 & 38,91 & 22,89 & 54,82 & 28,94 \\
\hline Obrero & 14,00 & 7,46 & 2,99 & 18,47 & 10,36 & 3,08 & 13,09 & 18,61 & 9,61 \\
\hline Ama de casa & 10,28 & 2,72 & 0,00 & 11,13 & 3,37 & 1,10 & 20,75 & 0,00 & 2,15 \\
\hline Estudiante & 7,10 & 17,33 & 30,46 & 5,39 & 9,01 & 28,36 & 4,42 & 3,18 & 29,60 \\
\hline Retirado & 33,56 & 9,87 & 8,09 & 26,85 & 12,43 & 1,99 & 25,68 & 5,29 & 4,66 \\
\hline Total & $99 \%$ & $97,06 \%$ & $98,70 \%$ & $100 \%$ & $100 \%$ & $100 \%$ & $98,67 \%$ & $97,49 \%$ & $93,91 \%$ \\
\hline \multicolumn{10}{|l|}{ Ingreso familiar } \\
\hline$<\$ 10 \mathrm{~K}$ & 34,28 & 9,02 & 15,62 & 30,92 & 12,63 & 4,55 & 26,80 & 4,75 & 8,56 \\
\hline$\$ 10 K-\$ 19,9$ & 19,87 & 11,31 & 2,90 & 28,80 & 12,23 & 4,24 & 21,50 & 22,54 & 6,98 \\
\hline$\$ 20 K-\$ 29,9$ & 17,70 & 22,00 & 10,63 & 15,43 & 19,71 & 11,93 & 19,07 & 27,86 & 12,44 \\
\hline$\$ 30 \mathrm{~K}-\$ 39,9$ & 8,87 & 8,32 & 11,23 & 6,00 & 16,33 & 19,36 & 12,00 & 14,33 & 14,48 \\
\hline$\$ 40 K-\$ 59,9$ & 10,94 & 24,28 & 27,43 & 12,52 & 26,46 & 18,81 & 11,25 & 19,81 & 24,75 \\
\hline$\$ 60 \mathrm{~K}+$ & 8,34 & 25,07 & 32,30 & 6,33 & 12,64 & 41,11 & 9,38 & 10,71 & 32,79 \\
\hline Total & $100 \%$ & $100 \%$ & $100 \%$ & $100 \%$ & $100 \%$ & $100 \%$ & $100 \%$ & $100 \%$ & $100 \%$ \\
\hline \multicolumn{10}{|l|}{ Género } \\
\hline Masculino & 38,15 & 53,55 & 55,40 & 38,68 & 44,01 & 55,78 & 34,10 & 46,46 & 53,61 \\
\hline Femenino & 61,85 & 44,65 & 44,60 & 61,32 & 55,99 & 44,22 & 65,90 & 53,54 & 46,39 \\
\hline Total & $100 \%$ & $100 \%$ & $100 \%$ & $100 \%$ & $100 \%$ & $100 \%$ & $100 \%$ & $100 \%$ & $100 \%$ \\
\hline \multicolumn{10}{|l|}{$\%$ de quien... } \\
\hline Tiene PC & 16,70 & 44,18 & 65,05 & 14,82 & 34,53 & 65,62 & 12,09 & 29,30 & 68,24 \\
\hline $\begin{array}{l}\text { Tiene acceso a una PC en } \\
\text { el trabajo }\end{array}$ & 18,74 & 65,39 & 63,54 & 24,49 & 58,20 & 67,49 & 24,45 & 44,85 & 63,00 \\
\hline
\end{tabular}

Tomado de Donna L. Hoffman, Thomas P. Novak y Ann E. Schlosser, "The evolution of the digital divide: examining the relationship of race to Internet access and usage over time", en Benjamin M. Compaine (ed.), The digital divide: facing a crisis or creating a myth? (Cambridge, Mass.: MIT Press, 2001), 56-57. 
Figura 95

Diferencias demográficas sobre el acceso y uso de la red por hispanos

\begin{tabular}{|c|c|c|c|c|c|c|c|c|c|}
\hline \multicolumn{10}{|c|}{\begin{tabular}{|l|} 
Tabla 3.3 \\
Diferencias demográficas sobre el acceso y uso de la red por hispanos durante tres periodos de tiempo
\end{tabular}} \\
\hline & \multicolumn{3}{|c|}{ IDS 2} & \multicolumn{3}{|c|}{ IDS3 } & \multicolumn{3}{|c|}{ IDS4 } \\
\hline & $\begin{array}{c}\operatorname{Sin} \\
\text { acceso }\end{array}$ & $\begin{array}{c}\text { Sólo } \\
\text { acceso }\end{array}$ & $\begin{array}{l}\text { Usuarios } \\
\text { Web }\end{array}$ & $\begin{array}{c}\sin \\
\text { acceso }\end{array}$ & $\begin{array}{c}\text { Sólo } \\
\text { acceso }\end{array}$ & $\begin{array}{l}\text { Usuarios } \\
\text { Web }\end{array}$ & $\begin{array}{c}\operatorname{Sin} \\
\text { acceso }\end{array}$ & $\begin{array}{c}\text { Sólo } \\
\text { acceso }\end{array}$ & $\begin{array}{l}\text { Usuarios } \\
\text { Web }\end{array}$ \\
\hline $\mathrm{N}$ & 182 & 32 & 93 & 278 & 41 & 121 & 84 & 15 & 61 \\
\hline \multicolumn{10}{|l|}{ Edad } \\
\hline$<25$ & 16,85 & 46,51 & 55,20 & 13,92 & 34,30 & 45,99 & 10,01 & 33,56 & 46,91 \\
\hline $25-45$ & 61,51 & 36,09 & 36,39 & 53,83 & 58,02 & 40,92 & 45,86 & 41,13 & 41,22 \\
\hline $46-64$ & 16,98 & 17,40 & 5,45 & 21,29 & 7,68 & 10,17 & 30,41 & 25,32 & 8,36 \\
\hline$>64$ & 4,67 & 0,00 & 2,96 & 10,96 & 0,00 & 0,92 & 13,72 & 0,00 & 3,51 \\
\hline Total & $100 \%$ & $100 \%$ & $100 \%$ & $100 \%$ & $100 \%$ & $100 \%$ & $100 \%$ & $100 \%$ & $100 \%$ \\
\hline \multicolumn{10}{|l|}{ Educación } \\
\hline Menor que preparatoria & 35,00 & 29,67 & 41,20 & 55,55 & 36,21 & 28,85 & 52,01 & 14,60 & 34,38 \\
\hline Preparatoria completa & 32,70 & 28,18 & 8,64 & 27,95 & 35,94 & 14,11 & 24,58 & 37,44 & 20,62 \\
\hline Educación superior incompleta & 22,58 & 29,98 & 30,62 & 12,12 & 21,39 & 32,49 & 18,26 & 43,94 & 22,37 \\
\hline Graduado universitario & 9,67 & 25,78 & 19,55 & 4,37 & 6,46 & 24,55 & 5,15 & 4,02 & 22,63 \\
\hline Total & $100 \%$ & $100 \%$ & $100 \%$ & $100 \%$ & $100 \%$ & $100 \%$ & $100 \%$ & $100 \%$ & $100 \%$ \\
\hline \multicolumn{10}{|l|}{ Ocupación } \\
\hline Profesional & 11,83 & 14,18 & 16,22 & 6,95 & 11,22 & 21,77 & 8,93 & 16,14 & 23,32 \\
\hline Empleado de oficina & 28,59 & 32,88 & 30,62 & 26,86 & 30,59 & 43,83 & 16,35 & 45,55 & 30,77 \\
\hline Obrero & 19,37 & 8,35 & 4,36 & 25,62 & 35,24 & 4,91 & 14,02 & 0,00 & 0,00 \\
\hline Ama de casa & 19,52 & 3,62 & 2,09 & 20,09 & 0,00 & 0,62 & 37,98 & 0,00 & 2,52 \\
\hline Estudiante & 5,60 & 40,97 & 38,14 & 3,75 & 17,51 & 26,32 & 3,20 & 33,56 & 35,50 \\
\hline Retirado & 14,50 & 0,00 & 7,37 & 16,73 & 5,44 & 2,54 & 18,05 & 4,76 & 2,37 \\
\hline Total & $99,42 \%$ & $100 \%$ & $98,77 \%$ & $100 \%$ & $100 \%$ & $100 \%$ & $98,53 \%$ & $100 \%$ & $94,48 \%$ \\
\hline \multicolumn{10}{|l|}{ Ingreso familiar } \\
\hline$<\$ 10 \mathrm{~K}$ & 10,33 & 3,70 & 12,24 & 20,94 & 29,03 & 5,85 & 20,25 & 4,01 & 10,79 \\
\hline$\$ 10 K-\$ 19,9$ & 30,70 & 2,54 & 13,11 & 32,70 & 16,75 & 3,50 & 27,38 & 0,00 & 6,10 \\
\hline$\$ 20 K-\$ 29,9$ & 19,09 & 4,50 & 11,65 & 21,78 & 17,12 & 9,39 & 19,79 & 20,13 & 7,23 \\
\hline$\$ 30 \mathrm{~K}-\$ 39,9$ & 14,34 & 27,27 & 10,29 & 11,20 & 10,67 & 16,03 & 10,34 & 9,06 & 8,05 \\
\hline$\$ 40 \mathrm{~K}-\$ 59,9$ & 15,02 & 25,24 & 18,83 & 9,25 & 21,84 & 24,56 & 10,22 & 12,69 & 25,81 \\
\hline$\$ 60 \mathrm{~K}+$ & 10,52 & 36,77 & 33,87 & 4,14 & 4,59 & 40,67 & 12,02 & 54,11 & 42,02 \\
\hline Total & $100 \%$ & $100 \%$ & $100 \%$ & $100 \%$ & $100 \%$ & $100 \%$ & $100 \%$ & $100 \%$ & $100 \%$ \\
\hline \multicolumn{10}{|l|}{ Género } \\
\hline Masculino & 42,93 & 38,91 & 56,35 & 45,42 & 63,21 & 55,60 & 31,99 & 40,72 & 70,86 \\
\hline Femenino & 57,07 & 61,09 & 43,65 & 54,58 & 36,79 & 44,40 & 68,01 & 59,28 & 29,14 \\
\hline Total & $100 \%$ & $100 \%$ & $100 \%$ & $100 \%$ & $100 \%$ & $100 \%$ & $100 \%$ & $100 \%$ & $100 \%$ \\
\hline \multicolumn{10}{|l|}{$\%$ de quien... } \\
\hline Tiene PC & 26,26 & 58,21 & 61,99 & 13,90 & 36,16 & 72,00 & 11,54 & 20,09 & 77,45 \\
\hline $\begin{array}{l}\text { Tiene acceso a una PC en el } \\
\text { trabajo }\end{array}$ & 24,23 & 0,92 & 49,58 & 21,85 & 61,62 & 59,52 & 19,02 & 54,52 & 50,00 \\
\hline
\end{tabular}

Tomado de Donna L. Hoffman, Thomas P. Novak y Ann E. Schlosser, "The evolution of the digital divide: examining the relationship of race to Internet access and usage over time", en Benjamin M. Compaine (ed.), The digital divide: facing a crisis or creating a myth? (Cambridge, Mass.: MIT Press, 2001), 58-59. 
Hoffman, Novak y Schlosser han examinado la relación entre raza y acceso a Internet; en su estudio incluyen aspectos demográficos como edad, nivel educativo, ocupación, ingreso económico y género de tres grupos raciales: blancos, afroamericanos e hispanos. Los resultados de su trabajo se pueden observar en las figuras 93, 94 y 95 , que se complementan y permiten la comparación de estos tres grupos raciales.

En general se puede afirmar que la brecha digital es muy grande entre los tres grupos y aunque en algunos rubros parece cerrarse, en otros es de tal magnitud que da la impresión de que será imposible lograr su desaparición, al menos en un corto plazo, mientras no desaparezcan las diferencias sociales que caracterizan a cada grupo.

Tras analizar las figuras 92, 93 y 94, resulta interesante que entre blancos, afroamericanos e hispanos, sean los primeros donde se observa más amplia la brecha digital entre géneros. También hay que destacar que hay más usuarios de Internet entre los afroamericanos y los hispanos con nivel educativo inferior a la preparatoria que entre blancos. 


\title{
Determinantes culturales de la brecha digital
}

\begin{abstract}
n este capítulo se abordarán los aspectos culturales que determinan la brecha digital, concentrándonos específicamente en la lengua, la educación, la alfabetización, la lectura, la inclusión y marginación social y la participación política.
\end{abstract}

\section{La lengua en que está la información}

La utilización de la red proporciona una sensación de libertad, pareciera que una vez conectados no hay impedimentos para comunicarse con todos los servidores, todas las páginas y todas las personas. Sin embargo esta impresión es errónea, dada la imposibilidad de acceder a la información en un idioma de uso común para todos.

La mayor parte del contenido de Internet se encuentra en un solo idioma: el 87 por ciento de todo lo disponible en la red está en inglés. ${ }^{1} \mathrm{Y}$ aunque hay algunas otras lenguas, como el chino, que han ido incrementando su presencia, la información en esos idiomas no

1 Pippa Norris, The Worldwide Digital Divide: information poverty, the Internet and development (Cambridge, Mass.: John F. Kennedy School of Government, Harvard University, 2000), 5. Disponible http://ksghome.harvard.edu/ pnorris/ acrobat/psa2000dig.pdf [Agosto 1, 2005], y Nolan A. Bowie, "The digital divide: making knowledge available in a global context", en Centre for Educational Research and Innovation [y] National Center on Adult Literacy, Learning to bridge the digital divide. Education and skills (París: OCDE, 2000), 41. 
es trascendental por necesidad ya que la industria editorial, en particular en los campos científico y técnico, ha recurrido tradicionalmente al inglés. No se pretende decir que la información que se produce en idiomas distintos al inglés no sea relevante, sino indicar que es por estar en idiomas de menor cobertura mundial que los contenidos no llegan fácilmente a un público más amplio.

La proporción de sitios web en inglés es del 80 por ciento; sin embargo solamente el uno por ciento de la población mundial tiene como lengua materna ese idioma. ${ }^{2}$

El conocimiento del idioma es muy importante aun para los países de habla inglesa; así por ejemplo en los países anglófonos con niveles de analfabetismo alto, la utilización de Internet se dificulta, pues aunque muchos supusieron que con el uso de la tecnología se iba a depender menos de la lengua escrita, esto no ha resultado cierto. Se había pensado que con la capacidad de las computadoras para mostrar gráficos, ilustraciones, fotografías y videos, la lectura y la escritura no serían necesarios. En los países de habla diferente al inglés se requiere, además de utilizar la lengua materna correctamente, un cierto grado de dominio de la lengua inglesa ya que éste es un factor que hará posible utilizar con éxito Internet y beneficiarse de la información que en ella se encuentra.

Se puede suponer que los usuarios prefieren el uso de la información en su propio idioma, sin embargo el contenido de Internet es muy reducido en algunas lenguas debido al número de sus hablantes y a la capacidad de éstos para producir y distribuir información relevante (mediante la industria editorial y de servicios de información, entre otros) que se integre continuamente a la red y desde luego con la capacidad de utilizar la TIC. Se puede afirmar que el contenido de la red guarda correlación con la capacidad de producir información.

2 Servon, 43 . 
Por otra parte hay idiomas que están representados cada vez más, como es el caso del chino, que sin lugar a dudas satisfará poco a poco y en mayor medida las necesidades de los sinoparlantes, pero que será de poca utilidad para las personas que no hablen esa lengua.

Hay una diferencia sustancial entre los idiomas más utilizados por los seres humanos y su relación con las páginas de la red.

Así por ejemplo, más de mil millones hablan chino, 332 millones hablan español, 170 millones hablan portugués y otros 170 millones hablan ruso. De los millones de páginas en la red, sólo 3.87 están escritas en chino, 2.42 en español, 1.37 en portugués y 1.88 en ruso. Con un contenido que no es posible utilizar por el idioma materno, Internet es funcionalmente, y a causa del idioma, inútil para la mayoría de la población mundial.3

En 2000 se realizó en Estados Unidos un estudio patrocinado por Children's Partnership, que encontró cuatro tipos de barreras para el uso de Internet, éstas eran:

21 millones no utilizaban la red por falta de información local;

44 millones no lo hacían por no saber leer;

32 millones tenían problemas con el idioma en que está la información; y

26 millones debido a la falta de contenido diversamente cultural. ${ }^{4}$

Estados Unidos tiene 32 millones de habitantes cuya lengua materna no es el inglés y el 87 por ciento de los sitios de la red está en ese idioma. Sólo el dos por ciento de los sitios más populares pueden ser consultados por ese segmento de la población que no habla inglés. ${ }^{5}$

La figura 96 muestra la distribución de las páginas web de acuerdo con el idioma en que fueron producidas. Como se puede observar, las páginas web en inglés son casi el 70 por ciento, seguidas por

3 Kuttan y Peters, 110.

$4 \quad$ Ibid., 21.

5 The Children's Partnership, "Online content for low-income and underserved Americans", citado por Appu Kuttan y Laurence Peters, From digital divide to digital opportunity (Lanham, Maryland: Scarecrow Press, 2003), 21. 
Figura 96

Distribución de las páginas web por lengua

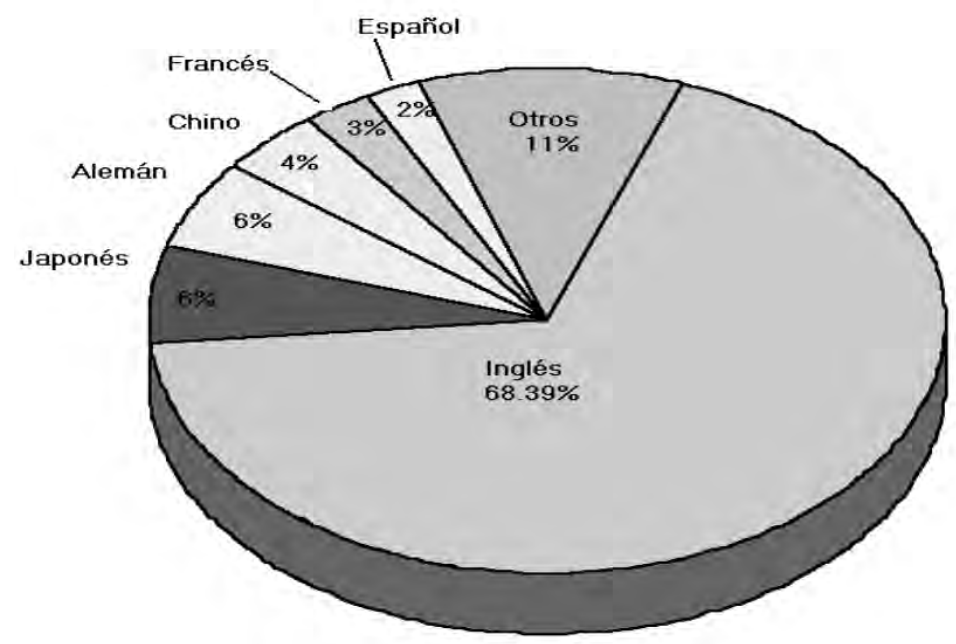

Tomado de Appu Kuttan y Laurence Peters, From digital divide to digital opportunity (Lanham, Maryland: Scarecrow Press, 2003), 110.

aquellas en japonés y alemán, que tienen tan sólo un seis por ciento cada una. La páginas en español representan el dos por ciento del total. Así que la mayoría de la información útil o es consultada en inglés o dejada al margen cuando el usuario carece de un nivel apropiado de comprensión e interacción en ese idioma.

La cuestión del uso de los diferentes idiomas utilizados en Internet es un asunto que aunque parece exclusivamente lingüístico, no lo es. El idioma es uno de los más complejos y significativos temas relacionados con el contenido y con otros argumentos más amplios de la tecnología de la información. El idioma se relaciona con muchas formas de división social que a su vez se vinculan con la nacionalidad, la economía, la cultura, la educación y la lectura; afecta dramáticamente la posibilidad de diversos grupos de tener acceso a Internet 
y publicar en ella en la medida en que es un medio de expresión de las diferentes identidades culturales. ${ }^{6}$

El inglés es necesario no sólo en Internet, es utilizado por grupos muy grandes de personas como lengua materna, segunda lengua o lengua de trabajo, entre otras formas. Así por ejemplo Warschauer menciona que 85 por ciento de los organismos internacionales hacen uso del inglés como una de sus lenguas oficiales, y el 85 por ciento del mercado cinematográfico realiza sus actividades básicamente en inglés. ${ }^{7}$

Sin embargo el uso del inglés como lingua franca en Internet no es bien visto por muchas personas; posiblemente quien mejor ha expresado ese rechazo ha sido Anatoly Voronov, director de una empresa proveedora de servicios de Internet, a quien le parece que lejos de facilitar el acceso a la información, el uso del inglés establece barreras en el uso de la red:

Es increíble cuando oigo a las personas hablando de cuán abierta es Internet. La red es el último acto de colonialismo intelectual. El producto viene de Estados Unidos, por lo tanto o nos adaptamos a usar ese idioma o dejamos de utilizar la red. Este es el derecho de cualquier negocio. Pero si se está hablando de tecnología que supuestamente abre el mundo a millones de seres humanos, parece que se está bromeando. 8

La figura 97 presenta información interesante sobre la relación entre el número de personas que hablan una lengua y las páginas web producidas en ese mismo idioma. En esta figura se aprecia que poco más de 320 millones de personas hablan inglés y que existen cerca de 215 millones de páginas en este idioma, por lo que la relación entre anglófonos por páginas web es de 1.5. En el extremo opuesto de la figura tenemos a los 202 millones de personas que hablan árabe y que disponen de tan sólo 127 mil páginas, por lo que la

6 Warschauer, Technology, 92.

7 Ibíd., 95.

8 David Crystal, English as a global language (Cambridge: Cambridge University Press, 1997), 68. 
Figura 97

Proporción de hablantes de una lengua y

páginas web en esa lengua, 2001

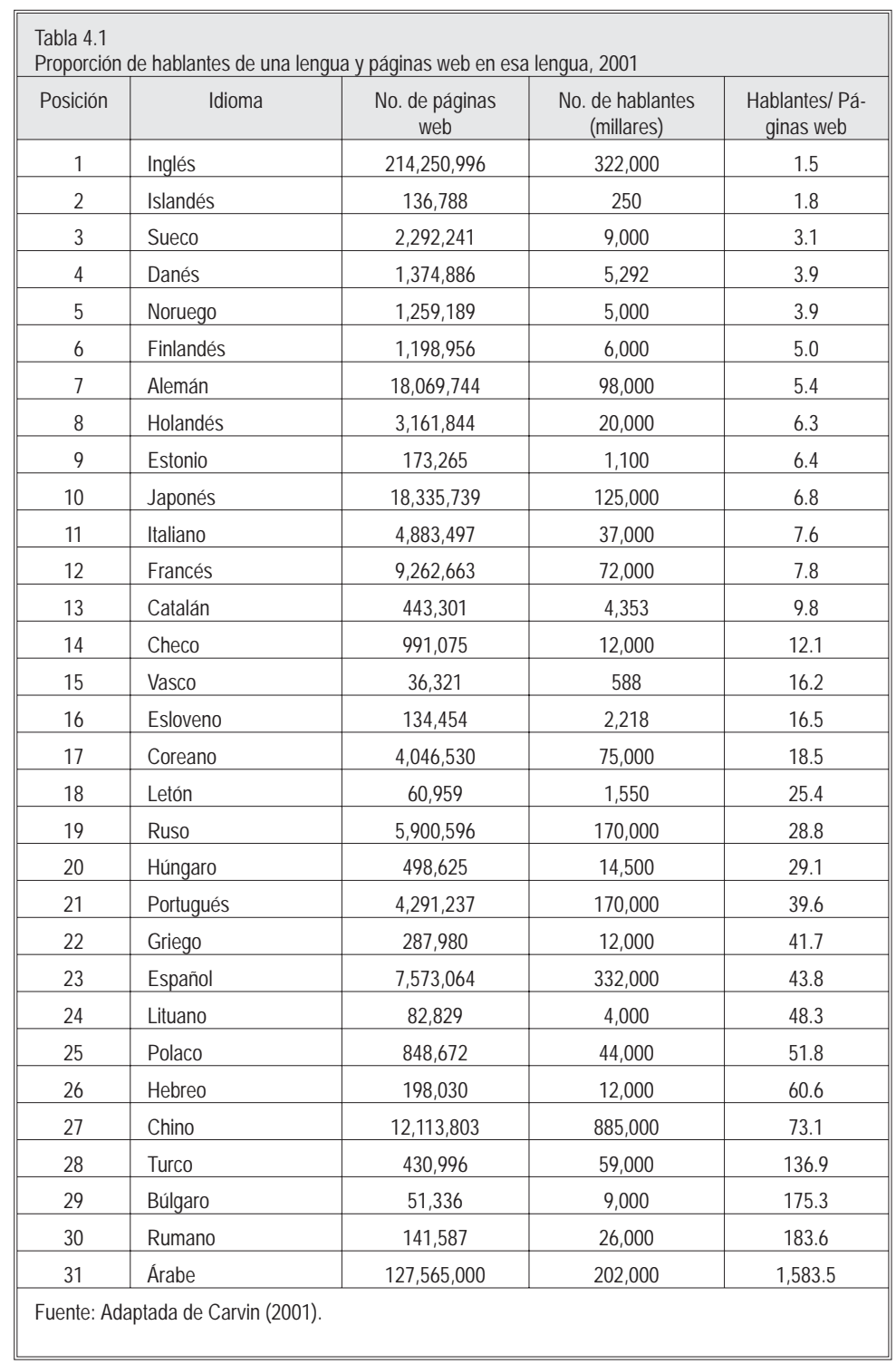

Tomado de Mark Warschauer, Technology and social inclusion: rethinking the digital divide (Cambridge, Mass.: MIT Press, 2003), 97. 
relación entre hablantes y páginas es de 1,583. Es importante señalar que hay un error en la figura en el caso del árabe ya que se anotaron tres ceros de más en el rubro de páginas web, por lo que parece que hay un número elevado de sitios web en esa lengua cuando no es así.

Como puede observarse, el empleo de un idioma u otro es un elemento que debe considerarse cuando se estudia el uso de las tecnologías de la información. Sin embargo hay dos formas de analizar el fenómeno:

La primera aproximación responde a la lógica de que cada nación emplee su propia lengua y además utilice un idioma predominante en el contexto internacional, el inglés. Ante esta situación sería necesario que los usuarios tuvieran un cierto nivel de dominio en esta lengua para poder usarla óptimamente. En este caso estamos hablando de una marginación ocasionada por la lingua franca de la red, dado que su uso es un asunto voluntario e individual de quienes deseen navegar en la red.

El segundo acercamiento se refiere a los países multiétnicos, como el caso de Estados Unidos, en que una parte muy grande de la población queda marginada por no ser capaz de emplear la lengua predominante. En este caso aprender inglés no es asunto de voluntad individual para aprovechar los contenidos de la red; es una obligación ciudadana utilizar la lengua predominante para comunicarse a través de las tecnologías de la información, pero también a niveles más simples como en la calle, el comercio, el doctor y la escuela, entre otros.

En México una de las mayores limitaciones para la utilización y aprovechamiento de Internet es que gran parte de la información está en inglés, y sólo una pequeña fracción de la población domina ese idioma al nivel de suficiencia para buscar información e interactuar con otras personas que se encuentren conectadas. Pero incluso los niveles de lectura y escritura de los mexicanos son bastante bajos, lo que impide tener usuarios capaces de aprovechar óptimamente los recursos disponibles en Internet. Hay 10 millones de indígenas que no hablan el español, o no lo usan como primera lengua; y un número muy grande de usuarios potenciales que no dominan el español, su lengua 
materna, a un nivel de suficiencia para una exitosa explotación de los recursos que ofrece Internet.

\section{Educación y brecha digital}

La educación es uno de los elementos más destacados en el desarrollo de los pueblos, no existe una nación que se haya podido desarrollar sin que sus habitantes contaran con altos niveles educativos. El fenómeno de la brecha digital se determina por el nivel educativo de las personas; este aspecto no es el único ni el más importante pero sí uno de los factores que determinan el acceso y uso de la red y por ello es necesario analizar su influencia.

El proceso educativo, hasta la aparición de las tecnologías de la información, ponía a todos los estudiantes en igualdad de condiciones y las diferencias en él se basaban en cualidades humanas como inteligencia, comprensión y habilidad. En esos tiempos no existía una gran diferencia entre poseer un libro o usarlo en la biblioteca, especialmente desde que las autoridades educativas se encargaron de hacer posible que todos los estudiantes tuvieran la posibilidad de consultar un libro de texto. Sin embargo, con la adopción de las tecnologías de la información los factores humanos ya no son los únicos que marcan la diferencia; ahora también lo es la posibilidad de tener acceso a una computadora que esté conectada a la red y la habilidad para poder usar Internet. Estos elementos, aunque creados por los seres humanos, no son propiamente un atributo personal, tanto del alumno como del maestro; corresponden más bien a los instrumentos con que se cuenta en la actualidad y que inciden de forma sustancial en el proceso educativo en la medida en que se tiene acceso a información relevante y actualizada.

De distintos estudios que se han hecho se desprende con toda claridad que el nivel educativo es relevante para determinar si las personas se conectan a Internet o no. A mayor nivel educativo, mayor utilización de Internet; globalmente, el 30 por ciento de los usuarios 
de Internet han obtenido un grado en alguna institución de educación superior.9

En Estados Unidos, un estudio de la Universidad de Massachusetts encontró que en la medida en que se incrementa la educación, también aumenta la posesión de computadoras: el 60 por ciento de aquellos que tienen formación universitaria poseen una computadora, mientras que 70 por ciento de quienes tienen educación media o menos no tienen computadora. En la Universidad de Stanford se concluyó que la educación facilita el acceso a Internet: de aquellos que tienen grado universitario, el 49 por ciento tienen más posibilidades de poseer y usar Internet que aquellos que no tienen el mismo nivel de escolaridad. Un estudio de la Universidad de California, Los Ángeles (UCLA) determinó que entre más alto es el nivel de estudios que tiene una persona, es más posible que tenga Internet: 86.3 por ciento de aquellos que han terminado la universidad o tienen un nivel más alto, usan Internet. El Pew Internet Project informa que 82 por ciento de aquellos que tienen un grado universitario y 71 por ciento de aquellos que tienen estudios en ese nivel usan Internet, comparado con 37 por ciento de aquellos que tienen educación media o menos. ${ }^{10}$

La tendencia observada en Estados Unidos es común en algunos otros países sin que necesariamente el nivel de desarrollo socioeconómico de éstos sea el mismo. Algunos ejemplos sobre el uso de las tecnologías de la información con relación a los niveles de estudio son:

- El 87 por ciento de los usuarios de Zambia y 98 por ciento de los usuarios de Etiopía tienen un grado universitario. 11

- El 76 por ciento de los hindúes que usan Internet tienen un grado de educación superior y sólo nueve por ciento no son graduados. 12

9 Servon, 43.

10 Kuttan y Peters, 15-16.

11 Ibid., 113.

12 Ibid., 117. 
- Más de 58.5 por ciento de los usuarios árabes tienen un grado profesional y 14.5 tienen un posgrado. 13

Si la TIC es incorporada adecuadamente a los programas educativos, puede ser de gran beneficio, pero si sólo se tiene acceso a los recursos tecnológicos y los alumnos utilizan éstos para actividades distintas a las académicas -como hacer búsquedas no relacionadas con los programas o jugar-, el acceso a esta tecnología puede ser un gran distractor que lejos de ayudar, perjudique. Al respecto Bolt y Crawford ${ }^{14}$ señalan que algunos estudios han encontrado que estudiantes que tienen acceso a la tecnología obtuvieron calificaciones menores en matemáticas a las de aquellos que no tienen posibilidad de usar la TIC. Esto ocurre porque no es suficiente con contar con computadora y conexión a la red, es necesario que estos recursos estén integrados a las actividades académicas que involucran el proceso enseñanza-aprendizaje.

Sin duda alguna es necesario tener en claro que:

Internet no es en sí misma educación, no enseña a leer, y requiere el desarrollo de habilidades altamente especializadas para acceder e interpretar la información encontrada. Una mejor solución para la mayoría de las comunidades aún descansa en el uso de tecnologías básicas para promover las formas tradicionales de educación, fortalecer la prestación de servicios de salud, mejorar la crianza de ganado y el manejo de cultivos. 15

En muchas escuelas surge el temor de que al no contar con equipo de cómputo y telecomunicaciones, los estudiantes del plantel queden rezagados, y por este motivo hacen el esfuerzo de adquirir programas, y se anuncian incluso como las escuelas con las más modernas tecnologías que permiten navegar por la red. Pero desgraciadamente en muchas de ellas no se profundiza en el uso tecnológico, los profesores no tienen los conocimientos ni la experiencia para hacer uso adecuado de las tecnologías y mucho menos para adiestrar a los alumnos.

13 Ibid., 119.

14 Bolt y Crawford, 39-40.

15 Cullen, 248. 
Pero peor aún es que la tecnología no está integrada a las actividades del proceso de enseñanza, sino que se ve como elemento aislado que puede ser de utilidad para quien sepa cómo utilizarla.

En esto del acceso a la TIC no debe haber diferencia entre escuelas públicas y privadas. En algunos países las escuelas públicas tienen más recursos que las privadas y por ello tienen mayores posibilidades de que sus estudiantes usen la tecnología de la información. En otros países decir escuelas privadas es sinónimo de escuelas a las que asisten estudiantes con mayores recursos económicos, escuelas que cobran cuotas de inscripción y mensuales muy elevadas que les permiten contar con mayores recursos que las escuelas públicas. En cualquier caso, se debe asegurar que ambas cuenten con los recursos tecnológicos suficientes y el entrenamiento de los profesores para que incorporen esas tecnologías a las actividades docentes de forma exitosa.

De acuerdo con el Banco Mundial [...] en los países desarrollados las escuelas secundarias, y en algunos casos cada vez más las escuelas primarias, están conectadas a Internet y por lo tanto se pueden beneficiar de la información de la red. Si vemos el caso de Irlanda, en 1998 tenía 14 por ciento de sus escuelas primarias conectadas, pero esa proporción cambió y un año después alcanzaba el 95 por ciento. Durante el mismo periodo las condiciones cambiaron en Portugal, que tenía 30 por ciento en 1998 y un año después había logrado una cobertura total y llegó a 100 por ciento... En otro orden de cosas, la relación de computadoras por estudiante también cambió grandemente. Entre 1997 y 1998 Irlanda modificó su proporción de 37 a 18 estudiantes por computadora en sus escuelas primarias y Portugal lo hizo de 65 a 35 estudiantes por computadora en sus escuelas secundarias. 16

Respecto al equipamiento en tecnología de información y comunicación en las escuelas estadounidenses, Kuttan y Peters señalan que:

En 1997 el Comité Presidencial para la Asesoría en Ciencia y Tecnología recomendó que "un nivel razonable para el uso efectivo de computadoras en las escuelas" estaba en una relación de cuatro o cinco

16 Kelley-Salinas, 25. 
estudiantes por computadora. Sin embargo la relación entre estudiantes que tienen acceso a una computadora dedicada a la instrucción con acceso a Internet disminuyó de 12 a 9 por ciento de 1998 a 1999. Hay aún grandes diferencias entre las escuelas, que se basan en la pobreza y la matrícula de grupos minoritarios. 17

Es necesario hacer una distinción entre escuelas que cuentan con conexión a la red y salones de clases que tienen esa facilidad, es frecuente que en las estadísticas oficiales las autoridades cuenten exclusivamente las escuelas que tienen una conexión a la red. La diferencia entre una y otra condición es relevante toda vez que cuando se tiene la posibilidad de una conexión, los alumnos no tendrán posibilidad de emplearla ya que las escuelas no pueden obtener acceso para todos los estudiantes dado que no disponen de los recursos necesarios para extender la comunicación dentro de la escuela.

Un desafío importante es lograr que las escuelas dispongan de acceso a la red y que además de contar con las tecnologías, consigan que los profesores no sólo aprendan cómo utilizar esos recursos sino que los incorporen íntegramente a sus actividades docentes; esto incluye el adiestramiento de los alumnos en los recursos tecnológicos y que los escolares los empleen no sólo para el correo electrónico, sino para obtener un mayor provecho y mejorar la calidad de su aprendizaje.

Es recomendable que los profesores que tienen acceso a las tecnologías de información no lo tengan solamente en la escuela, sino que también puedan preparar sus trabajos escolares en casa. Esta misma recomendación debe aplicarse a todos los estudiantes, de no hacerlo así, la brecha digital entre quienes sí tienen acceso y aquellos que dependen de los recursos de la escuela para informarse, provocará que los segundos estén en desventaja con relación a quienes en cualquier momento, durante su estancia en casa o bien los fines de semana, pueden acceder a la información.

17 Kuttan y Peters, 80-81. 
Una serie de investigaciones ha demostrado que ayudar a los profesores a integrar las tecnologías en el currículo es un factor crítico en la incorporación exitosa de las tecnologías en las escuelas. ${ }^{18}$ Esto implica que los profesores tienen que estar capacitados en la utilización de la tecnología, en la forma en que pueden incorporarla a sus planes de estudio, y en cómo pueden ayudar a sus estudiantes a beneficiarse de ella. Pero este fenómeno no es responsabilidad exclusiva de los profesores; hay distritos educativos, estados y países en los que el sistema educativo no contempla la incorporación de la tecnología a las actividades de enseñanza, en estos casos se considera suficiente la instalación de los equipos, condenándolos a la subutilización y a la pérdida de su valor pues en muy poco tiempo se vuelven obsoletos.

Una encuesta realizada por el National Center for Education Statistics (NCES) de Estados Unidos determinó que sólo un tercio de los profesores se sienten "muy bien" o "bien preparados" para usar Internet en sus labores de enseñanza. Por eso no es extraño que según la Teaching, Learning and Computing Survey de H. J. Becker:

Las computadoras no han transformado la práctica docente de la mayoría de los profesores, particularmente de materias secundarias. 19

Como los recursos no se incrementan al mismo ritmo que las necesidades, para que las escuelas y los salones sean dotados de tecnologías de la información, en muchos lugares los recursos se obtienen sacrificando otras actividades como labores humanísticas, las bibliotecas o las actividades deportivas. De esta manera la actualización de la TIC constituye un riesgo para otras actividades que son igual de

18 Ibid., 81.

19 H. J. Becker, "Findings from the teaching and learning and computing survey: is Larry Cuban right?", revisión del documento escrito para la Conferencia sobre Liderazgo Tecnológico del Consejo de Oficiales Escolares Estatales en Jefe, enero de 2000, Washington, D.C., citado por Appu Kuttan y Laurence Peters, From digital divide to digital opportunity (Lanham, Maryland: Scarecrow Press, 2003), 84. 
importantes en el desarrollo educativo de una persona y del proceso educativo en general. ${ }^{20}$

Los niños participan en experimentos educativos más fácilmente cuando han crecido en un medio en el que la educación es apreciada, como es el caso de la inclusión de la TIC en el proceso educativo. Los niños que no han crecido en un ambiente como el descrito anteriormente, tienden a oponer mayor resistencia a la utilización de nuevos experimentos o a la utilización de nuevas tecnologías. ${ }^{21}$

Lentamente, los padres y la comunidad se percatan de que cuando hay poca intervención en el proceso educativo de los hijos también hay una educación ineficiente; es necesario que los diferentes elementos que componen el proceso educativo se vean involucrados y no pensar que es suficiente con que los chicos estén conectados a la computadora para que los niveles educativos sean de calidad. Internet ofrece muchas cosas a sus usuarios, entre ellas información sobre los temas de interés de cada uno, pero eso no es suficiente, se ha de contar con una buena educación que proporcionen la escuela y el hogar para que los usuarios puedan utilizar provechosamente la información disponible. Si no se cuenta con una rigurosa educación, se corre el riesgo de no poder utilizar el alud de datos e información; de no poder separar lo bueno de lo que carece de calidad. ${ }^{22}$

Además de computadoras es necesario que en el proceso educativo intervengan otros aspectos que permitan que éste sea exitoso, entre los cuales se encuentran las relaciones sociales, los aspectos físicos, digitales, humanos, el contenido idiomático, la capacidad de lectura y las estructuras institucionales y comunitarias. ${ }^{23}$

Existe una correlación entre los niveles de educación masiva y el acceso a Internet. Como ejemplo de esta aseveración encontramos que los países que tienen económicamente un mayor nivel terciario -basado en el consumo y producción de servicios propios de las economías

20 Bolt y Crawford, 44-45.

21 Ibid., 64.

22 Warschauer, Technology, 29.

23 Ibid., 6. 
postindustriales-, presentan una correlación entre educación de masas y acceso a Internet. ${ }^{24}$

La educación y la alfabetización también son importantes a nivel individual, ya que la lectura, la escritura y las habilidades para pensar son esenciales para el uso de Internet. Como hemos visto en otras partes de este trabajo, conseguir los equipos de cómputo no es suficiente, se tiene que contar con otra serie de atributos que permitan obtener la información de la red y lograr de ella un beneficio importante. ${ }^{25}$

En la medida en que se cuente con personas mejor educadas, las posibilidades de uso fructífero de Internet se incrementan y el empleo de la tecnología de la información facilita el mejoramiento educativo. Así entonces el nivel educativo y la TIC forman un círculo virtuoso en el que un elemento impulsa al otro y éste a su vez apoya al segundo.

La tecnología digital transforma el papel de los profesores y la comprensión que tenemos del proceso de aprendizaje. Ayuda a que los estudiantes cuenten con una serie de instrumentos que los acercan a la información, y la forma en que la localizan y la relacionan con otra es diferente a la forma tradicional; no estamos haciendo un juicio de valor, no decimos si es mejor o peor, solamente sostenemos que es diferente. El estudiante tiene acceso directo a un amplio cuerpo de conocimiento, que puede analizar y buscar de acuerdo con sus intereses. ${ }^{26}$

La brecha digital está precedida por otras brechas en los sistemas educativos en las diferentes zonas geográficas, por ejemplo entre zonas urbanas y rurales. Es decir, las condiciones de las escuelas y sus profesores, así como el nivel de los recursos complementarios, son aspectos determinantes de la brecha digital. Los profesores rurales, al menos en México, normalmente enfrentan dificultades socioeconómi-

24 Ibid., 109.

25 Ibid.

26 McNair, 15. 
cas y tienen menos oportunidades para el desarrollo profesional y para adquirir las nuevas habilidades requeridas. ${ }^{27}$

En resumen, una característica en el acceso a la red es el nivel educativo; a mayor nivel de estudios, mayor posibilidad de acceso a la red. Esta situación se refleja en los diferentes estudios realizados por el Departamento de Comercio de los Estados Unidos, y en el caso de México, en el trabajo de Arellano López y Meza Contreras. ${ }^{28}$

Respecto de Estados Unidos, a continuación se presentan algunos gráficos para ilustrar la relación que existe en la sociedad estadounidense entre nivel escolar y accesibilidad a Internet.

Los datos de la figura 98 indican el porcentaje de hogares estadounidenses que tenían computadora en 1998, dividido por zona rural, urbana y central de las ciudades (inner) y por niveles educativos. Se debe destacar que hay un gran salto en la posesión de computadoras, aun en las áreas centrales de las ciudades, que se incrementa en razón de los niveles educativos. También debe observarse que las discrepancias en cada nivel educativo, no son muy amplias entre las diferentes zonas.

En la figura 99 se señalan los datos sobre la distribución geográfica -en zonas rural, urbana y central de las ciudades (inner)- de las personas que de acuerdo con su nivel educativo utilizaban Internet en Estados Unidos en 1998. En ella encontramos que los grupos que están más conectados a la red son aquellos que tienen una educación superior terminada, mientras que el grupo que cuenta con menos usuarios es el de las personas que sólo tienen educación primaria. Llama la atención que no son los habitantes de las zonas rurales quienes utilizan menos la red, sino los habitantes de las zonas centrales de las ciudades en todos los niveles educativos representados en esta figura.

27 Kelley-Salinas, 23.

28 Consuelo Arellano López y Zaida Meza Contreras, "Características de acceso y uso de la computadora y la Internet en los hogares mexicanos", Boletín de Politica Informática, 1 (2003): 13-23. 
Figura 98

Porcentaje de hogares estadounidenses que tenían computadora en 1998, dividido por zona rural, urbana y central de las ciudades

(inner) y por nivel educativo

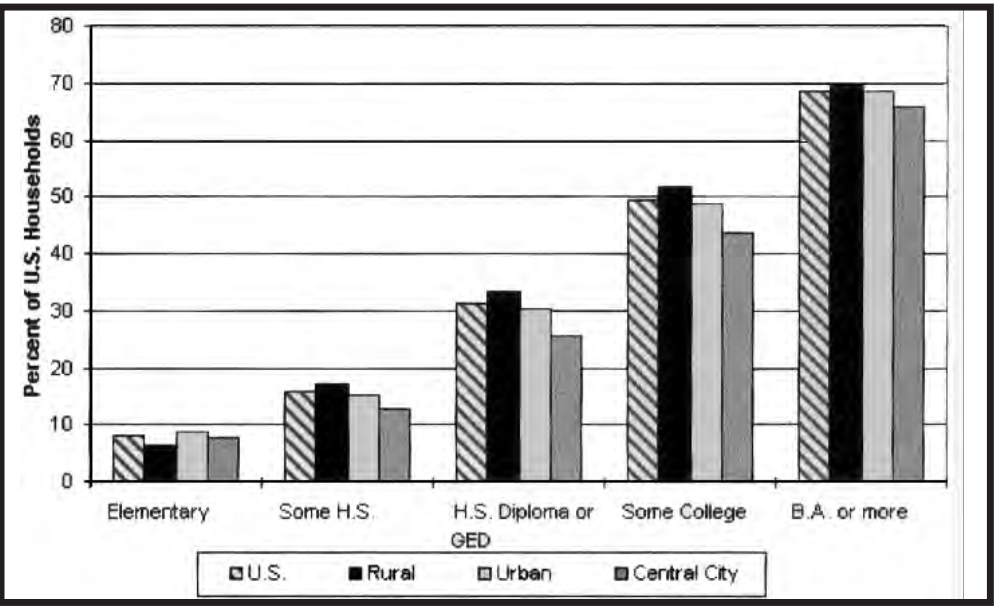

Tomado de David B. Bolt y Ray A. K. Crawford, Digital divide: computers and our children's future (Nueva York: TV Books, 2002), 181.

Figura 99

Porcentaje de hogares estadounidenses que usaban Internet en 1998 dividido por zona rural, urbana y central de las ciudades (inner) y nivel educativo

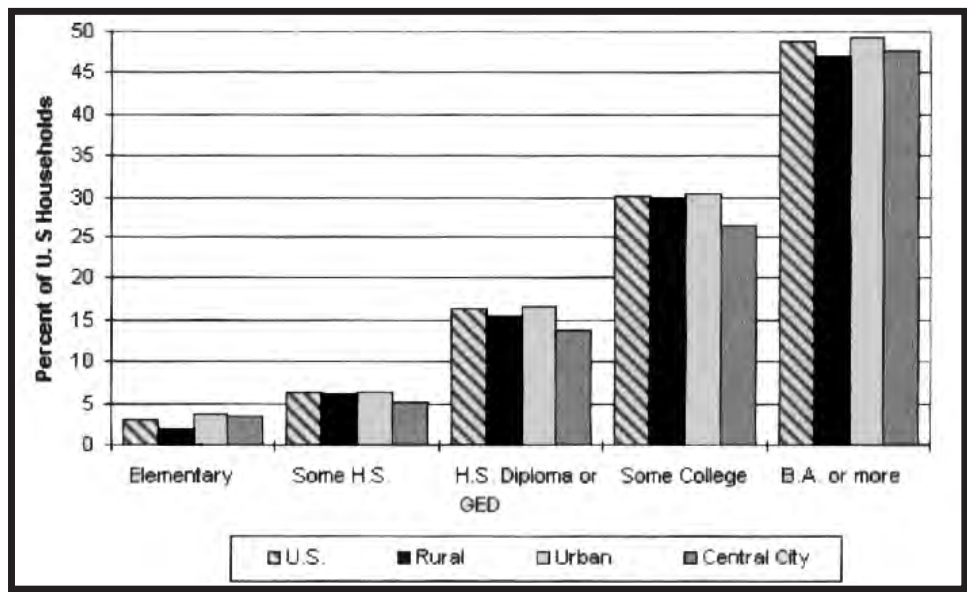

Tomado de David B. Bolt y Ray A. K. Crawford, Digital divide: computers and our children's future (Nueva York: TV Books, 2002), 189. 
Una vez más queda de manifiesto que un aumento en el nivel educativo implica un incremento en el uso de los instrumentos de la tecnología de la información. Como se puede observar en la figura 99, en cada zona los niveles son muy similares, diferenciándose un poco quienes tienen los niveles más bajos de educación y siendo casi iguales a partir de que se cuenta con un diploma de educación media superior.

En el informe Falling through the Net se presentan ciertas características relacionadas con la brecha digital, y entre ellas hacen mención del siguiente aspecto educativo:

Aquellos que tienen un grado universitario tienen ocho veces más posibilidades de poseer una computadora en casa y dieciséis veces más de estar conectados a Internet que aquellos que sólo tienen una educación elemental.29

El Secretariado de la OCDE cita sin indicar la fuente un párrafo de Wadi D. Haddad que parece resumir claramente el problema desde el punto de vista educativo:

Con el sobresaliente avance en las tecnologías de la información y comunicación (TIC), existe ahora una preocupación auténtica sobre la brecha digital, la diferencia entre quienes tienen acceso a ellas y quienes no. Preocupación justificada de acuerdo con los datos que [sobre el acceso a las TIC] se muestran en cada nivel [educativo y que ponen de manifiesto desigualdades en el aprendizaje]. Pero reducir la brecha - publicando un periódico en cada comunidad, instalando radios y televisión en cada casa, poniendo una computadora en cada salón de clase, y cableando cada edificio para tener acceso a Internet- no soluciona automáticamente el problema. La brecha más importante está relacionada con lo difundido que esté el conocimiento humano y su

29 U.S. Department of Commerce, National Telecommunications and Information Administration, Falling through the net: defining the digital divide (Washington, D.C.: Department of Commerce, National Telecommunications and Information Administration (1999), citado por Benjamin M. (ed.), The digital divide: facing a crisis or creating a myth? (Cambridge, Mass.: MIT, 2001), 18. 
aprendizaje de calidad. El problema de la brecha no es digital, es educativo. 30

Conforme los precios de la tecnología declinan en el mercado, el acceso a la red parece ser más sencillo, pero esto último no será posible si los niveles educativos no se mejoran. No cabe duda de que los países desarrollados que tienen el mayor porcentaje de acceso, no lo tienen exclusivamente porque son ricos: sus comunidades marginadas desde la óptica educativa, las que cuentan con los niveles más bajos de escolaridad, también se encuentran en el lado negativo de la brecha digital. Es pues indispensable aceptar que la brecha no podrá ser cerrada de manera significativa si no se mejoran los niveles educativos, desde los que comprenden la lectura hasta los de mayor escolaridad.

En Alemania los usuarios de Internet eran predominantemente varones, jóvenes empleados y bien educados en la mitad de la década de 1990. Esta característica demuestra que en aquel país la educación es el aspecto más relevante de la brecha digital. En el año 2000, el 86 por ciento de los alemanes que tenían acceso a Internet poseían un grado equiparable al College norteamericano o mayor, mientras que sólo el ocho por ciento de quienes estaban conectados a la red tenían educación media. El crecimiento de los usuarios de Internet ha sido mayor y más rápido entre los mejor educados que entre aquellos que no lo son. ${ }^{31}$

En México el INEGI ha establecido una relación entre el nivel de escolaridad de los jefes de familia y posesión de computadoras, encontrando lo siguiente:

En 1996 los hogares con computadora y cuyos jefes de familia habían cursado estudios superiores constituían el 64.8 por ciento, y con educación media superior el 16.1 por ciento (en total el 80.9 por

30 Wadi D. Haddad, citado por el Secretariado de la OCDE, "Emerging trends and issues: the nature of the digital divide in learning", en Centre for Educational Research and Innovation [y] National Center on Adult Literacy, Learning to bridge the digital divide. Education and skills (París: OCDE, 2000), 52.

31 Chen y Wellman, 12. 
ciento), mientras que la tasa de quienes tenían sólo la primaria era del orden del 0.3 por ciento.

En 1998 los hogares con computadora y cuyos jefes de familia habían cursado estudios superiores sumaban el 61.8 por ciento, y con educación media superior el 14.4 por ciento (en total el 76.2 por ciento), entre tanto la tasa de quienes tenían sólo la primaria se había incrementado al $\mathbf{1 1 . 6}$ por ciento.

En 2000 los hogares con computadora y cuyos jefes de familia habían cursado estudios superiores representaba el 56.6 por ciento, y con educación media superior el 14 por ciento (en total el 70.6 por ciento), al mismo tiempo que la tasa de quienes tenían sólo la primaria presentaba un incremento marginal al llegar al 11.9 por ciento.

Finalmente, en 2002 los hogares con computadora y cuyos jefes de familia habían cursado estudios superiores eran el 49.1 por ciento, y con educación media superior el 18.2 por ciento (en total el 67.3 por ciento), mientras que la tasa de quienes tenían sólo la primaria era del orden del 14 por ciento.

Según estos datos parece existir una clara tendencia de crecimiento en la propiedad de computadoras en los hogares a cargo de jefes de familia con instrucción elemental. Si bien durante los años que cubren estas cifras se pueden observar fluctuaciones entre los jefes de familia con educación media superior y superior, en su conjunto se distingue su decremento en la propiedad de computadoras. ${ }^{32}$

Por su parte la AMIPCI, en los resultados de su encuesta de 2002, señala que el 65 por ciento de los usuarios de Internet tenían estudios universitarios, el 18 por ciento estudios preparatorios y el uno por ciento la primaria. Esta situación no sufrió cambios significativos en su estudio de 2003, según el cual el 69 por ciento de los cibernautas poseían educación superior y el 11 por ciento preparatoria; en 2004 el 64 por ciento de quienes usaban la red habían recibido edu-

32 INEGI, Hogares con computadora por edad y escolaridad del jefe de familia, 1996 a 2002, disponible http://www.inegi.gob.mx/est/contenidos/espanol/rutinas/ ept.asp?t $=$ tinf038\&c $=3462$ [Julio 13, 2005]. 
cación superior, el 14.4 instrucción preparatoria y el 0.8 por ciento educación primaria. Sin embargo en los resultados de su última encuesta (2005), la situación cambió drásticamente, ya que sólo el 38 por ciento de los usuarios de Internet estudian o han estudiado una licenciatura, mientras que el 30 por ciento tienen preparatoria completa (13 por ciento) o preparatoria incompleta (17 por ciento), y la tasa de usuarios con instrucción primaria el uno por ciento.

Llama la atención que en México la brecha digital entre hombres y mujeres no sea significativa en lo que se refiere a la educación media; pero en los niveles educativos más bajos, de los hombres que tienen educación básica, utilizan Internet el 17 por ciento, mientras que las mujeres lo hacen en 69 por ciento.

Un elemento también importante en el uso de las tecnologías de la información es el esfuerzo realizado por cada país para dar impulso al desarrollo de la ciencia y la tecnología. En los países con mayor desarrollo en esas actividades, la utilización de las tecnologías de la información es más intensa, tanto por las personas involucradas en los procesos de creación científica y tecnológica, como por las empresas, oficinas públicas y personas que se benefician de ese desarrollo. Por lo tanto, la falta de acceso a la TIC margina a una parte importante de la sociedad, en los diferentes países, del beneficio de la ciencia y la cultura que son dos elementos importantes en el bienestar social. ${ }^{33}$

El desarrollo de capital humano -es decir la inversión en habilidades digitales y mejoramiento de las capacidades mediante la educación, el entrenamiento o adiestramiento y el aprendizaje a lo largo de toda la vida-representa uno de los más importantes factores que pueden facilitar el acceso a Internet. El capital humano representa las propiedades que permiten a la gente vivir y trabajar productivamente. La educación es una de las más importantes formas de desarrollo social, la producción de instrumentos y de experiencias que más contribuyen a la utilización de computadoras. 34

33 Norris, Digital divide, 57.

34 Ibid., 59. 
La gente más educada está más abierta a las innovaciones en cualquier campo. Las personas que tienen bajos niveles educativos tienden a ser más tradicionales y por lo tanto presentan mayor resistencia al cambio y en nuestro caso a la utilización de los instrumentos tecnológicos que les permitan informarse.

\section{Lectura y tecnología de la información}

Hay muchas similitudes entre la lectura y la tecnología de la información. Como primer aspecto podemos decir que ambas están relacionadas con la comunicación humana y con la producción de conocimiento; para obtener una idea más clara sobre este aspecto, véase la figura 100. Sin lectura y escritura, el avance de la humanidad en sus diferentes aspectos, sociales, culturales y económicos, entre otros, hubiera sido más lento, dado que las posibilidades de comunicación y de transferencia de información serían más difíciles e inciertas.

Figura 100

Comparación entre alfabetización y tecnología de la información

\begin{tabular}{||l|l|l||}
\hline \hline \multicolumn{2}{||l||}{ Tabla 1: Comparando en analfabetismo y en acceso a la TIC } \\
\hline Etapa de la comunicación & Escribir, imprimir & \multicolumn{1}{c||}{ Acceso a la TIC } \\
\hline Era económica & Capitalismo industrial & Comunicación mediada por computadora \\
\hline Artefacto físico & Libros, diarios, revistas & Computadora la información \\
\hline Organización del contenido & $\begin{array}{l}\text { Novelas, historias cortas, ensayos, } \\
\text { artículos, reportes, poemas }\end{array}$ & $\begin{array}{l}\text { Sitios web, correo electrónico, mensajes } \\
\text { instantáneos }\end{array}$ \\
\hline Habilidades receptivas & Lectura & $\begin{array}{l}\text { Lectura + multimedios, interpretación, bús- } \\
\text { queda, navegación }\end{array}$ \\
\hline Habilidades productivas & Escritura & $\begin{array}{l}\text { Escritura + multimedios, autoría y } \\
\text { publicación }\end{array}$ \\
\hline Brechas & ¿Una brecha de alfabetización o de & ¿Una brecha digital? \\
\hline
\end{tabular}

Tomado de Mark Warschauer, "Reconceptualizing the digital divide", First Monday 7, no.7 (Julio 2002), disponible en http://firstmonday.org/issues/issue7_7/Warschauer/index.html [Mayo 5, 2004]. 
La lectura ha sido y es un requisito para integrarse completamente a la actividad cultural. El avance del arte y de la ciencia, los negocios y el comercio, así como de la industria y la cultura en general, han requerido que los individuos sepan leer y escribir para una plena participación. Se puede participar sin esos conocimientos pero el papel que le espera al individuo es el de un protagonista marginal del acontecer de la civilización.

Tanto la lectura como el acceso a Internet necesitan de un instrumento físico, en el caso de la lectura el libro y en el de Internet la computadora.

Entre los elementos que determinan la brecha digital está la existencia de otra brecha que viene de muchos siglos atrás y es la brecha en la lectura. Existen estudios que demuestran que el rezago en las habilidades lectoras tiene un efecto negativo en los aspectos económicos, sociales, educativos y de salud en una sociedad. Hay evidencias de que la capacidad para leer está relacionada con mejores formas de vida y que el avance educativo permite a la sociedad despegar en el camino del desarrollo. Al respecto Warschauer señala:

Lo que se discute es el tema de la causalidad, esto es, si la alfabetización favorece el desarrollo o si un desarrollo desigual (y la correspondiente inequitativa distribución de la riqueza, del poder político, económico y social) restringe el acceso de las personas a la lectura; quienes apoyan el punto de vista anterior sostienen que existe una brecha en la lectura. Desde este punto de vista hay diferencias cognoscitivas fundamentales entre los individuos alfabetizados y aquellos que no lo son; esto da como resultado una brecha de lectura tanto a nivel individual como social. Se ha dicho que la escritura y la lectura separan a la historia de la prehistoria (Godoy y Watt, 1993) y a las sociedades primitivas de las civilizadas (Lerner, 1958; véase la discusión en Scribner y Cole, 1981). A escala individual se ha dicho que forma a las personas en el manejo lógico funcional del lenguaje (Godoy, 1968; Olson, 1977) y a manejar planteamientos abstractos (Greefield, 1972; Luria, 1976). 35

35 Mark Warschauer, "Reconceptualizing the digital divide", First Monday 7, no. 7 (Julio 2002), disponible http://firstmonday.org/issues/issue7_7/warschauer/index. html [Mayo 5, 2004]. 
El tema de la alfabetización tiene diferentes ángulos que en ocasiones hacen difícil definir el concepto "alfabetizado"; su liga con la educación provoca que la alfabetización y la educación escolarizada se confundan, pero lo cierto es que no se puede dar la una sin la otra. No es posible que una persona posea un adecuado nivel de escolaridad y que no sepa leer y escribir correctamente, como tampoco se puede concebir a alguien alfabetizado que lo haya sido sin un proceso educativo que lo ubique en un nivel de habilidades y capacidades. Se lee no como un fin en sí mismo, sino para satisfacer diversas necesidades, y éstas no serán satisfechas si la capacidad lectora no es la adecuada a los requerimientos que tiene un hombre o mujer en su vida educativa, sociocultural y económica, entre otros.

Cuando existen diferencias entre los individuos en su capacidad para leer y escribir, es que hablamos de la brecha de la alfabetización. Con esta brecha como antecedente, no importa cuánta tecnología incorporemos a la vida de los ciudadanos, ya que éstos no serán capaces de integrarla eficientemente debido a sus dificultades para leer $y$ escribir.

Abordemos ahora las conclusiones que Warschauer incluye en su trabajo Reconceptualizing the Digital Divide sobre la alfabetización y las tecnologías de la información:

1. No hay un solo tipo de alfabetización, hay muchos;

2. El significado y valor de la alfabetización varía, en particular en el contexto social;

3. La capacidades de lectura existen en diferentes niveles, más que en una relación bipolar de alfabetizados contra analfabetos;

4. La alfabetización por sí misma no tiene beneficios automáticos, fuera de sus funciones particulares;

5. La alfabetización es una práctica social, que comprende artefactos físicos, contenido, habilidades y el apoyo social; y

6. La alfabetización no es solamente un asunto de educación, sino de poder. 36

36 Mark Warschauer, "Reconceptualizing the digital divide", 13. 
Un estudio realizado por el Banco Mundial en 1998 sobre la calidad de vida, mostró que algunos de los países más pobres y que menos acceso tienen a las tecnologías de la información, presentan los niveles más altos de analfabetismo y son de las naciones en que la expectativa de vida al nacer es de las más bajas como se puede ver mediante la figura 101.

La habilidad para leer es un elemento primordial para el acceso a la red porque aun si todos tuvieran una computadora personal y acceso gratuito a Internet, no sería suficiente. La tecnología no puede sustituir el conocimiento de la lectura, en la sociedad actual el ser alfabetizado es de importancia no sólo para los individuos, sino para el desarrollo individual, local, regional y nacional. ${ }^{37}$

Figura 101

Analfabetismo y expectativa de vida al nacer

\begin{tabular}{||l|c|c|c|c||}
\hline \multicolumn{1}{|c|}{ País } & \multicolumn{2}{c|}{ Adultos analfabetas } & \multicolumn{2}{c|}{ Expectativa de vida al nacer } \\
\hline & Hombres & Mujeres & Hombres & Mujeres \\
\hline Nigeria & 79 & 93 & 44 & 49 \\
\hline Burkina Faso & 71 & 91 & 45 & 47 \\
\hline Burundi & 51 & 78 & 45 & 48 \\
\hline Guinea & 50 & 78 & 46 & 47 \\
\hline Mali & 62 & 77 & 48 & 52 \\
\hline Senegal & 57 & 77 & 49 & 52 \\
\hline Sierra Leona & 55 & 82 & 35 & 38 \\
\hline Togo & 33 & 63 & 49 & 52 \\
\hline Uganda & 26 & 50 & 43 & 43 \\
\hline Guinea-Bissau & 32 & 58 & 42 & 45 \\
\hline República Centroafricana & 32 & 48 & 46 & 51 \\
\hline Países de alto ingreso, promedio & $<5$ & $<5$ & 74 & 81 \\
\hline
\end{tabular}

Tomado de Nolan A. Bowie, "The digital divide: making knowledge available in a global context", en Centre for Educational Research and Innovation [y] National Center on Adult Literacy, Learning to bridge the digital divide, Education and skills (París: OCDE, 2000), 42.

37 Bowie, 41. 
El estudio de Children's Partnership analizó los 1,000 sitios web más populares y encontró que sólo el uno por ciento de ellos puede ser leído fácilmente por los 44 millones de estadounidenses que leen por abajo del nivel promedio de lectura. ${ }^{38}$

La brecha verdadera no es tanto la tecnológica como la brecha que existe entre quienes son capaces de leer y quienes no lo son. Quienes pueden leer tienen una ventaja sobre aquellos que no, para obtener información, aunque sea mediante la utilización de los instrumentos más tradicionales, como libros, periódicos y revistas. La información digital no es la única que se produce y consume. Cuando los individuos se ven impedidos de actualizarse, de informarse, porque sus habilidades lectoras no se lo permiten, estamos ante una situación catastrófica que el uso de la tecnología de la información no puede resolver por sí misma. Sin embargo, si los individuos aprenden a leer, se pueden beneficiar de la consulta y uso de la información que se encuentra en la red y que marca una diferencia en las formas de obtener información. 39

La carencia de la habilidad para leer es una barrera importante en al acceso a la TIC, aun si los equipos de cómputo se abarataran, si se tuviera mayor disponibilidad de ellos mediante compra, cibercafés, escuelas, bibliotecas públicas y centros comunitarios, la mayoría de la población mundial estaría excluida de la revolución de la información. Una quinta parte de la población mundial es analfabeta, de la cual el 40 por ciento vive en las regiones del sur del Sahara, el Medio Oriente y los países asiáticos, y las mujeres constituyen la mayor parte. Estos datos nos llevan a considerar que en aquellas zonas las mujeres prácticamente están excluidas por motivos religiosos, ya que la mayoría de las áreas con alta concentración de mujeres analfabetas corresponden a países musulmanes.

38 Kuttan y Peters, 21.

39 Lloyd Moriste, "Prólogo", en Benjamin M. (ed.), The digital divide: facing a crisis or creating a myth? (Cambridge, Mass.: MIT Press, 2001), ix-x. 
Por otra parte, un aspecto importante relacionado con la lectura de diarios y periódicos a escala mundial es que muchos de ellos están disponibles en la red y además son de acceso gratuito, como el New York Times. Para acceder a ellos el lector sólo debe registrarse con fines de identificación, con lo cual obtiene libre acceso a la edición del día, y con ello puede conocer cómo ha sido tratada la información por los distintos periodistas y periódicos. Además, esos periódicos van incorporando a su página nuevas noticias en la medida en que éstas se van produciendo. Otros periódicos no solicitan ninguna identificación, aunque es posible que mediante el código de identificación de la computadora sepan en qué parte del mundo los están consultando. Por último están los periódicos que sólo permiten la consulta de su versión en Internet si quien lo hace es suscriptor de la versión en papel.

Cuatro de cada 10 periódicos están en la red, en Europa la densidad de periódicos es la más alta y dos tercios de todos los periódicos europeos están en red. ${ }^{40}$

En la figura 102 encontramos información sobre los periódicos que se publican en el mundo, así como cuántos de ellos están en línea. El 30 por ciento de los periódicos ya cuentan con versión electrónica, pero en algunas regiones el porcentaje es menor como por ejemplo en la zona Asia/Pacífico, que tiene tan sólo el ocho por ciento de sus periódicos en versión electrónica; América del Sur cuenta también con el ocho por ciento, mientras que Europa tiene casi el 30 por ciento y América del Norte el 70 por ciento.

La figura 103 refuerza nuestros argumentos acerca de que la información se concentra en los países desarrollados de Europa y Norteamérica, mientras que las naciones en desarrollo tienen muy baja cobertura tanto de periódicos, revistas, estaciones de radio y televisión y servicios noticiosos. Todos los países, exceptuando a los europeos y a los Estados Unidos, reúnen un poco más que los medios de comunicación europeos y 5.5 veces menos que los estadounidenses.

40 Norris, Digital divide, 181. 


\section{Esto hace que la información se concentre en los asuntos norteame- ricanos y europeos y excluya casi todo lo relacionado con las nacio- nes en desarrollo.}

Figura 102

El mundo de los periódicos en línea

\begin{tabular}{|c|c|c|c|c|}
\hline & $\begin{array}{l}\text { Número total de } \\
\text { periódicos en línea } \\
(2000)\end{array}$ & $\begin{array}{l}\text { Número total de } \\
\text { periódicos diarios } \\
(1966)(s i c)\end{array}$ & $\begin{array}{l}\text { Proporción de to- } \\
\text { dos los periódicos } \\
\text { diarios en línea }\end{array}$ & $\begin{array}{l}\text { Número total } \\
\text { de naciones }\end{array}$ \\
\hline Todos & 2,494 & 8,145 & 40 & 161 \\
\hline Europa Occidental & 388 & 1,134 & 63 & 15 \\
\hline América del Norte & 1,355 & 1,922 & 53 & 3 \\
\hline América del Sur & 165 & 981 & 52 & 26 \\
\hline Escandinavia & 133 & 275 & 50 & 5 \\
\hline Oriente Medio & 55 & 198 & 45 & 14 \\
\hline África Subsahariana & 67 & 212 & 39 & 47 \\
\hline Asia-Pacífico & 238 & 2,712 & 30 & 28 \\
\hline Europa Central y Oriental & 93 & 711 & 24 & 23 \\
\hline Desarrollo humano alto & 1,982 & 3,752 & 51 & 42 \\
\hline Desarrollo humano medio & 427 & 4,171 & 36 & 80 \\
\hline Desarrollo humano bajo & 34 & 175 & 28 & 31 \\
\hline Democracias establecidas & 2,000 & 3,937 & 53 & 64 \\
\hline Democracias consolidadas & 298 & 1,739 & 35 & 67 \\
\hline No democracias & 50 & 469 & 20 & 30 \\
\hline \multicolumn{5}{|c|}{$\begin{array}{l}\text { Nota: La tabla resume la distribución de periódicos en línea en } 179 \text { naciones en fecha junio de } 2000 \text { de acuerdo } \\
\text { con AJRNewslink, www.Ajr.newslink.org. Estos datos fueron verificados en forma cruzada y comparados } \\
\text { contra las listas de periódicos (media links) mantenidos por Editor \& Publisher, www.mediainfo.com. The } \\
\text { World News Index, http://wni.Harold.nu; y la lista provista por Yahoo, www.Dir.yahoo.com/News and Me- } \\
\text { dia/Newspapers/By region/Countries. } \\
\text { El número de periódicos diarios por nación: el último año disponible, normalmente 1996, en } 174 \text { países } \\
\text { con los datos del UNESCO Statistical Yearbook 1999, París: UNESCO. El nivel de desarrollo humano fue } \\
\text { derivado del UnDP Human Development Index 1999, UNDP, Human Development Report 1999. Nueva York: } \\
\text { UNDP/Oxford University Press. Tipo de democracias: el nivel de democracia de cada país fue clasificado } \\
\text { según la escala de siete puntos de Freedom House de derechos políticos y libertades civiles. Los países } \\
\text { fueron clasificados como democracias establecidas (1.0 a 2.5), democracias consolidadas (3.0 a 4.5) y no } \\
\text { democracias (5.0 a 7.0). Freedom House Survey of Political Rights and Civil Liberties 1999-2000, } \\
\text { www.freedomhouse.org. }\end{array}$} \\
\hline
\end{tabular}

Tomado de Pippa Norris, Digital divide: civic engagement, information poverty and the Internet worldwide (Cambridge, R.U.: Cambridge University Press, 2001), 180. 
Figura 103

El mundo de los medios noticiosos en línea

\begin{tabular}{||l|c|c|c|c|c|c|c||}
\hline \hline & Periódicos & Revistas & $\begin{array}{c}\text { Estaciones } \\
\text { de radio }\end{array}$ & $\begin{array}{c}\text { Sitios de } \\
\text { TV }\end{array}$ & $\begin{array}{c}\text { Nuevos } \\
\text { servicios }\end{array}$ & $\begin{array}{c}\text { Todos } \\
\%\end{array}$ & Todos N \\
\hline Estados Unidos & 65.2 & 64.2 & 66.7 & 75.0 & 74.3 & 66.4 & 7,880 \\
\hline Europa & 14.2 & 18.9 & 11.7 & 13.6 & $p .2$ & 15.3 & 1,813 \\
\hline Asia & 4.8 & 4.7 & 7.6 & 5.0 & 1.8 & 5.2 & 616 \\
\hline Canadá & 5.7 & 4.2 & 6.9 & 0.1 & 6.3 & 4.8 & 566 \\
\hline América del Sur & 6.7 & 2.3 & 1.5 & 2.5 & 1.4 & 3.8 & 452 \\
\hline Oceania & 1.1 & 3.0 & 3.7 & 2.2 & 1.4 & 2.3 & 268 \\
\hline África & 1.3 & 1.6 & 1.4 & 0.7 & 1.4 & 1.3 & 160 \\
\hline Oriente Medio & 1.1 & 1.2 & 0.4 & 0.8 & 1.4 & 1.0 & 117 \\
\hline Total & 100.0 & 100.0 & 100.0 & 100.0 & 100.0 & 100.0 & 11,872 \\
\hline Fuente: Editor \& Publisher, Junio 2000, www.mediainfo.com. \\
\hline
\end{tabular}

Tomado de Pippa Norris, Digital divide: civic engagement, information poverty, and the Internet worldwide (Cambridge, R.U.: Cambridge University Press, 2001), 183.

Como puede verse en la figura anterior, en unos cuantos países desarrollados se concentran los diferentes medios de comunicación, particularmente en Estados Unidos y Europa. Aunque la proporción entre Estados Unidos y Europa es muy desigual, lo es más en comparación con el resto de las regiones; así, en los extremos tenemos por una parte a Estados Unidos y por la otra a Medio Oriente. En todos los rubros la diferencia es dramática ya que mientras que los norteamericanos cubren el 66.4 por ciento, el Medio Oriente sólo logra el uno por ciento.

\section{Brecha digital e inclusión y marginación social}

El fenómeno de la brecha digital también comprende el aspecto de la inclusión social; esto es, no sólo se limita a estudiar el acceso a la red, o a los aspectos tecnológicos relacionados con los elementos digitales, sino que comprende otros aspectos sociales que tienden a igualar a las personas o a marginarlas de la corriente principal de la sociedad. 
El error al considerar a la brecha digital como un mero problema tecnológico, limitándolo a soluciones digitales, relacionadas con las computadoras y las telecomunicaciones, ocasiona el olvido de aquellos aspectos que tienen que ver con la inclusión social de los grupos marginales. La tecnología de la información y comunicación se relaciona con los aspectos sociales, pero por sí misma es insuficiente para explicarlos. ${ }^{41}$

Por inclusión social nos referimos principalmente a que los individuos, las familias y las comunidades participen en la vida social y además tengan el control de sus propios destinos. Esto se logra teniendo en cuenta la existencia de elementos de distinto tipo relacionados con los recursos económicos, el empleo, la salud, la educación, la habitación, la cultura y el compromiso social. ${ }^{42}$

En consecuencia, la inclusión social es un concepto que tiene muchos elementos que lo determinan y que están relacionados con la brecha digital. Cerrar la brecha digital sin atacar los elementos mencionados anteriormente es prácticamente imposible, es un espejismo pretender que el uso de la tecnología es suficiente para superar todos los elementos de retraso que tienen las comunidades. No se puede llegar a hacer un uso fructífero de la tecnología sin antes atacar los elementos sociales que retrasan el cierre de la brecha.

La inclusión social se relaciona con una adecuada participación de los recursos, y a su vez tiene que ver con las oportunidades, tanto individuales como colectivas. La inclusión social puede pensarse como algo semejante a la igualdad económica, pero no es del todo equivalente, es más bien el conjunto de oportunidades que tienen el individuo y la colectividad. Hay muchas formas en las que los pobres pueden tener una participación completa, aun cuando les falte disfrutar de una parte de los recursos. Si no fuese así, la movilidad social no se daría, los segmentos sociales tendrían que permanecer estáticos en su estrato social, cultural, educativo y económico. Por otra

41 Warschauer, Technology, 6.

42 Ibid. 
parte, aun quienes tienen muchos recursos, en ocasiones se ven excluidos socialmente por motivo de persecución política o por la discriminación basada en la edad, el género, las preferencias sexuales o la discapacidad. El concepto de inclusión social no ignora el papel de las clases, pero reconoce que otras fuerzas importantes actúan para explicar cómo interactúan éstas. ${ }^{43}$

El problema de la exclusión puede ser visto desde la óptica de la limitación de los derechos de los individuos a las mismas oportunidades de información y de esparcimiento. Como ha establecido Eric Cohen, editor director de The Public Interest, en un número de abril de 2000 de The Weekly Standard:

La brecha digital es ahora el tema de política social más candente de Washington. Es un nuevo aspecto en el tema de los derechos civiles. 44

Otras personas han opinado sobre el significado de la brecha digital como una forma de marginación social. Así por ejemplo Kweisi Mfume, presidente de la National Association for the Advancement of Colored People (NAACP), se ha referido al problema como "segregación tecnológica", y el reverendo Jesse Jackson ha dicho que la brecha digital representa una forma clásica de Apartheid. ${ }^{45}$

Bill Gates ha argumentado que él no pretende que los niños pobres reciban primero una computadora que las vacunas básicas para lograr tener una vida sin enfermedades y con expectativas de vida amplia. Lo que sí ha dicho es que la posesión de computadoras debe ser vista como si esos grupos marginales tuvieran una escalera que les permita ascender en la escala social y salir de la pobreza, y adicionalmente superarse y salir adelante.

43 Ibid.

44 Thierer, "How free computers are filling the digital divide", 1.

45 Ibid., 2. 


\section{La participación civil}

Kuttan y Peters, al referirse a la participación política de los ciudadanos estadounidenses y la TIC, han señalado:

La brecha digital impacta los principios fundamentales de la participación política en la democracia americana. Si un segmento de la población no tiene acceso igual a Internet, ese grupo tampoco tendrá acceso igual a los recursos en línea. Por lo tanto, sin las posibilidades de utilización de la misma información que el resto de la sociedad, a aquellos en el lado negativo de la brecha se les niega una participación política igual a la de quienes sí tienen acceso. 46

Aunque las líneas anteriores tratan sobre los Estados Unidos, la tecnología de la información ha influido en la participación civil de muchas formas y en diversas partes del mundo; posiblemente la más común ha sido aquella que encabezan los partidos políticos. En el año 2000 fue publicada por Elections Around the World una lista de 1371 partidos registrados como que poseen una página en la red. ${ }^{47}$ Aunque con una diferencia en el número de partidos políticos que poseen un sitio en la red, la figura 104 muestra el detalle de la distribución geográfica de tales sitios.

Los partidos políticos han construido sitios para divulgar sus objetivos, sus principios ideológicos, sus formas de afiliación o de apoyo al partido. Los ciudadanos también pueden participar en muchas otras actividades organizadas por grupos que aunque no son partidos políticos propiamente dichos, realizan actividades similares, como las llamadas organizaciones no gubernamentales. A escala mundial, los partidos de todas las corrientes ideológicas y representaciones proporcionales han construido su sitio en la red, como podemos observar a través de la figura 105.

46 Kuttan y Peters, 69.

47 Norris, Digital divide, 151. 


\section{Figura 104 \\ Los sitios web de partidos políticos}

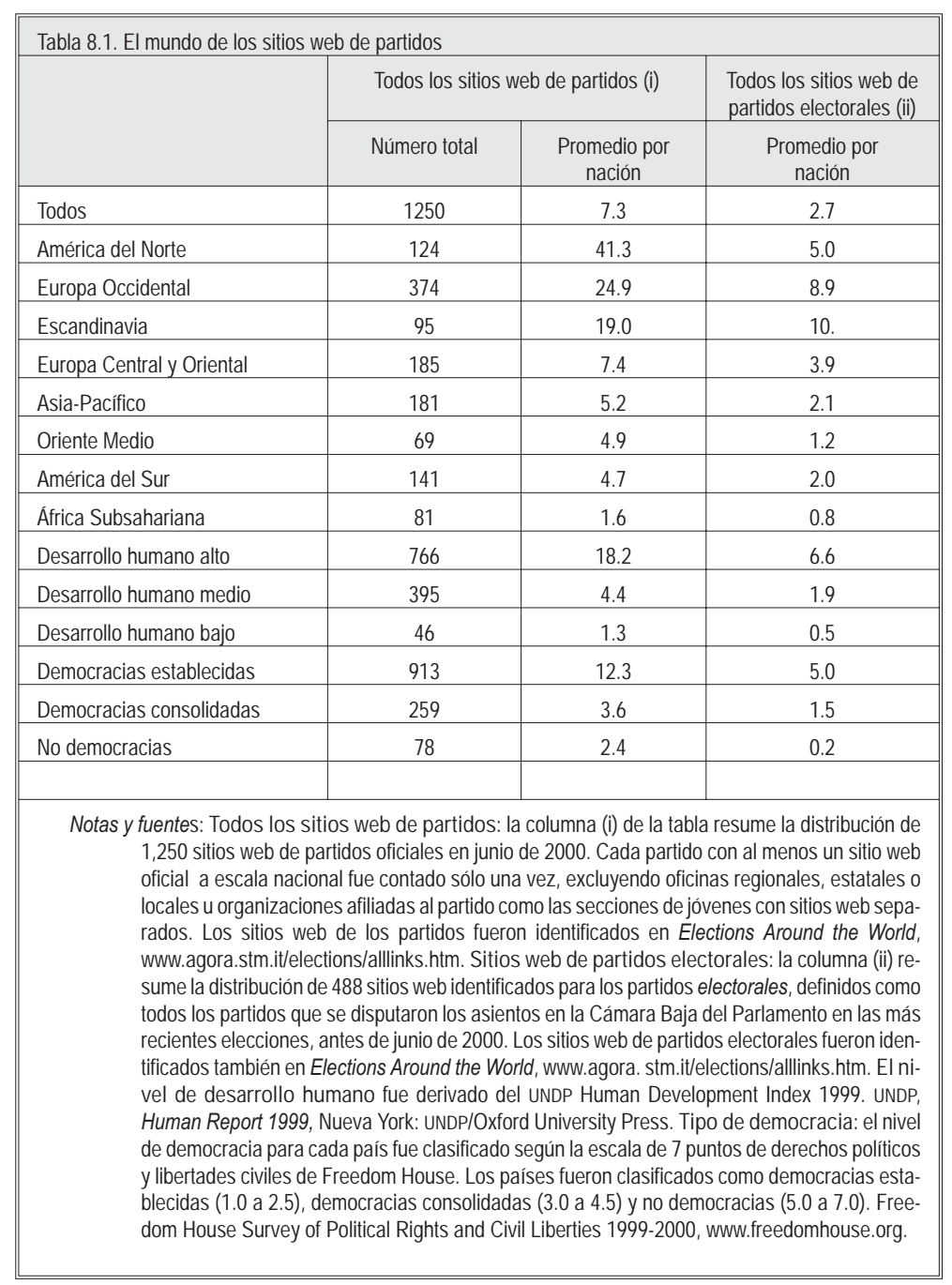

Tomado de Pippa Norris, Digital divide: civic engagement, information poverty, and the Internet worldwide (Cambridge, R.U.: Cambridge University Press), 155. 


\section{La brecha digital y sus determinantes}

Figura 105

Tipificación de partidos electorales en línea

\begin{tabular}{|c|c|c|c|c|}
\hline & $\begin{array}{c}\text { Partidos } \\
\text { marginales (\%) }\end{array}$ & $\begin{array}{c}\text { Partidos } \\
\text { minoritarios (\%) }\end{array}$ & $\begin{array}{c}\text { Partidos } \\
\text { mayoritarios (\%) }\end{array}$ & $\begin{array}{c}\text { Todos } \\
(\%)\end{array}$ \\
\hline Extrema izquierda & 35 & 65 & 44 & 42 \\
\hline Social-demócrata & 38 & 53 & 74 & 52 \\
\hline Ecologistas & 59 & 88 & 0 & 71 \\
\hline Centro & 33 & 45 & 28 & 37 \\
\hline Liberales & 39 & 73 & 82 & 57 \\
\hline Demócratacristianos & 52 & 71 & 78 & 62 \\
\hline Conservadores & 36 & 55 & 66 & 51 \\
\hline Nacionalistas, extrema derecha & 49 & 41 & 32 & 41 \\
\hline $\begin{array}{l}\text { Otros incluyendo religiosos, agrarios y } \\
\text { partidos regionales que carecen de otra } \\
\text { identificación }\end{array}$ & 18 & 22 & 19 & 19 \\
\hline Todos & 31 & 47 & 52 & 39 \\
\hline \multicolumn{5}{|c|}{$\begin{array}{l}\text { Notas y fuentes: la tabla muestra el porcentaje de todos los partidos electorales con un sitio web oficial en } 179 \text { países } \\
\text { en junio de 2000, y la familia ideológica de cada partido, de acuerdo a Elections Around the World, www. } \\
\text { agora.stm.it/elections/alllinks.htm. Se analizaron en total 1,244 partidos electorales encontrándose que } \\
488 \text { tenían un sitio web. } \\
\text { Partidos electorales fueron definidos como todos aquellos que se disputaron los asientos en la Cámara } \\
\text { Baja del Parlamento en la más reciente elección. Los partidos fueron clasificados por tamaño de acuerdo } \\
\text { con la distribución de asientos en la Cámara Baja del Parlamento en los resultados de la última elección. } \\
\text { Partidos marginales incluyen aquellos con menos del } 3 \text { por ciento de los lugares en el Parlamento. Parti- } \\
\text { dos minoritarios tienen más del } 3 \text { por ciento y menos del } 20 \text { por ciento de los lugares. Partidos mayorita- } \\
\text { rios tienen más del } 20 \text { por ciento de los asientos. }\end{array}$} \\
\hline
\end{tabular}

Tomado de Pippa Norris, Digital divide: civic engagement, information poverty, and the Internet worldwide (Cambridge, R.U.: Cambridge University Press), 157.

La tecnología de la información ha permitido que se establezcan sistemas de votación electrónica que hacen posible que el ciudadano conozca con precisión cuál es el resultado unos cuantos minutos después de que se cierran las urnas, evitando con ello la manipulación de los votos. El conteo de los votos ayudado por recursos electrónicos como el teléfono, fax, computadoras e Internet entre otros, también ha contribuido a que los procesos electorales sean más equitativos. 
Incluso en los casos en que han surgido problemas, como la elección presidencial de México en 1988, en la que el sistema sufrió una interrupción en su funcionamiento mientras se contabilizaban los resultados, se puso de manifiesto que la prontitud en los resultados que ofrecían las tecnologías de la información, no posibilitaba la manipulación de los resultados, a menos que el sistema electrónico sufriera un desperfecto. Debido a ese incidente se reconoció la necesidad de que el recuento de votos fuera hecho por un órgano no controlado por el gobierno; provocó toda una serie de reformas electorales donde las tecnologías de la información fueron un apoyo indispensable.

Las democracias están en riesgo si los ciudadanos no están igualmente informados, la hipótesis de que todos los ciudadanos son iguales debe suponer la misma capacidad y oportunidad de informarse. Aquellos que no se pueden informar están en desventaja con respecto a quienes sí pueden hacerlo.

El uso de Internet en la vida política es visto con las mismas o mejores perspectivas que el de otros medios de comunicación masiva como la radio y la televisión, los cuales han sido utilizados de forma muy amplia, en especial la segunda, a partir del último tercio del siglo pasado.

La utilización de Internet para fomentar la participación civil genera una división de criterios con respecto a si será buena o no, dada la similitud que tiene con otros medios de comunicación masiva. Los pesimistas piensan que la información estará controlada por unas cuantas personas como ha sucedido con la radio y la televisión; los intereses privados serán dominantes y la manipulación de la información estará presente. Adicionalmente hay un grupo de personas que no tienen acceso a la red y por lo tanto se encuentran excluidas del acceso a la información.

Quienes asumen una visión positiva sobre la utilidad de Internet ven en ella factible que los individuos tengan parte del control de la información, al ver y seleccionar solamente lo que ellos desean, así como al tener la posibilidad de producir información que viaje en la red, facilidad con la que no se contaba hasta ahora. El ciudadano común tiene en sus manos la oportunidad de participar en grupos de 
discusión o formar los suyos propios, opinar en encuestas y otras opciones que antes no tenía.

Algunos países, con diferentes pretextos, entre los que se encuentran la protección de los niños y de la moral pública y el cuidado de las culturas autóctonas, limitan el acceso y uso de Internet. En realidad lo que se controla es el acceso a la información y a la posibilidad de que los individuos entren en contacto con otros grupos que apoyen sus ideas o acciones políticas. En la mayoría de los países totalitarios, este control sobre el uso de Internet puede llevar a una persona a la cárcel.

El uso de Internet permite que los individuos entren en contacto con los distintos actores políticos mediante el uso de páginas web y del correo electrónico; cada vez es más común que las organizaciones civiles, los partidos políticos y los políticos cuenten con estos dos medios que bien manejados facilitan la comunicación con actores políticos y el activo intercambio de opiniones favorables o contrarias.

El uso de Internet con fines políticos ha sido lento y es más usual naturalmente en los países con mayor acceso a la red. En la medida en que más personas utilizan la TIC, los políticos y las actividades políticas son más variados. Esto no significa, como se ha establecido anteriormente, que con la utilización de Internet las actividades o tecnologías anteriores se descontinúen; los partidos políticos siguen teniendo sus reuniones locales, asambleas regionales, estatales o nacionales. Lo que implica el uso de la TIC es la oferta de nuevas oportunidades de obtener información y participar. Pero la posibilidad de acción política en la que es necesario interactuar con otras personas, seguirá siendo de gran utilidad y uso durante los próximos años. Así por ejemplo, es común que se realicen todo tipo de consultas o encuestas utilizando la red y que los ciudadanos participen y dejen escuchar su opinión de forma más frecuente. Es común que medios como la prensa, la radio o la televisión realicen consultas que sean respondidas vía telefónica, pero en los últimos años también han ofrecido sus conexiones a la red para recibir opiniones y/o comentarios.

Además, los usuarios de la red pueden obtener información sobre los servicios que prestan los gobiernos locales, los partidos políticos y las organizaciones civiles, esto hace que la relación entre el indivi- 
duo y los otros actores políticos se facilite, pero aquellos que no tienen acceso a la red se ven marginados de todos los beneficios anteriores.

Los partidos políticos de todo el orbe utilizan las tecnologías de la información, no importa de qué tendencia sean y en qué lugar del mundo se encuentren. De una u otra forma también las organizaciones no gubernamentales u organizaciones de la sociedad civil tienen acceso a las tecnologías de la información; con ello difunden sus principios ideológicos, programas de acción y documentos básicos, su integración y dan a conocer sus cuadros dirigentes, así como las actividades que organizan y cuándo y dónde se celebrarán. Mediante estos mecanismos los ciudadanos entran en contacto con esas organizaciones. Otro punto de vista en esta materia es cómo los partidos se benefician de Internet: para reunir fondos que los ayuden a realizar su trabajo, reclutar nuevos miembros y simpatizantes, organizar a los trabajadores, obtener una retroalimentación de lo que piensan los miembros y simpatizantes de sus actividades. ${ }^{48}$

Sin embargo, hay un punto de vista contrario a la utilización de Internet en la vida política en general; esta oposición sostiene que el uso de Internet provoca un aislamiento entre los dirigentes partidistas y sus bases.

48 Ibid., 148. 



\section{Obras consultadas}

Action Consumers Union. "Exploring the digital divide." Test Inform Protect (Febrero 2001) : 69.

Afele, John Senyo C. Digital bridges: developing in the knowledge economy. Hershey, Pensilvania: Idea Group, 2003.

Applebaum, Simon. Cablevision. Septiembre 27, 1999.

—. "Facing the digital divide." News Multichannel. Disponible en http://www.multichannel.com/index.asp?layout = article \&display $=$ Archives $\&$ articleid $=$ CA59445 [Diciembre 13, 2005].

Arellano López, Consuelo. "Características de acceso y uso de la computadora y la Internet en los hogares mexicanos." Boletín de Política Informática 1 (2003): 13-23.

Arrison, Sonia. "What digital divide?" CNET News.com, marzo 13, 2002. Disponible http://news.com.com/2010-1071-858537.html [Marzo 21, 2004].

Banco Mundial. Entering the 21st century: world development report 1999/2000. Washington, D.C.: Oxford University Press, 1999.

Bédard, François y Boualem Kadri. Réduction de la fracture numérique en tourisme: role des grandes organizations internationals. Saint-Foy: Presses de l'Université du Québec, 2003.

Black, Jane. "Plugging into the revolution." BBC News on Line, enero 15, 2001. Disponible http://www.news.bbc.co.uk [Marzo 21, 2004 ].

Blau, Andrew. “Access isn't enough.” American Libraries (Junio/Julio 2002): 50-52. 
Bolt, David y Ray A. K. Crawford. Digital divide: computers and our children's future. Nueva York: TV Books, 2002.

Brady, Mick. "The digital divide myth." E-Commerce Times, agosto 4, 2000. Disponible http:///www.ecommercetimes.com/story/ 3953.html [Agosto 11, 2005].

Browing, Graeme. Electronic democracy: using the Internet to influence American politics. Wilton, Connecticut: Pemberton Press, 1996.

Centre for Educational Research and Innovation [y] National Center on Adult Literacy. Learning to bridge the digital divide. Education and skills. París: Organización para la Cooperación y el Desarrollo Económico, c2000.

CEPAL. Los caminos hacia una sociedad de la información en América Latina y el Caribe. Santiago de Chile: CEPAL, 2003. Disponible http://www.eclac.cl/publicaciones/DesarrolloProductivo/1/LCG2195Rev1P/lcg2195e2.pdf [Octubre 2, 2005].

Chen, Wenhong y Barry Wellman. Charting and bridging digital divides: comparing socio-economic, gender, life stage, and rural-urban Internet access and use in eight countries. Octubre 27, 2003. Disponible http://www.amd.com/us-en/assets/content_type/DownloadableAssets/FINAL_REPORT_CHARTING_ DIGI_DIVIDES.pdf [Agosto 6, 2004].

Clancy, Roger E., ed. A nation on line: how Americans are expanding their use of the Internet. Nueva York: Novinka Books, c2002.

Comisión Federal de Telecomunicaciones. Comparativo internacional de penetración de computadoras, computadoras por cada 100 babitantes. Disponible en http://www.cofetel.gob.mx/ wb2/COFETEL/COFE_Comparativo_Internacional_de_Penetracion_de_2 [Octubre 4, 2005]. 
Comisión Federal de Telecomunicaciones. Densidad de líneas telefónicas fijas en servicio por entidad federativa, líneas por cada cien habitantes 1990-2005. Disponible en http://www.cofetel.gob.mx/wb2/COFETEL/COFE_Densidad_de_lineas_telefonicas_fijas_en_serv [Octubre 4, 2005].

-. Usuarios de Internet por disponibilidad de computadora en el hogar, según lugar de acceso 2000-2004. Disponible en http:// www.cofetel.gob.mx/wb2/COFETEL/COFE_Usuarios_estimados_de_internet_en_Mexico_2 [Octubre 4, 2005].

Compaine, Benjamin M., ed. The Digital divide: facing a crisis or creating a myth? The MIT Press Sourcebooks. Cambridge, Mass.: MIT Press, 2001.

Conhaim, Wallys W. "The Internet: the digital divide." Link-Up 17, no. 4 (Julio/Agosto 2000): 10-11. Disponible http://www.infotoday.com/lu/jul00/conhaim.htm [Agosto 9, 2004].

Cooper, Joel y Kimberlee D. Weaver. Gender and computers: understanding the digital divide. Nueva Jersey: Lawrence Erlbaum Associates, 2003.

Corrocher, Nicoletta y Andrea Ordanini. "Measuring the digital divide: a framework for the analysis of cross-country differences." Journal Information Technology 17, no. 1 (2002): 9-19. Disponible EbscoHost (AN 6705498).

Cottrell, R. Les y Warren Matthews. Measuring the digital divide with PingER. Octubre 2003. Disponible http://www.slac.stanford.edu/pubs/slacpubs/10000/slac-pub-10186.html [Agosto 5, 2004].

Crystal, David. English as a global language. Cambridge: Cambridge University Press, 1997.

Cullen, Rowena. "The digital divide: a global and national call to action." The Electronic Library 21, no. 3 (2003): 247-257. Disponible http://www.emeraldinsight.com/0264-0473.htm. 
Davis, Thomas y Mark Trebian. "Shaping the destiny of native American people by ending the digital divide." Educase Review 36, no. 1 (Enero/Febrero 2001): 38-46. Disponible http://www.educase.edu/ir/library/pdf/erm0112.pdf [Agosto 6, 2004].

Day, Peter y Doug Schuler. Community practice in the society: local action, global interaction. Londres, Nueva York: Routledge, 2004.

Digital divide. Disponible http://www-cs-education.stanford. edu/classes/cs201/projects-99-00/digital-divide/overview.html [Agosto 4, 2004].

Dymond, Andrew y Sonja Oestman. Information and communication technologies (ICTs): poverty and universal access policies. Nairobi, Kenya: African Technology Policy Studies Network, 2002.

EUA. Department of Commerce, National Telecommunications and Information Administration. Falling through the net: defining the digital divide: a report on the telecommunications and information technology gap in America. Washington, D.C.: Department of Commerce, National Communications and Information Administration, 1999.

EUA. National Archives and Records Administration. Falling through the net: toward digital inclusion: a report on Americans' access to technology tools. Washington, D.C.: Department of Commerce, National Communications and Information Administration, 2000.

- Falling through the net II: new data on the digital divide. Washington, D.C.: Department of Commerce, National Communications and Information Administration, 1998.

Federal Reserve Bank of San Francisco. "Is there a digital divide?" FRBSF Economic Letter 38, diciembre 26, 2003. Disponible http://www.frbsf.org/publications/economics/letter/2003/ el2003-38.html [Agosto 30, 2005]. 
Gere, Charlie. Digital culture. Londres: Reaktion, 2002.

Gilster, Paul. Digital literacy. Nueva York: Wiley Computer Publishing, 1997.

Goldsborough, Reid. "Bridging the Digital Divide." Link-Up 17, no. 3 (Mayo/Junio 2000). Disponible http://www.infotoday.com/LU/ may00/personalcomputing.htm [Agosto 9, 2004].

Gordon, David T. "The New Digital Divide." NEA Today (Marzo 2001). Disponible http://www.nea.org/neatoday/0103/cover. html [Mayo 10, 2004].

Grossman, L. y Minow Newton. "A Universal library." New York Times Art, abril 10, 2001, a21.

Hamilton, Stuart y Niels Ole Pors. "Freedom to access to information and freedom to expression: the Internet as a tool for global social inclusion." Library Management 24, no. 8/9 (2003): 407416. Disponible http://www.emeraldinsight.com/0143-5124.htm [Mayo 5, 2004].

Hardeck, Erwin, Tatjana Mrowka, Anette Seiler y Heiko Jansen. "Bits, bytes, and user comfort: the digital library (DigiBib)." Libri 53, no. 1 (Marzo 2003): 11-22.

Harrington, Jonathan. "Bridging the digital divide." Problems of Post-Communism 48, no. 1 (Enero/Febrero 2001): 65. Disponible EbscoHost (AN 4009155) [Agosto 10, 2004].

Hellawell, Samantha. Beyond access: ICT and social inclusion. Londres: Fabian Society, 2001.

Hoffman, Donna L., Thomas P. Novak y Ann E. Schlosser. "The evolution of the digital divide: how gaps in Internet access may impact electronic commerce." Journal of Computer-Mediated Communication 5, 3 (Marzo 2000). Disponible http://www.ascusc.org/jcmc/vol5/issue3/hoffman.html [Agosto 4, 2004].

Hull, Barbara. "Can librarians help to overcome the social barriers to access?” New Library World 102, no. 1169 (2001): 382-388. 
INEGI. Disponibilidad de bienes seleccionados en viviendas y sus ocupantes, 2000. Disponible http://www.inegi.gob.mx/est/con-

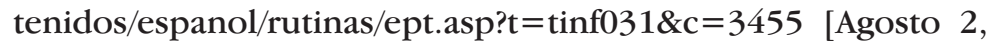
2005].

- Hogares con computadora por edad y escolaridad del jefe de familia, 1996 a 2002. Disponible http://www.inegi.gob.mx/est/

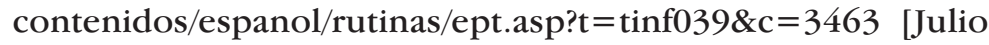
$13,2005]$.

- Hogares con equipamiento de tecnología de información y comunicaciones por tipo de equipo, 2001 a 2005. Disponible http://www.inegi.gob.mx/est/contenidos/espanol/rutinas/ept. asp? $\mathrm{t}=\operatorname{tinf} 196 \& \mathrm{c}=5585$ [Enero 12, 2006].

- Población de seis años y más que utiliza computadora por grupos de edad, 2001, 2002 y 2004. Disponible http://www.inegi. gob.mx/est/contenidos/espanol/rutinas/ept.asp?t $=$ tinf $214 \& \mathrm{c}$ $=5567$ [Julio 13, 2005].

- Población de seis años y más que utiliza computadora por sexo, 2001, 2002 y 2004. Disponible http://www.inegi.gob.mx/ est/contenidos/espanol/rutinas/ept.asp?t $=\operatorname{tinf} 211 \& \mathrm{c}=5570 \quad[\mathrm{Ju}-$ lio 2, 2005].

- Población de seis años y más usuaria de las tecnologías de la información, 2001, 2002 y 2004. Disponible http://www.inegi. gob.mx/est/contenidos/espanol/rutinas/ept.asp?t $=$ tinf $204 \&$ $\mathrm{c}=5577$ [Agosto 2, 2005].

-. Usuarios de Internet por género, 2001 a 2005. Disponible http://www.inegi.gob.mx/est/contenidos/espanol/rutinas/ ept.asp?t $=$ tinf $216 \& c=5565$ [Noviembre 22, 2005].

—. Usuarios de Internet por grupos de edad, 2001 a 2005. Disponible http://www.inegi.gob.mx/est/contenidos/espanol/rutinas/ ept.asp? $\mathrm{t}=\operatorname{tinf} 214 \& \mathrm{c}=5567$ [Noviembre 22, 2005]. 
James, Jeffrey. "Bridging the digital divide with low-cost information technologies." Journal of Information Science 27, no. 4 (2001): 211-217.

-. Bridging the global digital divide. Cheltenham, R.U.: Northampton, Mass.: Edward Elgar, 2003.

Johnson, Paul. "Narrowing the digital divide: initiatives undertaken by the Association of South-East Asian Nations (ASEAN)." Program: Electronic Library and Information Systems 36, no. 1 (2002): 13-22. Disponible http://www.emeraldinsight.com/ 0033-0337.htm.

Kagami, Mitsuhiro y Masatsugu Tsuji. Digital divide or digital jump: beyond "IT" revolution. Tokyo: Institute of Developing Economics, 2002.

Katz, J. y P. Aspeden. "Internet dropouts in the USA." Telecommunications Policy 22, no. 4/5 (1998): 327-339.

Katz, James E. y Ronald E. Rice. Social consequences of Internet use: access, involvement, and interaction. Cambridge, Mass.: MIT Press, c2002.

Kelley-Salinas, Guillermo. "Different educational inequalities: ICT an option to close the gaps." En Centre for Educational Research and Innovation [y] National Center on Adult Literacy. Learning to bridge the digital divide. Education and skills. $\mathrm{Pa}-$ rís: OCDE, c2000.

Kuk, George. "The digital divide and the quality of electronic service delivery in local government in the United Kingdom." Government Information Quarterly 20, no. 4 (2002): 353-363. Disponible Elsevier ScienceDirect doi:10.1016/j.giq.2003. 08.004 .

Kuttan, Appu y Laurence Peters. From digital divide to digital opportunity. Lanham, Maryland: Scarecrow Press, 2003. 
Law, Derek. "Bridging the digital divide: a review of current progress." Library Management 25, no. 1/2 (2004) : 17-21. Disponible http://www.emeraldinsight.com/0143-5124.htm.

Loader, Brian D., ed. Cyberspace divide: equality, agency and policy in the information society. Londres: Routledge, 1998.

Levy, Steven. "2001: Why HAL never happen. "Newsweek Special Edition 20 (Febrero 2001): 58.

Light, Jennifer S. "Rethinking the Digital Divide." Harvard Educational Review 71, no. 4 (Invierno 2001): 709-733.

Mack, Raneta Lawson. The Digital Divide: standing at the intersection of race and technology. Durham, Carolina del Norte: Academic, c2001.

Marshall, Stewart, Wallace Taylor y Xinghuo Yu, eds. Closing the digital divide: transforming regional economies and communities with information technology. Westport, Conn.: Praeger, 2003.

-. Using community informatics to transform regions. Hershey, Pensilvania: Idea Group, 2004.

Maurrasse, David, ed. Future for everyone: innovative social responsibility and community partnership. Nueva York: Routledge, 2003.

McNair, Stephen. "The emerging policy agenda." En Centre for Educational Research and Innovation [y] National Center on Adult Literacy. Learning to bridge the digital divide. Education and skills. París: OCDE, c2000.

Moorhead, Patrick. A profile of the digital divide. Advanced Micro Devices, 2004. Disponible http://www.amd.com/de-de/Corporate/ Careers/0\%2C\%2C51_82_621_52^5806^9935\%2C00.html [Marzo 23, 2004]. 
Mossberger, Karen, Caroline J. Tolbert y Mary Stansbury. Virtual inequality: beyond the digital divide. Washington, D. C.: Georgetown University, 2003.

Munster, Irene L. de. "La brecha informativa en Latinoamérica: un caso de estudio." World Library and Information Congress: 70 th IFLA General Conference and Council, 22-27 August 2004, Buenos Aires. Argentina. Disponible http://www.ifla.org/IV/ifla70/ papers/031s-Munster.pdf [Agosto 8, 2004].

Murelli, Elena. Breaking the digital divide: implications for developing countries. S.1.: Commonwealth Secretariat: SFI Publ. c2002.

Navas-Sabater, Juan, Andrew Dymond y Niina Juntunen. Telecommunications and information services for the poor: toward a strategy for universal access. World Bank Discussion Paper, no. 432. Washington, D. C.: Banco Mundial, 2002.

Network Wizards. ISC Internet domain survey, 2004. Internet Systems Consortium. Disponible http://www.isc.org/index.pl?/ ops/ds [Agosto 18, 2005].

Nielsen Net Ratings. Global Net population increases (2003). Disponible http://www.nua.com/surveys/index.cgi?f=VS\&art_id= 905358729\&rel $=$ true [Septiembre 30, 2005].

Norris, Pippa. Digital divide: civic engagement, information poverty, and the Internet worldwide. Communication, society and politics. Cambridge, R. U.: Cambridge University Press, 2001.

- The worldwide digital divide: information poverty, the Internet and development. Harvard University, John F. Kennedy School of Government, 2003.

NUA Internet Surveys. How many on line? Jupitermedia Corporation. Disponible http://www.nua.ie/surveys/how_many_online/ index.html [Septiembre 1, 2005]. 
Osterroth, María. "Aumentan usuarios de Internet en México." Reforma, mayo 20, 2003. Disponible http://www.reforma.com/parseo/printage.asp?pagetoprint $=$../economiayfinanzas/articulo [Mayo 21, 2003].

Peters, Teresa. "Bridging the digital divide." Global Issues. Noviembre 2003. Disponible http://usinfo.state.gov/journals/itgic/1103/ ijge/gj08.htm [Marzo 23, 2004].

Peterson, Ann Bharat y Mehra Smith Cynthia. "Public Libraries and the Digital Divide." First Monday no. 5 (Enero 2001): 1-4.

Policy Action Team 15. Closing the digital divide: information and communication technologies in deprived areas: a report. Londres: Department of Trade and Industry, 2000.

Pro Active. Digital divide still apparent in Europe, 2000. Disponible http://www.nua.com/surveys/?f=VS\&art_id=905355714 $\&$ rel=true [Septiembre 30, 2005].

Rao, Dandhya y Bruce C. Klopfenstein, eds. Cyberpath to development in Asia: issues and challenges. Westport, Connecticut: Praeger, 2002.

Reddick, A. y C. Boucher. Tracking the dual digital divide. Ekos Research Associates, 2002. Disponible http://www.nald.ca/fulltext/ digital/tracking/cover.htm [Septiembre 2, 2005].

Remenyi, Dan. "As the first 50 years of computing draw to and end... what kind of society do we want?" Journal of Information Technology 17, no. 1 (2002): 3-7. Disponible EbscoHost (AN 6705499).

Rideout, Vanda. "Digital inequalities in Easter Canada." The Canadian Journal of Information and Library Science 27, no. 2, (2002/03): 3-31.

Rod, Nordland. "The missing win the Web." Newsweek (Diciembre 2000/Febrero 2001): 72-73. 
Roseman, Walda. "Gender and the digital divide." Gender and the digital divide seminar series \#5. Marzo 22, 2001. The World Bank Group. Disponible http://www.worldbank.org/gender/digitaldivide/digitaldivide6a.htm [Abril 26, 2003].

Ryan, Joe. Digital divide and libraries: equity and the Internet. Disponible http://web.syr.edu/ jryan/infopro/divide.html [Agosto 4, 2004].

Servon, Lisa J. Bridging the digital divide: technology, community, and public policy. Malden, Mass.: Blackwell Publishing, 2002.

Shaw, Jean. "African digital divide." Library and Information Update 1, no. 5 (Agosto 2002): 49.

Slevin, James. The Internet and society. Cambridge, R.U.: Polity Press, 2000.

Smith, Craig Warren. Digital corporate citizenship: the business response to the digital divide. Indianapolis: The Center on Philanthropy at Indiana, 2002.

Solomon, Gwen, Nancy J. Allen y Paul Resta, eds. Toward digital equity: bridging the divide in education. Boston: Allyn and Bacon, 2003.

Thierer, Adam D. "How free computers are filling the digital divide." The Heritage Backgrounder no. 1361 (Abril 20, 2000).

Traventon, Gregory F. y Lee Mizell, eds. The future of the information revolution in Latin America: proceedings of a International Conference (S. L.: RAND, 2001), 5. Disponible http://www.rand. org/publications/CF/CF166.1/ [Agosto 10, 2004].

Turati, Marcela. "Da Sedesol PCs pero no hay luz." Reforma, febrero 28, 2003. http://www.reforma.com/nacional/articulo/273434 [Febrero 28, 2003]. 
UNDP. Human development report. Nueva York: UNDP, 1999.

Valdiosera R., Cuauhtémoc. "Crece uso de correo electrónico." Reforma, abril 2, 2003. http://www.reforma.com/encuestas/articulo/ 281680/default.htm [Abril 2, 2003].

Valletta, Rob y Geoffrey MacDonald. "Is there a digital divide?" FRBSF Economic Letter no. 38 (Diciembre 26, 2003). Disponible http://www.sf.frb.org/publications/economics/letter/2003/ el2003-38.pdf [Marzo 23, 2004].

Warschauer, Mark. "Reconceptualizing the digital divide." First Monday 7 no. 7 (Julio 2002). Disponible http://firstmonday.org/issues/ issue7_7/warschauer/index.html [Mayo 5, 2004].

-..Technology and social inclusion: rethinking the digital divide. Cambridge, Mass.: MIT Press, c2003.

Wilhelm, Anthony G. Democracy in the digital age: challenges to political life in cyberspace. Nueva York: Routledge, 2000.

Wresch, William. Disconnected: haves and haves-nots in the information age. New Brunswick, Nueva Jersey: Rutgers University Press, 1996.

Zenker, Alejandro. "Navegan más las mujeres." Reforma, mayo 10, 2004: Cultura, 2C. 
La brecha digital y sus determinantes. La edición consta de 500 ejemplares. Coordinación editorial, Zindy E. Rodríguez Tamayo. Formación editorial, Carlos Ceballos Sosa. Revisión especializada, Martha Castro López. Revisión de pruebas, Minerva del Ángel Santillán. Centro Universitario de Investigaciones Bibliotecológicas/UNAM. Fue impreso en papel cultural ahuesado de 90 gr. en Desarrollo Gráfico Editorial, S. A. de C. V. ubicado en Municipio Libre 175, Nave Principal, Col. Portales, México D. F. Se terminó de imprimir en el mes de octubre de 2006. 